\title{
NONLINEAR SEISMIC RESPONSE OF GROUND \\ SUPPORTED CYLINDRICAL REINFORCED CONCRETE \\ TANKS
}

by

\author{
Maryam Rafieeraad \\ Master of Applied Science, \\ Sharif University of Technology, \\ Tehran, Iran, 2012
}

\author{
A dissertation \\ presented to Ryerson University \\ in partial fulfillment of the \\ requirements for the degree of \\ Doctor of Philosophy \\ in the program of \\ Civil Engineering
}

Toronto, Ontario, Canada, 2018

(C) Maryam Rafieeraad 2018 


\section{AUTHOR'S DECLARATION}

I hereby declare that I am the sole author of this dissertation. This is a true copy of the dissertation, including any required final revisions, as accepted by my examiners.

I authorize Ryerson University to lend this dissertation to other institutions or individuals for the purpose of scholarly research.

I further authorize Ryerson University to reproduce this dissertation by photocopying or by other means, in total or in part, at the request of other institutions or individuals for the purpose of scholarly research.

I understand that my dissertation may be made electronically available to the public. 


\title{
NONLINEAR SEISMIC RESPONSE OF GROUND \\ SUPPORTED CYLINDRICAL REINFORCED CONCRETE \\ TANKS
}

\author{
Doctor of Philosophy, 2018 \\ Maryam Rafieeraad \\ Department of Civil Engineering \\ Ryerson University
}

\begin{abstract}
Seismic behavior of Liquid Containing Structures has been studied for decades. Being able to have these structures functioning during and after an earthquake is imperative for wellbeing of a society hence importance of their design. Response Modification Factor known as "R factor" is one of the key parameters in seismic design. However, in case of LCS's, a justifiable guideline to determine the $\mathrm{R}$ factor is yet to be developed and current codes have utilized empirical values in design of these structures. The design intend for LCS's is to meet the serviceability limits as opposed to life safety and collapse prevention which is the case of design of buildings.

This study aims to investigate the effect of various parameters such as material nonlinearity, tank dimensions, base condition, concrete compressive strength, characteristics of seismic excitation records on the seismic behavior of concrete tanks. In this study, a finite element
\end{abstract}


method is developed to investigate the seismic behavior of circular ground supported reinforced concrete tanks. First, the accuracy of current practice is investigated by employing the analytical and numerical methods, experimental studies. Finite element technique and pushover analysis are utilized to set up the pushover curve and achieve over-strength and ductility factors. The response modification factor $(\mathrm{R})$ is then evaluated based on the nonlinear static analysis. Second, using the nonlinear dynamic analysis (time-history), the seismic behavioral aspects of full liquid tanks are studied taking into account the material nonlinearity, wall flexibility, effect of impulsive component, fluid-surface interaction and vertical ground acceleration. Thereafter, a parametric study is conducted to study the influence of tank dimensions, base fixity conditions and earthquake frequency content on the response modification factor.

This study shows the over-strength and ductility factor of RC ground-supported tanks are significantly influence by tank size, height, height/diameter ratio and fundamental period. Also, fixed based tanks and shallow tanks have higher $\mathrm{R}$ values compared to hinged based and tall tanks respectively. The time history results show that the effect of material nonlinearity, vertical ground acceleration, base condition and earthquake frequency content on the dynamic behavior of liquid ground supported tanks is significant. 


\section{ACKNOWLEDGEMENTS}

I would like to express my special sense of gratitude to many individuals who helped and supported me bring this study into reality.

First and foremost, it is a great pleasure to acknowledge my honest gratitude to my supervisor Dr. Reza Kianoush who gave me the golden opportunity to perform this wonderful project and impart his knowledge, insight, and expertise in this study. Without his guidance and persistent help, this dissertation would not have been possible. Also, my appreciation to my co-supervisor Dr. Ahmad Varvani and his kind support.

I would like to express my deepest gratitude towards my beloved and supportive parents who are always by my side and their unconditional love and encouragement helped me in the completion of this achievement.

I offer my regards and appreciation to Dr. Amirreza Ghaemmaghami and Dr. Mehdi Moslemi for their constant guidance and providing necessary information regarding this research, and also all of my colleagues in the Civil Engineering Department at Ryerson University.

Finally, I greatly appreciate the financial support from Ryerson University in the form of a scholarship. 


\section{TABLE OF CONTENTS}

AUTHOR'S DECLARATION

$\begin{array}{lll}\text { ABSTRACT } & \text { iii }\end{array}$

ACKNOWLEDGEMENTS

LIST OF TABLES X X

LIST OF FIGURES - xi

LIST OF APPENDICES XV XV

LIST OF SYMBOLS Xvi

1 INTRODUCTION 1

1.1 Overview 1

1.2 Objectives and scope of the study 4

1.3 Thesis layout 5

2 LITERATURE REVIEW 9

2.1 Introduction 9

$\begin{array}{lll}2.2 & \text { Design Codes and Standards } & 15\end{array}$

$\begin{array}{lll}2.3 & \text { Tank classifications based on ACI code } & 17\end{array}$

2.4 Methods of seismic analysis $\quad 19$

2.4.1 Nonlinear Static Analysis $\quad 19$

2.4.2 Time-history Analysis 22

2.5 Response Modification Factor 23

2.6 Nonlinearity in Reinforced Concrete Structure Analysis 27

$\begin{array}{lll}2.7 & \text { Concrete Cracking } & 27\end{array}$

3 Effect of Tank Parameters on Seismic Response 30

$\begin{array}{lll}3.1 & \text { Introduction } & 30\end{array}$

3.2 Tank behavior under seismic loads 30

3.3 ACI 350.3 design requirements 32

3.4 FE load distribution on the wall 35

3.4.1 Validation of FE load distribution 37 
3.5 Tank configurations and results of load distribution on FE models 44

3.5.1 Effect of tank size on FE results 46

3.5.2 Effect of base fixity on FE results 49

$\begin{array}{lll}3.6 & \text { Summary } & 54\end{array}$

4 FINITE ELEMENT MODEL DEVELOPMENT AND VERIFICATION 55

$\begin{array}{lll}4.1 & \text { Introduction } & 55\end{array}$

4.2 Finite element model $\quad 55$

4.3 Element type $\quad 56$

4.3.1 Reinforced concrete 56

4.3.2 Fluid Domain $\quad 57$

4.4 Damping characteristics of fluid domain 58

4.5 Reinforced concrete finite element formulation 59

4.5.1 FE formulation of SOLID65 element in linear state 59

4.5.2 FE formulation of SOLID65 element after cracking 60

$\begin{array}{lll}4.5 .3 & \text { Failure criteria for concrete } & 62\end{array}$

4.6 Fluid finite element formulation 63

4.7 Solution of static and dynamic nonlinear finite element equations 65

4.7.1 Solution method for static analysis equation 65

$\begin{array}{ll}\text { 4.7.2 Solution method for dynamic equations of motion } & 67\end{array}$

$\begin{array}{lll}4.8 & \text { Material properties } & 68\end{array}$

4.8.1 Stress-strain curve of concrete $\quad 69$

$\begin{array}{lll}\text { 4.8.2 Stress-strain curve of steel } & 70\end{array}$

4.8.3 Elastomeric bearing pad and seismic cables 71

4.9 Validation of proposed FE method in modeling of RC tank 74

$\begin{array}{lll}\text { 4.9.1 Finite element modeling of reinforced concrete } & 74\end{array}$

4.9.2 Reinforced concrete shear wall test verification 80

4.9.3 Parametric study on shear transfer coefficient effect 84

$\begin{array}{lll}4.10 & \text { Summary } & 86\end{array}$

5 NONLINEAR BEHAVIOR OF CONCRETE CIRCULAR TANKS UNDER PUSHOVER ANALYSIS AND SEISMIC RESPONSE FACTORS 88

$\begin{array}{lll}5.1 & \text { Introduction } & 88\end{array}$

5.2 Nonlinear static response of circular tank (Pushover analysis) 88

5.3 Tanks configuration and material properties $\quad 89$

5.3.1 Design of circular tanks based on code requirements 89

5.3.2 Load pattern on tank walls 92

$\begin{array}{lll}5.4 & \text { Mesh Sensitivity analysis } & 93\end{array}$ 
5.5 Quantification of Structure Seismic Response Factors 95

5.5.1 Response Modification Factor (R) 97

5.5.2 Over-strength Factor $\left(\mathrm{R}_{\mathrm{s}}\right) \quad 97$

5.5.3 Ductility Reduction Factor $\mathrm{R} \mu \quad 98$

$\begin{array}{lll}5.6 & \text { Interpretation of push-over curve } & 100\end{array}$

5.7 Finite element results of pushover analysis 106

$\begin{array}{lll}5.8 & \text { Calculation of seismic response factors } & 113\end{array}$

$\begin{array}{lll}\text { 5.8.1 Effect of tank dimension } & 114\end{array}$

$\begin{array}{ll}\text { 5.8.2 Effect of base fixity } & 116\end{array}$

$\begin{array}{ll}\text { 5.8.3 Effect of concrete strength }\left(f_{\mathrm{c}}{ }^{\prime}\right) & 118\end{array}$

$\begin{array}{lll}5.9 & \text { Summary } & 121\end{array}$

6 TIME HISTORY ANALYSIS 122

$\begin{array}{lll}6.1 & \text { Introduction } & 122\end{array}$

$\begin{array}{lll}6.2 & \text { Verification of numerical model } & 123\end{array}$

6.3 Effect of earthquake frequency content on the dynamic behavior of circular ground $\begin{array}{ll}\text { supported tanks } & 130\end{array}$

6.4 Tanks configurations and material properties 136

6.4.1 Design of concrete tank wall 136

6.4.2 Applying earthquake ground motions 139

6.5 Results of time-history FE analysis 141

$\begin{array}{lll}6.6 & \text { Summary } & 150\end{array}$

7 SUMMARY, CONCLUSIONS AND RECOMMENDATIONS 153

$\begin{array}{lll}7.1 & \text { Summary } & 153\end{array}$

$\begin{array}{lll}7.2 & \text { Conclusions } & 155\end{array}$

$\begin{array}{lll}\text { 7.3 Recommendations for future research programs } & 158\end{array}$

APPENDIX A: EARTHQUAKE DESIGN LOADS AND LOAD DISTRIBUTION OF GROUND-SUPPORTED NONFLEXIBLE-BASE CIRCULAR TANK 159

APPENDIX B: ANALYTICAL SOLUTION OF CYLINDRICAL TANK UNDER HYDROSTATIC LOADING 165

APPENDIX C: DESIGN OF CONCRETE SECTION OF GROUND-SUPPORTED NONFLEXIBLE-BASE CIRCULAR TANK 169

APPENDIX D: EARTHQUAKE DESIGN LOADS AND LOAD DISTRIBUTION OF GROUND-SUPPORTED FLEXIBLE-BASE CIRCULAR TANK 176 
APPENDIX E: TEXT COMMAND FILES OF THE TANK'S PARAMETRIC MODEL AND THE POST-PROCESSOR ALGORITHMS IN PUSH-OVER ANALYSIS 


\section{LIST OF TABLES}

Table 3.1 Importance factor I (Adopted from ACI 350.3-06)

Table 3.2 Response modification factors R (Adopted from ACI 350.3-06) 33

Table 3.3 Summary of tanks dimensions and properties $\quad 45$

Table 4.1 Beam section dimensions $\quad 75$

Table 4.2 Material properties for TIMA and J4 beam specimens $\quad 75$

Table 4.3 Material and section properties of specimens (Mickleborough et al. 1999) 81

Table 4.4 Experimental results of walls $\quad 82$

Table 5.1 Summary of tank dimensions and reinforcement ratio 91

Table 5.2 Sensitivity analysis results on four different mesh size $\quad 94$

Table 5.3 Values of a and $b$ according to strain hardening ration $(\alpha) \quad 99$

Table 5.4 Summary of response modification factor for fixed and hinged base tanks 115

Table 5.5 Summary of response modification factor for fixed and hinged base tanks 117

Table 5.6 Summary of response modification factor for two groups of A and B 119

Table 6.1 Modal analysis results for a ground-supported rigid tank model $\quad 125$

Table 6.2 Characteristics of ground motions 132

Table 6.3 Summary of tank dimensions and reinforcement ratios based on the seismic design 138

Table 6.4 Seismic cable and elastometic bearing pad details for flexible base tanks (Hafez, 2012) 139

Table 6.5 Normalized earthquake records $\quad 141$

Table 6.6 Response modification factors from FE analysis $\quad 145$ 


\section{LIST OF FIGURES}

Figure 2.1 Housner's model $\quad 10$

Figure 2.2 Types of ground-supported tanks base connections 17

Figure 2.3 Details of seismic cables; Anchored flexible base (Adopted from Hafez, 2012) 18

Figure 2.4 Transferred tangential shear at anchored flexible base tanks 18

Figure 2.5 Typical pushover curve 21

Figure 3.1 Ground supported liquid containing tank; a) Fluid motion, b) Dynamic model, c) dynamic equilibrium of horizontal forces 31

Figure 3.2 Design response spectrum (Adopted from ACI 350.3-06) 34

Figure 3.3 Seismic force distribution an tank walls; (a) Vertical distribution, (b) Horizontal distribution 36

Figure 3.4 Design hydrostatic and hydrodynamic load on the wall at $\theta=0$ degree 37

Figure 3.5 Frame analogy simulations; a) Continuous Winkler foundation, b) Discretized foundationFrame analogy with hydrostatic pressure distribution, c) Seismic vertical pressure distribution, d)

Detail of equivalent strut (Priestley et al. 1985) 39

Figure 3.6 Radial deflection in tank wall due to hydrostatic pressure $\quad 41$

Figure 3.7 Hoop stress in tank wall due to hydrostatic pressure 41

Figure 3.8 Vertical bending moment in tank wall due to hydrostatic pressure $\quad 42$

Figure 3.9 Radial deflection in tank wall due to hydrodynamic pressure 43

Figure 3.10 Hoop stress in tank wall due to hydrodynamic pressure 43

Figure 3.11 Vertical bending moment in tank wall due to hydrodynamic pressure 44

Figure 3.12 Maximum radial displacement at $\theta=0 \quad 46$

Figure 3.13 Hoop force on the wall at $\theta=0 \quad 47$

Figure 3.14 Vertical bending moment on the wall at $\theta=0 \quad 47$

Figure 3.15 Maximum radial displacement at $\theta=0 \quad 48$

Figure 3.16 Hoop force on the wall at $\theta=0 \quad 48$

Figure 3.17 Vertical bending moment on the wall at $\theta=0 \quad 49$

Figure 3.18 Maximum radial deflection at $\theta=0$; under hydrostatic pressure 49

Figure 3.19 Hoop force on the wall at $\theta=0$; under hydrostatic pressure 50

Figure 3.20 Vertical bending moment on the wall at $\theta=0$; under hydrostatic pressure 51

Figure 3.21 Radial deflection on anchored flexible base tank; under hydrodynamic pressure $\quad 52$

Figure 3.22 Hoop stress distribution on the wall for anchored flexible base tank; under hydrodynamic

$\begin{array}{ll}\text { pressure } & 52\end{array}$

Figure 3.23 Hoop force on the wall; under hydrodynamic pressure 53 
Figure 3.24 Vertical bending moment on the wall; under hydrodynamic pressure

Figure 4.1 Geometry and node positions of a) SOLID65 and b) LINK8

Figure 4.2 Geometry and node positions of a) FLUID80 and b) FLUID30 (Adopted from ANSYS,

Figure 4.3 Tensile stress relaxation in concrete element (Adopted from ANSYS) 62

Figure 4.4 Schematic view of "Newton_Raphson" numerical equation solver 66

Figure 4.5 Stress-strain curve for concrete material with $f c^{\prime}=30 \mathrm{MPa} \quad 70$

Figure 4.6 Stress-strain idealization for steel material with $\mathrm{f}_{\mathrm{y}}=400 \mathrm{MPa} \quad 70$

Figure 4.7 Stress-strain curve for steel material $\quad 70$

Figure 4.8 Values of Tangential or Slope Static Moduli for Rubber in Shear (Handbook of Molded and Extruded Rubber, Goodyear, second edition, 1959)

Figure 4.9 a) Geometry of COMBIN40, b) FE flexible support model 74

Figure 4.10 Cross-section, loading location and geometry of beam specimens; (a) Typical crosssection, (b) J4 beam, (c) TIMA beam

Figure 4.11 Meshing of concrete beam (J4) and boundary condition $\quad 77$

Figure 4.12 Experimental versus FE results for J4 beam at mid-span $\quad 78$

Figure 4.13 Experimental versus FE results for TIMA beam at mid-span $\quad 78$

Figure 4.14 Crack pattern on FE model (Beam J4); a) Location of first crack, b) Location of flexural and tension cracks at ultimate stage $\quad 79$

Figure 4.15 Schematic geometry of RC wall specimens (Mickleborough et al. 1999) 80

Figure 4.16 Volumes of concrete wall (SH-L) and steel plates, meshing and boundary condition 82

Figure 4.17 Experimental versus FE results for walls: a) SH-L, b) SM-H, c) SL-H 83

Figure 4.18 Crack pattern on the wall type SH-L; a) Initiation of flexural cracking, b) Crack pattern at ultimate stage $\quad 84$

Figure 4.19 Deflection comparison between experimental test and models A, B and C 86

Figure 5.1 Hydrodynamic load distribution on finite element model 92

Figure 5.2 Results of mesh sensitivity analysis on four FE models 94

Figure 5.3 Definition of seismic response factors on a typical pushover curve 96

Figure 5.4 Comparison of ductility reduction factor between "Newmark", "Krawinkler", and Miranda assuming ductility factor $(\mu)$ of 3 . 99

Figure 5.5 Load-deflection curve; Tank A-F3-40 101

Figure 5.6 Initial cracking pattern on the tank wall in FE model; Tank A-F3-40 101

Figure 5.7 Contour hoop strain on the tank wall for FE model (Corresponding to point B); Tank A-F3$40 \quad 102$

Figure 5.8 Load-deflection curve; Tank A-F6-40 103

Figure 5.9 Cracking pattern on the tank wall in FE model (Corresponding to point B); Tank A-F6-40 
Figure 5.10 Contour hoop strain on the tank wall for FE model (Corresponding to point B); Tank AF6-40

Figure 5.11 Load-deflection curve; Tank A-F9-40

Figure 5.12 Cracking pattern on the tank wall in FE model (Corresponding to point B); Tank A-F9-40

Figure 5.13 Contour hoop strain on the tank wall for FE model (Corresponding to point B); Tank A-

Figure 5.14 Load-deflection response; a) Tank A-F3-40, b) Tank A-F6-40, c) Tank A-F9-40 107

Figure 5.15 Load-deflection response; a) Tank A-F3-30, b) Tank A-F6-30, c) Tank A-F9-30 108

Figure 5.16 Load-deflection response; a) Tank A-F3-20, b) Tank A-F6-20, c) Tank A-F9-20 109

Figure 5.17 Load-deflection response; a) Tank A-H3-40, b) Tank A-H6-40, c) Tank A-H9-40 110

Figure 5.18 Load-deflection response; a) Tank A-FL3-40, b) Tank A-FL6-40, c) Tank A-FL9-40 111

Figure 5.19 Comparing Load-deflection curves for two Groups A and B; (a) Tank F3-40, (b) Tank F640, (c) Tank F9-40

Figure 5.20 Effect of D/H $\mathrm{H}_{\mathrm{L}}$ on response modification factor $\left(\mathrm{R}_{\mathrm{i}}\right) \quad 116$

Figure 5.21 Effect of tank dimension on over-strength factor $\left(\mathrm{R}_{\mathrm{S}}\right) \quad 116$

Figure 5.22 Effect of D/H $\mathrm{H}_{\mathrm{L}}$ on over-strength factor (Rs) 118

Figure 5.23 Effect of D/H $\mathrm{H}_{\mathrm{L}}$ on response modification factor $\left(\mathrm{R}_{\mathrm{s}}\right) \quad 118$

Figure 5.24 Effect of fundamental period on over-strength factor (Rs) 120

Figure 5.25 Effect of fundamental period on response modification factor (Rs) 120

Figure 6.1 Coefficient $C_{w}$ for ground-supported circular tanks (Adopted from ACI350.3-06) 124

Figure 6.2 Mode shapes of cylindrical ground-supported tank; a) First convective mode (FE), b) First impulsive mode (FE), c) First convective mode (adapted from Veletsos (1984)) 126 Figure 6.3 Impulsive hydrodynamic pressure distribution on the tank wall under horizontal excitation; Haroun's study, FE results $\quad 127$

Figure 6.4 Time history impulsive pressure at the base ( $\mathrm{r}=\mathrm{R}, \phi=0, \mathrm{z}=0) \quad 127$

$\begin{array}{ll}\text { Figure 6.5 Hydrodynamic pressure distribution on the wall } & 128\end{array}$

Figure 6.6 Impulsive hydrodynamic pressure distribution on the flexible tank wall for different base

fixities

Figure 6.7 Arias Intensity versus time of the earthquake records (Adopted from Seismosoft, 2016) 132 Figure 6.8 Scaled seismic records (horizontal component): a) 1994 Northridge, b) 1940 El-Centro, c) 1957 San-Francisco

Figure 6.9 Time history of base shear response of the tank 3F under different seismic motions; a)

Northridge, b) El-Centro, c) San-Francisco

Figure 6.10 Normalized peak base shear corresponding to FE responses; a) Tank 3F, b) Tank 6F 135

Figure 6.11 Design spectral response acceleration for Imperial Valley 136

Figure 6.12 Pseudo acceleration response spectra for El-Centro 140 
Figure 6.13 Effect of reinforcement strain on response modification factor under El-Centro record; a) $\mathrm{H}=3.25 \mathrm{~m}, \mathrm{~b}) \mathrm{H}=6.5 \mathrm{~m}, \mathrm{c}) \mathrm{H}=9.6 \mathrm{~m}$

Figure 6.14 Effect of reinforcement strain on response modification factor under San-Francisco

record; a) $\mathrm{H}=3.25 \mathrm{~m}$, b) $\mathrm{H}=6.5 \mathrm{~m}$, c) $\mathrm{H}=9.6 \mathrm{~m}$

Figure 6.15 Effect of reinforcement strain on response modification factor under Northridge record; a)

$\mathrm{H}=3.25 \mathrm{~m}, \mathrm{~b}) \mathrm{H}=6.5 \mathrm{~m}, \mathrm{c}) \mathrm{H}=9.6 \mathrm{~m}$

Figure 6.16 Effect of tank dimension and base fixity on response modification factor; a) El-Centro, b)

San-Francisco, c) Northridge

Figure 6.17 Effect of seismic frequency content on response modification factor; a) Fixed base, b)

Hinged base, c) Flexible base 


\section{LIST OF APPENDICES}

APPENDIX A: EARTHQUAKE DESIGN LOADS AND LOAD DISTRIBUTION OF GROUND-SUPPORTED NONFLEXIBLE-BASE CIRCULAR TANK

APPENDIX B: ANALYTICAL SOLUTION OF CYLINDRICAL TANK UNDER HYDROSTATIC LOADING

APPENDIX C: DESIGN OF CONCRETE SECTION OF GROUND-SUPPORTED NONFLEXIBLE-BASE CIRCULAR TANK

APPENDIX D: EARTHQUAKE DESIGN LOADS AND LOAD DISTRIBUTION OF GROUND-SUPPORTED FLEXIBLE-BASE CIRCULAR TANK

APPENDIX E: TEXT COMMAND FILES OF THE TANK'S PARAMETRIC MODEL AND THE POST-PROCESSOR ALGORITHMS IN PUSH-OVER ANALYSIS 183 


\section{LIST OF SYMBOLS}

Ac

$\mathrm{A}_{\mathrm{f}}$

$\mathrm{A}_{\mathrm{i}}$

AI

As

$\mathrm{A}_{\mathrm{s}, \min }$

[C]

$\mathrm{C}_{\mathrm{c}}$

$\left[\mathrm{C}_{\mathrm{f}}\right]$

$\mathrm{C}_{\mathrm{i}}$

Cs

D

$\left[D^{c}\right]$

$\left[D^{r}\right]_{i}$

$\mathrm{d}_{\mathrm{c}}$

$\left[\mathrm{D}_{\mathrm{c}}{ }^{\mathrm{ck}}\right]$

$\mathrm{D}_{\mathrm{s}}$

Ec

$\mathrm{E}(\mathrm{D})$

$\mathrm{E}_{\mathrm{i}}$

$\mathrm{E}_{\mathrm{s}}$

EQ

F

$[\mathrm{F}]$

$\mathrm{F}_{\mathrm{a}}$

$\left\{F^{a}\right\}$
Area of concrete section

Area of face of element

Strut's cross sectional area

Arias intensity

Area of seismic cable

Minimum area of reinforcement specified by ACI350-06 for shrinkage and temperature

Damping matrix

Period-dependent seismic response coefficients for convective terms

Fluid damping

Period-dependent seismic response coefficients for impulsive terms

Seismic response coefficient

Inside diameter of circular tank, significant duration of earthquake, dead load

Concrete elastic stiffness matrix

Elastic stiffness matrix for reinforcement number "i"

Distance from the center of bar to extreme tension fiber

Modified concrete stiffness matrix

Diameter of seismic cables

Modulus of elasticity of concrete

Total energy input during time D

Strut elastic modulus

Modulus of elasticity of steel, and seismic cable

Actual earthquake pressure at tank base based on ACI 350 (R included)

Function of principal stresses

Vector of forces

Short-period site coefficient (at 0.2 second period)

Applied load vector 
$f_{c}$

$f_{c}^{\prime}$

$\left\{F_{D}\right\}$

$f_{h}$

$f_{i}$

$\left\{\mathrm{F}_{\mathrm{I}}\right\}$

$\left\{F_{i}^{r}\right\}$

$\mathrm{F}_{\max }$

$\left\{F_{p r}\right\}$

fs

$\left\{\mathrm{F}_{\mathrm{S}}\right\}$

$f_{t}$

$\mathrm{F}_{\mathrm{V}}$

fv

fy

g

$g_{i}$

Gp

$\mathrm{H}$

$\mathrm{h}_{\mathrm{c}}$

HD

$h_{i}$

$\mathrm{H}_{\mathrm{L}}$

HS

$\mathrm{H}_{\mathrm{w}}$

I

$I_{1}(y)$

$\mathrm{I}_{1}^{\prime}(\mathrm{y})$

K

[K]

$\mathrm{k}_{\mathrm{d}}$

[ $\left.\mathrm{K}_{\mathrm{f}}\right]$
Ultimate uniaxial compressive strength

Compressive strength of concrete

Damping force vector

Hoop tension

Natural frequency of the fundamental impulsive mode of vibration

Internal force vector

Restoring load vector

Maximum force acting each seismic cable

Fluid pressure load vector

Stress in reinforcement

Stiffness force vector

Uniaxial tensile cracking stress

Long-period site coefficient (at 1.0 second period)

Bending stress

Yield strength of reinforcement

Acceleration due to gravity

Acceleration in "i" direction

Shear modules of elastomeric bearing pad

Hinged base

Equivalent height of convective mass

Hydrodynamic water pressure at tank base

Equivalent height of impulsive mass

Liquid/Water depth

Hydrostatic water pressure at tank base

Wall height

Importance factor

Modified Bessel function of the first kind of order one with the argument

$y$

Derivative of $I_{I}(y)$ with respect to $y$

Fluid elastic (bulk) modulus

Stiffness matrix

Post decay stress softening coefficient

Stiffness matrix 


\begin{tabular}{|c|c|}
\hline$\left[K_{i}^{T}\right]$ & Jacobian or tangent matrix \\
\hline $\mathrm{K}_{\mathrm{r}}$ & Stiffness of the anchored flexible support in radial direction \\
\hline $\mathrm{K}_{\mathrm{S}}$ & Spring stiffness \\
\hline $\mathrm{K}_{\mathrm{t}}$ & Stiffness of the anchored flexible support in tangential direction \\
\hline$\left[\mathrm{K}_{\mathrm{t}}\right]$ & Tangent stiffness matrix \\
\hline Lc & Length of the RUBATEX Sleeve plus embedded length \\
\hline$l_{i}$ & Strut length \\
\hline Lp & Length of elastomeric bearing pad \\
\hline$\left[\mathrm{M}_{\mathrm{f}}\right]$ & Mass matrix \\
\hline $\mathrm{Mi}$ & Twisting force about axis i \\
\hline $\mathrm{M}_{\mathrm{y}}$ & Bending moment \\
\hline $\mathrm{n}$ & Curve fitting factor \\
\hline $\mathrm{Nr}$ & Number of reinforcing material \\
\hline$P$ & Pressure \\
\hline $\mathrm{Pa}$ & Power index \\
\hline $\mathrm{P}_{\mathrm{c}}$ & Hydrodynamic convective force \\
\hline PGA & Peak ground acceleration \\
\hline PGV & Peak ground velocity \\
\hline $\mathrm{Pi}$ & Hydrodynamic impulsive force \\
\hline $\mathrm{P}_{\mathrm{r}}$ & Inertia force exerted on the roof \\
\hline$P_{v y}$ & $\begin{array}{l}\text { Equivalent hydrodynamic pressure due to the effect of vertical } \\
\text { acceleration }\end{array}$ \\
\hline $\mathrm{P}_{\mathrm{w}}$ & Inertia force exerted on the wall \\
\hline Q & Earthquake load \\
\hline$q_{h y}$ & Hydrostatic pressure at level y above the base \\
\hline $\mathrm{q}_{\max }$ & Maximum shear force \\
\hline $\mathrm{q}_{\mathrm{r}}$ & Shear force per unit length at angle $\theta$ \\
\hline $\mathrm{r}$ & Tank radius \\
\hline $\mathrm{R}$ & Response modification factor, and tank radius \\
\hline$[\mathrm{R}]$ & Coupling matrix \\
\hline Rc & Response modification factor corresponding to convective term \\
\hline $\mathrm{R}_{\mathrm{f}}$ & Restoring force at the beginning of each load increment \\
\hline $\mathrm{Ri}$ & Response modification factor corresponding to impulsive term \\
\hline
\end{tabular}




\begin{tabular}{|c|c|}
\hline $\mathrm{RR}$ & Redundancy factor \\
\hline Rs & Over-strength factor \\
\hline $\mathrm{r}_{\mathrm{s}}$ & Redundancy strength index \\
\hline $\mathrm{R}^{\mathrm{t}}$ & Tensile stress relaxation coefficient, and secant modulus \\
\hline$R_{\mu}$ & Ductility factor \\
\hline $\mathrm{S}$ & $\begin{array}{l}\text { Spacing between reinforcement and spacing between cracks, and failure } \\
\text { surface which is a function of principal stresses and various strength } \\
\text { factors }\end{array}$ \\
\hline $\mathrm{Sc}$ & Spacing between seismic cables \\
\hline $\mathrm{S}_{\mathrm{d}}$ & Environmental durability factor \\
\hline $\mathrm{S}_{\mathrm{DS}}$ & Design spectral response acceleration at short periods \\
\hline $\mathrm{S}_{\mathrm{D} 1}$ & Design spectral response acceleration at 1 -second period \\
\hline $\mathrm{Sp}$ & Spacing of elastomeric bearing pad \\
\hline Ss & $\begin{array}{l}\text { Mapped MCE (Maximum Considered Earthquake) spectral response } \\
\text { acceleration at short periods }\end{array}$ \\
\hline $\mathrm{S}_{1}$ & Mapped MCE spectral response acceleration at one-second period \\
\hline $\mathrm{t}$ & Wall thickness \\
\hline $\mathrm{T}$ & Fundamental period \\
\hline $\mathrm{Tc}$ & Natural period of convective mode, and relaxation parameter \\
\hline$t_{e}$ & Effective concrete cover \\
\hline $\mathrm{Tg}$ & Predominant period of ground motion \\
\hline $\mathrm{Ti}$ & Natural period of impulsive mode \\
\hline tp & Thickness of elastomeric bearing pad \\
\hline $\mathrm{t}_{\mathrm{r}}$ & Total duration of the ground motion \\
\hline $\mathrm{tw}$ & Wall thickness \\
\hline $\mathrm{t}_{0}$ & Time at beginning of strong shaking phase \\
\hline$[\mathrm{U}]$ & Displacement matrix \\
\hline$\{u\}$ & Displacement vector \\
\hline$\{\dot{u}\}$ & Velocity vector \\
\hline$\{\ddot{u}\}$ & Acceleration vector \\
\hline Umax & Maximum radial deflection \\
\hline$\ddot{U}_{v}$ & Spectral acceleration \\
\hline
\end{tabular}




\begin{tabular}{|c|c|}
\hline$\ddot{u}_{0}$ & Horizontal ground acceleration \\
\hline $\mathrm{V}$ & Total Horizontal base shear \\
\hline $\mathrm{V}_{\mathrm{c}}$ & Tensile cracking stress \\
\hline $\mathrm{V}_{\mathrm{d}}$ & Design base shear (FEMA 450) \\
\hline $\mathrm{V}_{\mathrm{e}}$ & Maximum base shear in an equivalent entirely linear-elastic system \\
\hline$V_{i}^{R}$ & Reinforcement ratio \\
\hline $\mathrm{V}_{\max }$ & Ultimate base shear capacity \\
\hline $\mathrm{V}_{\mathrm{y}}$ & Base shear at yield - Yielded strength \\
\hline $\mathrm{W}$ & Gravity load \\
\hline$w c$ & Crack width \\
\hline $\mathrm{W}_{\mathrm{c}}$ & $\begin{array}{l}\text { Effective weight of the stored liquid corresponding to convective } \\
\text { component }\end{array}$ \\
\hline $\mathrm{W}_{\mathrm{i}}$ & $\begin{array}{l}\text { Effective weight of the stored liquid corresponding to impulsive } \\
\text { component }\end{array}$ \\
\hline$w_{\max }$ & Maximum tensile crack width \\
\hline $\mathrm{W}_{\mathrm{p}}$ & Width of elastomeric bearing pad \\
\hline $\mathrm{W}_{\mathrm{r}}$ & Weight of the tank roof \\
\hline $\mathrm{W}_{\mathrm{w}}$ & Weight of the tank wall \\
\hline$y$ & Radial deformation \\
\hline$\alpha$ & $\begin{array}{l}\text { Rayleigh damping constant, angle of inclined cable, and strain } \\
\text { hardening ratio }\end{array}$ \\
\hline$\beta$ & $\begin{array}{l}\text { Ratio of distance between neutral axis and tension face to distance } \\
\text { between neutral axis and centroid of reinforcement, and Rayleigh } \\
\text { damping constant }\end{array}$ \\
\hline$\beta_{c}$ & Coefficient for closed crack condition \\
\hline$\beta_{t}$ & Shear transfer coefficient \\
\hline$\varepsilon$ & Effective mass coefficient \\
\hline$\varepsilon^{c k}$ & Cracking strain \\
\hline$\varepsilon_{\text {bulk }}$ & Bulk strain \\
\hline$\varepsilon_{c}$ & Strain in concrete \\
\hline$\varepsilon_{c}^{\prime}$ & Concrete strain at the peak compressive stress level \\
\hline$\varepsilon_{s}$ & Strain in reinforcement \\
\hline$\varepsilon_{y}$ & Yield strain of reinforcement \\
\hline
\end{tabular}


Shear strain

$\gamma_{c}$

Density of concrete

$\tau$

Shear stress

$\eta$

Viscosity

$\Psi_{\mathrm{s}}$

Crack spacing factor

$\Omega$

Over-strength factor

$\xi$

Damping ratio

$v_{c}$

Poisson's ratio of concrete

$v_{s}$

Poisson's ratio of reinforcement

$\rho$

Reinforcement ratio

$\rho_{l}$

Liquid mass density

$\Delta_{\mathrm{y}}$

Effective yield displacement

$\Delta_{\max }$

Maximum displacement prior to onset of stiffness reduction

$\mu$

Displacement ductility

$\omega_{i}$

Circular frequency of fundamental impulsive mode of vibration

$\omega_{c}$

Circular frequency of oscillation of convective mode of sloshing 


\section{CHAPTER 1 INTRODUCTION}

\subsection{Overview}

Different types of tanks such as ground-supported and elevated tanks have become widespread over the last decades. These structures are used in the municipal water supply and firefighting systems, and are used extensively for the storage of liquid and liquid-like materials including, oil, liquefied natural gas, chemical fluids, and wastes of different forms. These tanks vary in dimensions considerably to satisfy the capacity requirements. Among different configurations for such structures, ground-supported tanks are more common in use because of their simplicity in design and construction. In addition, they have more resistance against the hydrostatic and hydrodynamic applied loads.

These structures are considered as lifeline facilities, and their functional performance is of significance. Ever since these structures are always subjected to different types of loads including wind, hurricane, hydrostatic and other dynamic excitations, it is important that rational and efficient methods for their analysis and design are formulated. A properly designed tank must be able to withstand the applied loads without any damage. As numbers and sizes of the storage tanks have increased over the years, so have their importance and the need to better understand their behavior.

For these structures, there are some concerns on dynamic interaction between fluid and structure. This condition can occur when they are full and subjected to the dynamic excitations such as seismic load. This interaction has a significant influence on the nonlinear response of the structure to transient and cyclic excitation as the result of changing the dynamic characteristics of the structure. This need has been particularly pressing for developing an accurate model of these systems including the fluid-structure interaction (FSI) effect that can account for the applied dynamic load. Even though, there are extensive studies on the response 
of liquid storage tanks subjected to hydrostatic and seismic loading, still very little attention has been given to the nonlinear response of at or above ground-supported concrete tanks under seismic load.

A great deal of concrete tanks damage has been reported over the past years either during construction or during their life span due to high intensity seismic events. For instance, some of these severe damages happened in Long beach 1933, Niigata in 1964, Alaska in 1964, Parkfield in 1966, Imperial County in 1979, Coalinga in 1983, Northridge in 1994 and Kocaeli in 1999. Those reports show a weakness in structure durability and a complex behavior of ground-supported liquid storage tanks during the seismic load (Rinne (1967), Shibata (1974), Kono (1980), and Sezen and Whittaker (2006)).

Design and analysis of liquid tanks involve many fundamental parameters. For instance, tank configuration, location and environment, structural flexibility, material and fluid properties, fluid-structure interaction and soil-structure interaction have great influence on analyzing the tank behavior. Dynamic excitations produce hydrodynamic pressure in liquid storage tanks. Extensive studies have been performed on the interaction effects between structure and contained liquid clarifying the effect that hydrodynamic pressure in a flexible tank can be significantly higher than the corresponding rigid container. Accordingly, it is proved that the impulsive component governed by the interaction between tank wall and liquid depends on the flexibility of the wall while the convective component is induced by slosh waves.

Over the past decades, researchers and engineers have developed different methods to simulate the structures accompanied by real boundary conditions to predict the earlier potential failure and proper design. Consequently, this demand has resulted in establishment of mechanical models and numerical techniques for modeling of structures and finding approximate solutions. 
Finite Element Method (FEM) is a good choice among the numerical methods to study the dynamic behavior of liquid storage tanks subjected to ground motions. This method has been employed widely in simulation of fluid-structure interaction phenomenon in similar system including off-shore and submerged structures such as dam reservoir-foundation models. In this study, a 3-dimensional ground-supported concrete tank is modeled using finite element model to investigate the nonlinear seismic response of the structure. Main challenging parts in predicting the seismic behavior of a liquid containing structure are the identification of the vibration response of the structure with regards to the fluid-structure interaction and the simulation of the concrete nonlinearity.

Tanks may be filled partially or fully by liquid. The behavior of empty concrete tanks is simulated as a one-mass system, while they are usually full. In this case, there is always sloshing due to the free liquid surface oscillation during ground motions, making the behavior of liquid-containing structures a complicated coupled problem. Consequently, the response of the system is quite changed due to the different dynamic behavior of the system as a result of sloshing. Therefore, an understanding of the seismic behavior of liquid-containing tanks requires an understanding of the hydrodynamic pressures and forces associated with the oscillating water.

Currently ACI 350.3-06 (2006) is the design code in North America to address the structural design aspects for design and construction of different components of tanks. In addition, and ASCE/SEI 7-10 (2013) are employed in order to determine design aspects such as loading parameters, seismic factors and so on. ACI350.3-06 (2006) calculates the hydrodynamic pressure considering the rigid wall boundary condition. In this approach rectangular liquid tanks are commonly analyzed using a two-dimensional model supported on a rigid foundation. The effects of wall flexibility and 3-dimensional geometry effect are not 
considered in the procedure recommended in this standard. As a result, more studies and investigations are needed under real conditions to better identify such effect.

For a proper seismic design of liquid-containing concrete structures, the structures are designed for forces, which are much less than the expected design earthquake forces. It results in the structure suffering from inelastic deformations under severe ground motions.

The main concern of the seismic design of a liquid storage tank is the vibration of the structure under the ground motions. The stored liquid applies impulsive and convective hydrodynamic pressures on the wall. The aim of structural analysis under seismic loading is to compute the design response quantities of interest including forces and displacements of the whole system.

This research has focused on the nonlinear behavior of circular tanks particularly discussing their load-deformation response, strength, stiffness and modes of failure using analytical investigations. It purpose of this research is to further clarify the behavior of ground supported RC circular tanks and consequently improve the design codes.

The use of an appropriate R value is imperative when designing LCS's in order to avoid potential failures due to earthquakes and consequential environmental hazards that it could cause. Therefore this research aims to investigate the validity of R-values currently being used in practice using a parametric study taking into account the effect of aspect ratio, construction methods and support conditions.

\subsection{Objectives and scope of the study}

The main purpose of the current study is to study the nonlinear response of concrete liquid storage tanks under seismic excitations. Specifically, the study involves evaluating tanks with different base condition to investigate the response modification factors. For this purpose, a finite element approach is employed to investigate the seismic behavior of liquid tanks including the effect of concrete nonlinearity, wall flexibility, three-dimensional geometry, 
liquid sloshing, fluid-structure interaction, impulsive and convective modes, and base fixity. In this study, different types of analysis are performed including push-over, modal and timehistory analysis.

A complete system is modeled and analyzed as a coupled structural system including the structure and stored liquid. The tank structure is assembled by finite elements with appropriate degrees of freedom like substructure approach. The finite element modeling is carried out using the finite element software ANSYS which is practical and suitable to consider the fluid-tank interaction. To validate the proposed FEM and investigate the accuracy of code provisions in seismic design and analysis of liquid-containing structures, the calculated FE results are compared with those offered by analytical and experimental studies. The response modification factor is calculated using the parameters obtained from push-over curves. Moreover, the effect of various parameters in seismic response factors including the ductility and over-strength factors is investigated. The seismic response of liquid tanks can be calculated in terms of impulsive and convective components which can be separately obtained using the proposed FE method. The scope of this study is summarized in the following.

1. Study comprehensively the effect of nonlinearity of concrete and fluid-structure interaction on the seismic response of concrete tanks as well as response modification factor using ANSYS computer program.

2. Employ the finite element method (FEM) to develop a rigorous numerical model to predict the nonlinear response of reinforced concrete.

3. The FE models are verified by comparing their results with analytical solutions and experimental studies.

4. Determine impulsive and convective hydrodynamic pressure distributions for various tank configurations and investigate the effect of seismic frequency content on 
impulsive and convective components and on the dynamic behavior of liquidcontaining tanks.

5. Analyze liquid storage tanks under horizontal ground motions to investigate the effect of different excitations on the dynamic behavior of the tanks.

6. Investigate the nonlinear behavior of tanks with different sizes and dimensions constructed in today's practice and investigate the effect of several key parameters on this behavior.

7. Compare the FE results with those of previous experimental studies and exact analytical procedure to validate the proposed FE model.

8. Calculate over-strength factor and propose response modification factor for ground supported RC tanks based on ATC 19 (1995).

9. Discuss the influence of tank dimensions, base fixity conditions and concrete strength on over-strength and response modification factors using pushover analysis.

10. Simulate liquid domain and fluid-structure interaction in ground-supported cylindrical tanks and investigate the nonlinear response of the tanks using time history analysis.

11. Dynamic behavior of liquid containing cylindrical tanks considering tank dimensions, wall flexibility, base fixity and ground motion frequency content is discussed utilizing a parametric study.

The assumptions and limitations of this study are as follows:

1. Tanks are assumed to be fully fixed to the rigid base, so there is no sliding and uplift. Consequently, the soil-structure interaction effect is ignored.

2. Uniform wall thickness and open top boundary condition are assumed for all models studied through this research.

3. Concrete is assumed to have nonlinear behavior and fluid is assumed as inviscid and incompressible. 


\subsection{Thesis layout}

This thesis is divided into seven chapters. Chapter 1 includes the overview, objective and scope of this study.

Chapter 2 presents a literature review on the dynamic response of liquid containing structures, and continues with a review of design codes and standards. Then, tank classifications as per ACI code are described and an explanation of various methods of dynamic analysis is presented. Previous research studies on response modification factor are discussed finally. Chapter 3 provides a summary on tanks behavior under seismic loads according to ACI350.306 (2006). In this chapter, pressure distribution patterns under both hydrostatic and hydrodynamic actions are described. Then, the accuracy of load distribution in finite element tank models is verified by employing the analytical methods. The effect of tank dimensions and base fixity on the deflection, forces and moments along the tank wall is investigated in this chapter.

Chapter 4 describes the finite element method to be used for modeling the ground supported circular tanks in this study. The finite element software and different elements employed in tank modeling are introduced. The mathematical models used to define the stressstrain relationships of different materials are provided in this chapter. The finite element formulation for both concrete and fluid domains and the solution of nonlinear static and dynamic equations are described. Finally, the proposed finite element model is validated by comparing the FE results with some experimental test results.

Chapter 5 describes the procedure for the design of reinforced tanks and load pattern on the tank wall. Then, pushover analysis is performed on finite element models to investigate seismic performance parameters. In addition, pushover curves are developed based on the nonlinear static analysis results. Finally, the quantification of tanks seismic response factors is 
performed and the effect of various parameters such as concrete compressive strength, tank size and base fixity is discussed.

Chapter 6 describes the finite element modeling and investigates the seismic behavior of the models under dynamic loading. First, the numerical model is verified by performing modal analyses and comparing the results with analytical methods. Subsequently, various tank configurations based on a wide range of tank sizes, base fixities, and $\mathrm{R}$ modification factors are designed and analyzed under different earthquake records. Finally, using FE analysis, the obtained $\mathrm{R}$ values are validated and compared to those given in current standards.

Finally, Chapter 7 provides the thesis outline and lists the conclusions drawn as a result of this study. Furthermore, some recommendations are presented for further studies and future works. List of references and Appendices is included at the end of the thesis. Appendix A provides some details on seismic design loads calculation and load distribution as per ACI 350.3-06 (2006). Appendix B represents the details of deflection, force, and moment calculations according to the analytical solution referred to as the plates and shells theory. The details of concrete wall design are provided in Appendix C. Appendix D presents the ACI 350.3-06 method for calculation of earthquake design loading and its distribution on flexible base tanks. The input text commands used for the FE model to conduct the parametric study and post processors used in push-over analysis are presented in Appendix D. 


\section{CHAPTER 2 \\ LITERATURE REVIEW}

\subsection{Introduction}

As storage tanks used in engineering and industry have high importance, extensive and comprehensive researches have been carried out both experimentally and theoretically over the years. In the late 1940 's, extensive researches were done related to the dynamic response of the fuel tanks in aerospace engineering. Jacobsen (1949) and Jacobsen and Ayre (1951) investigated the dynamic response of cylindrical tanks exposed to horizontal ground motions and approximated the hydrodynamic masses and mass moments for the storage tanks. As it is mentioned before, structural flexibility, fluid properties, fluid-structure interaction, soilstructure interaction, and earthquake frequency content are the factors which affect the dynamic behavior of the liquid-containing structures. First large scale damage to liquid tanks was happened by the Alaska earthquake in 1964. After that earthquake, the necessity for the seismic safety of structures forced the researchers to achieve a reliable technique for investigating the dynamic response of liquid stored structures. The earliest studies reported by Hoskins and Jacobsen (1934) performed an analytical and experimental investigation on the rectangular tanks subjected to horizontal motion to obtain the hydrodynamic pressure distribution on the structures. In the following, Housner (1957 and 1963) presented a new method to estimate the liquid response of the rectangular and cylindrical tanks. In this method, two impulsive and convective components introduce the hydrodynamic pressure induced by seismic excitations. The liquid oscillating and accelerating in the tank causes the convective and impulsive pressure, respectively. This approach is developed based on the lumped mass approximation. The impulsive component modeled as a lumped mass is rigidly connected to the tank wall, and springs are used to connect the convective component to the tank wall as 
shown in Figure 2.1. This method is widely used with some modifications in most of the current codes and standards.
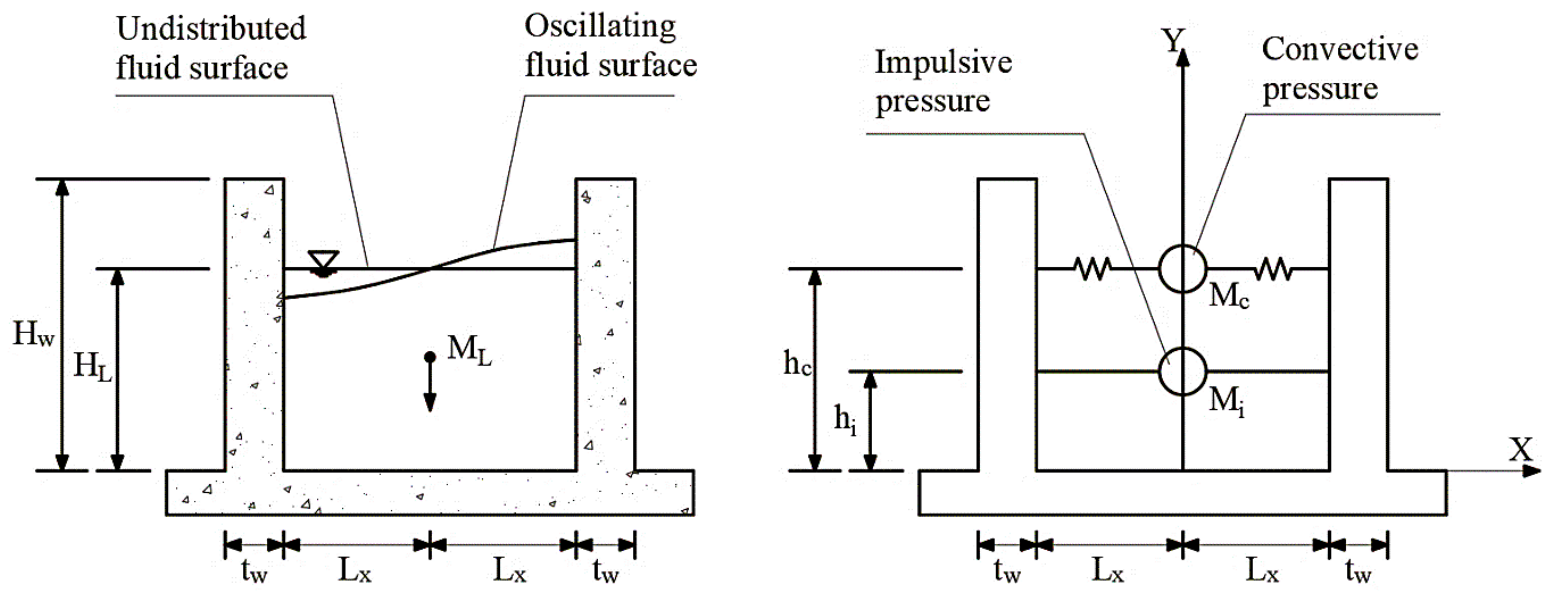

Figure 2.1 Housner's model

In 1976, Epstein employed Housner's model to present the design curves. This method was developed to evaluate the bending and overturning moments caused by hydrodynamic pressure in liquid stored tanks. For the first time, Edward (1969) reported same analysis results regarding the fluid-structure interaction using a computer program. In this research, a program was written using the finite element method and refined shell theory to anticipate stresses and displacements in a cylindrical tank. Moreover, the interaction was coupled between the liquid stored in the tank and the elastic wall of the tank. Yang (1976) proved through an analytical method that wall flexibility had a significant effect on hydrodynamic pressure distribution. Veletsos and Yang (1977) proved that the pressure distribution for the impulsive modes of flexible and rigid tanks was similar using a flexible anchored tank linear model. It was further presented that the pressure magnitude depended on the flexibility of the tank wall because of the liquid-structure interaction effects. Later, Minowa (1980 and 1984) studied the effect of tank wall flexibility on liquid pressure distribution.

Hunt and Priestley (1978) studied the dynamic behavior of both rectangular and cylindrical storage tanks subjected to horizontal accelerations which led to the derivation of 
mathematical equations regarding the fluid motion. In this study, the displacement of liquid free-surface of a cylindrical tank was measured through a shaking table test under both seismic and sinusoidal excitations. The study showed that the theoretical results were close to the experimental ones.

Haroun (1983) carried out a series of experimental studies on flexible ground-supported cylindrical tanks including ambient and forced vibration tests to determine the natural frequencies and mode shapes of vibration. In addition, Haroun (1984) evaluated bending moments in rectangular concrete tank walls subjected to simultaneous horizontal and vertical components of earthquake excitations using a detailed analytical approach. The liquid was assumed incompressible and homogeneous and the walls were assumed to behave as elastic plates. The classical potential flow theory was used to evaluate hydrodynamic pressure and the obtained results were compared with those of approximate analyses. The analytical expressions were used in computing the internal moments and the obtained numerical values for moment coefficients were classified to be employed in seismic analysis and design of the tanks.

Haroun and Tayel (1985) employed the finite element method to analyze the dynamic elastic response of cylindrical liquid stored tanks exposed to vertical seismic excitations. First, free axisymmetric vibrational modes were obtained numerically based on the finite element method. Then, these modes were verified analytically and the load vector formulation was confirmed by a static analysis. In this study, both stresses and axial and radial displacements were calculated. In addition, the tanks were modeled in both fixed and partly fixed base conditions to evaluate the effect of base fixity on the tank's behavior. Finally, different types of seismic excitation including the simultaneous action of vertical and lateral ground motions were considered in evaluating the tank's response. It was proved that the vertical component of ground motion had a relatively important impact on the overall seismic behavior of these structures. 
Veletsos and tang (1986) presented that hydrodynamic effects were reduced due to the soil-structure interaction effect. This was investigated for both rigid and flexible liquid storage tanks subjected to vertical ground motions. Haroun and Abou-Izzeddine (1992) employed a lumped-parameter idealization technique for foundation to organize a parametric study for investigating a variety of factors affecting the seismic soil-structure interaction under both vertical and horizontal excitations.

Veletsos et al. (1992) introduced a refined method to evaluate the convective and impulsive components effects on the dynamic response of the tanks. It was proved that the convective component was not sensitive to the flexibility of the tank wall and supporting soil. As a result, this component would be calculated considering the rigidity of the tank.

Kim et al. (1996) offered an analytical solution for flexible rectangular tanks under vertical excitation. The method is practical and simple but the wall flexibility effect was not considered completely. Park et al. (1992) employed boundary element method (BEM) to take into account to the hydrodynamic pressure response of rectangular tanks. Finite element method was then used to analyze the behavior of the solid wall.

Subhash and Bhattacharyya (1996) used finite element method to develop a numerical scheme and evaluate the sloshing displacement of liquid and pressure development within liquid domain. Koh et al. (1998) analyzed three-dimensional rectangular storage tanks subjected to horizontal excitations using coupled finite element boundary element method. This study presented the free sloshing motion. Dogangun et al. (1997 and 2004) carried out an analytical analyses to investigate the seismic response of liquid filled rectangular storage tanks. In this study, the computer code SAPIV was employed for the purpose of structural analysis. A displacement-based type fluid finite element was used to consider liquid sloshing effects. Regarding their investigations, the effect of tank wall flexibility and the seismic design of the tanks was employed using Lagrangian approach. 
Chen and Kianoush (2005) calculated the hydrodynamic pressure response in twodimensional rectangular tanks including the tank wall flexibility effect using the sequential method. Fluid sloshing was ignored in their study. In addition, Kianoush and Chen (2006) studied the dynamic response of two-dimensional rectangular tanks subjected to vertical seismic excitations to investigate the effect of the vertical component of ground motion on the dynamic behavior of such structures. Kianoush et al. (2006) introduced a new method to account for the effect of both impulsive and convective components in the seismic analysis of rectangular containers in a two-dimensional space.

Livaoglu (2008) used a simplified numerical model to investigate the dynamic behavior of a rectangular fluid tank-foundation system. The fluid-structure interaction effect was presented using the Housner's two mass approximation. The soil-foundation system was represented using the cone model.

Ghaemmaghami and Kianoush (2009) studied the dynamic behavior of threedimensional concrete rectangular storage tanks under both vertical and horizontal seismic excitations. The base was assumed to be rigidly fixed and both convective and impulsive components were considered. Also, both tank wall flexibility and fluid-structure interaction effects were considered. Results showed that fluid damping properties, wall flexibility, and vertical acceleration could have a significant effect on the dynamic behavior of the tanks. It was proved that the effect of combined vertical-horizontal excitation on dynamic response was more significant than the effect of vertical acceleration alone.

Moslemi et al. (2011) investigated the seismic behavior of liquid-filled elevated tanks using finite element method. Both free vibration transient analyses using the modal superposition technique were employed to study the fluid-structure interaction effect in elevated storage tanks. The study represented that the results of Housner's formulations were 
very close to those obtained from FE analysis. The accuracy of the proposed model study was confirmed by comparing the results with the experimental results from the past.

Damages resulting from seismic load effects on steel and concrete liquid containing structures are different. These loads cause damage such as deformations, cracks and leakage in the tank walls of concrete LCS. However, these damage could be different in steel LCS including anchorage system failure, sloshing damage to the roof or upper shell of the tank, buckling of the shell around the base, etc.

During past decades, extensive researched studies have been carried out to understand dynamic behavior of these structures. Failure of a steel molasses tank took place in Boston, Massachusetts, USA in 1919 (Puleo, 2003). The explosion of this full large tank with $15 \mathrm{~m}$ high and $27 \mathrm{~m}$ diameter killed 12 and injured 150 people. However, development of carbon dioxide as a result of fermentation inside the tank and increasing the internal pressure had been considered as a failure contribution. Also, the poor design and construction leading to very thin steel wall and weak resistance of repeated loads from the contents were the reason for failure. In 1991, Turkey earthquake caused several tank failure. For instance, 50 metric tons of diesel fuel spilled form a broken fuel loading arm, 6500 metric tons of toxic acrylonitrile from ruptured tanks leaked, 200 metric tons of hazardous anhydrous ammonia released in the air, oil spilled at oil refinery and the enormous fires triggered as a result of storage tank failure. It also damaged the environment and caused to death of million animals and deteriorated the vegetation, Steinberg and Cruz, 2004).

Extensive damage to major facilities including five steel LCS took place during the Northridge earthquake in Los Angeles, USA in 1994. All of the tank damages showed the uplift and buckling in the tank walls. The impact of the sloshing liquid waves led to collapse of tank roofs. Moreover, many storage tanks in the power generating plant were damaged due to the earthquake. Some steel tanks were uplifted $100 \mathrm{~mm}$ from the base, however they had 
been anchored to a reinforced concrete foundation by steel anchored bolts. In addition, two fire-fighting tanks lost their water contents due to severe damage. One of them was a bolted steel tank which failed in an elephant-foot buckling around the base and the other one was a welded one with very strong anchorage systemwhich prevented significant damage to the tank (Lund, 1996).

\subsection{Design Codes and Standards}

Various codes and standards are available for seismic design of liquid-containing structures such as International Building Code (2017), ASCE 7-10 (2013), ACI 350.3-06 (2006), etc. In this study, the main focus is on the codes and standards used in North America. The ASCE 7-10 (2013) is employed for general design of structures. In this code, the response spectrum is applied to simulate the ground motion corresponding to the maximum considered earthquake (which represents an earthquake with a $2 \%$ probability of exceedance in a 50 -year period equivalent to a recurrence interval of approximately 2500 years).

In Canadian design standards, there is not a specific and practical guideline to design liquid- containing structures; however, there are other useful guidelines such as ACI 350.3-06 (2006), British Standard BS 8007 (1987), European Eurocode-8 (2012), and New Zealand Standard NZS 3106 (2009). Among currents standards, the ACI 350.3-06 (2006) standard reported by the American Concrete Institute, Committee 350, is widely adopted and used for seismic design of reinforced concrete liquid storage tanks in North America. As an additional guideline, the ACI 371R-08 (2017) is used for the design and analysis of elevated and composite steel-concrete water storage tanks.

In special cases, other standards are available for analysis and design of liquid storage tanks. For instance, AWWA D110 (2013) and AWWA D115 (2017) standards were published to design the prestressed concrete liquid tanks, and AWWA D100 (2011) provided the guidelines regarding the design of welded steel liquid storage containers. To design the tanks 
used in petroleum industry, the American Petroleum Institute (API) published two standards; API 650 (2013), and API 620 (2013). Furthermore, two ASCE 4-98 (2000) and ASCE 58 (1980) standards were developed by American society of Civil engineers regarding the seismic design of storage tanks used in nuclear industry.

ACI 350.3-06 (2006) standard is based on the ultimate strength design method. In most of the aforementioned standards including ACI 350.3-06, AWWA D100, AWWA D110, and API 650. The resultant seismic forces acting on the rigid walls of the liquid containers can be estimated by simulating a mechanical model based on the Housner's method (Housner (1963)). In NZS 3106 (2009) and Eurocode-8 (2012), the mechanical model proposed by Veletsos and Yang (1977) is used for dynamic analysis of rigid tanks. However, for seismic evaluation of flexible liquid containers, the models developed by Veletsos (1984), Haroun and Housner (1981B) and Malhotra et al. (2000) are employed.

All standards and codes except the Eurocode- 8 employ square root of sum of squares (SRSS) to combine the impulsive and convective seismic effects. Eurrocode- 8 suggests absolute summation combination rule. Damping ratio associated with impulsive and convective liquid components significantly affects the response spectra provided in liquidcontaining structures design codes and standards. Damping ratio corresponding to the impulsive component is assigned based on tanks' material, geometry, aspect ratio, etc. For example, Eurocode- 8 proposed the damping ratio of $5 \%$ for the impulsive component of concrete tanks while it is presented as $2 \%$ for steel tanks. Different standards including ACI 350.3-06, ASCE 7-05, AWWA D100, AWWA D110, AWWA D115, and API 650 agree on considering the damping ratio of 5 and $0.5 \%$ associated with impulsive and convective liquid components for all tank types. 


\subsection{Tank classifications based on ACI code}

According to ACI 350-3.06 (2006), there are various liquid containing tank classifications including at-grade and below grade. Ground-supported tanks can be classified on the basis of general figuration (rectangular, circular), wall-base joint type (fixed, hinged and flexible) and construction method (reinforced or prestressed concrete). Figure 2.2 shows three different tank support conditions.

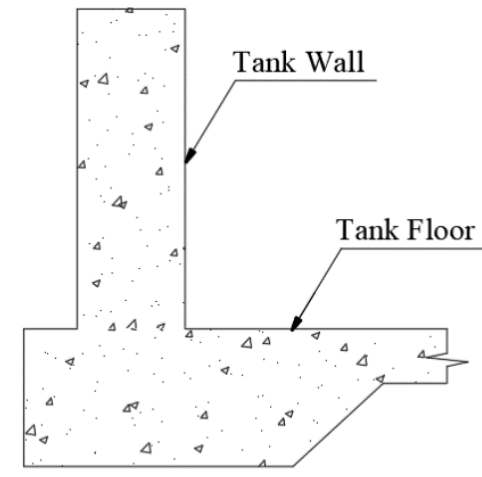

FIXED

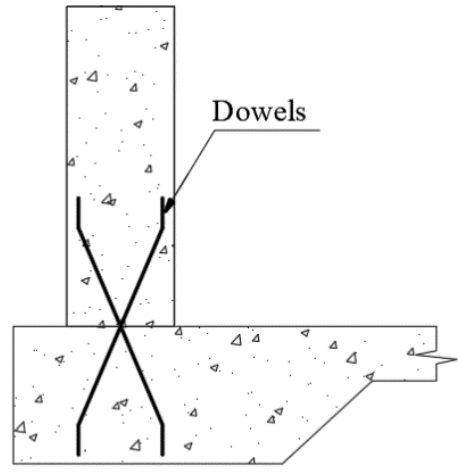

HINGED or PINNED

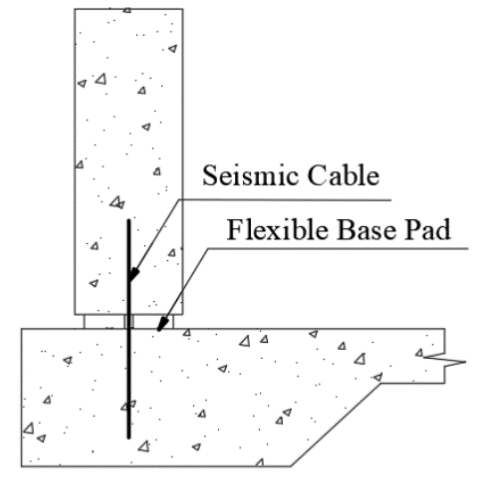

ANCHORED FLEXIBLE BASE

Figure 2.2 Types of ground-supported tanks base connections

In this study, three different base fixities (fixed, hinged and flexible base) are taken into consideration for reinforced concrete ground-supported open top circular tanks. The fixed base connection limits any radial and tangential movement at the base and vertical reinforcements used in base connection will withstand the bending moment. On the other hand, the hinged base allows rotation at tank base and thus bending moment cannot be transferred to the base. In both fixed and hinged base supports, the radial and partially tangential shear can be transmitted from the tank wall to the base.

Based on ACI 350.3-06 (2006), flexible base is only considered for prestressed circular tanks. Anchored flexible base supports includes bearing pad and seismic cables connecting the tank wall and the footing. J. A. Blume and Associates (1950's) conducted some tests to confirm the validity of seismic cables used as seismic load-resisting systems. The system of seismic 
cables develops a tangential resistance which transmits the entire base shear from the wall to the foundation. As shown in Figure 2.3, typically these cables of $15 \mathrm{~mm}$ diameter include 7wire high-strength strands inclined at $45^{\circ}$ from the horizontal and attached to the wall in tangential direction.

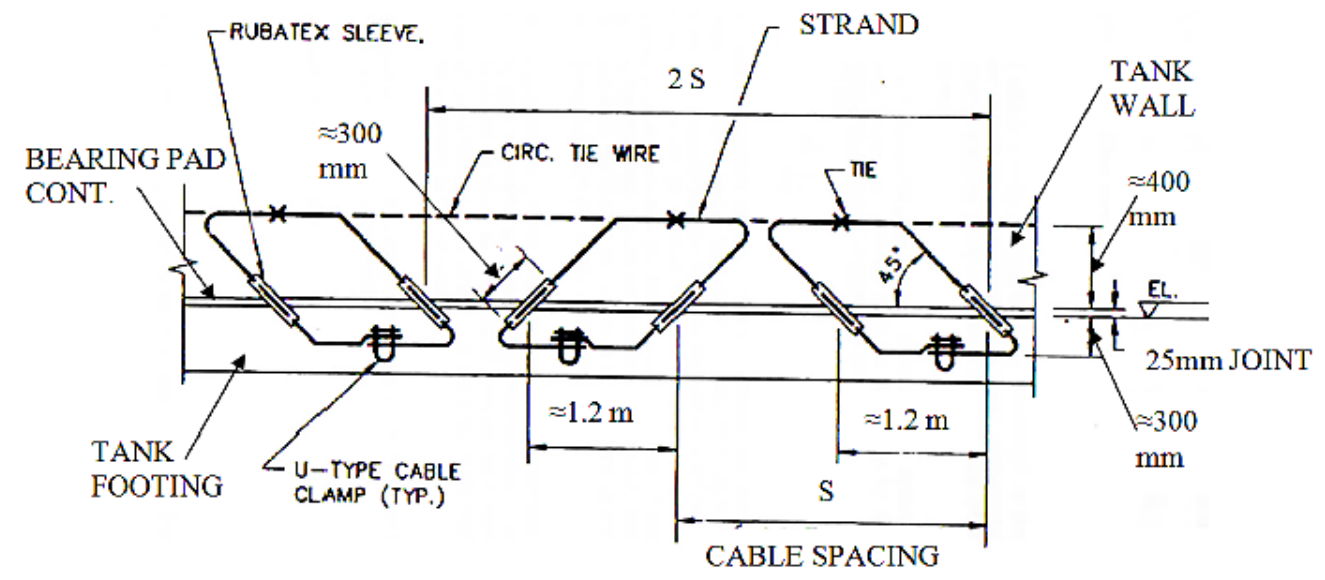

Figure 2.3 Details of seismic cables; Anchored flexible base (Adopted from Hafez, 2012)

As the seismic force direction changes during the earthquake, the cable inclination alternates. Based on the mechanism of these cables, under seismic action, the maximum resistance is developed in cables parallel to the force, while cables normal to the force hold little or no resistance. It means that there are some active cables in tension and inactive cables in compression at the same time which can resist the seismic force when the force direction is changed.

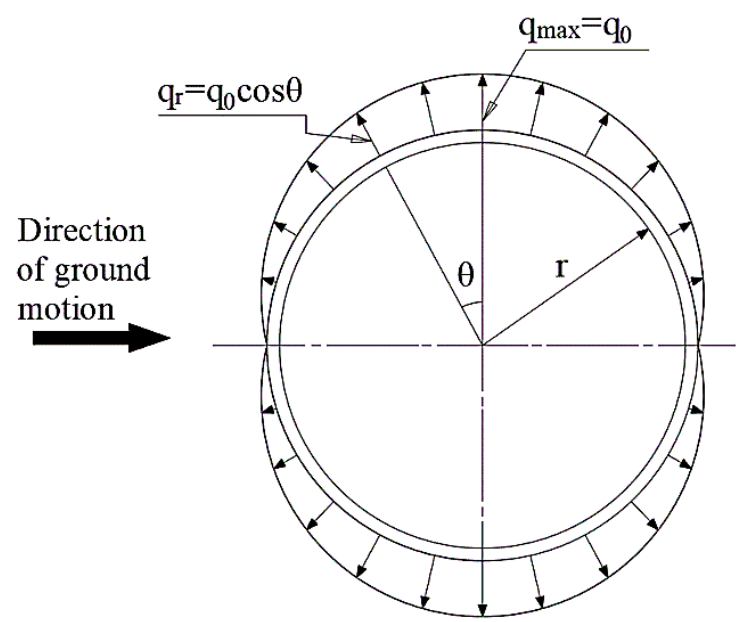

Figure 2.4 Transferred tangential shear at anchored flexible base tanks 
As shown in Figure 2.4, the cable resistance can be modified according to the cosine of the angel. According to ACI350.3-06 (2006), the maximum force acting on each seismic cable $\left(\mathrm{F}_{\max }\right)$ can be calculated by the following equation (Eq. 2.1):

$F_{\max }=2\left(q_{0} . S_{c}\right)$

$\mathrm{q}_{0}=\mathrm{q}_{\max }=\mathrm{V} / \pi \mathrm{r}$

where, $\mathrm{q}_{\mathrm{r}}$ and $\mathrm{q}_{\max }$ are shear force per unit length at angle $\theta$ and the maximum shear force, respectively. $\mathrm{r}$ is tank radius, $\mathrm{S}_{\mathrm{c}}$ is cable spacing, and $\mathrm{V}$ is the total base shear.

\subsection{Methods of seismic analysis}

The aim of structural analysis under seismic load is computing the design loads including forces and displacements on the whole system and its components. There are different methods for seismic analysis of liquid concrete tanks. Selecting the type of the method depends on different features such as configuration and type of the structure, performance of the structure and its importance. There are two classifications including static and dynamic for seismic analysis of structures each of which could be accomplished as linear or nonlinear. Static analysis is classified as code design and analysis, and nonlinear static analysis. Modal, spectral, as well as incremental and transient analysis types are categorized as dynamic analysis. However, both modal and spectral analyses employ the linear superposition approach and ignore nonlinear variations and thus they are not applicable to nonlinear systems. In this study, the nonlinear response of liquid-containing structures is appraised using both nonlinear static (pushover) and transient dynamic (time-history) analysis. To find the real response of structures to seismic loads, time-history analysis is a more practical and precise method.

\subsubsection{Nonlinear Static Analysis}

Pushover analysis is a nonlinear static procedure to evaluate seismic structural deformations employing a simplified nonlinear strategy. In the early 1980s, the pushover 
analysis was introduced as an analytical method and used to evaluate the potential structural damages throughout the earthquake. Saiidi and Sozen (1981) and Fajfar and Gaspersic (1996) are considered as the first studies on pushover analysis. As this method is simple computationally and conceptually, most rehabilitation guidelines and codes have employed this method as a tool for seismic performance evaluation of structures. In 1997, it was introduced in a guideline named FEMA 273 published by National Earthquake Hazard Reduction Program as a technique for seismic assessment of structures.

The main purpose of performing a pushover analysis is to form capacity curves of the structures. Through a typical pushover curve, some significant information including maximum developed base shear, maximum deformation prior to collapse and maximum available ductility of the structure is obtained.

In this method, to simulate real loading condition, the axial gravity load is initially applied to the structural model. Then, the structural model is exposed to the lateral load incrementally based on the defined load pattern similar to the force or deformations produced in the structure during an earthquake. The lateral load is then increased until the structure collapses; meaning that the displacement at controlling point reaches a certain target. The pushover curve illustrated in Figure 2.5 represents base shear versus lateral displacement at the controlling point at each incremental level.

Generally, the static equilibrium of the structure with small deformation in linear regime is shown by Equation 2.3.

$\Delta F=K \Delta U$

where, $F$ is vector of forces, $K$ is stiffness matrix, and $U$ is vector of displacements. Since this method considers the material nonlinearity and consequently the tangent stiffness matrix, Equation 2.3 is revised to a nonlinear equation defined in Equation 2.4.

$F=K_{t} \Delta U+R_{f}$ 
where $K_{t}$ represents the tangent stiffness matrix and $R_{f}$ is the restoring force at the beginning of each load increment defined in Equation 2.5.

$R_{f}=\sum_{i=1}^{j-1} K_{t, i} \Delta U_{i}$

where "i" denotes the current equilibrium iteration.

There are different numerical methods to solve the nonlinear equations including Newton-Raphson, Modified Newton-Raphson, and Quasi-Newton method. Choosing a proper method is important to avoid the convergence predicaments and numerical instability.

The pushover analysis could be performed either as "Conventional" or "Adaptive" (Elnashai, 2008) depending on the configuration of the structure. In a conventional pushover analysis, the load or displacement pattern is assumed to be constant. Alternatively, the adaptive pushover analysis employs the changed load or displacement pattern in different steps of analysis due to the nonlinear response of the structure. Papanikolaou et al. (2006) investigated the effect of the configuration of the structure on the two types of pushover analysis. Adaptive analysis demonstrated a better performance compared to the conventional analysis for irregular structures. However, the conventional analysis had generally more advantages over the adaptive analysis.

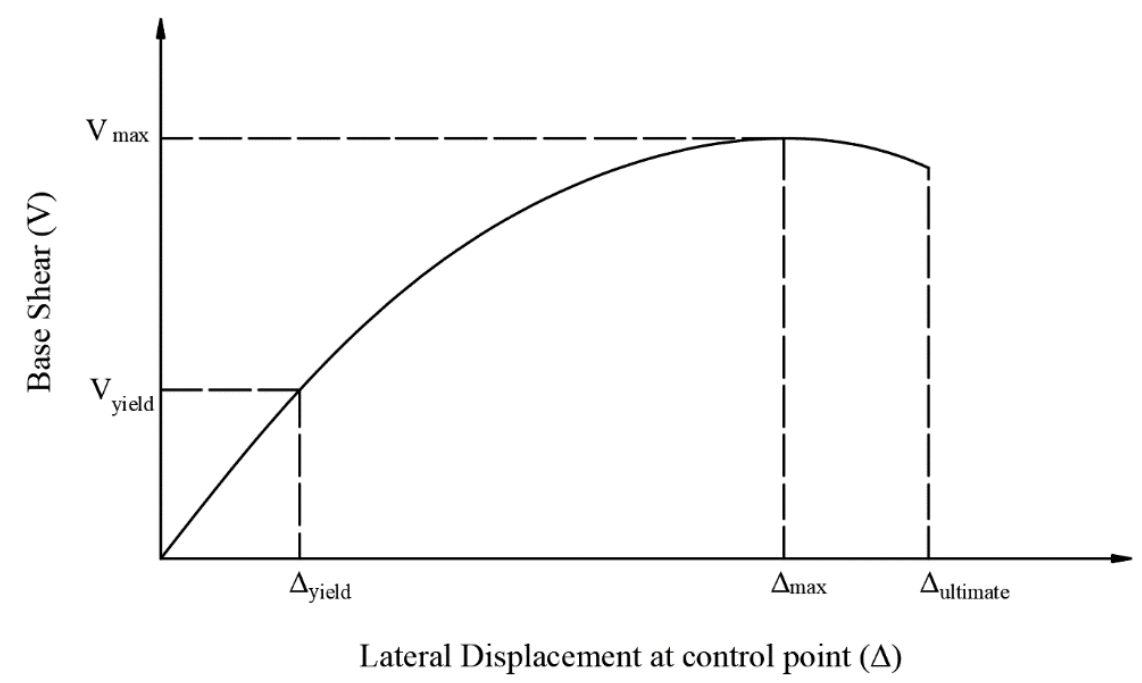

Figure 2.5 Typical pushover curve 


\subsubsection{Time-history Analysis}

Time-history analysis having nonlinear characteristics is employed to understand the complete behavior of the structure and predict its stability after earthquake. Both linear and nonlinear dynamic structural response under loading could be evaluated by time-history analysis. This analysis is an appropriate and practical method to account for the structural timedependent response and properly represents the fluid-structure interaction effects. Timehistory analysis characterizes different aspects of a ground motion such as number of cycles, duration, presence of high energy pulse and pulse sequencing. A full time-history analysis predicts the response of the structure over time and represents the level of damage to the structure at the final stage of loading. Time-history analysis is more realistic compared to response spectrum analysis and more useful for flexible structures. Response history is calculated either using a step by step numerical integration in time domain or by applying Fourier transformation in frequency domain. A typical nonlinear time-history analysis is affected by various parameters such as higher modes of vibration, damping of material, as well as geometrical and material nonlinearities.

The equation of motion of MDOF dynamic systems could be solved in both frequency and time domains. Though, to consider the nonlinearity effects on the response of the structure in more details, the time domain analysis is more the appropriate and practical. The approach of the time domain analysis is based on the step-by-step integration. According to the step-bystep method, the response history and the loading are divided into time intervals. Through the step-by-step procedure, the equation of motion stays elastic and material properties are assumed constant in each time increment, and the response is evaluated from initial condition at each time increment. In a nonlinear dynamic analysis, the equation of motion is modified by changing the tangent stiffness matrix at each time interval. 
The step-by-step analysis could be performed as either implicit or explicit. In the explicit method, the calculated response values for each time increment rely on the response quantities calculated in the previous time increment existing at the beginning of each step.

\subsection{Response Modification Factor}

Seismic design of structures is affected by a critical element named response modification factor (R-factor). This factor is currently used in seismic design codes all over the world. Selecting an incorrect $\mathrm{R}$ factor could significantly result in an underestimation or overestimation of seismic design loads. The $\mathrm{R}$ factor is defined as the ratio of the maximum force developed in a complete elastic system under lateral loading to the calculated maximum lateral load in the structure.

As a result of new developments in technology, the seismic resisting systems of modern structures have been enhanced. Since some of the seismic resisting systems have never been exposed to extreme seismic events during their life time, the actual response of such systems are not yet fully revealed. Consequently, further researches and development of practical and reliable methods are demanded for establishing more accurate R-factors.

ATC-3-06 proposed the first response modification factor in 1978. Because of the ductile behavior and reserved strength of structural members, it was proved that structures constructed based on code provisions were more resistant to higher load values in comparison to the prescribed design loads. In reality, R-factor values are evaluated by engineering judgment and committee consensus based on the approximate values of stiffness and damping and previous performance of similar structures under seismic excitations.

University of California carried out first set of experimental studies to establish the Rfactor in the mid-1980s. Uang and Bertero (1986) introduced force-displacement curves for a code-compliant concentrically braced steel frame. Whittaker et al (1987) employed similar tests on eccentrically braced steel frames. Later on, researchers at Berkley University 
investigated and introduced the first R-factor formulation. The proposed R-factor was represented as the product of strength factor $\left(\mathrm{R}_{\mathrm{s}}\right)$, ductility factor $\left(\mathrm{R}_{\mu}\right)$, and damping factor $\left(\mathrm{R}_{\xi}\right)$. Freeman (1990) offered new definitions as ductility-type and strength-type R-factors. Later, Uang (1991) proposed the R factor as the product of over-strength factor $(\Omega)$ and ductility reduction factor $\left(\mathrm{R}_{\mu}\right)$ including the effect of the damping factor implicitly. In addition, using a constant $\mathrm{R}$ factor value did not guarantee the same level of safety against the structure collapse. Accordingly, evaluating the structure over-strength throughout the design is necessary to ensure that the over-strength is more than the one employed in establishing the $\mathrm{R}$ factor.

ATC 19 was published in 1995 with a major focus on the establishment of a rational basis for the development of R-factors used for different structures. According to this new publication, the R-factor depended on period-dependent ductility $\left(\mathrm{R}_{\mu}\right)$ and strength factors $\left(\mathrm{R}_{\mathrm{s}}\right)$ as well as the redundancy factor $\left(R_{R}\right)$. Osteraas and Krawinkler (1990) investigated ductility and stored strength for distributed, perimeter and concentric moment frames. The range for reported strength factors was varied from 1.8 to 6.5 for the three framing systems considered. Since higher period structures represented smaller strength factors, it was concluded that the strength factor depended on the period of the structure. Uang and Maarouf (1993) reported a strength factor of 1.9 for a six story reinforced concrete moment frame building under 1989 Loma Prieta earthquake.

Hwang and Shinozuka (1994) determined a value of 2.2 as a strength factor by analyzing a four story reinforced concrete intermediate moment frame. In 2002, Mwafy and Elnashai analyzed 12 medium-rise RC buildings by employing inelastic pushover and incremental dynamic collapse analyses to study the R factors. It was concluded that shear and vertical motion could affect the evaluation of the $\mathrm{R}$ factor. In addition, it was shown that force reduction factors were conservatively estimated by the design code (Eurocode8) and were 
safely increased for regular frame structures designed for higher ductility levels and lower PGAs.

Later on, Mwafy and Elnashai (2002) investigated the horizontal over-strength in modern code-designed RC buildings and estimated the lateral capacity and over-strength factors through inelastic static pushover and time-history collapse analyses for $12 \mathrm{RC}$ buildings. It was concluded that buildings considering high over-strength factors led to the dominant role of gravity loads; as a result, they could resist low seismic intensity levels. The minimum reported over-strength factor was 2.

One of the studies on ductility factor $\left(\mathrm{R}_{\mu}\right)$ was made by Newmark and Hall (1982) in which a piecewise function is introduced to calculate the ductility factor $\left(R_{\mu}\right)$ without considering soil type effects. Krawinkler and Nassar (1992) introduced a relationship for SDOF systems on hard rock and soils by investigating a statistical study based on 15 Western U.S. earthquake records with the magnitude of 5.7 to 7.7 .

Since the measurement of redundancy factor $\left(R_{R}\right)$ was made indirectly and it was a complicated task, there were few studies dealing with redundancy factor. However, strength factor $\left(R_{s}\right)$ and period dependent ductility factor $\left(R_{\mu}\right)$ have been widely investigated. First effort for studying the redundancy factor was performed by Moses in 1974. This study showed that the framing system had more reliability than individual members and a partial safety factor less than or equal to one was adequate for the redundant system.

Gollwitzer and Rackwitz (1990) verified once that components of small systems have enough ductile stress-strain behavior and small dependency and if the load variability does not affect the variability of strength, those system show significant extra reliability. In addition, while the components of redundant structural systems were highly dependent and separated, a significant reliability was provided in the systems. For small brittle systems, a negative effect of redundancy for small coefficients of variation was concluded as well. Wang and Wen (2000) 
introduced a new parameter defined as the ratio of spectral displacement capacity over the spectral displacement corresponding to a specified allowable probability (for incipient collapse). In this study, a uniform-risk redundancy factor was calculated by employing this ratio.

Husain and Tsopelas (2004) performed a parametric study employing two-dimensional $\mathrm{RC}$ frames to introduce redundancy strength index $\left(\mathrm{r}_{\mathrm{s}}\right)$ and variation strength index $\left(\mathrm{r}_{\mathrm{v}}\right)$. The results represented that increasing the member ductility of RC frames enhanced the frames redundancy. However, increasing the member ductility for RC frames with a member ductility ratio of 10 or more did not add to the frames redundancy. It was proved that same number of plastic hinges at failure are developed for both ductile and moderately ductile RC frames. It means that the only contribution of redundancy depends on the redundancy strength index $\left(\mathrm{r}_{\mathrm{s}}\right)$. Next, Husain and Tsopelas (2004) studied 2D frames and investigated the effect of different factors on the structural redundancy such as number of stories, beam span length, building height, number of vertical lines of resistance, and number ductility capacity. Then, an equation for calculating the redundancy factor was proposed which required some parameters to be obtained from the nonlinear static analysis (pushover) of the structure.

FEMA-P695 (2009) proposed a different methodology compared to other proposed approaches to compute the response modification factor. This method is a combination of code design concepts, static and dynamic nonlinear analysis, and risk and probability based procedures. To establish the R factor, FEMA-P695 assesses some trial values and confirms the best one that matches the required performance level of the structure. Recommended procedure by FEMA-P695 validates the proposed values for the $\mathrm{R}$ factors instead of using the explicit calculation of the $\mathrm{R}$ factor. 


\subsection{Nonlinearity in Reinforced Concrete Structure Analysis}

Nonlinearity appears in most of the physical problems. Nonlinearities are classified into various major types for the structure including geometrical nonlinearity and material nonlinearity. Geometrical nonlinearity takes place as a result of large deformation. Deformation involves the translation and rotation of the body simultaneously implying the change in shape and/or size of the body from an initial configuration to a deformed configuration. Large deformation would change the stiffness matrix and equilibrium equation of the structure and consequently would affect the structural analysis.

Material nonlinearity is correlated with the inelastic behavior of material. Inelastic behavior is characterized by the nonlinear stress-strain relationship of material. Material property changes with the applied load; additional loading causes stress level increment beyond the elastic limit resulting in material nonlinearity.

\subsection{Concrete Cracking}

Concrete relatively behaves brittle and weak under tension. It means when it is subjected to significant tensile stresses, it will be cracked. To increase concrete resistance in tension, and reduce the concrete cracking, reinforcements are employed in concrete section. In this study, since the design of circular liquid containing tanks is affected by the hoop force and concrete cracking is due to direct tension, the ACI report (ACI 224.2R-92, 2004) is employed to study the concrete cracking behavior. However, the ACI Committee has also reported a code (ACI 224R-01, 2008) which is applicable to control of cracking of concrete members in general.

After a member cracks under direct tension, the stress pattern changes in between the cracks (ACI224.2R-92). By increasing the stress level, additional primary cracks continue to develop until the average cracks spacing reaches almost twice the concrete cover thickness (Broms and Lutz 1965). 
According to ACI 224.2R-92 (2004), the maximum crack spacing at high steel stress is approximately 4 times of concrete cover, and the crack width can be estimated by multiplying the maximum crack spacing by the average strain of reinforcement $\left(\varepsilon_{s}\right)$. Since the actual concrete cover is not an appropriate variable for calculating the maximum crack width when more than one reinforcing bar is assumed for tensile member, the effective concrete cover $\left(t_{e}\right)$ is employed. Brooms and Lutz (1965) suggested the following equation for calculating the effective concrete cover $\left(t_{e}\right)$ and the maximum tensile crack width $\left(w_{\max }\right)$.

$t_{e}=\sqrt{1+\left(S / 4 d_{c}\right)^{2}}$

$w_{\max }=4 t_{e} \varepsilon_{s}$

$w_{\max }=0.1 f_{S} \sqrt[3]{d_{c} A_{c}} \times 0.145 \times 10^{-3}$

where, $w_{\max }$ is maximum tensile crack width, $t_{e}$ is the concrete cover, $\varepsilon_{s}$ is the reinforcement strain, $S$ is bar spacing $(\mathrm{mm}), d_{c}$ is the distance from the center of the bar to the extreme tension fiber $(\mathrm{mm}), A_{c}$ is the area of concrete symmetric width reinforcing steel divided by number of bars $\left(\mathrm{mm}^{2}\right)$, and $f_{s}$ is the reinforcement stress (MPa).

Although the cracking behavior of RC members is analogous under both axial tension and flexure, these members exposed to axial tension tend to develop wider cracks. The reason behind this difference is the compression zone in flexural members that restricts the cracks from developing through the section.

According to ACI 224.2R-92 (2004) and ACI 224R-01 (2008), the maximum flexural crack width for flexural members can be calculated by the following equation:

$w_{\max }=(0.076 \beta) f_{S} \sqrt[3]{d_{c} A_{c}} \times 0.145 \times 10^{-3}$

where, $\beta$ is the ratio of distance between neutral axis and tension face to distance between neutral axis and centroid of reinforcement. If $\beta$ is considered approximately as 1.2 , 
the coefficient $0.076 \beta$ changes to 0.091 . Consequently, the maximum tensile crack width will be about $\% 10$ wider than the maximum flexural crack.

Kianoush et al. (2006) carried out a study on the Froschs' approach (1999) to estimate the crack width in liquid containing structures. According to this research, the flexural cracking width can be estimated using the following equation:

$w_{c}=112 \varepsilon_{S} \Psi_{S}$

where, $\varepsilon_{\mathrm{s}}$ is the strain reinforcement, $w_{c}$ is the crack width, and $\Psi_{\mathrm{s}}$ is the crack spacing factor. A crack spacing factor of 1.0 was suggested by Kianoush et al. (2008) when Equation (2.10) was employed in finite element analysis. In typical LCS, using Equation (2.10) and assuming the crack spacing factor of 1.0 and yield strain reinforcement of 0.002 , the flexural cracking width will be equal to $0.224 \mathrm{~mm}$. According to ACI 350-06 (2006), the value of 0.224 $\mathrm{mm}$ is less than the crack width limit of $0.25 \mathrm{~mm}$ recommended for normal environment exposure conditions. In water-retaining structures, the allowable crack width is limited to 0.1 mm based on ACI 224R-01 (2008).

Self-healing phenomenon of concrete has been a controversial topic in past decades. Edvardsen (1999) performed studies on concrete members under direct tension and proved that initial effective crack width of $0.2 \mathrm{~mm}$ was closed after seven weeks of exposure to the water. In 2009, Ziari and Kianoush implemented research on concrete leakage and cracking under direct tension. They noticed that the tension crack width of $0.25 \mathrm{~mm}$ healed itself as a result of being exposed water. 


\section{Chapter 3 \\ Effect of Various Parameters on Seismic Response of Uncracked RC Tanks}

\subsection{Introduction}

This chapter investigates the effect of ground motion response on linear elastic concrete circular tanks. Presented information and concepts in this chapter indicate that the critical hydrodynamic pressure affects the structural design. First, basic concepts in seismic analysis of liquid containing structure and a basic theory to compute earthquake-induced forces are discussed. The specific elastic design response spectrum based on lateral seismic force equations of ACI $350.3(2001,2006)$ is discussed. Thereafter, the influence of vertical and horizontal distribution of hydrodynamic forces on the tank wall is investigated. The accuracy of pressure distribution on the circular tank wall in FE model is examined by comparing FE results with analytical solutions. Lastly, the effect of tank dimension and base fixity on stress, moment and force distribution on tank wall is studied.

\subsection{Tank behavior under seismic loads}

General liquid containing structures investigated in this study have circular crosssections. This LCS is supported through a rigid foundation and filled with a homogeneous, incompressible and inviscid liquid. The wall thickness is constant and connected to its base to prevent any sliding or uplift.

ACI 350.3 (2006) considers an equivalent static model to calculate seismic force values acting on ground supported liquid-containing tanks with rigid wall. As shown in Figure 3.1, the resultant effect of impulsive and sloshing fluid pressures on the tank wall is represented by equivalent masses of impulsive and convective components of the stored liquid $\left(\mathrm{W}_{\mathrm{i}}, \mathrm{W}_{\mathrm{c}}\right)$, 
respectively. The fluid motion associated with wave oscillation causes sloshing pressure on the wall. The sloshing applies fluid pressure on the wall and so if the dead load is not sufficient, the tank will tend to uplift due to this convective pressure.

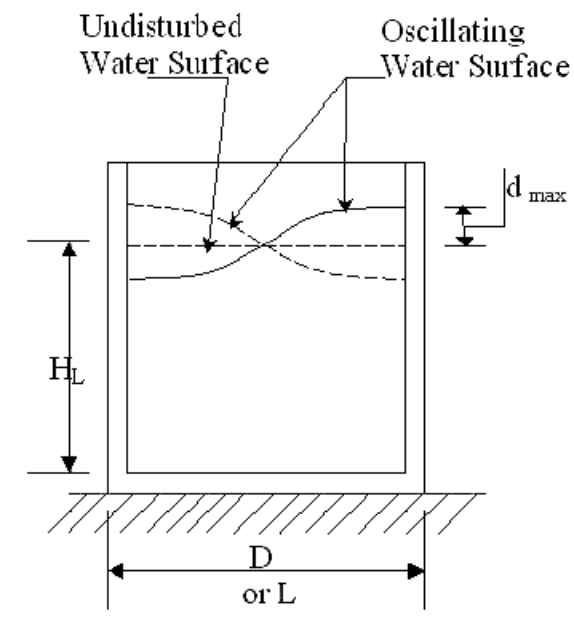

(a)

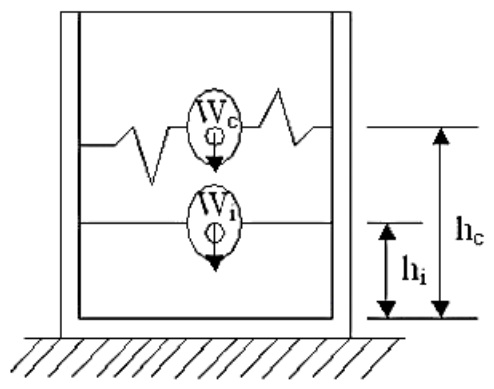

(b)

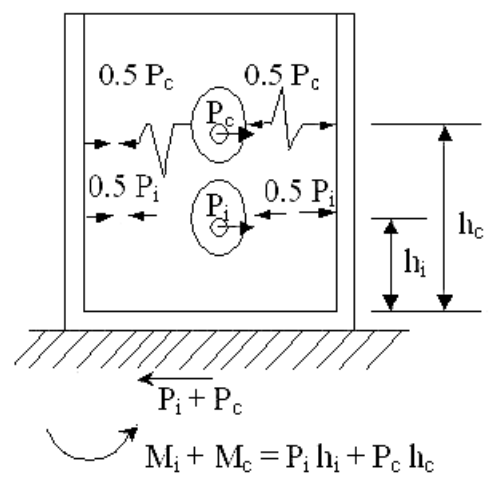

(c)

Figure 3.1 Ground supported liquid containing tank; a) Fluid motion, b) Dynamic model, c) dynamic equilibrium of horizontal forces

The seismic acceleration of tank walls leads to an impulsive pressure. The resultant impulsive pressure $\left(\mathrm{P}_{\mathrm{i}}\right)$ is classified into a pressure on the wall accelerating into the fluid, and a suction on the wall accelerating away from the fluid. The impulsive force $\left(\mathrm{P}_{\mathrm{i}}\right)$ direction changes by varying direction of the base acceleration. In an equivalent model, it is assumed that $\mathrm{W}_{\mathrm{i}}$ is rigidly attached to the tank wall at an equivalent height $\left(\mathrm{h}_{\mathrm{i}}\right)$ where the resultant impulsive force $\left(\mathrm{P}_{\mathrm{i}}\right)$ is applied. The convective force $\left(\mathrm{P}_{\mathrm{c}}\right)$ is produced by the equivalent mass of oscillating fluid $\left(\mathrm{W}_{\mathrm{c}}\right)$, applied at an equivalent height of $\mathrm{h}_{\mathrm{c}}$. A period of vibration corresponding to the period of sloshing fluid is produced by connecting $\mathrm{W}_{\mathrm{c}}$ flexibly to the walls.

The impulsive and convective forces acting simultaneously and independently on the wall apply an overturning moment at the base. Distribution of stresses on the tank wall is 
produced as a result of the impulsive force and its associated pressure, and the convective force exerts uplift of the tank wall. In addition, vertical ground vibrations transmitted to the fluid could also produce pressure and hoop stress in the wall.

\subsection{ACI 350.3 design requirements}

ACI 350.3 (2006) is employed to design liquid-containing structures and their components such as the wall, roof and floor to resist horizontal and vertical accelerations along with static loads. According to ACI 350.3-06 (2006), liquid-containing structures are designed for both dynamic and static effects. Dynamic lateral forces above the base are calculated using the following equations:

$P_{w}=C_{i} I\left[\frac{\varepsilon W_{w}}{R_{i}}\right]$

$P_{r}=C_{i} I\left[\frac{W_{r}}{R_{i}}\right]$

$P_{i}=C_{i} I\left[\frac{W_{i}}{R_{i}}\right]$

$P_{c}=C_{c} I\left[\frac{W_{c}}{R_{c}}\right]$

where $\mathrm{P}_{\mathrm{w}}$ and $\mathrm{P}_{\mathrm{r}}$ are inertia forces exerted on the wall and the roof, respectively; $\mathrm{P}_{\mathrm{i}}$ is hydrodynamic impulsive force due to accelerated contained liquid; $\mathrm{P}_{\mathrm{c}}$ is hydrodynamic convective force due to accelerated contained liquid. Moreover, terms $C_{i}$ and $C_{c}$ are perioddependent seismic response coefficients for impulsive and convective terms, respectively; $I$ is the importance factor as listed in Table 3.1 which is used to increase the factor of safety for some categories of structures; $\varepsilon$ is the effective mass coefficient defined as the ratio of equivalent dynamic mass of the tank wall to its actual total mass; $\mathrm{W}_{\mathrm{w}}$ and $\mathrm{W}_{\mathrm{r}}$ are the weights of the wall and the roof, respectively. As discussed, $\mathrm{W}_{\mathrm{i}}$ and $\mathrm{W}_{\mathrm{c}}$ are the effective weights of the stored liquid corresponding to impulsive and convective components, respectively adapted from Housner's method (Housner, 1957, 1963); $\mathrm{R}_{\mathrm{i}}$ and $\mathrm{R}_{\mathrm{c}}$ are response modification factors 
corresponding to impulsive and convective terms, respectively (Table 3.2). Since maximum horizontal and vertical acceleration effects should be considered at the same time, the impulsive and convective terms of response can be combined using the square root sum of the squares (SRSS) method as mentioned in ACI 350.3-06.

Table 3.1 Importance factor I (Adopted from ACI 350.3-06)

\begin{tabular}{|c|c|c|}
\hline & Tank Use & Factor I \\
\hline III & Tanks containing hazardous materials & 1.5 \\
\hline II & $\begin{array}{c}\text { Tanks that are intended to remain usable for } \\
\text { emergency purposes after an earthquake, or tanks } \\
\text { that are part of lifeline systems }\end{array}$ & 1.25 \\
\hline I & Tanks not listed in Categories II or III & 1.0 \\
\hline
\end{tabular}

Table 3.2 Response modification factors R (Adopted from ACI 350.3-06)

\begin{tabular}{|c|c|c|c|}
\hline \multirow{2}{*}{ Type of structure } & \multicolumn{2}{|c|}{$\mathrm{R}_{\mathrm{i}}$} & \multirow{2}{*}{$\mathrm{R}_{\mathrm{c}}$} \\
\cline { 2 - 4 } & $\begin{array}{c}\text { On or } \\
\text { above } \\
\text { grade }\end{array}$ & Buried & \\
\hline Anchored, flexible-base tanks & 3.25 & 3.25 & 1.0 \\
\hline Fixed or hinged-base tanks & 2.0 & 3.0 & 1.0 \\
\hline $\begin{array}{c}\text { Unanchored, contained, or } \\
\text { uncontained tanks }\end{array}$ & 1.5 & 2.0 & 1.0 \\
\hline Pedestal-mounted tanks & 2.0 & - & 1.0 \\
\hline
\end{tabular}

The impulsive seismic response coefficient $C_{i}$ is determined as follows:

For $T_{i} \leq T_{S}, C_{i}=S_{D S}$

For $T_{i}>T_{S}, C_{i}=\frac{S_{D 1}}{T_{i}} \leq S_{D S}$

The convective seismic response coefficient $\mathrm{C}_{\mathrm{c}}$ is determined as follows as per ACI 350.3-06:

For $T_{c} \leq 1.6 / T_{S}, \quad C_{c}=\frac{1.5 S_{D 1}}{T_{c}} \leq 1.5 S_{D S}$ 
For $T_{C}>1.6 / T_{S}, \quad C_{C}=6 \frac{0.4 S_{D S}}{T_{c}{ }^{2}}=\frac{2.4 S_{D S}}{T_{C}^{2}}$

where,

$\mathrm{S}_{\mathrm{DS}}=2 / 3 \mathrm{~F}_{\mathrm{a}} \mathrm{S}_{\mathrm{S}}$ : Design spectral response acceleration at short periods,

$\mathrm{S}_{\mathrm{D} 1}=2 / 3 \mathrm{FV}_{\mathrm{V}}$ : Design spectral response acceleration at one-second period,

$\mathrm{T}_{\mathrm{S}}=\mathrm{S}_{\mathrm{D} 1} / \mathrm{S}_{\mathrm{DS}}$

$\mathrm{T}_{\mathrm{i}}, \mathrm{T}_{\mathrm{c}}$ : Natural period of impulsive mode and convective mode, respectively,

$\mathrm{S}_{\mathrm{S}}$ : Mapped Maximum Considered Earthquake (MCE) spectral response acceleration at short periods,

$\mathrm{S}_{1}$ : Mapped MCE spectral response acceleration at one-second period,

$F_{a}$ : Short-period site coefficient (at 0.2 second period),

$\mathrm{F}_{\mathrm{V}}$ : Long-period site coefficient (at 1.0 second period).

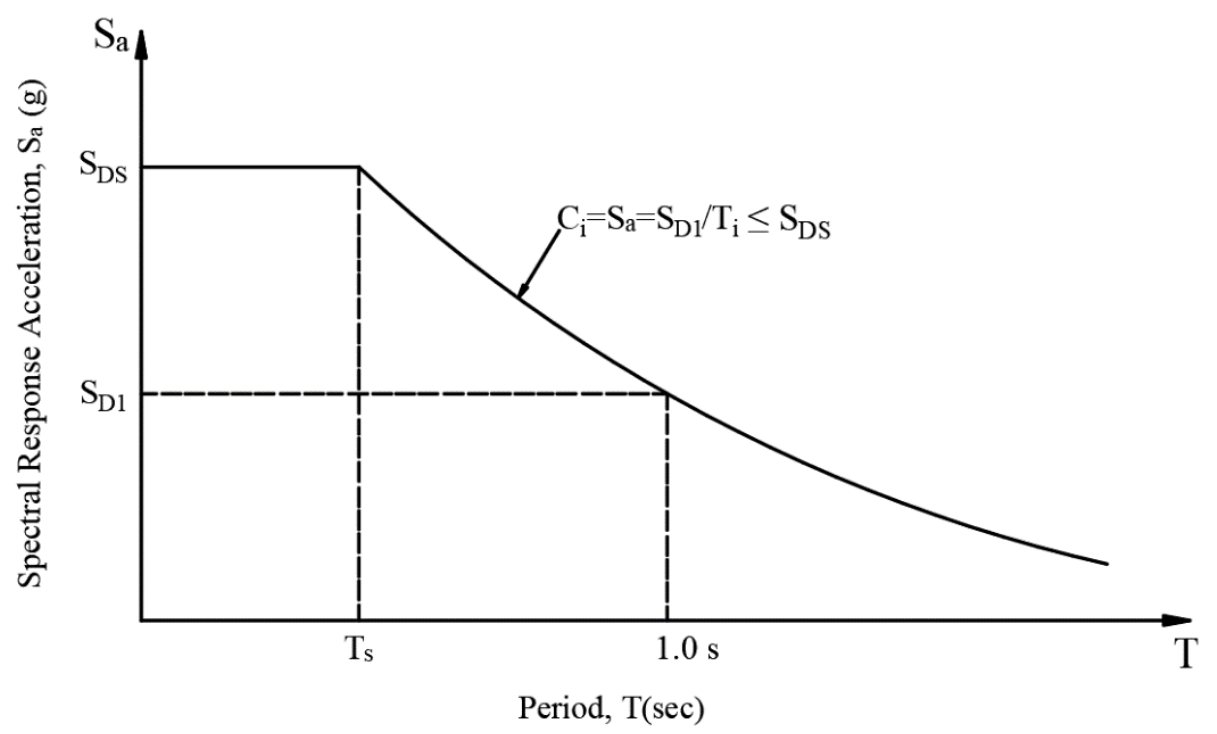

Figure 3.2 Design response spectrum (Adopted from ACI 350.3-06)

The coefficients $S_{S}, S_{1}, F_{a}$, and $F_{V}$ are determined in accordance with ASCE 7-010 (2013). Figure 3.2 adapted from ACI 350.3-06 shows the design response spectrum used in determining the impulsive seismic response coefficient $C_{i}$.

According to ACI 350.3-06, the LCS should be designed based on hydrodynamic pressures corresponding to horizontal and vertical accelerations. To calculate the equivalent 
hydrodynamic pressure due to the effect of vertical acceleration $\left(P_{v y}\right)$, the hydrostatic pressure $q_{h y}$ at level y above the base should be multiplied by the spectral acceleration $\left(\ddot{U}_{v}\right)$, which obtained by the following equation:

$P_{v y}=\ddot{U}_{v} q_{h y}$

If a site-specific response spectrum is not available, the ratio of vertical to horizontal acceleration should not be less than $2 / 3$. The details of hydrostatic and hydrodynamic force calculations as per ACI 350.3-06 are presented in Appendix A.

\subsection{FE load distribution on the wall}

For this study, a 3-D model of a full ground-supported open top circular tank is considered with different base conditions including fixed, hinged and flexible. For pushover analysis, both hydrostatic and hydrodynamic pressures should be applied on the wall.

The hydrostatic pressure has a triangle linear distribution along the wall height which is maximum at the tank base. Horizontally, the pressure is distributed uniformly around the circumference.

The hydrodynamic loading applied on the wall is calculated assuming a high seismic zone having $\mathrm{S}_{\mathrm{S}}=150 \%$ and $\mathrm{S}_{1}=60 \%$, where $\mathrm{S}_{\mathrm{S}}$ is the mapped maximum considered earthquake (MCE) spectral response acceleration at short periods, and $S_{1}$ is the MCE spectral response acceleration at one second period.

As per ACI 350.3-06, the hydrodynamic load acting perpendicular to the wall plane is distributed linearly per unit length along the height of the wall. On the other hand, pressure experiences a cosine distribution pattern circumferentially. As shown in Figure 3.3, the maximum vertical pressure along the height occurs at the base of the tank. In addition, for 

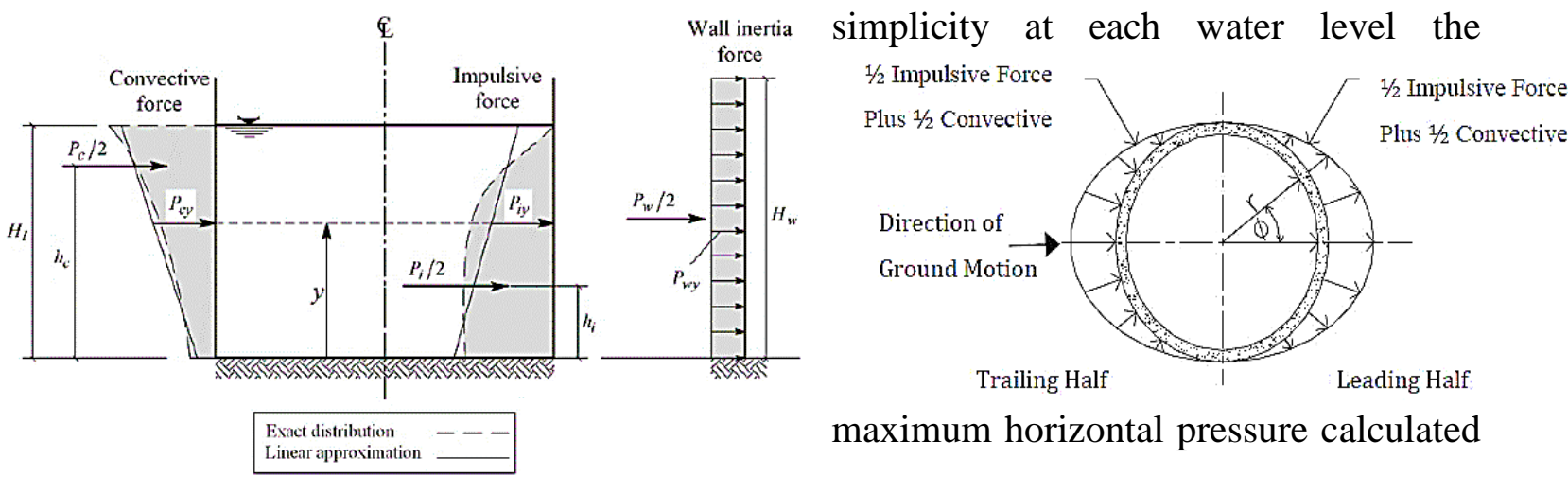

maximum horizontal pressure calculated

at $\theta=0$ is uniformly distributed at all angles across the entire cross-section of the tank.

(a)

(b)

Figure 3.3 Seismic force distribution an tank walls; (a) Vertical distribution, (b) Horizontal distribution

The design hydrostatic and hydrodynamic pressures calculated for a circular tank with a diameter of $40 \mathrm{~m}$, wall height of $6.5 \mathrm{~m}$, liquid height of $6 \mathrm{~m}$ and wall thickness of $400 \mathrm{~mm}$ is shown in Figure 3.4. In this figure, $\mathrm{P}_{\mathrm{iy}}, \mathrm{P}_{\mathrm{cy}}$, and $\mathrm{P}_{\mathrm{wy}}$ are hydrodynamic impulsive pressure, convective pressure, and inertia forces exerted on the wall, respectively. $\ddot{U}_{v} q_{h y}$ is equivalent hydrodynamic pressure due to the effect of vertical acceleration. Moreover, HS and HD refer to hydrostatic and hydrodynamic pressure, respectively. The earthquake design loads and detailed calculations are given in Appendix A. 


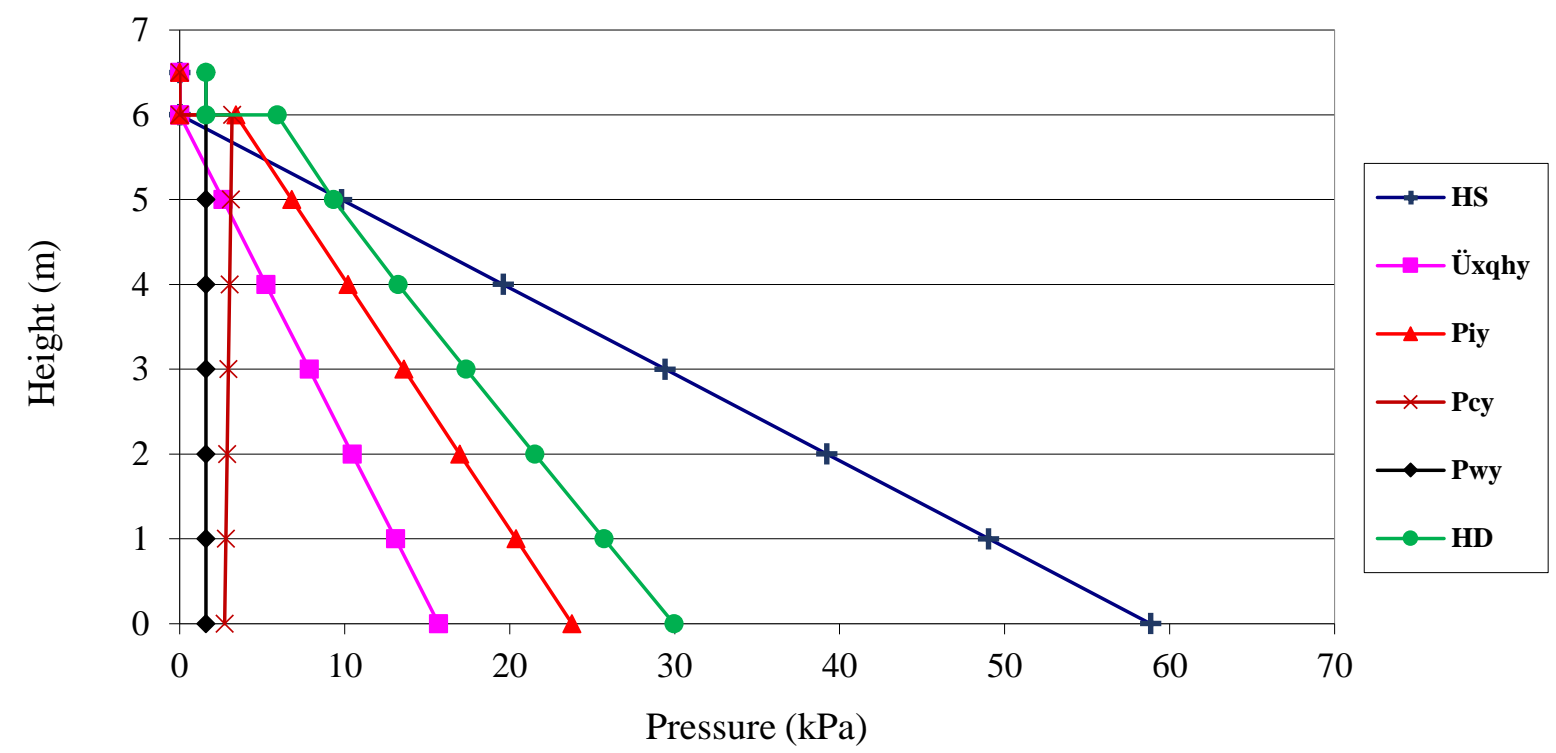

Figure 3.4 Design hydrostatic and hydrodynamic load on the wall at $\theta=0$ degree

\subsubsection{Validation of FE load distribution}

The objective of this section is to define and verify a finite element (FE) technique for modeling reinforced concrete (RC) tanks in order to perform a proper and accurate seismic analysis. The general purpose FE modeling software ANSYS is employed for this purpose.

\subsubsection{Linear static analysis of cylindrical tanks under hydrostatic and hydrodynamic loading}

In pushover study, horizontal earthquake loads are simplified as equivalent static lateral loads based on ACI 350.3-06 (2006). In this section, the structural response is assumed to remain linear elastic under both hydrostatic and hydrodynamic loadings. The verification of equivalent lateral static loading applied to the tank wall will be performed using analytical solutions as detailed in the following paragraphs.

To check the accuracy of horizontally distributed forces on the wall and finite element response, numerical results will be compared with analytical solution results. For the purpose of comparison, this study is performed in accordance with the theory of plates and shells proposed by Timoshenko (1976) and frame analogy proposed by Priestley (1985). Based on this comparison, the behavior of the tank in terms of deflection, hoop and shear force, and bending moment is investigated. 
Timoshenko (1976) proposed various equations required for solving problems in which cylindrical shells are exposed to the action of internal and symmetrical distributed forces on the height of the shell. Using this approach, cylindrical tanks are subjected to liquid pressure and the results are calculated under a linear static regime. Timoshenko's equations and detailed calculations are provided in Appendix B.

The response of a cylindrical tank wall under a symmetric loading condition includes two mechanisms; vertical bending and hoop tension. This behavior is identical to a vertical beam action which its radial deformation is constrained by some stiffness resulted from the hoop action. According to the analogy of Beam on Elastic Foundation (BEF), the vertical bending response of the wall is calculated by the beam action and the spring stiffness of the Winkler (1867) foundation is employed to represent the elastic radial stiffness due to hoop action. Based on simple statistics, the radial expansion can be calculated considering a unit height of tank wall subjected to pressure $p$, and released from cantilever action. This radial expansion can be calculated as:

$y=\frac{p R^{2}}{t E_{c}}$

where, $p$ is pressure, $R$ is tank radius, $t$ is wall thickness and $E_{c}$ is elastic modulus of concrete. Precise wall behavior can be modeled by a unit circumferential length of the wall supported by a horizontal Winkler foundation. Deflection of the foundation under pressure $\mathrm{p}$ is calculated by:

$y=p k$ 
where $k$ is subgrade modulus which is given by the following equation (Eq. 3.12):

$k=\frac{t E_{c}}{R^{2}}$
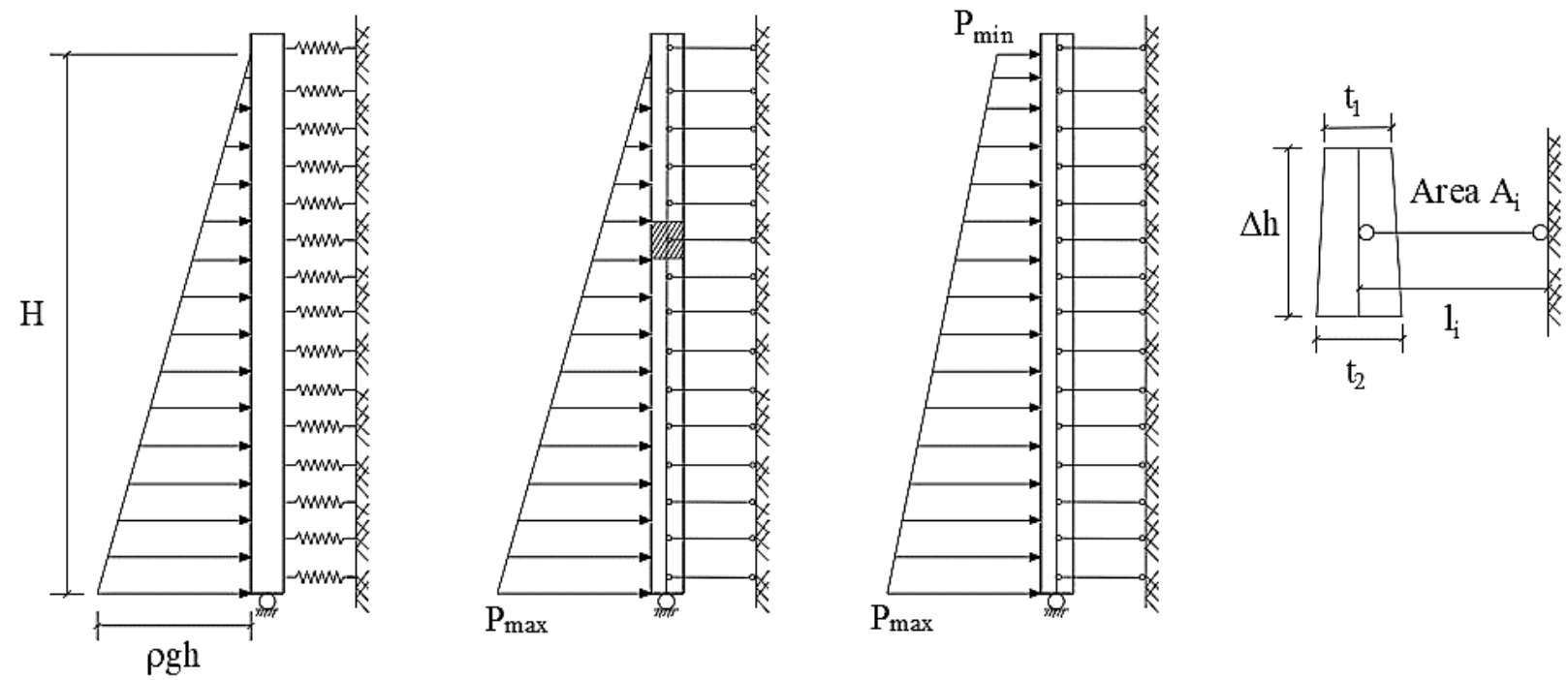

Figure 3.5 Framè analogy simulations; a) Continuous Winkler foundátion, b) Discretized foundationFrame analogy with hydrostatic pressure distribution, c) Seismic vertical pressure distribution, d) Detail of equivalent strut (Priestley et al. 1985)

Figure 3.5-a shows the Winkler foundation. It is important to note that this model can be replaced by a more convenient method of simulation called frame analogy. By employing the discrete system shown in Figure3.5-b, the tank wall is divided into a number of vertical beam elements with the nodes connected to a rigid foundation using lateral pin-ended struts. This system can be solved through a simple frame analysis.

In this analysis technique, the vertical bending stiffness properties are presented by beam elements, while the struts properties offer the radial stiffness of the wall. The simulation of the hoop stiffness for a unit circumferential width of the wall is practiced as:

$y=\frac{2 p R^{2}}{\left(t_{1}+t_{2}\right) E_{c}}=\frac{p \Delta h l_{i}}{A_{i} E_{i}}$ 
For convenience, the elastic modulus of concrete $\left(E_{c}\right)$ is set equal to the strut's elastic modulus $\left(E_{i}\right)$. The strut's cross sectional area $\left(A_{i}\right)$ and its length $\left(l_{i}\right)$ can be calculated by Equation (3.14):

$\frac{A_{i}}{l_{i}}=\frac{\left(t_{1}+t_{2}\right)}{2 R^{2}} \Delta h$

The moments developed in beam elements represent vertical bending moments and circumferential stresses are calculated by substituting nodal radial displacements in the following equation (3.15):

$f_{c}=f_{h} \mp v_{c} f_{v}$

$f_{c}=\frac{E_{c} y}{R} \mp v_{c} \frac{6 M_{y}}{t^{2}}$

where, $v_{c}$ is Poisson's ratio, $y$ is radial deformation, $f_{h}$ is hoop tension stress, $f_{v}$ is bending stress in vertical direction and $M_{y}$ is vertical bending moment. In this method, both vertical linear hydrostatic and hydrodynamic distributions of pressure can be applied vertical beam elements.

For frame analysis, ANSYS is employed to model vertical beam as well as link elements as struts. In this study, a full circular tank with a height of $6 \mathrm{~m}$, diameter of $40 \mathrm{~m}$ and thickness of $400 \mathrm{~mm}$ is considered. The specified compressive strength of concrete $\left(f_{c}^{\prime}\right)$ is 30 $\mathrm{MPa}$ and elastic modulus of concrete is assumed as $26 \mathrm{GPa}$. The hydrostatic pressure is assumed to be linear triangular along the height with its maximum at the base. The results obtained through Frame analysis are shown in Figures 3.6 to 3.8. 


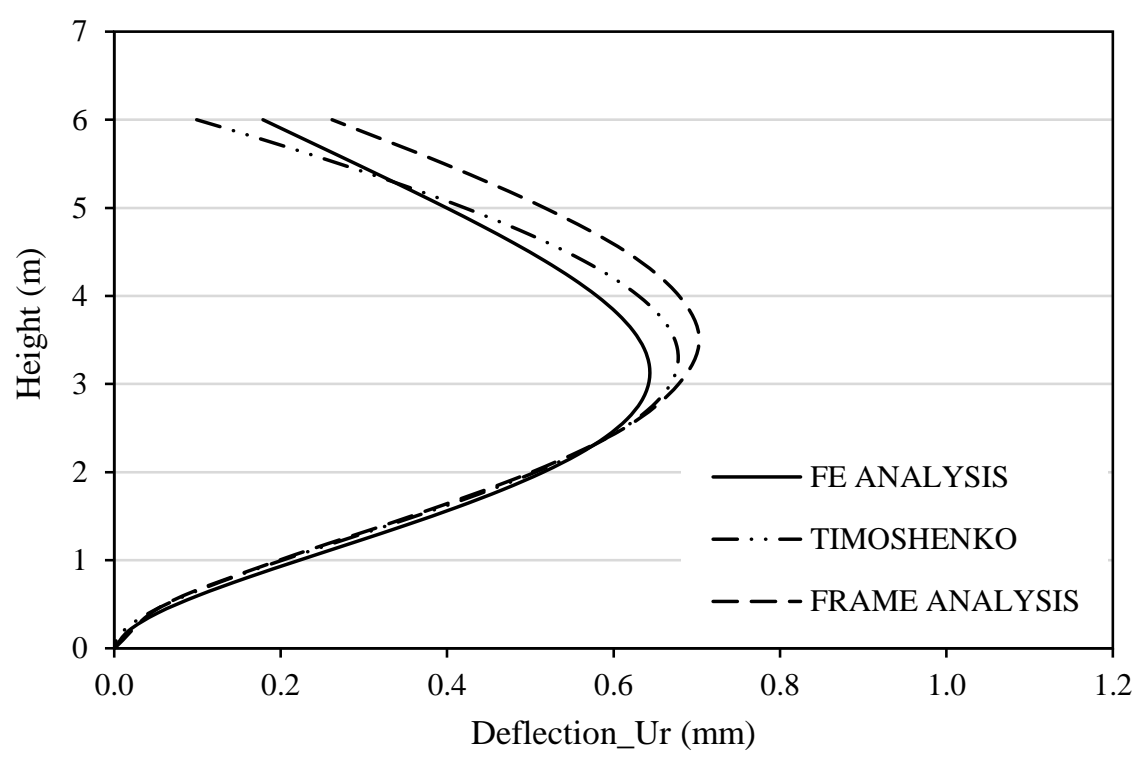

Figure 3.6 Radial deflection in tank wall due to hydrostatic pressure

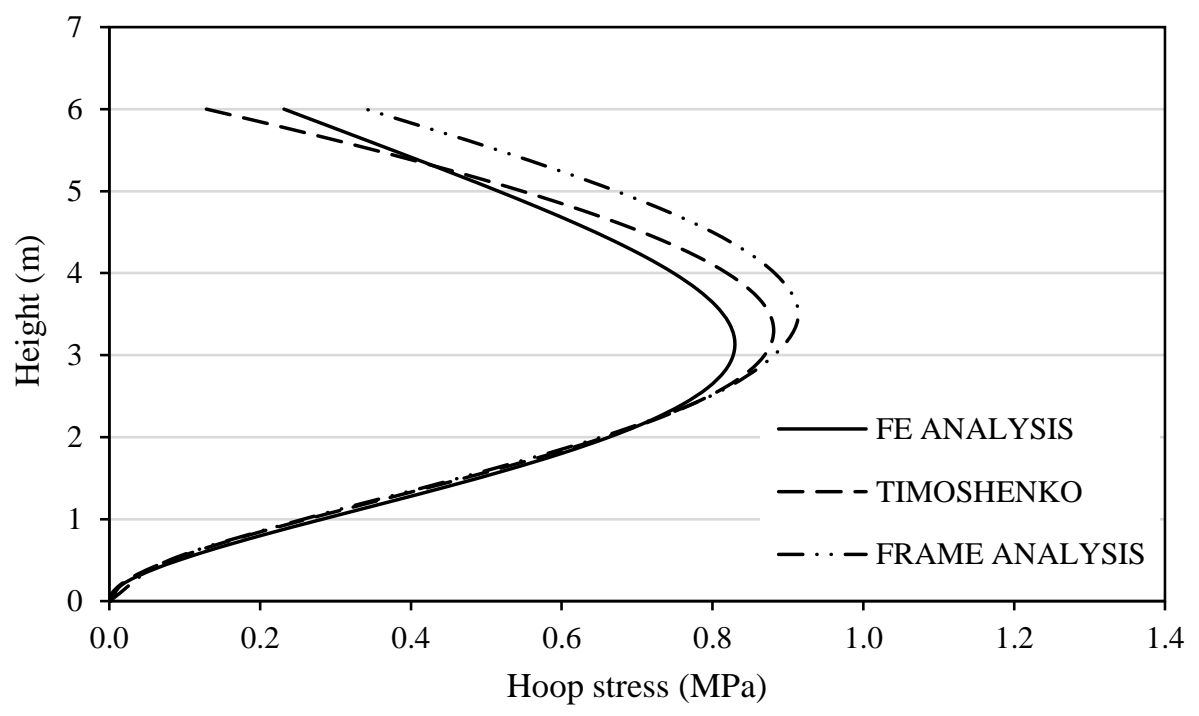

Figure 3.7 Hoop stress in tank wall due to hydrostatic pressure 


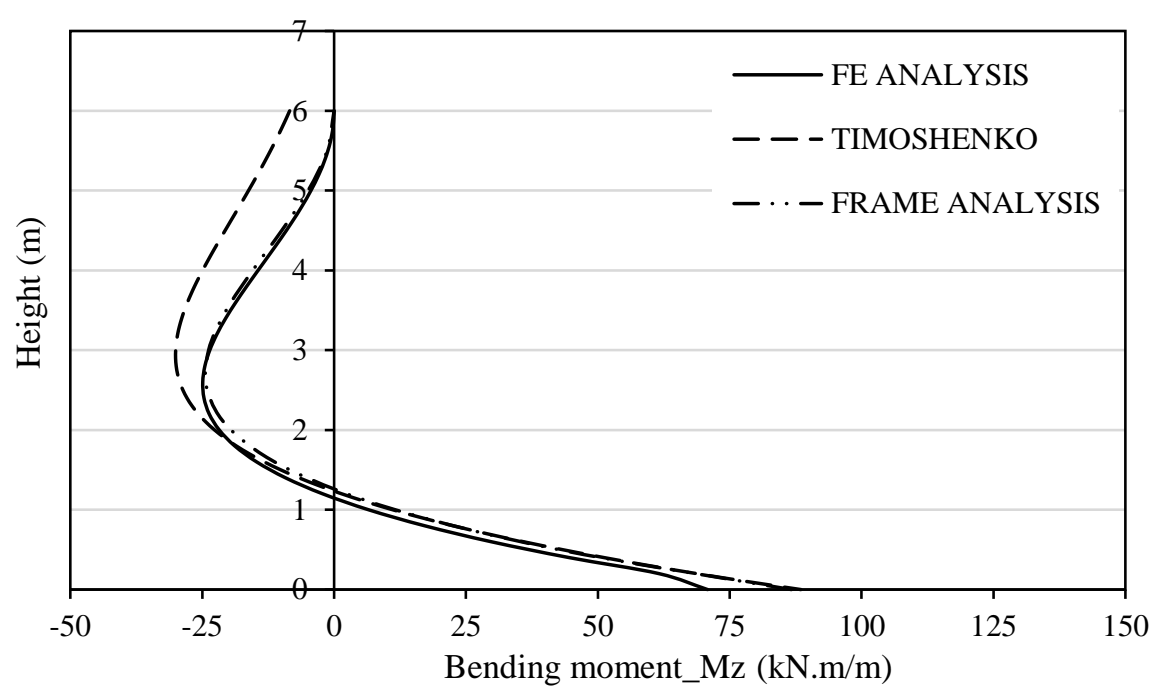

Figure 3.8 Vertical bending moment in tank wall due to hydrostatic pressure

As shown in Figures, the radial deflection, hoop stress and bending moment are within a close proximity along the tank height for all analysis: FE, Timoshenko and Frame analysis. Therefore, it can be concluded that the horizontal forces are properly distributed along the wall of FE model. The maximum difference of the wall radial deflection and hoop stress between FE and Timoshenko and Frame analysis is less than $30 \%$ and $15 \%$ at the top and middle of the wall, respectively. As Figure 3.8 shows, the maximum difference of bending moment occurs at the top of the tank between FE and Timoshenko analysis, and this results are almost the same for both FE and Frame analysis. 
For the purpose of seismic pressure distribution validation on the wall, the results of frame analysis are compared to those of FE analysis. In FE analysis, hydrodynamic pressure is applied on the wall assuming a cosine distribution circumferentially (ACI 350.3-06 (2006)). However in frame analysis, the maximum pressure value at polar coordinate angle $\theta$ is considered. Figure3.5-c shows the hydrodynamic load distribution on vertical beam elements in frame analysis. The results of frame and FE analyses are indicated in Figures 3.9 to 3.11.

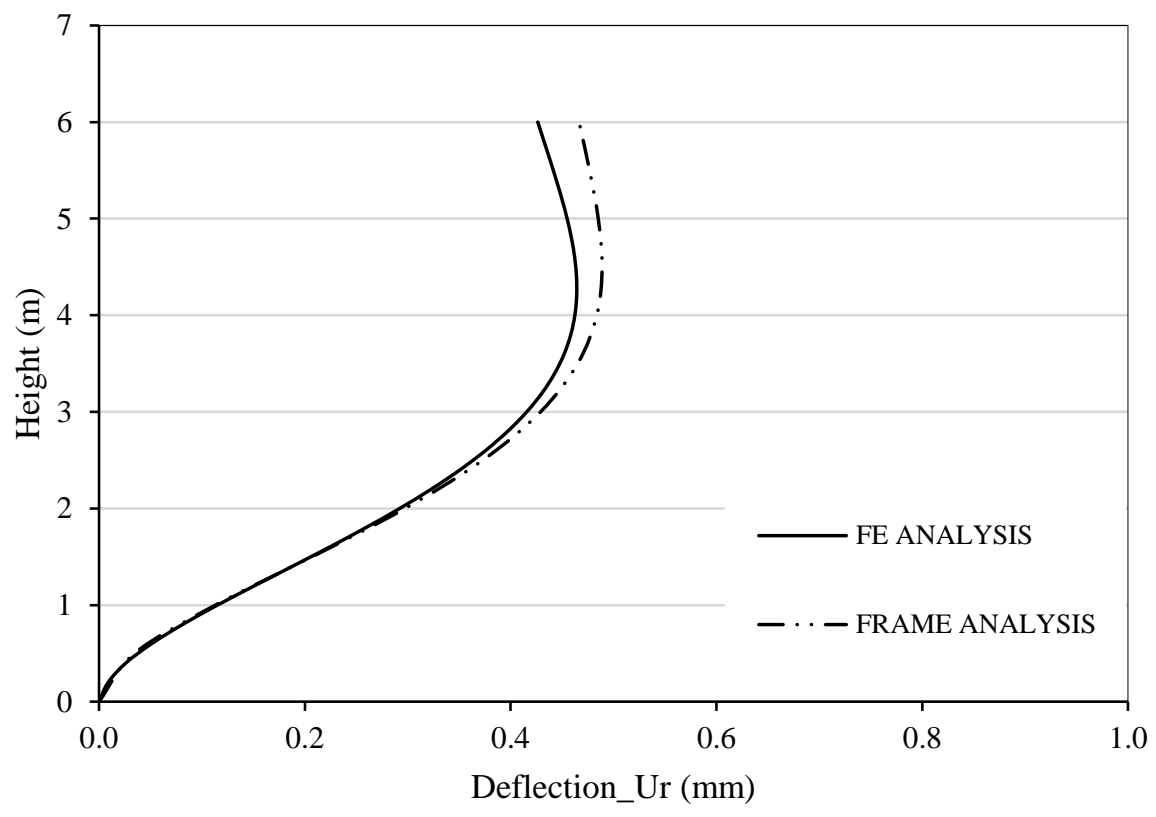

Figure 3.9 Radial deflection in tank wall due to hydrodynamic pressure

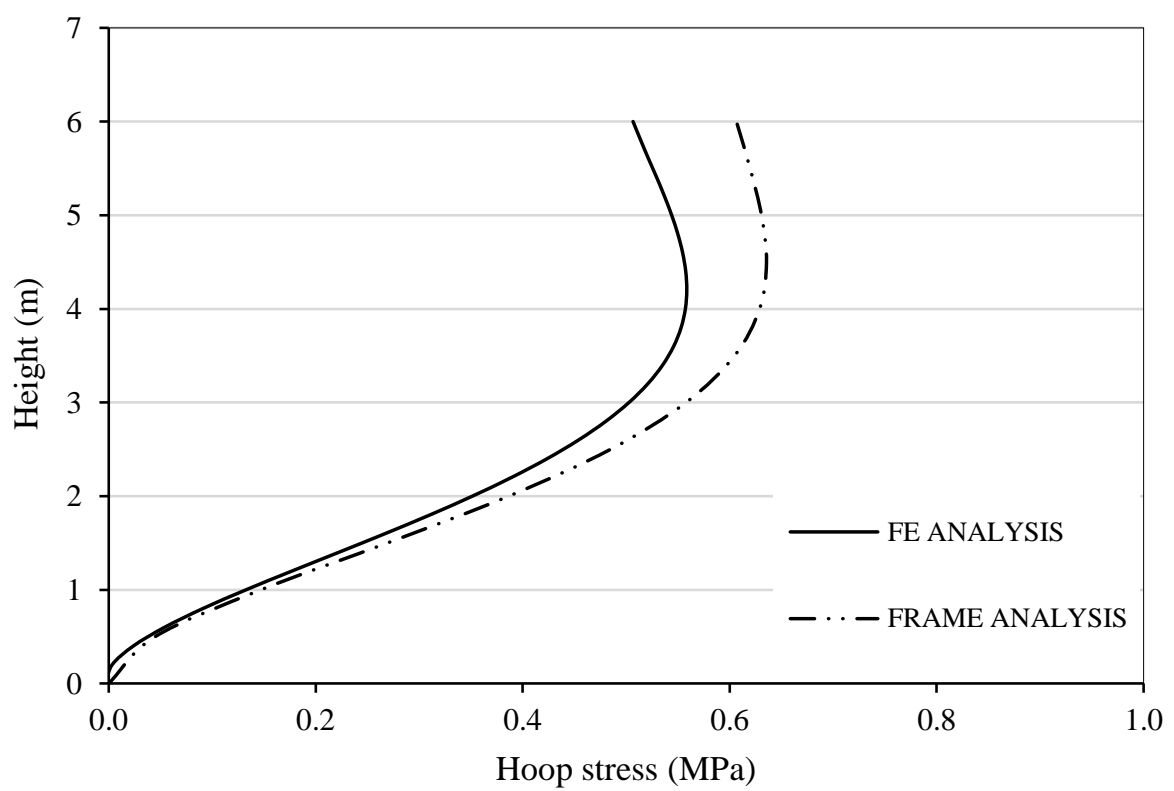

Figure 3.10 Hoop stress in tank wall due to hydrodynamic pressure 


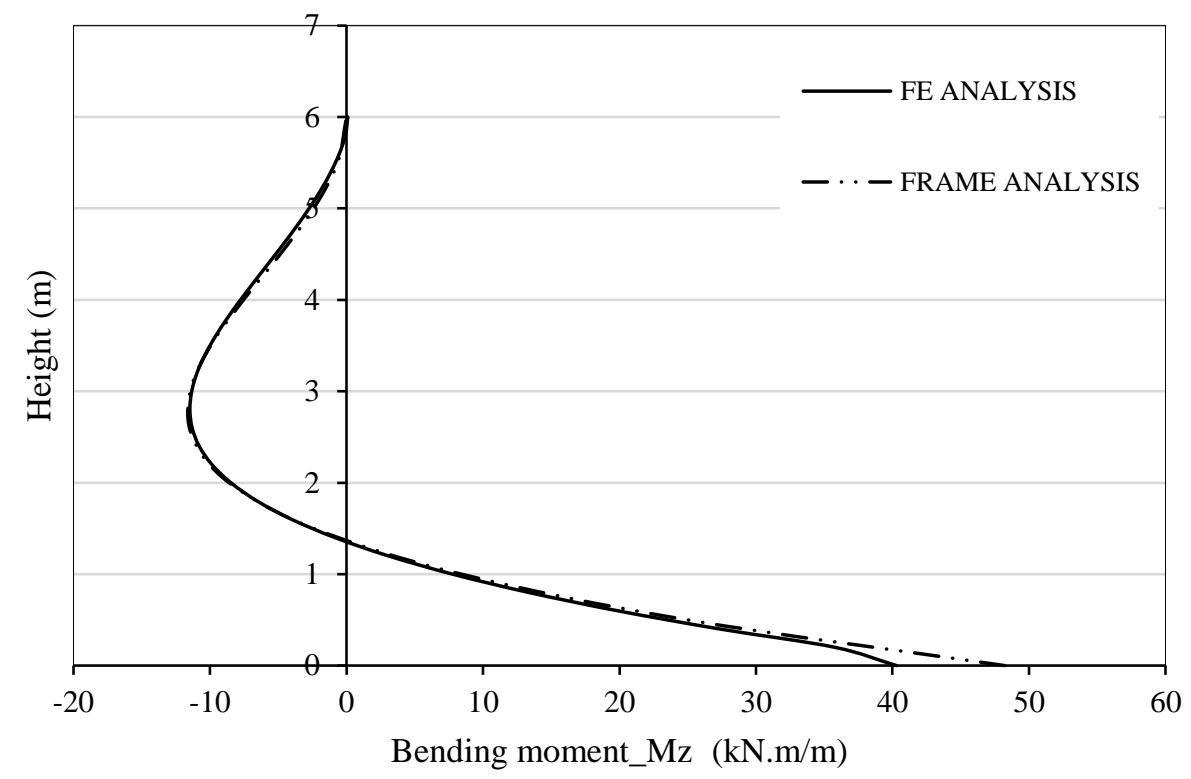

Figure 3.11 Vertical bending moment in tank wall due to hydrodynamic pressure

As shown in Figures 3.9 and 3.10, for radial deflection and hoop stresses at the top of the wall, the maximum difference in the results between FE and Frame analysis is around 19\% and 9\%, respectively. As presented in Figure 3.11, the bending moments are almost identical for both FE and Frame analyses.

As a matter of fact, both FE and Frame analyses are considered simple analogies for analyses of structures and they are not exact solutions. Since all internal forces and bending moments take place at the same location along the height of the tank, the differences in results are considered acceptable/reasonable for the design and analysis purposes.

\subsection{Tank configurations and results of load distribution on FE models}

In this study, different prototypes are chosen to investigate the effect of several parameters on the seismic response of tank models. For this reason, various criteria are considered including the height of the tank, tank diameter, compressive concrete strength, base fixity, and response modification factor. All porotypes are designed and studied assuming a high seismic intensity zone such that $\mathrm{S}_{\mathrm{S}}=160 \%$ and $\mathrm{S}_{1}=60 \%$. 
In this study, diverse 3-D ground supported open top circular tanks are investigated by considering different tank heights of 3.25, 6.5, and $9.6 \mathrm{~m}$ and different diameters of 20, 30, and $40 \mathrm{~m}$. It is well understood that tank size influences the fundamental period of the structure and consequently the resulting seismic load and structural response. In addition, effects of tank base fixity and response modification factor are investigated on seismic response. According to ACI 350.3-06, fixed, hinged, and flexible tanks are designed for $\mathrm{R}_{\mathrm{i}}=2.0$ and 3.25, respectively. Two groups of prototypes (Group A and B) are defined depending the compressive strength of concrete $\left(f_{c}^{\prime}\right)$.

According to all above mentioned criteria, 18 prototypes are developed in total as listed in Table 3.3. Each prototype is identified by a finite element ID shown under "Model" column; for example, "A-FL6-40" refers to a flexible base tank in group A with $f_{c}^{\prime}$ of $30 \mathrm{MPa}$, wall height of $6.5 \mathrm{~m}$, liquid height of $6 \mathrm{~m}$, and tank diameter of $40 \mathrm{~m}$. In this table, F, H, and FL refer to fixed, hinged, and flexible base fixity, respectively.

Table 3.3 Summary of tanks dimensions and properties

\begin{tabular}{|c|c|c|c|c|c|c|}
\hline Group & Model & $\begin{array}{c}\text { Base } \\
\text { condition }\end{array}$ & $\begin{array}{c}\text { Tank } \\
\text { height } \\
\mathrm{H}_{\mathrm{w}}(\mathrm{m})\end{array}$ & $\begin{array}{l}\text { Liquid } \\
\text { height } \\
\text { HL }_{L}(\mathrm{~m})\end{array}$ & $\begin{array}{c}\text { Tank } \\
\text { diameter } \\
\mathrm{D}(\mathrm{mm})\end{array}$ & $\begin{array}{c}\text { Wall } \\
\text { thickness } \\
\mathrm{t}_{\mathrm{w}}(\mathrm{mm})\end{array}$ \\
\hline \multirow{9}{*}{$\begin{array}{c}\text { Group A } \\
\left(f_{c}^{\prime}=30 \mathrm{MPa}\right)\end{array}$} & A-F3-40 & \multirow{9}{*}{ Fixed } & 3.25 & 3.0 & \multirow{3}{*}{40} & 400 \\
\hline & A-F6-40 & & 6.5 & 6.0 & & 400 \\
\hline & A-F9-40 & & 9.6 & 9.0 & & 450 \\
\hline & A-F3-30 & & 3.25 & 3.0 & \multirow{3}{*}{30} & 400 \\
\hline & A-F6-30 & & 6.5 & 6.0 & & 400 \\
\hline & A-F9-30 & & 9.6 & 9.0 & & 450 \\
\hline & A-F3-20 & & 3.25 & 3.0 & \multirow{3}{*}{20} & 400 \\
\hline & A-F6-20 & & 6.5 & 6.0 & & 400 \\
\hline & A-F9-20 & & 9.6 & 9.0 & & 450 \\
\hline
\end{tabular}




\begin{tabular}{|c|c|c|c|c|c|c|}
\hline & A-H3-40 & \multirow{3}{*}{ Hinged } & 3.25 & 3.0 & \multirow{3}{*}{40} & 400 \\
\hline & A-H6-40 & & 6.5 & 6.0 & & 400 \\
\hline & A-H9-40 & & 9.6 & 9.0 & & 500 \\
\hline & A-FL3-40 & \multirow{3}{*}{ Flexible } & 3.25 & 3.0 & \multirow{3}{*}{40} & 400 \\
\hline & A-FL6-40 & & 6.5 & 6.0 & & 400 \\
\hline & A-FL9-40 & & 9.6 & 9.0 & & 400 \\
\hline \multirow{3}{*}{$\begin{array}{c}\text { Group B } \\
\left(f_{c}^{\prime}=40 \mathrm{MPa}\right)\end{array}$} & B-F3-40 & \multirow{3}{*}{ Fixed } & 3.25 & 3.0 & \multirow{3}{*}{40} & 400 \\
\hline & B-F6-40 & & 6.5 & 6.0 & & 400 \\
\hline & B-F9-40 & & 9.6 & 9.0 & & 450 \\
\hline
\end{tabular}

\subsubsection{Effect of tank size on FE results}

In this section, static analysis is performed on all tank types using FE method assuming linear material behavior. The concrete compressive $\left(f_{c}^{\prime}\right)$ and steel yield strengths $\left(f_{y}\right)$ assumed as 30 and $400 \mathrm{MPa}$, respectively. Elastic modulus of concrete $\left(E_{c}\right)$ and reinforcement $\left(E_{s}\right)$ are considered as 24.65 and $200 \mathrm{GPa}$, respectively. To investigate the effect of tank size including the height and diameter, hydrostatic and hydrodynamic pressures are applied on models assuming the base to be fixed. Following figures (Figures 3.12 to 3.14) show the static analysis results of the static analysis of $6.5 \mathrm{~m}$ tall tanks under hydrostatic pressure with diameters of 20, 30 and 40m.

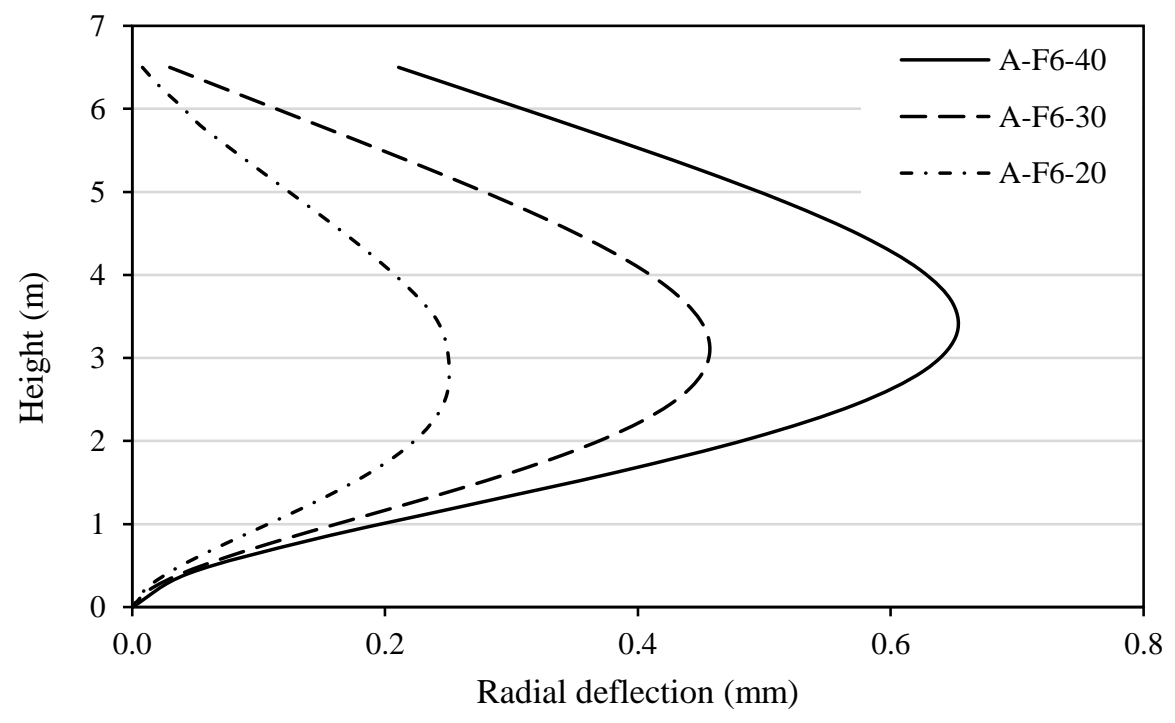

Figure 3.12 Maximum radial displacement at $\theta=0$ 
As demonstrated in these figures, for fixed base boundary condition, increasing the tank diameter assuming a constant tank height will result in an increase in radial deflection, hoop force and bending moment. It can be concluded that components of earthquake forces, bending moment, and hoop force can vary depending on the tank diameter. Application of hydrodynamic pressure also leads to similar results by increasing the tank diameter.

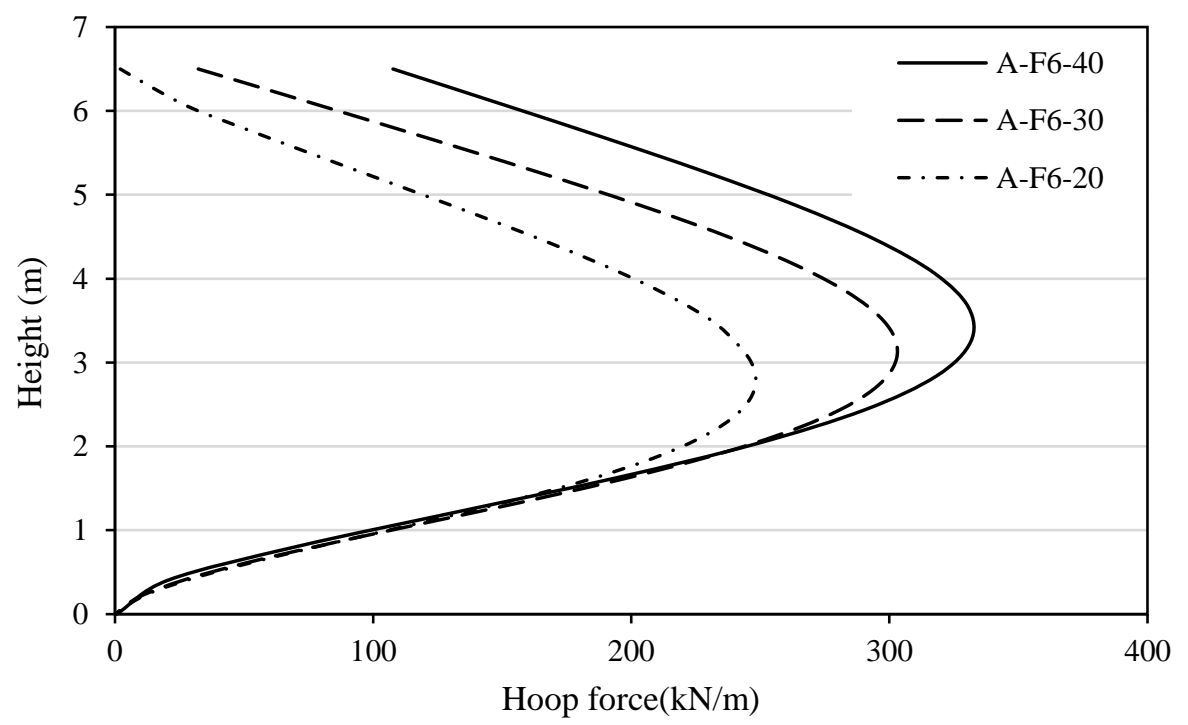

Figure 3.13 Hoop force on the wall at $\theta=0$

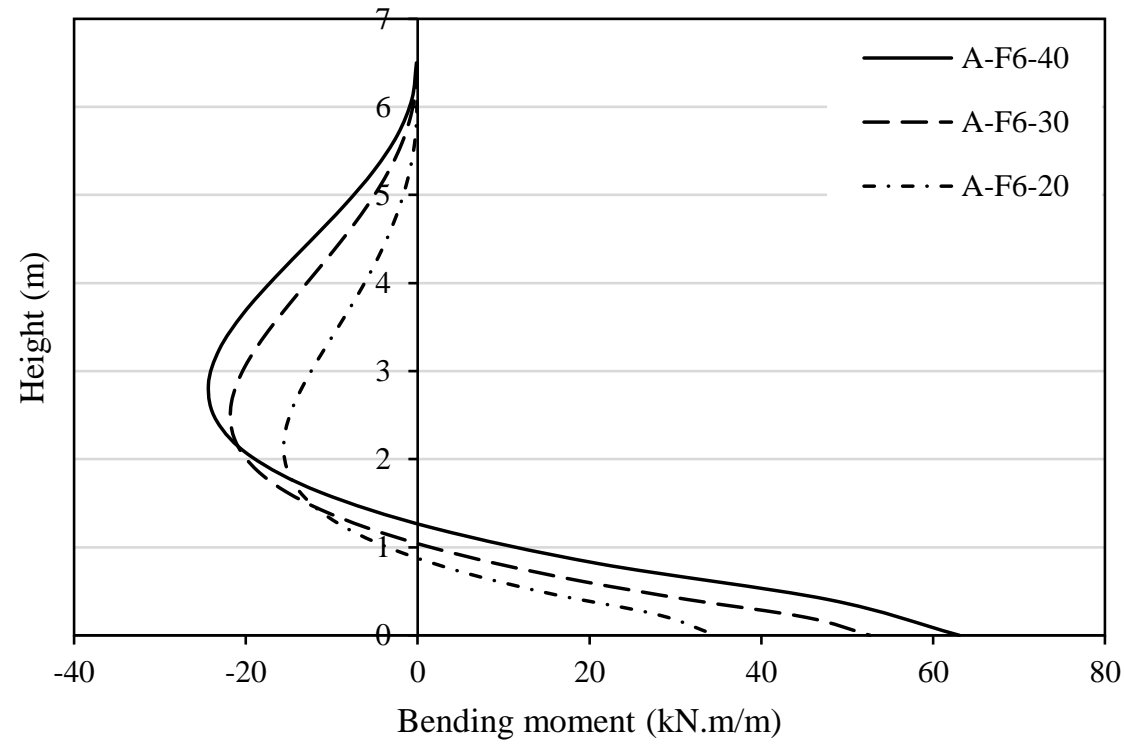

Figure 3.14 Vertical bending moment on the wall at $\theta=0$ 
In order to investigate the effect of wall height, tanks are modelled with constant diameter of $40 \mathrm{~m}$ and three different heights $(3.25,6.5$ and $9.6 \mathrm{~m})$. Figures 3.15 to 3.17 show the influence of tank height on maximum radial displacement, forces and moments.

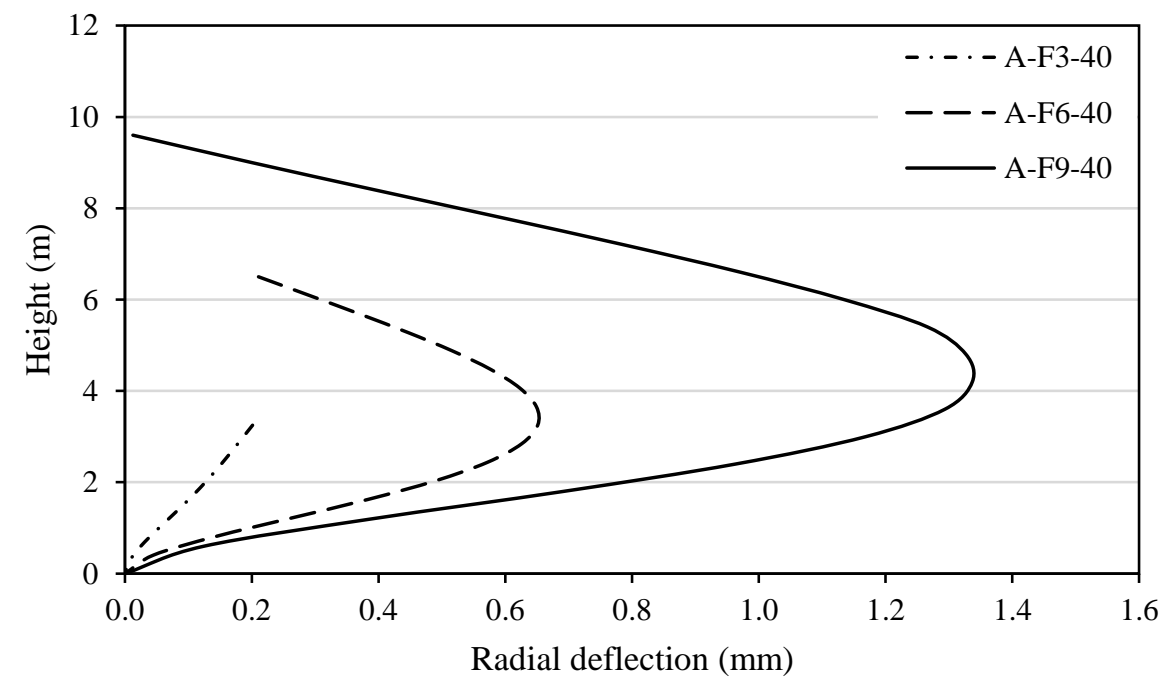

Figure 3.15 Maximum radial displacement at $\theta=0$

As shown in the Figures 3.15 and 3.16, the maximum displacement and hoop force for Tank A-F3 occurs at the top while for A-F6 and A-F9 happens at approximately the middle of the tank. As per Figure 3.17, maximum bending moment for all three tank types happens at the base of the tank. Based on these figures, maximum bending moment and internal forces are proportionate to the height of the tank when the diameter is constant.

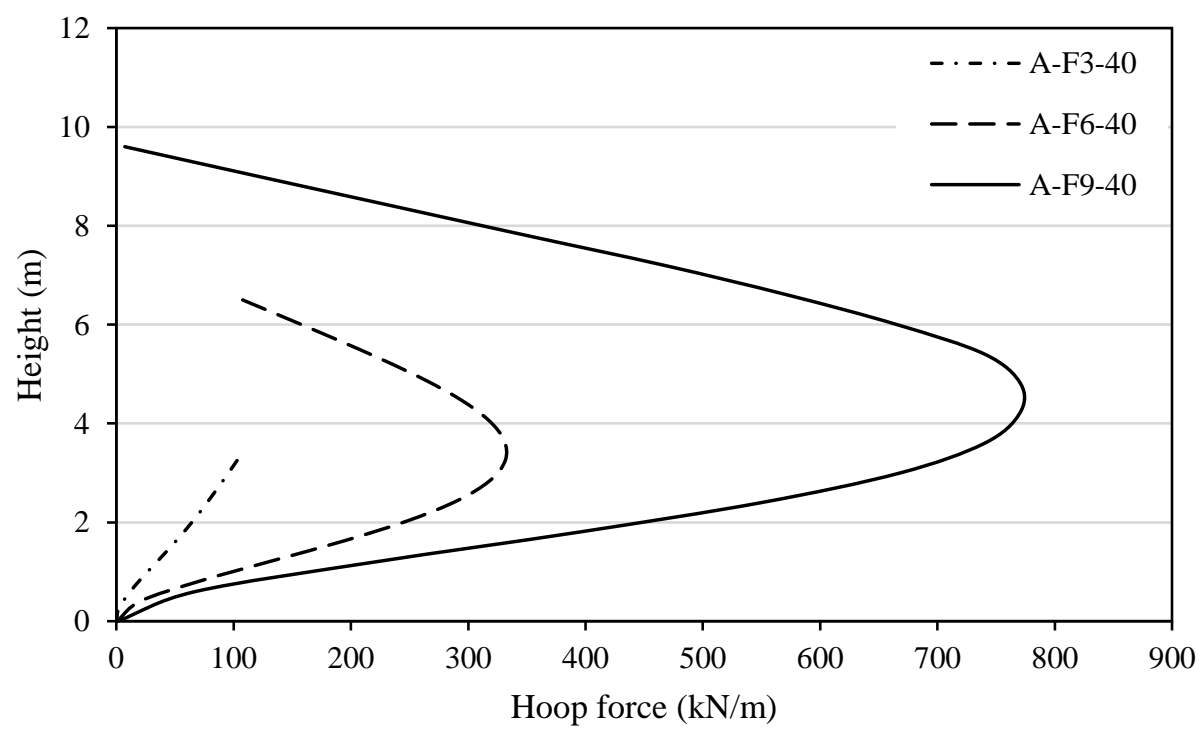

Figure 3.16 Hoop force on the wall at $\theta=0$ 


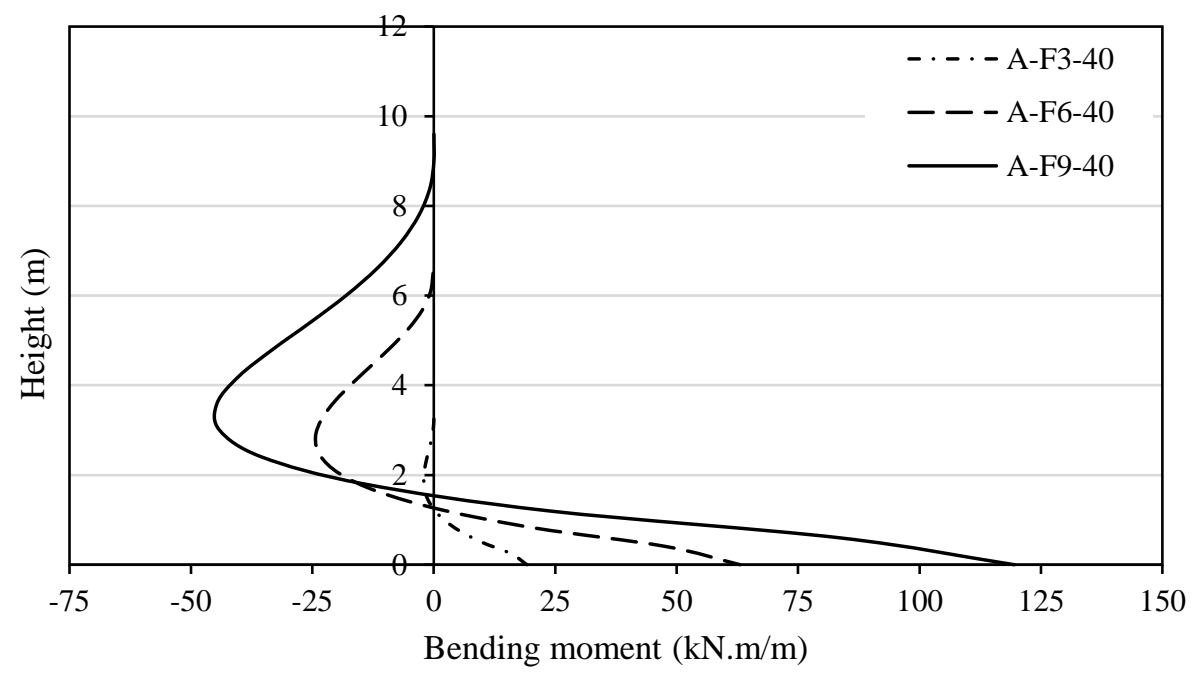

Figure 3.17 Vertical bending moment on the wall at $\theta=0$

\subsubsection{Effect of base fixity on FE results}

To investigate the effect of tank support condition, two base conditions namely nonflexible (fixed and hinged) and flexible are considered in this section. A $6.5 \mathrm{~m}$ high circular tank with a diameter of $40 \mathrm{~m}$ is modelled assuming three base conditions: fixed, hinged and flexible. Both hydrostatic and hydrodynamic loading conditions are considered for this comparison study.

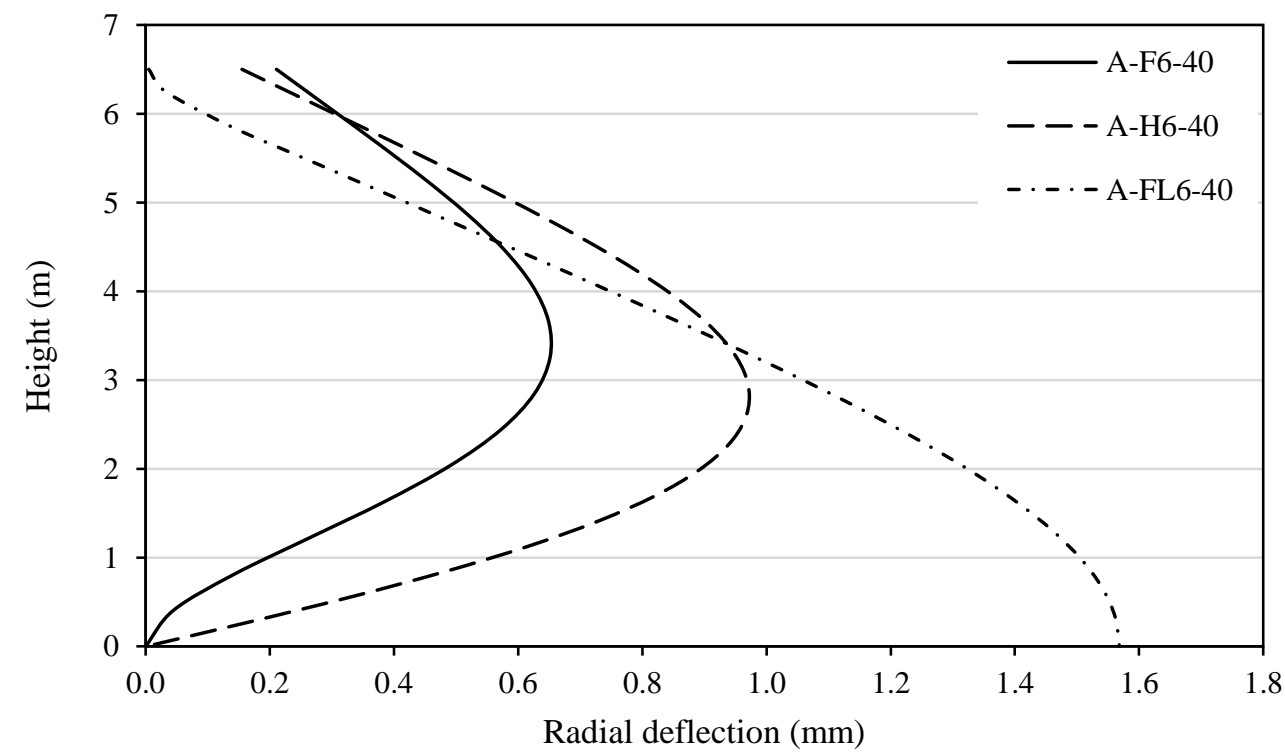

Figure 3.18 Maximum radial deflection at $\theta=0$; under hydrostatic pressure 
As Figure 3.18 shows the flexible base causes the maximum deflection at the base as there is no constraint in radial or tangential directions at the bottom. In addition, the flexible base model shows the maximum hoop force among the three cases considered. Fixed and hinged tanks are able to transfer the hoop force to the base through diaphragm action; however, such force cannot be carried down to the base in a free base condition. The results of FE analysis as shown in Figures 3.18 and 3.19 indicate that, $48 \%$ and $64 \%$ of the total seismic hoop forces are transferred to the tank base by diaphragm action for hinged and fixed base conditions, respectively. No force is transferred to the tank base in case of the free base tank. It should be noted that the fixed and hinged base tanks are designed for $R_{i}=2.0$ and free base tanks for $\mathrm{R}_{\mathrm{i}}=3.25$ based on ACI 350.3 (2006).

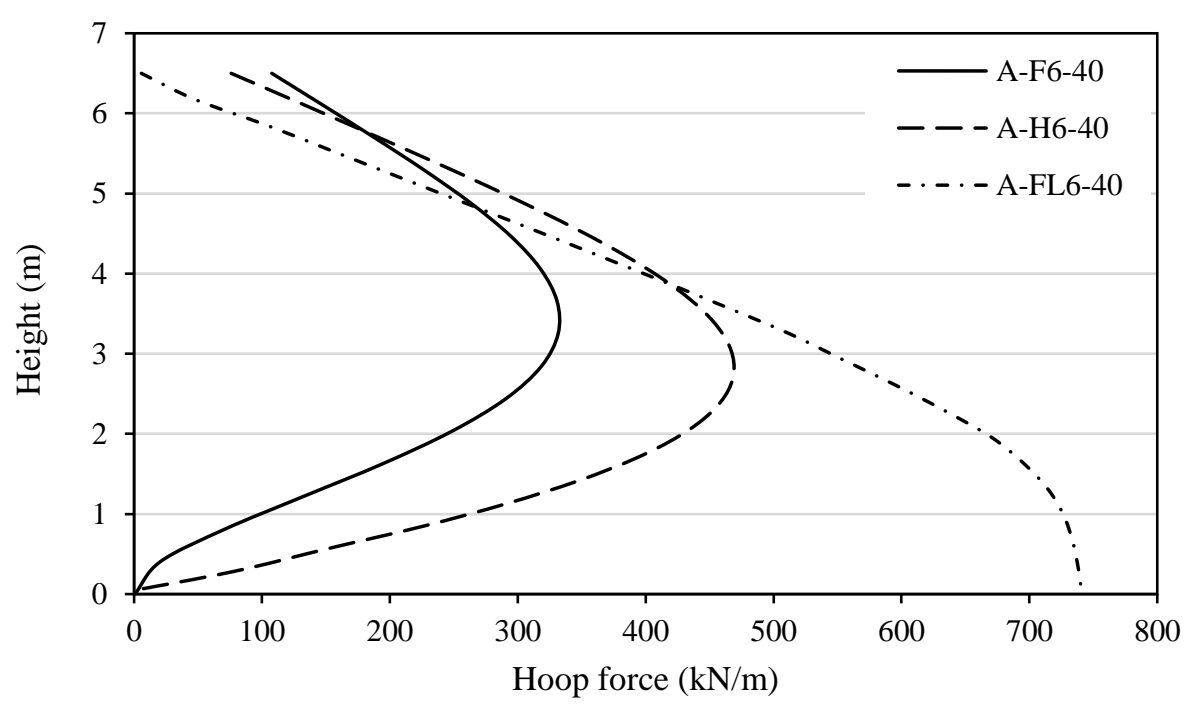

Figure 3.19 Hoop force on the wall at $\theta=0$; under hydrostatic pressure

A hinged support can resist both vertical and horizontal forces but not a moment. They will allow the structural member to rotate, but not to translate in any direction. However, in in fully fixed base condition, there is no movement or rotation at the tank base, and it results in maximum bending moment is expected in this base condition. The bending moment is zero at the base of hinged tanks and rotation is also permitted as per Figure 3.20. 


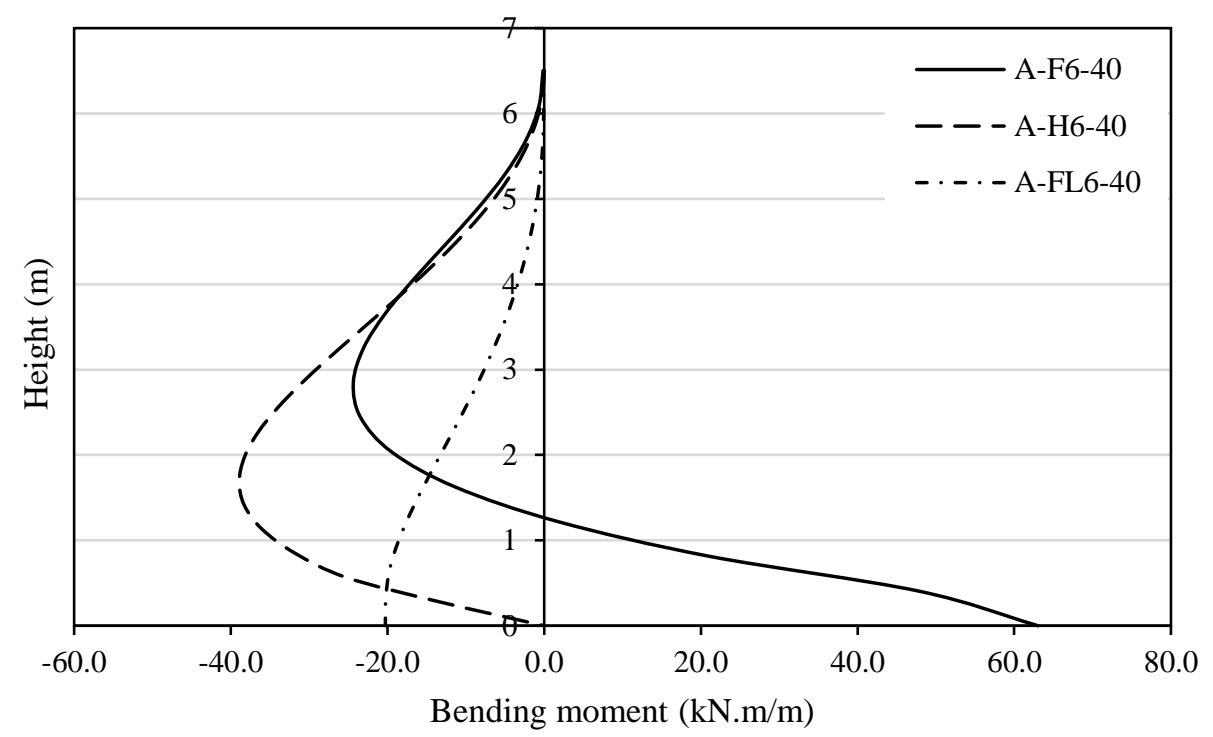

Figure 3.20 Vertical bending moment on the wall at $\theta=0$; under hydrostatic pressure

As explained in Chapter 2, anchored flexible base systems include seismic cables and bearing pads. Bearing pads are provided to resist movement in radial direction. Seismic cables are employed for both radial and tangential resistance.

Not only the bearing pad resistance prevents such radial movement, but also the seismic cables plays a role in further reducing these radial movements.

Tank behavior, internal forces and moments in anchored flexible base tanks are completely different from fixed and hinged base tanks under hydrodynamic pressure. In fixed and hinged base tanks, the maximum deflection, forces and moments occur at $\theta=0$ degree where the hydrodynamic pressure is maximum in cosine circumferential distribution.

As Figures 3.21 and 3.22 show, the maximum radial displacement occurs in seismic force direction $(\theta=0)$ for flexible base tanks; however, the maximum hoop stresses in the wall takes place at the location perpendicular to the seismic force direction.

As Figure 3.23 shows, the hoop force in anchored flexible base tanks is maximum among the three different boundary conditions considered. According to Figure 3.24, the bending moment of the fixed tank is greater than that of the flexible base model, while the moment is zero at the base of the hinged base tank. 

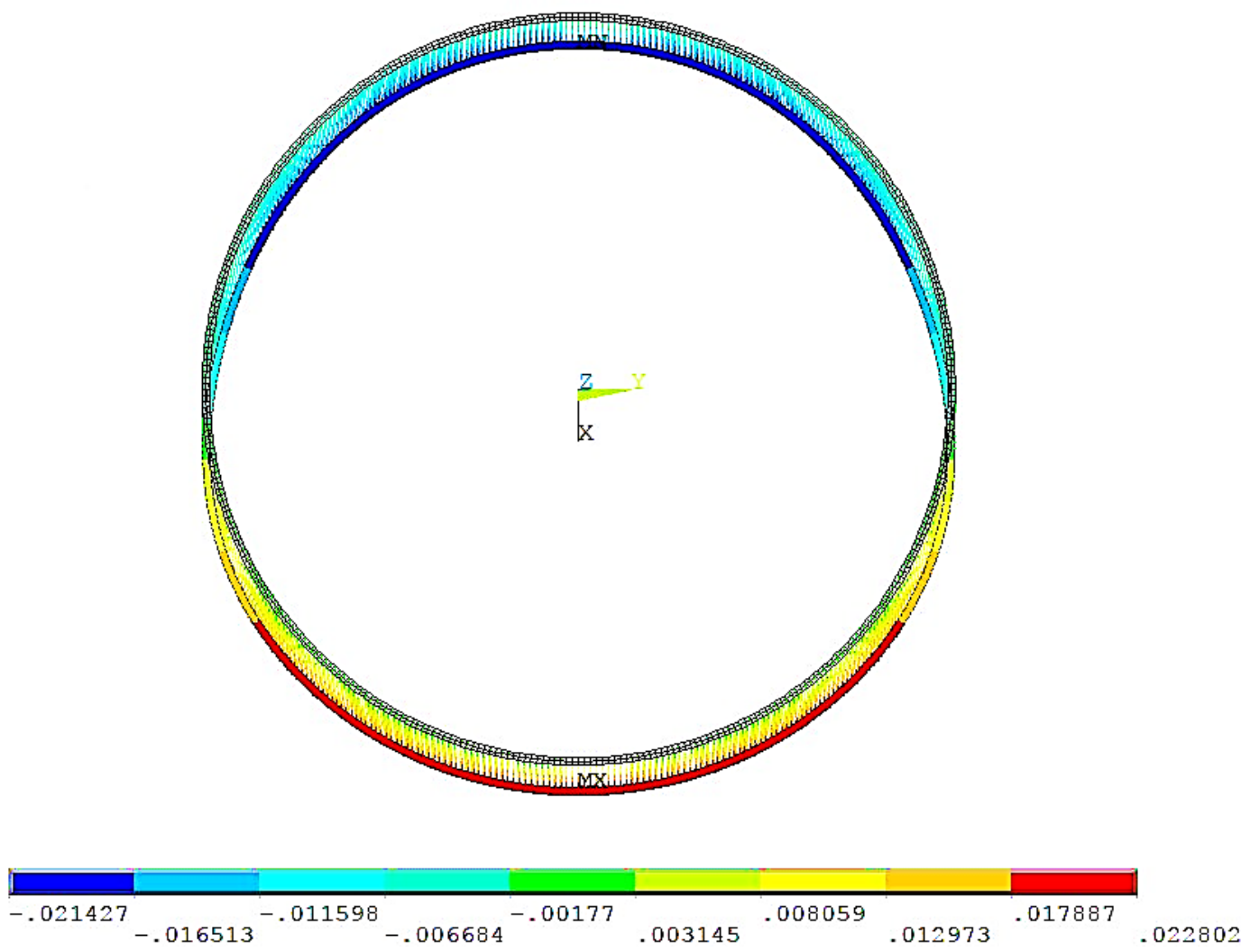

Figure 3.21 Radial deflection on anchored flexible base tank; under hydrodynamic pressure

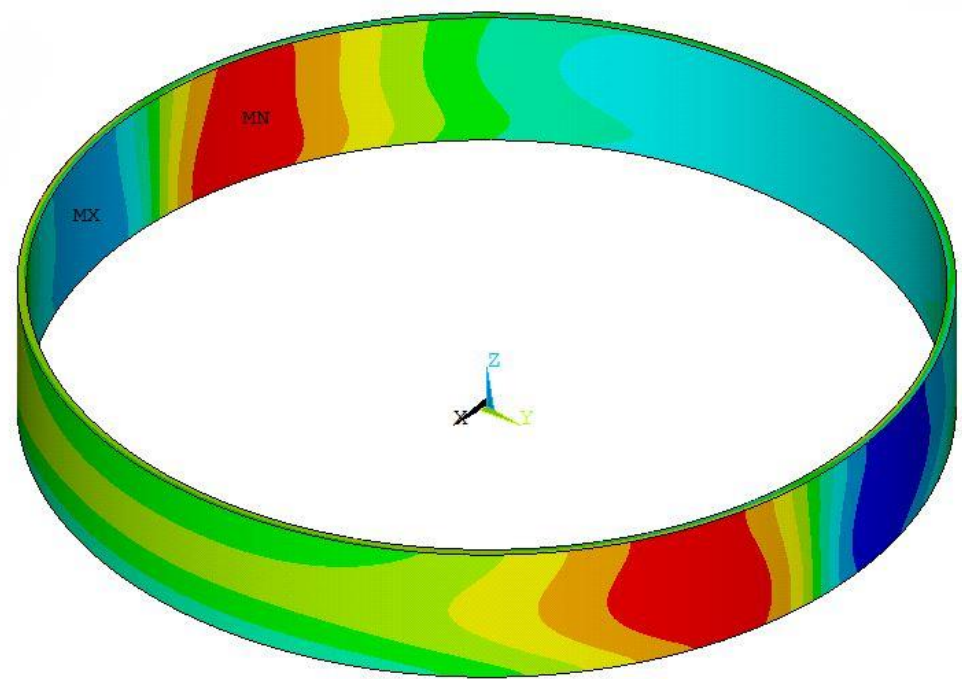

Figure 3.22 Hoop stress distribution on the wall for anchored flexible base tank; under hydrodynamic pressure 


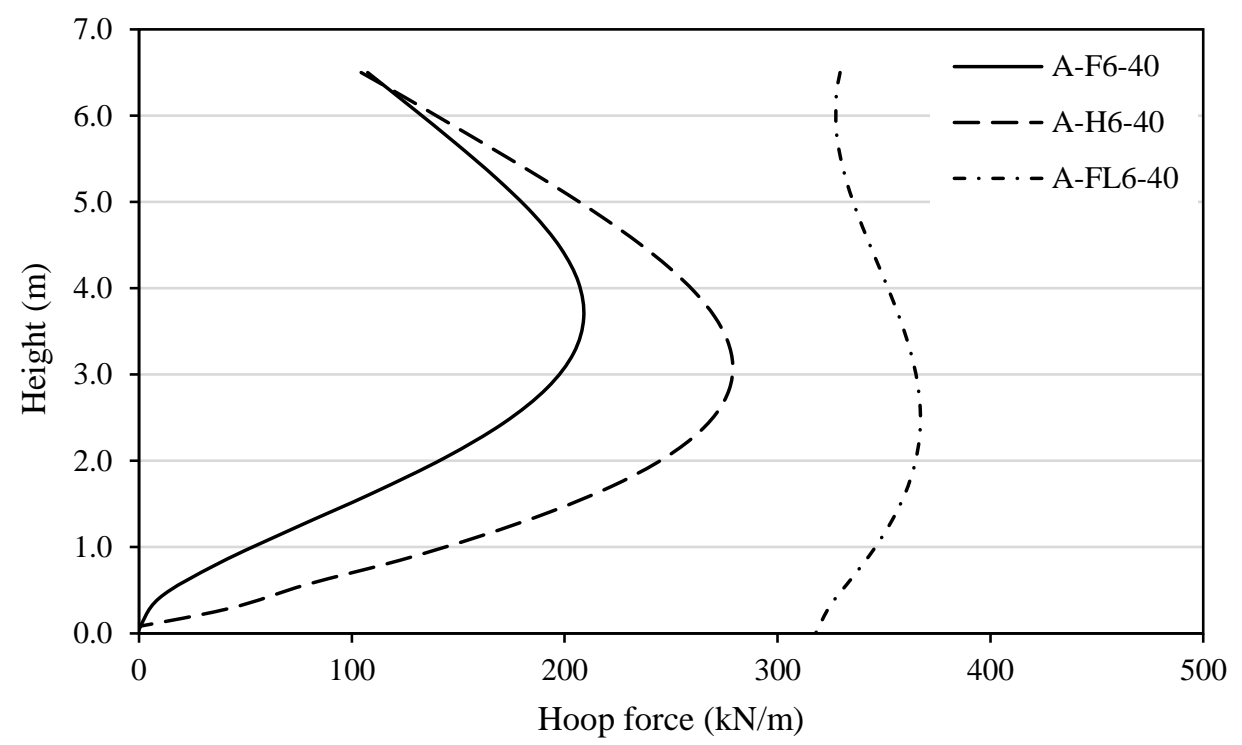

Figure 3.23 Hoop force on the wall; under hydrodynamic pressure

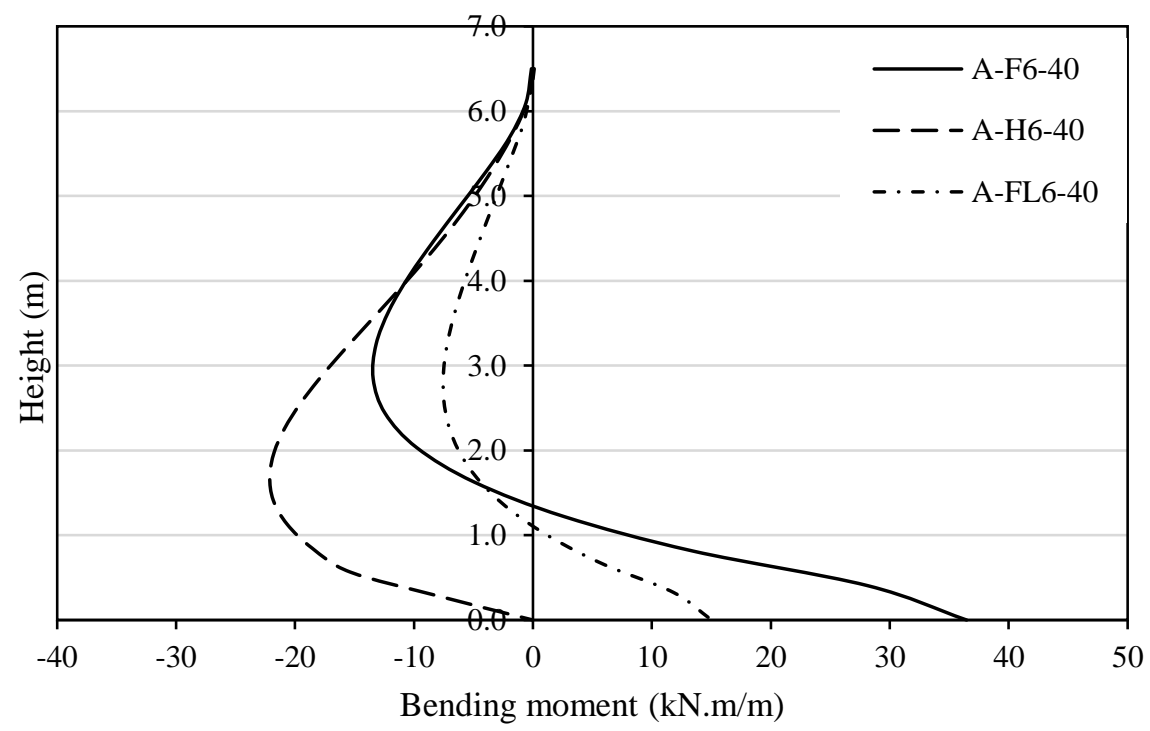

Figure 3.24 Vertical bending moment on the wall; under hydrodynamic pressure 


\subsection{Summary}

This chapter discussed the effect of circular tanks size and base condition on their seismic response. The accuracy of both hydrostatic and hydrodynamic pressure distribution on the tank wall was investigated. For this purpose, analytical approaches including the theory of plates and shell and frame analogy were employed. The cylindrical tank behavior in terms of the deflection, forces, and moment was investigated corresponding to both static and dynamic pressures. Comparing the analytical solution results with FE results verified the accuracy of pressure distributions.

In order to perform the pushover analysis, different open top circular tanks are required to be modeled by finite element method. For this reason, various parameters such as concrete strength, tank size, and base fixity were considered. In this study, all prototypes were chosen and designed for high level of seismicity. Then, the effect of tank size and base condition on finite element models was investigated. 


\section{CHAPTER 4 \\ FINITE ELEMENT MODEL DEVELOPMENT AND \\ VERIFICATION}

\subsection{Introduction}

First step in nonlinear analysis of a system is to correctly model an authentic system. One method to model reinforced concrete structures to achieve an accurate nonlinear analysis is finite element (FE) technique. For this reason, FE modeling software ANSYS is applied. Realizing the behavior and characteristic of each element under various loading phases is significant in developing the finite element model. This chapter begins with addressing the reinforced concrete element, link and fluid element, and continues with proposed mathematical approximations to model the concrete and steel stress-strain curve and ends with analyzing the failure criteria of reinforced concrete elements while subjecting to ultimate loading condition. Next, basic equations of motion and appropriate methods to solve these equations will be discussed. Finally, the accuracy of reinforced concrete element is verified by modeling some experimental specimens' tests.

\subsection{Finite element model}

Numerous general and specific finite element programs have been evolved over the past few decades. ANSYS is one of most the popular and accomplished software packages between these computer programs. ANSYS is able to model the concrete behavior by employing an eight-node solid brick element (SOLID65). This element is capable of showing the smeared crack similarity for cracking in tension regions and a plasticity algorithm to represent the concrete crushing in compression areas. Also, this element considers the nonlinear behavior of concrete including plastic deformation, nonlinear stress-strain response under loading, 
crushing, and cracking in three orthogonal directions. Reinforcements can be modeled using two different approaches. One of these approaches is using Solid65 which is capable of modeling reinforcements as smeared throughout the element. The other one is by employing a 3-D spar element (Link8), a uniaxial tension-compression element which allows for an elasticplastic response of the reinforcing bar.

For fluid modeling in ANSYS, there are two types of elements including displacementbased (FLUID80) and pressure-based (FLUID30) elements. FLUID80 is able to account for

fluid-structure interaction phenomenon. Specific effects in sloshing problems such as acceleration effects may be considered using this element. FLUID30 used in this study is also capable of simulating the fluid-structure interfaces (FSI) effect. The characteristics and features of SOLID65, Link8 and fluid elements will be explained in details in the next section.

\subsection{Element type}

\subsubsection{Reinforced concrete}

The 3-D solid element (SOLID65) includes eight nodes with three degrees of freedom at each node, translations in nodal $\mathrm{x}, \mathrm{y}$, and $\mathrm{z}$ directions and accepts up to three rebar materials. The element is quite efficient in representing the plastic deformation, cracking in three orthogonal directions and crushing. The geometry and node locations for a SOLID65 element are shown in Figure 4.1. In this work, steel reinforcements are modeled using Link8 elements. The geometry and locations for this element is shown in Figure 4.1. The element includes two nodes, and each node has three degrees of freedom, translations in nodal $\mathrm{x}, \mathrm{y}$ and $\mathrm{z}$ directions. This element is capable of considering plastic deformation effects. 


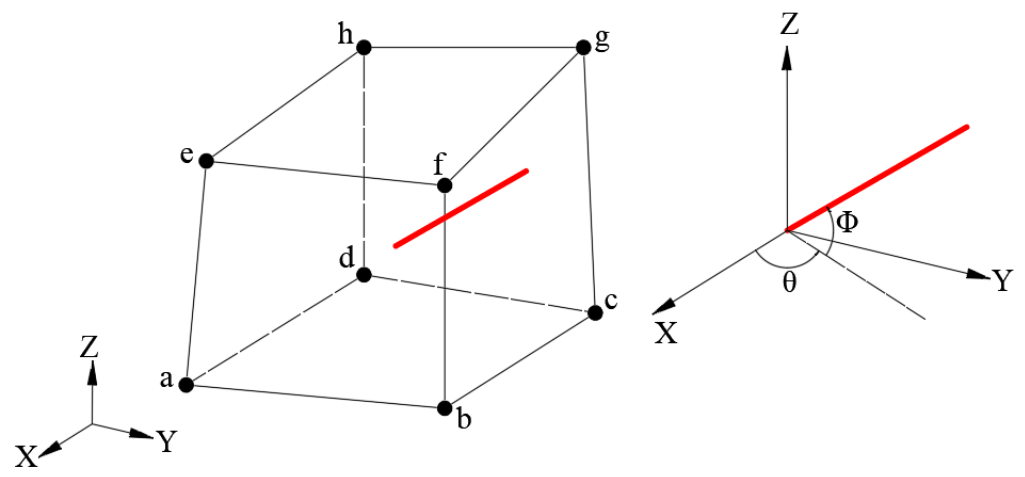

(a)

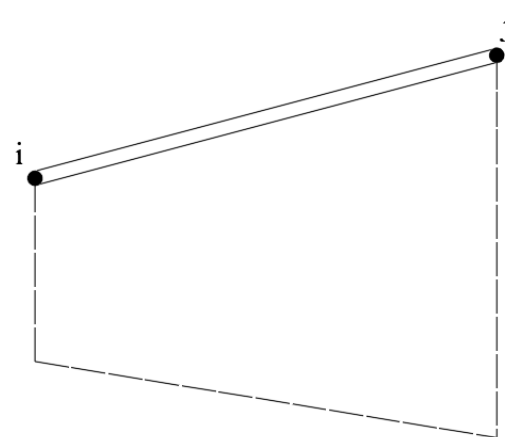

(b)

Figure 4.1 Geometry and node positions of a) SOLID65 and b) LINK8

\subsubsection{Fluid Domain}

In this study, fluid domain is modeled using eight-node 3-D solid elements. In this study, two different types of FLUID80 and FLUID30 elements are used to model the fluid domain. The geometry and associated properties of FLUID80 and FLUID30 elements are shown in Figure 4.2. FLUID80 is capable of calculating hydrodynamic pressures, fluid-solid interactions and acceleration effects such as sloshing. As shown in Figure 4.2, the element has eight corner nodes with three degrees of freedom per node, translations in the nodal $\mathrm{x}, \mathrm{y}$ and $\mathrm{z}$ directions. The element should be coupled with solid elements in the direction normal to the interface (radial direction).

FLUID30 (shown in Figure 4.2) has eight corner nodes with four degrees of freedom at each node, translations in the nodal $\mathrm{x}, \mathrm{y}$ and $\mathrm{z}$ directions and pressure. The translational degrees of freedom are required for nodes located on the interface. Fluid-structure interfaces (FSI) can be identified by surface loads at the element faces as indicated by the circled numbers in the figure. The structural motion and fluid pressure at the interface will be coupled by applying the FSI on the element faces. 


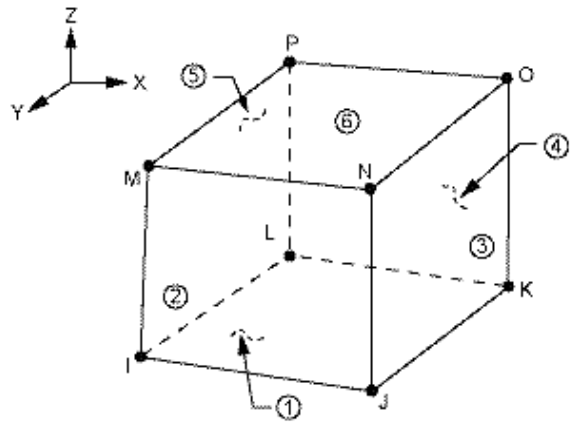

(a)

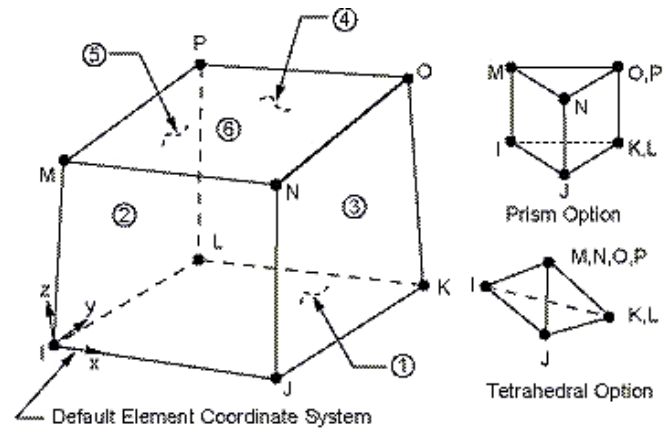

(b)

Figure 4.2 Geometry and node positions of a) FLUID80 and b) FLUID30 (Adopted from ANSYS, 2017)

\subsection{Damping characteristics of fluid domain}

In dynamic analysis, damping is a critical parameter in structures including liquid containers. Damping depends on several factors such as tank dimension, liquid height and liquid kinematic velocity. To evaluate the damping properties of a liquid tank, a classical damping scheme called Rayleigh damping is employed in finite element model. The fluid damping represented by Equation (4.1), includes two components based on the impulsive and convective parts of the fluid domain.

$\left[C_{f}\right]=\alpha\left[M_{f}\right]+\beta\left[K_{f}\right]$

$\left[M_{f}\right]$ and $\left[K_{f}\right]$ are mass and stiffness matrices of the fluid domain, respectively. $\alpha$ is evaluated based on the natural frequency of liquid sloshing to consider the convective effect on response. $\beta$ is calculated based on the fundamental frequency of the tank and is employed to simulate the damping due to the impulsive component. The ratio of actual to critical damping for each mode of vibration $(\zeta)$ can be calculated by Equation (4.2).

$\xi=\frac{\alpha}{2 \omega_{i}}+\frac{\beta \omega_{i}}{2}$

where $\omega_{i}$ is the natural circular frequency of mode $i$ corresponding to the fundamental impulsive and convective modes employed to calculate the damping constants $\alpha$ and $\beta$. Mikishev and Dorozhkin (1961) investigated the sloshing in storage tanks. They presented that the sloshing is damped by viscous forces and the value of viscous damping of a storage tank is 
less than $0.5 \%$. Corresponding damping of impulsive and convective components of liquid proposed in ACI 350.3-06 are 5 and $0.5 \%$ of critical damping, respectively. In this study, the structural damping of the tank for concrete is assumed as 5 percent of critical damping.

\subsection{Reinforced concrete finite element formulation}

\subsubsection{FE formulation of SOLID65 element in linear state}

Reinforced concrete elements may experience three different behavioral conditions such as linear elastic deflection, cracking and crushing. At the beginning stage of loading, SOLID65 indicates a linear elastic behavior. By gradually increasing the load, the tensile stress exceeds the cracking capacity of the material and the concrete cracks. After cracking, further increasing loading generates either crushing in concrete or yielding of reinforcements. In a properly designed concrete section, yielding in reinforcements occurs before crushing in concrete.

The stress-strain matrix of SOLID65 element in linear elastic stage is obtained as follows:

$[D]=\left(1-\sum_{i=1}^{N_{r}} V_{i}^{R}\right)\left[D^{c}\right]+\sum_{i=1}^{N_{r}} V_{i}^{R}\left[D^{r}\right]_{i}$

where,

$N_{r}$ : Number of reinforcing material (between one to three)

$V_{i}^{R}:$ Reinforcement ratio

$\left[D^{c}\right]$ : Concrete elastic stiffness matrix

$\left[D^{r}\right]_{i}$ : Elastic stiffness matrix for reinforcement number "i"

$\left[D^{c}\right]$ is stress-strain matrix based on the linear behavior of concrete which is defined as follows: 


$$
\left[D^{c}\right]=\frac{E}{(1+v)(1-2 v)}\left[\begin{array}{cccccc}
(1-v) & v & v & 0 & 0 & 0 \\
v & (1-v) & v & 0 & 0 & 0 \\
v & v & (1-v) & 0 & 0 & 0 \\
0 & 0 & 0 & \frac{(1-2 v)}{2} & 0 & 0 \\
0 & 0 & 0 & 0 & \frac{(1-2 v)}{2} & 0 \\
0 & 0 & 0 & 0 & 0 & \frac{(1-2 v)}{2}
\end{array}\right]
$$

where, $E$ and $v$ is elastic modulus, Poisson's ratio of concrete, respectively.

\subsubsection{FE formulation of SOLID65 element after cracking}

Including the plasticity and cracking effects in concrete requires some sophisticated modifications in the concrete stiffness matrix. Defining a weak plane normal to the crack face reflects the crack in the stiffness matrix. Two factors $\beta_{t}$ and $R_{t}$ are employed to apply the weak plane to the stiffness matrix. The following equation (Eq. 4.5) illustrates the modified stiffness matrix:

$$
\left[D_{c}^{c k}\right]=\frac{E}{(1+v)}\left[\begin{array}{cccccc}
\frac{R^{t}(1+v)}{E} & 0 & 0 & 0 & 0 & 0 \\
0 & \frac{1}{1-v} & \frac{v}{1-v} & 0 & 0 & 0 \\
0 & \frac{v}{1-v} & \frac{1}{1-v} & 0 & 0 & 0 \\
0 & 0 & 0 & \frac{\beta_{t}}{2} & 0 & 0 \\
0 & 0 & 0 & 0 & \frac{1}{2} & 0 \\
0 & 0 & 0 & 0 & 0 & \frac{\beta_{t}}{2}
\end{array}\right]
$$

The tensile stress relaxation coefficient $\left(\mathrm{R}^{\mathrm{t}}\right)$ is used to simulate the tensile cracks. In this equation which is used only for an open crack in one direction, the shear transfer coefficient $\beta_{t}$ accounts for some reduction in the shear strength of concrete due to crack opening. Compression load triggers the crack to close, so any compression normal to the cracking plane will cause modification in the shear transfer coefficient $\left(\beta_{t}\right)$. In this case, another coefficient $\left(\beta_{c}\right)$ is applied to modify the stiffness matrix. 
By changing the load direction and diminishing the tensile stress, the open cracks would close. The stiffness matrix of a concrete element with closed crack condition in one direction is given as:

$$
\left[D_{c}^{c k}\right]=\frac{E}{(1+v)(1-2 v)}\left[\begin{array}{cccccc}
(1-v) & v & v & 0 & 0 & 0 \\
v & (1-v) & v & 0 & 0 & 0 \\
v & v & (1-v) & 0 & 0 & 0 \\
0 & 0 & 0 & \frac{\beta_{C}(1-2 v)}{2} & 0 & 0 \\
0 & 0 & 0 & 0 & \frac{(1-2 v)}{2} & 0 \\
0 & 0 & 0 & 0 & 0 & \frac{\beta_{C}(1-2 v)}{2}
\end{array}\right]
$$

where,

$\beta_{c}$ : Coefficient for closed crack condition (generally $\beta_{c}$ must be greater than $\beta_{t}$ )

It should be noted that the complete degradation of material is represented by the crushing state of concrete material, in which no more contribution of the element in the stiffness matrix is observed.

The behavior of concrete in tension is linear prior to cracking and the stiffness matrix is considered isotropic. When the tensile stress reaches the concrete tensile strength, cracks develop normal to the direction of the stress. In SOLID65 element, concrete shows no tensile strength beyond its cracking point. After cracking, the tensile of remaining un-cracked length of specimen produced by the tensile reinforcement bonded with concrete is used to increase the overall tensile strength of reinforced concrete element. In SOLID65 element, the interaction between concrete and reinforcement called stress relaxation is addressed through a numerical technique. In this method, an initial value named relaxation parameter $\left(\mathrm{T}_{\mathrm{c}}\right)$ is defined in ANSYS. As shown in Figure 4.3, this parameter gradually reduces from its initially defined value to zero while the tensile strain reaches six times the cracking strain $\left(\varepsilon^{c k}\right)$. 


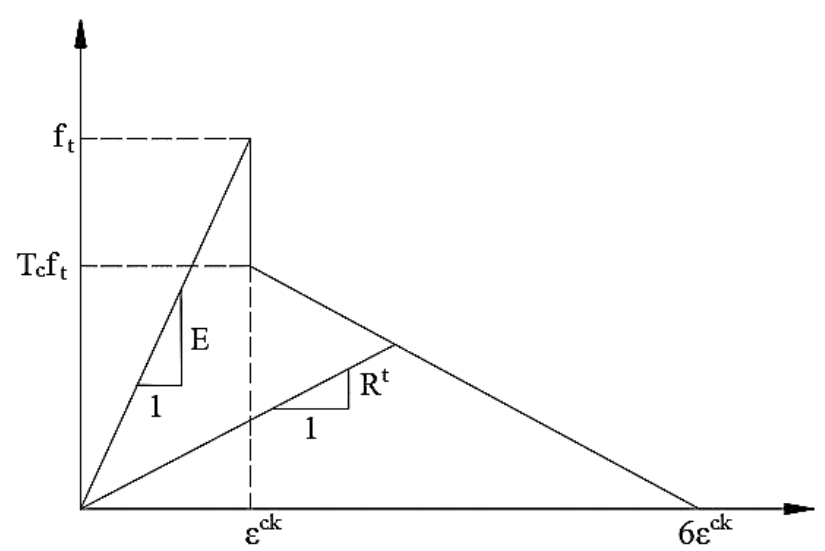

Figure 4.3 Tensile stress relaxation in concrete element (Adopted from ANSYS)

where, $f_{t}$ is uniaxial tensile cracking stress, $\mathrm{T}_{\mathrm{c}}$ is multiplier for amount of tensile stress relaxation, $E$ is elastic modulus, $\mathrm{R}^{\mathrm{t}}$ is slope (secant modulus) and $\varepsilon^{c k}$ cracking strain. $\mathrm{R}^{\mathrm{t}}$ declines adaptively after cracking and diminishes to zero as solution converges. (ANSYS, 2012)

\subsubsection{Failure criteria for concrete}

Cracking and crushing in concrete material makes the failure at the end. There are various failure theories such as maximum principal stress, strain and shear theory, internal friction theory and so on. ANSYS implements William and Warnke failure criterion (William and Warnke, 1975) to distinguish the failure of reinforced concrete element. According to this criterion, concrete failure under multiaxial stress can be calculated as:

$\frac{F}{f_{c}}-S \geq 0$

Where,

F: Function of the principal stresses $\left(\sigma_{x p}, \sigma_{y p}, \sigma_{z p}\right)$

S: Failure surface which is a function of principal stresses and various strength factors

$f_{c}$ : Ultimate uniaxial compressive strength

Concrete cracking and crushing occurs when Equation (4.7) is satisfied. There are four different domains for concrete failure defined based on the element stress state. The principal 
stresses $\left(\sigma_{1}, \sigma_{2}, \sigma_{3}\right)$ are used to establish the $\mathrm{F}$ and $\mathrm{S}$. In the following statements $\sigma_{1}$ and $\sigma_{3}$ are the maximum and minimum stresses, respectively.

1. (CCC) compression- compression- compression: $0 \geq \sigma_{1} \geq \sigma_{2} \geq \sigma_{3}$

2. (TCC) tensile- compression- compression: $\sigma_{1} \geq 0 \geq \sigma_{2} \geq \sigma_{3}$

3. (TTC) tensile - tensile - compression: $\sigma_{1} \geq \sigma_{2} \geq 0 \geq \sigma_{3}$

4. (TTT) tensile - tensile - tensile: $\sigma_{1} \geq \sigma_{2} \geq \sigma_{3} \geq 0$

These four domains of failure can be computed based on the configuration of the multiaxial loading of the concrete element. For example, according to William and Warnke failure criterion, for $\mathrm{CCC}$ domain, the function of principal stress $(F)$ is calculated as:

$F=\frac{1}{\sqrt{15}}\left[\left(\sigma_{1}-\sigma_{2}\right)^{2}+\left(\sigma_{2}-\sigma_{3}\right)^{2}+\left(\sigma_{3}-\sigma_{1}\right)^{2}\right]^{1 / 2}$

And the failure surface $(\mathrm{S})$ is defined as:

$S=\frac{2 r_{2}\left(r_{2}^{2}-r_{1}^{2}\right) \cos \eta+r_{2}\left(2 r_{1}-r_{2}\right)\left[4\left(r_{2}^{2}-r_{1}^{2}\right) \cos ^{2} \eta+5 r_{1}^{2}-4 r_{1} r_{2}\right]^{1 / 2}}{4\left(r_{2}^{2}-r_{1}^{2}\right) \cos ^{2} \eta+\left(r_{2}-2 r_{1}\right)^{2}}$

All the parameters in the above equations (Equation 4-8 and 4-9) are explicitly defined in William and Warnke (1975).

\subsection{Fluid finite element formulation}

As explained before, FLUID80 elements are used to model the fluid domain which is practical for employing transient as well as free vibration analyses. This element is a modification of a 3-D structural solid element in which the shear modulus is assumed as zero and bulk modulus $\mathrm{K}$ is applied to establish the stress-strain relation, as follows: 


$$
\left\{\begin{array}{c}
\varepsilon_{b u l k} \\
\gamma_{x y} \\
\gamma_{y z} \\
\gamma_{x z} \\
R_{x} \\
R_{y} \\
R_{z}
\end{array}\right\}=\left\{\begin{array}{c}
3 \alpha_{s} \Delta T \\
0 \\
0 \\
0 \\
0 \\
0 \\
0
\end{array}\right\}+\left[\begin{array}{ccccccc}
1 / K & 0 & 0 & 0 & 0 & 0 & 0 \\
0 & 1 / S & 0 & 0 & 0 & 0 & 0 \\
0 & 0 & 1 / S & 0 & 0 & 0 & 0 \\
0 & 0 & 0 & 1 / S & 0 & 0 & 0 \\
0 & 0 & 0 & 0 & 1 / B & 0 & 0 \\
0 & 0 & 0 & 0 & 0 & 1 / B & 0 \\
0 & 0 & 0 & 0 & 0 & 0 & 1 / B
\end{array}\right]\left\{\begin{array}{c}
P \\
\tau_{x y} \\
\tau_{y z} \\
\tau_{x z} \\
M_{x} \\
M_{y} \\
M_{z}
\end{array}\right\}
$$

10)

where $\varepsilon_{\text {bulk }}$ is bulk strain which equals to $\frac{\partial u}{\partial x}+\frac{\partial v}{\partial y}+\frac{\partial w}{\partial z}$, and

$\alpha_{s}=$ thermal coefficient of expansion

$\Delta \mathrm{T}=$ change of temperature

$\mathrm{K}$ = fluid elastic (bulk) modulus

$\mathrm{P}=$ pressure

$\gamma=$ shear strain

$\mathrm{S}=\mathrm{K} \times 10-9$ (arbitrarily small number to give element some shear stability)

$\tau=$ shear stress

$\mathrm{Ri}=$ rotation about axis $\mathrm{i}$

$\mathrm{B}=\mathrm{K} \times 10^{-9}$ (arbitrarily small number to give element some rotational stability)

Mi $=$ twisting force about axis $\mathrm{i}$

A damping matrix can be developed by the Equation 4-11:

$$
\left\{\begin{array}{c}
\dot{\varepsilon}_{b u l k} \\
\dot{\gamma}_{x y} \\
\dot{\gamma}_{y z} \\
\dot{\gamma}_{x z} \\
\dot{R}_{x} \\
\dot{R}_{y} \\
\dot{R}_{z}
\end{array}\right\}=\left[\begin{array}{ccccccc}
0 & 0 & 0 & 0 & 0 & 0 & 0 \\
0 & 1 / \eta & 0 & 0 & 0 & 0 & 0 \\
0 & 0 & 1 / \eta & 0 & 0 & 0 & 0 \\
0 & 0 & 0 & 1 / \eta & 0 & 0 & 0 \\
0 & 0 & 0 & 0 & 1 / C & 0 & 0 \\
0 & 0 & 0 & 0 & 0 & 1 / C & 0 \\
0 & 0 & 0 & 0 & 0 & 0 & 1 / C
\end{array}\right]\left\{\begin{array}{c}
P \\
\tau_{x y} \\
\tau_{y z} \\
\tau_{x z} \\
M_{x} \\
M_{y} \\
M_{z}
\end{array}\right\}
$$


where $\eta$ is viscosity and $\mathrm{C}=0.00001 \eta$.

One of the element's characteristics is its capability in simulating the sloshing. This element employs springs with some equivalent stiffness to hold the free surface of the liquid in place. These springs are required to be added to the nodes at the top of the element. They have negative constants for nodes on the bottom of the element. Therefore, these springs only work at the free surface of the fluid domain, and their effect are canceled out at interior nodes. The spring stiffness $\left(K_{S}\right)$ can be calculated based on the Equation 4.12:

$K_{S}=\rho_{l} A_{f}\left(g_{x} C_{x}+g_{y} C_{y}+g_{z} C_{z}\right)$

where, $A_{f}$ is area of face of element, $\rho_{l}$ is liquid density, $g_{i}$ is acceleration in " $i$ " direction, and $\mathrm{C}_{\mathrm{i}}$ is $\mathrm{i}^{\text {th }}$ component of the normal to face of the element.

\subsection{Solution of static and dynamic nonlinear finite element equations}

In this section, the solution method to solve the nonlinear differential equations of a multi degree of freedom system is discussed. A step by step numerical integration can be used to solve the nonlinear differential equations of a MDOF system. Time intervals known as time steps are employed by dividing each equation of motion. Then, the initial stage and loading condition during each step is used to find the response at the end of each time step sequentially. The stiffness matrix is updated at each load increment due to the material and geometrical nonlinearity of the structure.

\subsubsection{Solution method for static analysis equation}

The nonlinear static analysis is performed by applying the gravity load to the structure in the first step and subsequently increasing the lateral load incrementally until the structure collapses. In this analysis the lateral load pattern is similar to the dynamic force applied to the structure during the earthquake. The static equilibrium of a structure in a linear state at each load increment is represented by the Equation 4.13: 
where, $F$ is vector of forces, $K$ is stiffness matrix, and $U$ is vector of displacements. To solve the above equation, different numerical methods can be employed such as Newton_Raphson, modified Newton_Raphson and Arc-Length. Each of these methods has its own certain advantages and disadvantages however Newton_Raphson is a more suitable solver in ANSYS. In this method, the load is divided into a series of increments and a series of load steps are used to apply these increments. In this approach, the difference between the applied loads and restoring forces called out-of-balance load vector is calculated. Then, the convergence of linear solution is checked by considering the out-of-balance loads. If the problem does not converge, a new solution is performed by re-evaluating the out-of-balance load vector and an updated stiffness matrix. This iteration will be continued until the problem reaches the convergence. Figure 4.4 is a schematic view of the Newton_Raphson method.

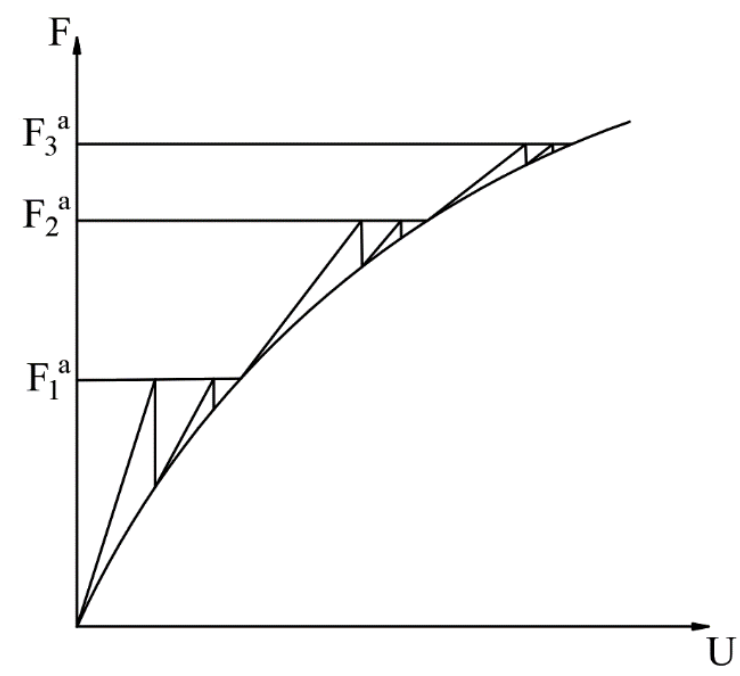

Figure 4.4 Schematic view of "Newton_Raphson" numerical equation solver

According to Newton_Raphson method, a number of load increments applied during load steps are created by load dividing. The static nonlinear equilibrium equation subjected to a load denoted by vector $\{\mathrm{F}\}$ is:

$\{\mathrm{F}\}=[\mathrm{K}]\{\mathrm{U}\}$ 
The stiffness matrix $[\mathrm{K}]$ depends on the geometry and primary stiffness and is a function of displacement vector $\{U\}$. The equilibrium equation for one iteration is calculated as:

$$
\begin{aligned}
& {\left[K_{i}^{T}\right]\left\{\Delta U_{i}\right\}=\left\{F^{a}\right\}-\left\{F_{i}^{r}\right\}} \\
& \left\{U_{i+1}\right\}=\left\{U_{i}\right\}+\left\{\Delta U_{i}\right\}
\end{aligned}
$$

$\left[K_{i}^{T}\right]$ is Jacobian or tangent matrix, (i) is an index indicating the existing iteration and $\left\{F_{i}^{r}\right\}$ is the restoring load vector. In initial stage, $\mathrm{U}_{0}$ is considered as zero, then the Jacobian matrix $\left[K_{i}^{T}\right]$, restoring vector $\left\{F_{i}^{r}\right\}$ and $\Delta U_{i}$ is calculated for each iteration. Finally, $\Delta U_{i}$ is substituted in Equation (4.16) and $\Delta U_{i+1}$ is calculated. This algorithm will be repeated till the convergence is attained.

\subsubsection{Solution method for dynamic equations of motion}

In a multi-degree-of-freedom (MDOF) system with $\mathrm{n}$ degrees of freedom, it is important to know the values of displacement at various points in order to define the system motion.

To develop the equations of motion for a typical MDOF system, it is assumed that the system is subjected to the following forces at each accelerated mass: external force $(F)$, inertial force $\left(F_{I}\right)$, damping force $\left(F_{D}\right)$, and stiffness force $\left(F_{S}\right)$. According to the dynamic equilibrium condition for each mass we have:

$F=F_{I}+F_{D}+F_{S}$

These forces can be written in a matrix form as:

$$
\begin{aligned}
& \left\{F_{I}\right\}=[M]\{\ddot{u}\} \\
& \left\{F_{D}\right\}=[C]\{\dot{u}\} \\
& \left\{F_{S}\right\}=[K]\{u\}
\end{aligned}
$$

where, $[M],[C]$ and $[K]$ are mass, damping and stiffness matrices, respectively and $\{\ddot{u}\},\{\dot{u}\}$ and $u$ are acceleration, velocity and displacement vector, respectively. By substituting 
Eq. 4.18, 4.19, and 4.20 into Eq. 4.17, the equations of motion for a MDOF system can be written as follows:

$[M]\{\ddot{U}\}+[C]\{\dot{U}\}+[K]\{U\}=\{F\}$

In the case of a tank filled with liquid, the hydrodynamic pressure as a result of the interaction between the fluid domain and the tank causes an external force on the tank's wall. Under this condition, the equation of motion can be modified as:

$[M]\{\ddot{U}\}+[C]\{\dot{U}\}+[K]\{U\}=\left\{F_{a}\right\}+\left\{F_{p r}\right\}$

where $\left\{F_{a}\right\}$ is the resultant of all other forces exerted on the tank, and $\left\{F_{p r}\right\}$ is the fluid pressure load vector at fluid-structure interface which can be calculated by integrating the pressure over the interface surface. By employing the coupling matrix $[R]$, the fluid pressure vector $\{p\}$ and the forces acting on the fluid-structure interface $\left\{F_{p r}\right\}$ can be related, and the final dynamic equations of motion can be revised as:

$[M]\{\ddot{U}\}+[C]\{\dot{U}\}+[K]\{U\}-[R]\{p\}=\left\{F_{a}\right\}$

\subsection{Material properties}

The objective of this section is to define and verify a finite element (FE) technique for modeling reinforced concrete (RC) tanks in order to perform a proper and accurate seismic analysis.

Defining an appropriate stress-strain curve for both concrete and steel materials is needed to acquire an accurate finite element modeling of $\mathrm{RC}$ structures. The objective of this research is investigating the response of structure in which both concrete and steel materials reach their respective failure points. To reach this goal, the responses of both concrete and steel under extreme stresses and strains should be known. There are several mathematical models for concrete and steel in finite element modeling. These mathematical models will be discussed in the following sections. 


\subsubsection{Stress-strain curve of concrete}

In this study, the stress-strain response of concrete element in compression is performed using the relationship suggested by Carrasquillo, et al (1981) for unconfined concrete. The concrete elastic modulus $\left(E_{c}\right)$ to calculate the compressive stress $\left(f_{c}^{\prime}\right)$ in elastic region is determined as follows:

$E_{c}=4500 \sqrt{f_{c}^{\prime}}$

The compressive stress $\left(f_{c}^{\prime}\right)$ beyond the compressive strain of 0.0002 is calculated as follows:

$f_{c}=\left\{\begin{array}{lr}f_{c}^{\prime} \times \frac{n \times\left(\frac{\varepsilon_{c}}{\varepsilon_{c}^{\prime}}\right)}{n-1+\left(\frac{\varepsilon_{c}}{\varepsilon_{c}^{\prime}}\right)^{n}} & \text { if } 0.0002<\varepsilon_{c} \leq \varepsilon_{c}^{\prime} \\ f_{c}^{\prime} \times \frac{n \times\left(\frac{\varepsilon_{c}}{\varepsilon_{c}^{\prime}}\right)}{n-1+\left(\frac{\varepsilon_{c}}{\varepsilon_{c}^{\prime}}\right)^{n k_{d}}} & \text { if } \varepsilon_{c}>\varepsilon_{c}^{\prime}\end{array}\right.$

In the above equation, the concrete strain at the peak compressive stress level $\left(\varepsilon_{c}^{\prime}\right)$ is calculated as follows,

$\varepsilon_{c}^{\prime}=-\frac{f_{c}^{\prime}}{E_{c}} \times \frac{n}{n-1}$

The curve fitting factor $(\mathrm{n})$, and post decay stress softening coefficient $\left(\mathrm{k}_{\mathrm{d}}\right)$ are defined

as,

$n=0.8+\frac{f_{c}^{\prime}}{17}$

and,

$k_{d}=0.67+\frac{f_{c}^{\prime}}{62}$

The multilinear stress-strain curve for the compressive strength $\left(f_{c}^{\prime}\right)$ of $30 \mathrm{MPa}$ is shown in Figure 4.5. Applying the multilinear curve reduces the computational effort and consequently helps with the convergence of the nonlinear solution algorithm. 


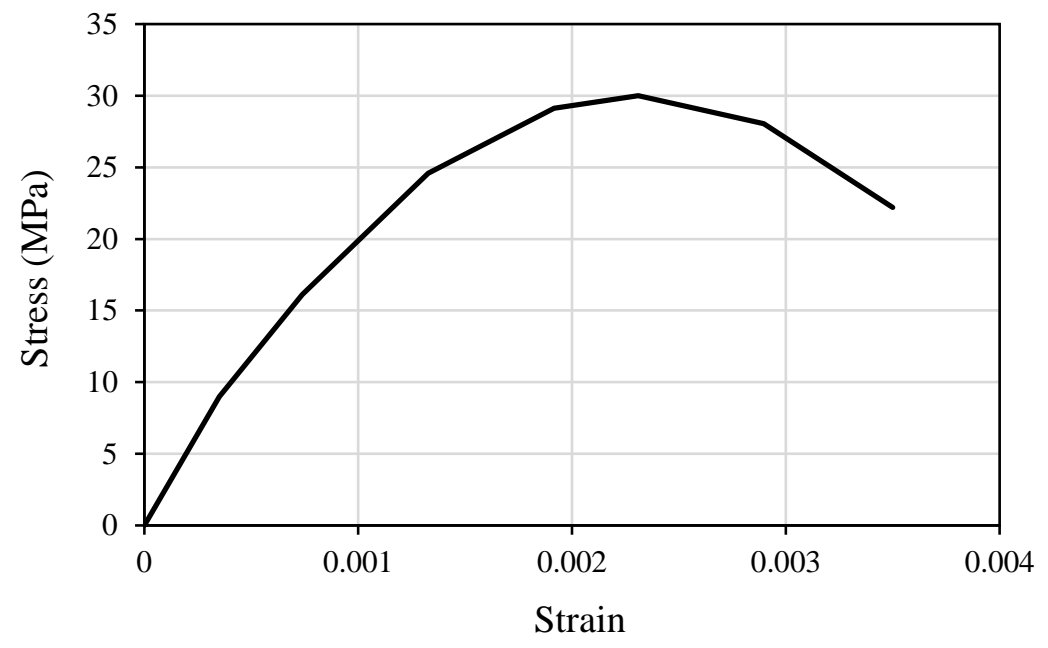

Figure 4.5 Stress-strain curve for concrete material with $f_{c}^{\prime}=30 \mathrm{MPa}$

\subsubsection{Stress-strain curve of steel}

In this study, the analytical approximation to the tension and compression stress-strain curve for reinforcement is modeled using elastic-perfectly-plastic curve. In this study, the grade 400 steel rebar with a yield strength $\left(f_{y}\right)$ of $400 \mathrm{MPa}$ is employed for the finite element modeling of reinforcement.

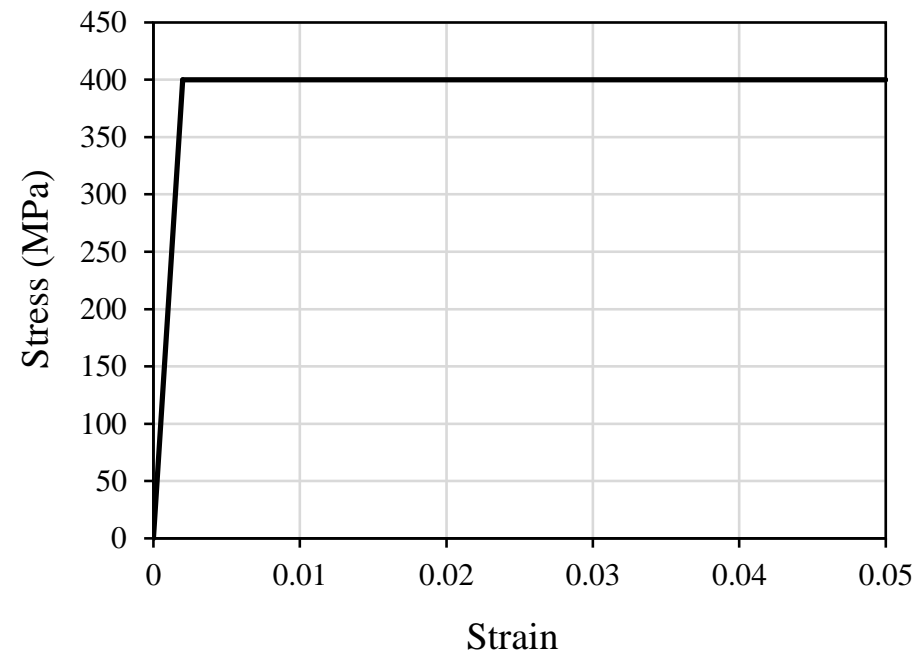

Figure 4.6 Stress-strain idealization for steel material with $f_{y}=400 \mathrm{MPa}$

The stress-strain curve for reinforcement is shown in Figure 4.6. As the figure indicates the stress-strain curve consists of two branches, linear and perfectly plastic. The linear part of this curve is defined as: 
$f_{s}=E_{s} \varepsilon_{s} \quad 0 \leq \varepsilon_{s} \leq \varepsilon_{y}$

And the perfectly plastic branch is defined as,

$f_{s}=f_{y} \quad \varepsilon_{y} \leq \varepsilon_{s}$

where, $f_{s}$ is steel strength, $E_{s}$ is elastic modulus of steel, $\varepsilon_{s}$ and $\varepsilon_{y}$ is strain and yield strain of steel, respectively.

\subsubsection{Elastomeric bearing pad and seismic cables}

Flexible ground supported tanks are classified based on their wall to footing connection details. There are two different type of flexible tanks: anchored and unanchored. In this study, the anchored flexible base is considered. The anchored base contains both the seismic cables connecting the wall to the footing and the bearing pad. Tangential resistance of seismic cables transfers the base shear from the wall to the footing. Typical seismic cables have $15 \mathrm{~mm}$ diameter including 7 -wire high strength strands inclined at $45^{\circ}$ from the horizontal. As the bearing pads of flexible base tanks, the most common type of elastomeric pads $40 \mathrm{H}$ is used. As shown in Figure 4.8, the shear modulus $\left(\mathrm{G}_{\mathrm{p}}\right)$ for this type of elastomeric pads $(40 \mathrm{H})$ is taken as $0.345 \mathrm{MPa}$ (50 psi). The elastomeric bearing pad is considered as continuous and its thickness $\left(t_{p}\right)$ between the tank wall and the base is $25 \mathrm{~mm}$. The shear strain is calculated as the ratio of linear deformation (d) to rubber thickness $\left(t_{p}\right)($ Hafez, 2012).

For anchored flexible base tanks, spring elements are employed to model the elastomeric bearing pads and the seismic cables. The behavior of seismic cables and bearing pads in both tangential and radial directions is considered to be linear. The tangential stiffness of the anchored flexible support $\left(K_{t}\right)$ including the stiffness of the seismic cables and bearing pads is calculated by the Equation 4.31:

$K_{t}=1000\left[\left(\frac{A_{S} E_{S} \cos ^{2} \alpha}{L_{c} S_{c}}\right)+\left(\frac{2 G_{p} W_{p} L_{p}}{t_{p} S_{p}}\right)\right]$ 
In the radial direction, the stiffness of the flexible support is based on the stiffness of the bearing pad only and it is calculated by the following equation (Eq. 4.32):

$K_{r}=1000\left(\frac{2 G_{p} W_{p} L_{p}}{t_{p} S_{p}}\right)$

where,
$A_{s}$ : Area of each seismic cable
$\mathrm{E}_{\mathrm{s}}$ : Elastic modulus of cable
$L_{c}$ : Length of the RUBATEX Sleeve plus the embedded length equalling $35 \times D_{s}$
$\mathrm{S}_{\mathrm{c}}$ : Spacing between the seismic cables
$\alpha$ : Angle of inclined cable
$\mathrm{G}_{\mathrm{p}}$ : Shear modulus of elastomeric bearing pad
$\mathrm{W}_{\mathrm{p}}$ : Width of elastomeric bearing pad
$\mathrm{L}_{\mathrm{p}}$ : Length of elastomeric bearing pad
$\mathrm{t}_{\mathrm{p}}$ : Thickness of elastomeric bearing pad
$\mathrm{S}_{\mathrm{p}}$ : Spacing of elastomeric bearing pad
$\mathrm{D}_{\mathrm{s}}$ : Diameter of seismic cables 


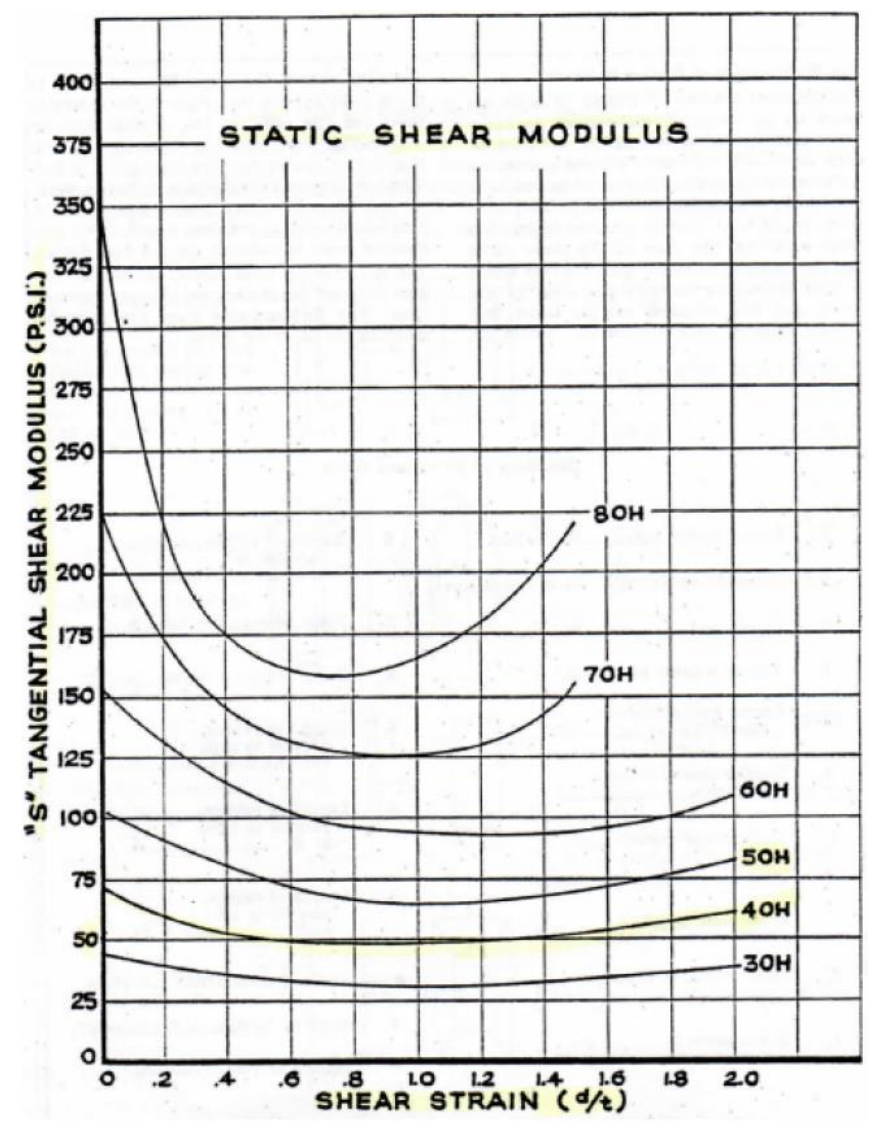

Figure 4.8 Values of Tangential or Slope Static Moduli for Rubber in Shear (Handbook of Molded and Extruded Rubber, Goodyear, second edition, 1959)

To model the flexible base, at each base node two springs one in tangential and one in radial direction are used. ANSYS models these springs by employing COMBIN40 element between two nodes. COMBIN40 is a combination of a spring-slider and damper in parallel, coupled to a gap in series and slider and damper can be removed from the element. This element has one degree of freedom at each node, either a nodal translation, rotation, or pressure. The geometry of this element is shown in Figure 4.9-a. In this study, COMBIN40 is defined by spring constant $\mathrm{K}_{\mathrm{s}}$ (force/length) and a gap size (length) in both radial and tangential direction.

The boundary conditions defined for tangential and radial springs are presented schematically in Figure 4.9-b: 


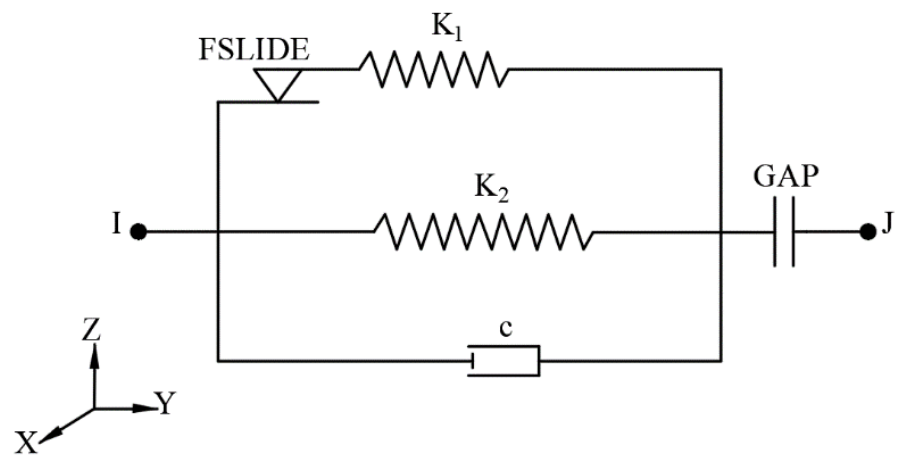

(a)

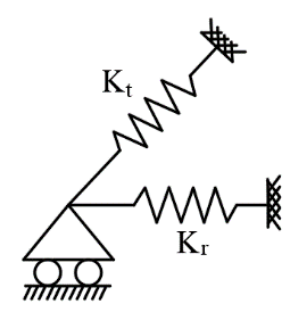

(b)

Figure 4.9 a) Geometry of COMBIN40, b) FE flexible support model

\subsection{Validation of proposed FE method in modeling of RC tank}

In this section, the capability of ANSYS program in modeling concrete structures and predicting the response will be verified. For this purpose, some experimental tests performed on a reinforced concrete wall will be modeled by finite element program, ANSYS, and the real experimental results and corresponding response of finite element model will be compared.

\subsubsection{Finite element modeling of reinforced concrete}

A comparison between the results of real experimental tests and the proposed finite element model is required for validating the finite element model. Some experimental tests performed on RC beams are selected for this purpose. In pushover analysis, the load is applied on the structure until it fails. Since all experimental tests have the same procedure, comparing the recorded results of finite element modeling and the actual load-deflection results of similar tests are more reliable. In this study, in order to verify the finite element modeling, a simply supported reinforced concrete beam specimen is chosen. These beams are TIMA and J4 specimens tested by Gaston et al. (1972) and Burns and Siess (1962), respectively. Information about beam section dimensions is indicated in Table 4.1 . 
Table 4.1 Beam section dimensions

\begin{tabular}{|c|c|c|c|}
\hline Beam & $\mathbf{b}(\mathbf{m m})$ & $\mathbf{h}(\mathbf{m m})$ & $\mathbf{d}(\mathbf{m m})$ \\
\hline TIMA & 152 & 305 & 272 \\
\hline J4 & 152 & 508 & 457 \\
\hline
\end{tabular}

Figure 4.10 shows the geometry, loading location, and cross-section of the beams.

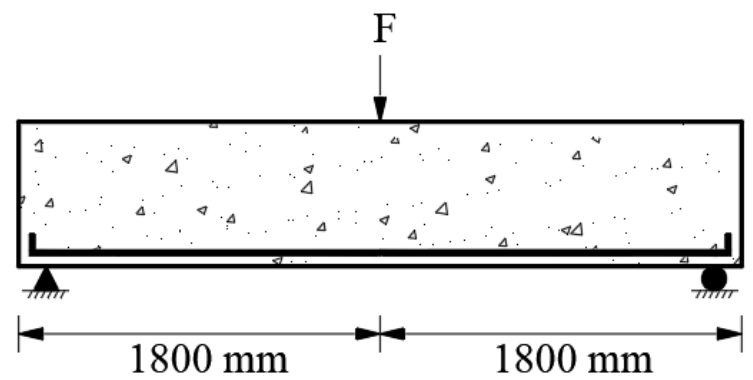

(b)

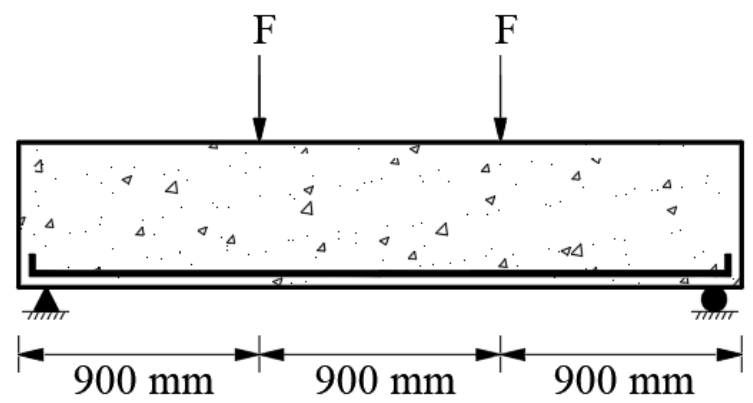

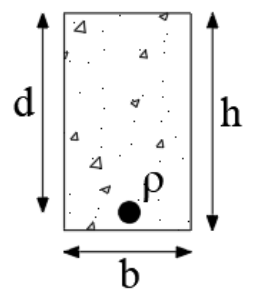

(a)

(c)

Figure 4.10 Cross-section, loading location and geometry of beam specimens; (a) Typical cross-section, (b) J4 beam, (c) TIMA beam

Table 4.2 displays the material properties for TIMA and $\mathrm{J} 4$ beam specimens.

Table 4.2 Material properties for TIMA and J4 beam specimens

\begin{tabular}{|c|c|c|c|c|c|}
\hline Beam & $E_{c}(\mathrm{MPa})$ & $E_{s}(\mathrm{MPa})$ & $f_{c}{ }^{\prime}(\mathrm{MPa})$ & $f_{y}(\mathrm{MPa})$ & $\rho=\mathrm{A}_{\mathrm{st}} / \mathrm{bd}(\%)$ \\
\hline TIMA & 26576 & 194172 & 31.6 & 318 & 0.62 \\
\hline J4 & 26184 & 202998 & 33.3 & 310 & 0.99 \\
\hline
\end{tabular}


For FE analysis, Solid65 and Link8 elements are used to model concrete and reinforcement, respectively. Solid45 is used to model steel plates at supports of the beam. This is a 3D solid element with eight nodes and three degrees of freedom at each node (translations in nodal $\mathrm{x}, \mathrm{y}$, and $\mathrm{z}$ directions). Cross-sectional area and number of reinforcements is calculated using the reinforcement ratio represented in Table 4.2. To define the nonlinear behavior of concrete, the mathematical model suggested by Carrasquillo et al. (1981) is used to implement the stress-strain curve in the model. For steel material of reinforcement, an elastic-perfectlyplastic model is assumed. In FE model, Poisson's ratio $(v)$ of concrete and steel is considered 0.167 and 0.3 , respectively. Figure 4.11 shows the FE modeling of $\mathrm{J} 4$ beam including the volume created in ANSYS, concrete, reinforcement, steel plate elements, location of load and constraints.

The material properties of concrete and reinforcement are implemented as per Table 4.2. Tensile strength of concrete is assumed to be $10 \%$ of the compressive strength of concrete. For steel loading and support plates, elastic modulus $\left(E_{s}\right)$ and Poisson's ratio $(v)$ are assumed as $200 \mathrm{GPa}$ and 0.3 , respectively. 


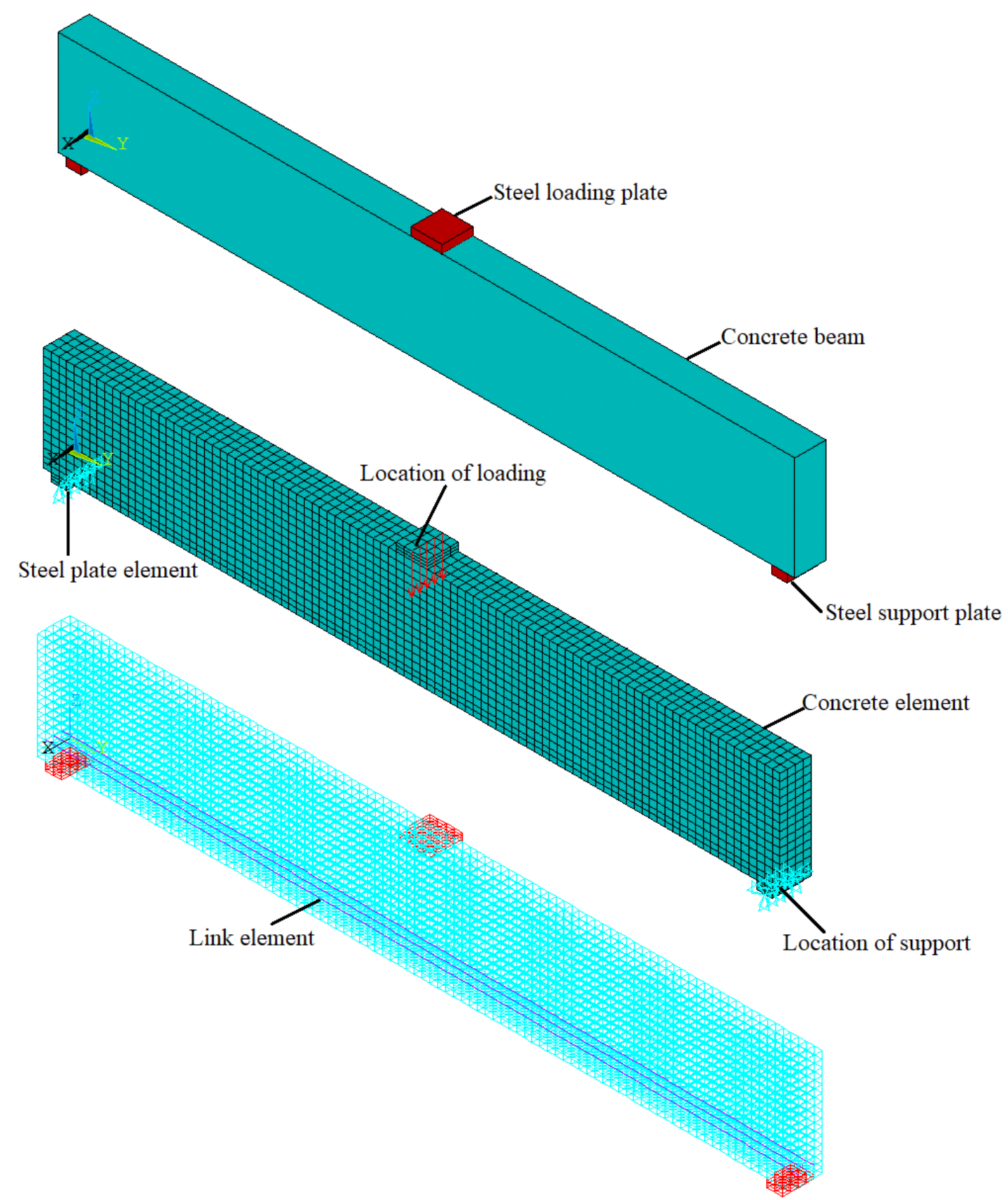

Figure 4.11 Meshing of concrete beam (J4) and boundary condition

As shown in Figure 4.11, pin support condition is modeled by constraining nodes in X, $\mathrm{Y}$ and $\mathrm{Z}$ directions at the bottom right of the beam. In addition, nodes at the bottom left end of the beam are constrained in $\mathrm{X}$ and $\mathrm{Z}$ direction to simulate roller support condition. Force, $\mathrm{F}$, is applied on the steel plate and distributed across the entire centerline of the plate to avoid premature failure. The force is applied at $1800 \mathrm{~mm}$ away from the edge of the beam. 
Figures 4.12 and 4.13 indicate the comparison of the mid-span deflection versus applied load curve according to both finite element and experimental results. These figures justify a good agreement between the finite element model load-deformation results and the experimental test results. To validate the FE results, there are some criteria. First, the loaddeflection curve of experimental load test should be similar to recorded results of FE modeling. Second, the FE model predicts the ultimate load before failure for both beam specimens with a very high accuracy.

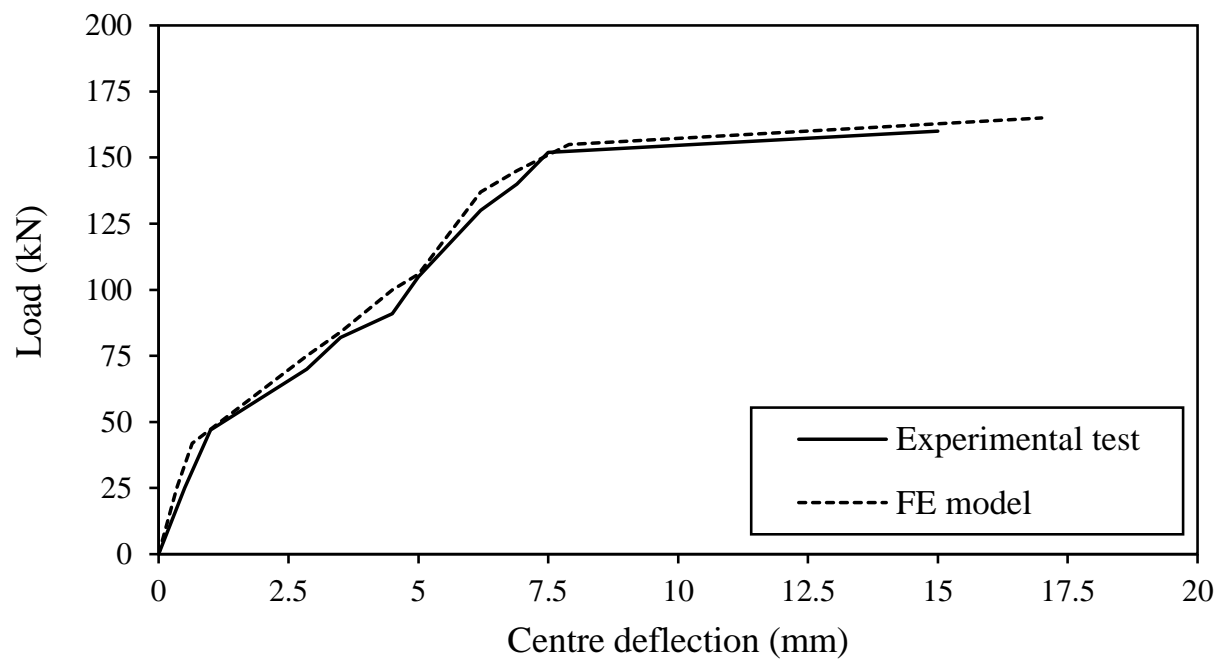

Figure 4.12 Experimental versus FE results for J4 beam at mid-span

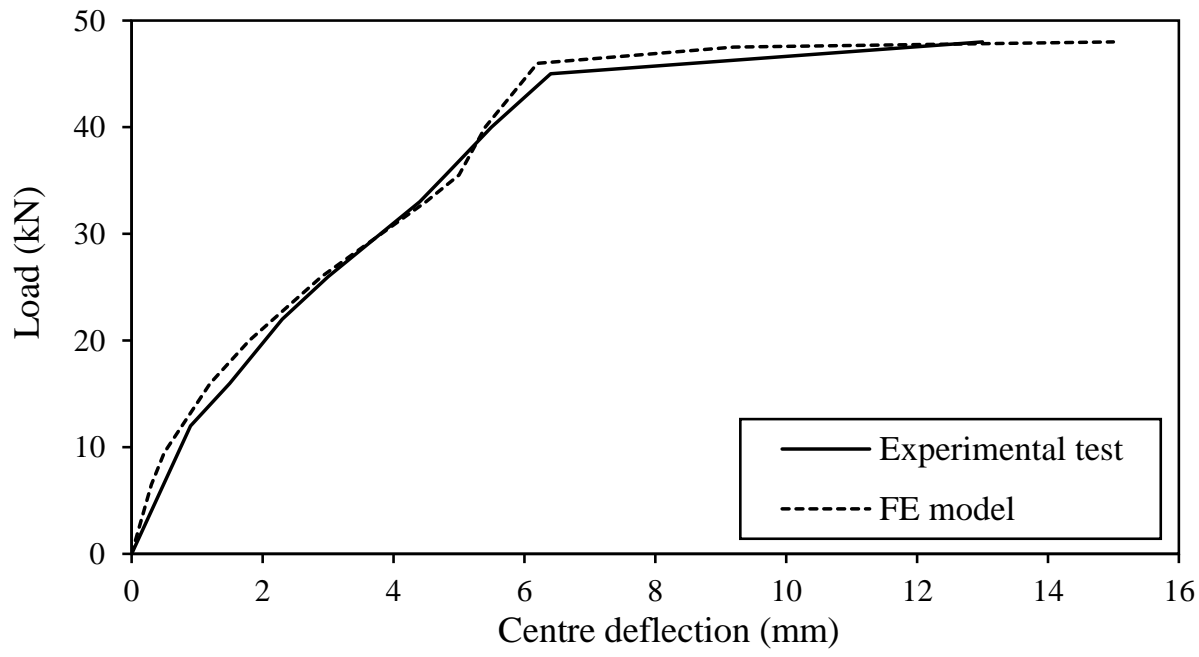

Figure 4.13 Experimental versus FE results for TIMA beam at mid-span 
Three different concrete failures can be observed under this loading condition: flexural, compression (crushing), and diagonal tension cracks. ANSYS is able to present cracking pattern(s) at each load step. Figure 4.13 shows location of first crack in the FE model of the beam J4. The initial flexural crack corresponding to $48 \mathrm{kN}$ takes place when the flexural stress reaches the rapture modulus of 3.3 MPa at the bottom fibre of the beam. Beyond the first crack, increasing load leads to subsequent flexural vertical cracks in the constant moment region, and spreads out towards the supports.

Figure 4.13 represents the significant flexural and diagonal tension cracks. Consequently, at ultimate stage, the beam no longer supports any additional loading and analysis stops due to convergence failure. The failure mode can be determined by the crack appearance.Based on these observations it can be concluded that the Finite element model is able to predict different types of concrete failure fairly accurately.
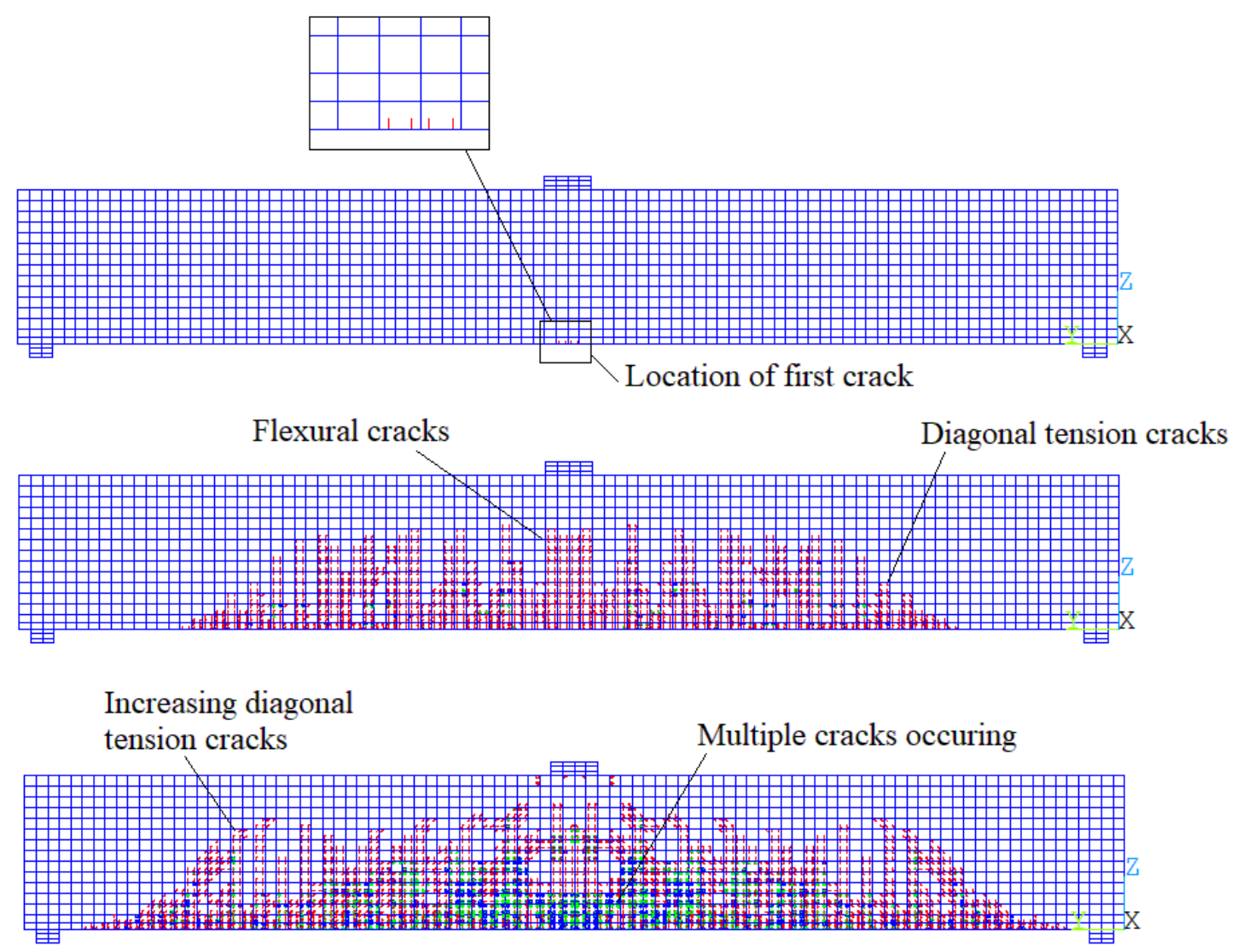

Figure 4.14 Crack pattern on FE model (Beam J4); a) Location of first crack, b) Location of flexural and tension cracks at ultimate stage 


\subsubsection{Reinforced concrete shear wall test verification}

In order to verify the capability of FEM in modeling RC walls and predicting their load-deformation behavior, the FEM results and real experimental test values are compared. A set of experimental tests performed on reinforced concrete shear walls conducted by Mickleborough et al (1999) are selected for this purpose. Three RC wall specimens with different height to width ratios are selected for FEM verification. Geometry, section dimensions, material properties including material strength and reinforcement ratio of the specimens are shown in Figure 4.15 and Table 4.3.

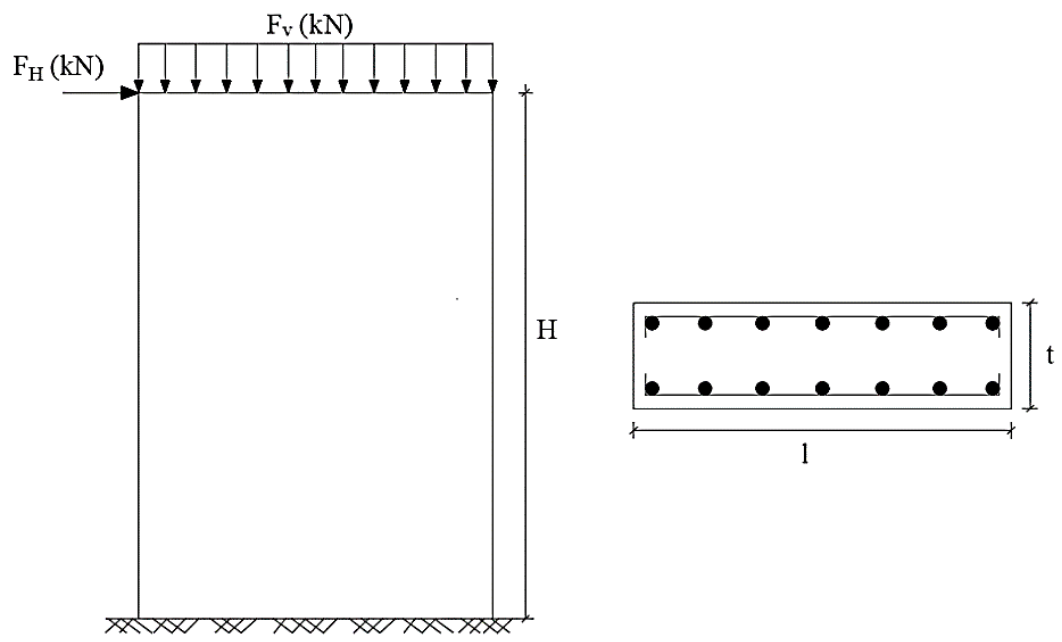

Figure 4.15 Schematic geometry of RC wall specimens (Mickleborough et al. 1999)

Test condition is similar to the pushover analysis of RC tanks. First, all RC shear walls are subjected to a constant vertical force $\left(\mathrm{F}_{\mathrm{v}}\right)$ and then are incrementally loaded with the horizontal force $\left(\mathrm{F}_{\mathrm{H}}\right)$ until they reach failure. 
Table 4.3 Material and section properties of specimens (Mickleborough et al. 1999)

\begin{tabular}{|c|c|c|c|c|c|c|c|c|c|}
\hline TYPE & $\begin{array}{c}\mathrm{H} \\
(\mathrm{mm})\end{array}$ & $1(\mathrm{~mm})$ & $\mathrm{t}(\mathrm{mm})$ & $\begin{array}{c}\text { Concrete } \\
\text { Young's } \\
\text { modulus, } \\
E_{c} \text { (Mpa) }\end{array}$ & $f_{c}^{\prime}$ (MPa) & $\begin{array}{c}\text { Steel } \\
\text { Young's } \\
\text { modulus, } \\
E_{s}(\mathrm{MPa})\end{array}$ & $f_{y}(\mathrm{Mpa})$ & $\begin{array}{c}\rho_{H} \\
(\%)\end{array}$ & $\rho_{V}$ \\
& & & & \\
\hline SH-L & 1500 & 750 & 125 & 23789 & 44.7 & $2 . \mathrm{E}+05$ & 460 & 0.39 & 1.17 \\
\hline SM-H & 1125 & 750 & 125 & 30629 & 57.3 & $2 . \mathrm{E}+05$ & 460 & 0.39 & 1.17 \\
\hline SL-H & 750 & 750 & 125 & 19769 & 29.5 & $2 . \mathrm{E}+05$ & 460 & 0.39 & 1.17 \\
\hline
\end{tabular}

For FE model, Solid65, Solid45 and Link8 elements are used to model concrete, steel loading plate and reinforcement, respectively. The reinforcement ratio is equal in both horizontal and vertical directions in all shear walls. $6 \mathrm{~mm}$ (diameter) horizontal rebars are modeled with $100 \mathrm{~mm}$ spacing and 14,10 $\mathrm{mm}$ vertical reinforcements at $110 \mathrm{~mm}$ placed in the wall thickness. The nonlinear behavior of concrete material is modeled using the relationship suggested by Carrasquillo et al. (1981) and elastic-perfectly-plastic behavior is assumed for steel material. Figure 4.16 shows the FE modeling of wall type SH-L including the volume of concrete and steel loading plates, elements, and boundary conditions. The vertical and lateral load are applied at top of the wall. To avoid the premature failure, the lateral concentrated load is distributed across the entire steel plate. To model fixed base condition, the nodes located at $\mathrm{Z}=0$ (base of the wall) are constraint for translation in $\mathrm{X}, \mathrm{Y}$ and $\mathrm{Z}$ direction. 


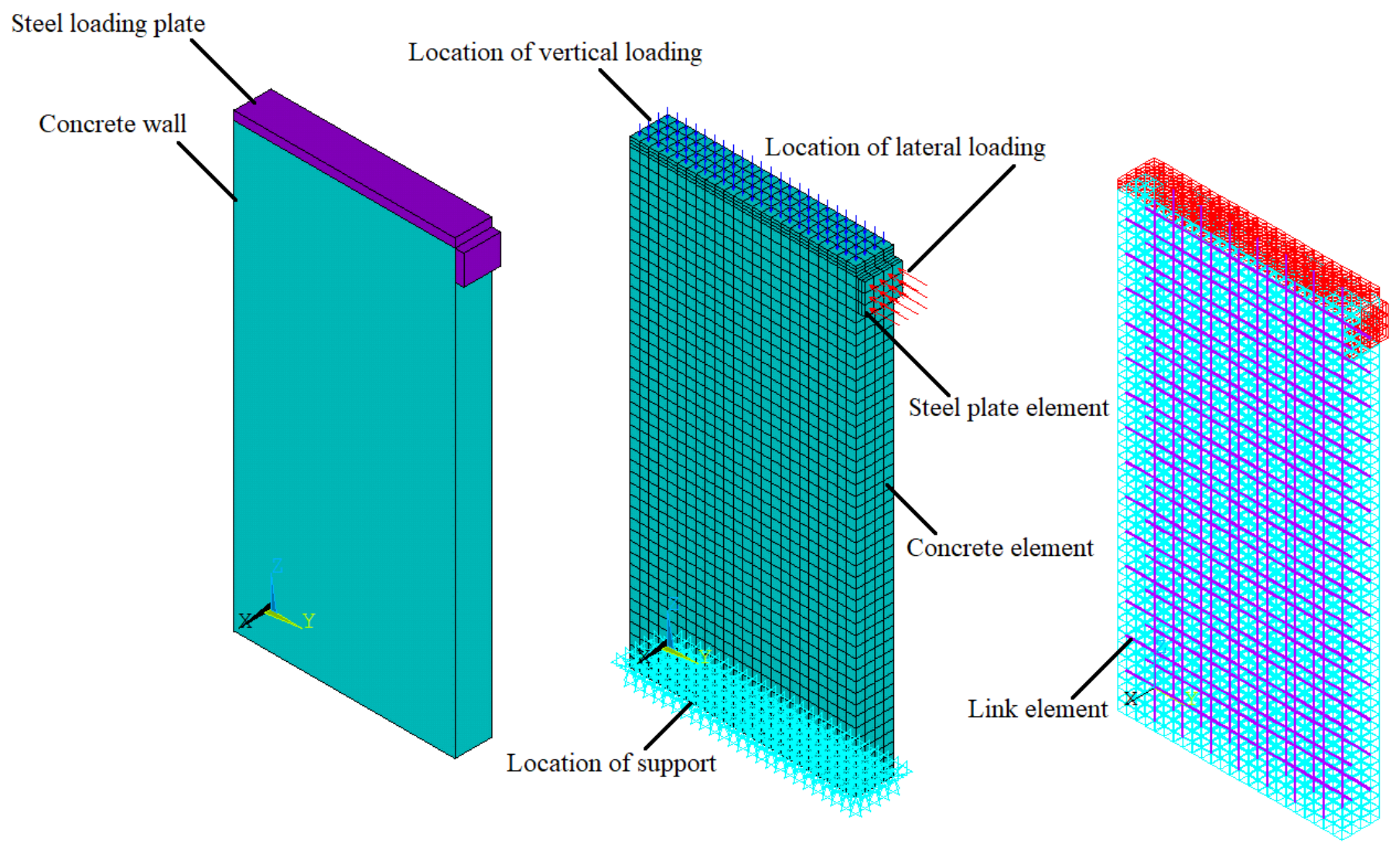

Figure 4.16 Volumes of concrete wall (SH-L) and steel plates, meshing and boundary condition

Loading and maximum deflection of the experimental tests at various stages such as initiation of flexural cracking, end of serviceability range and ultimate stage are presented in Table 4.4

Table 4.4 Experimental results of walls

\begin{tabular}{|c|c|c|c|c|c|c|c|c|}
\hline \multirow{3}{*}{ Type } & \multicolumn{2}{|c|}{ Axial load } & \multicolumn{6}{|c|}{ Lateral load level } \\
\hline & \multirow{2}{*}{$\begin{array}{c}\text { Actual } \\
\mathrm{F}_{\mathrm{v}} \\
(\mathrm{kN})\end{array}$} & \multirow{2}{*}{$\begin{array}{l}\text { Stress } \\
(\mathrm{MPa})\end{array}$} & \multicolumn{2}{|c|}{ Initiation of flexural cracking } & \multicolumn{2}{|c|}{$\begin{array}{l}\text { End of serviceability range } \\
\left(80 \% \mathrm{Fu}_{\mathrm{U}}\right)\end{array}$} & \multicolumn{2}{|c|}{ Ultimate } \\
\hline & & & $\mathrm{F}_{\mathrm{H}}(\mathrm{kN})$ & $\Delta(\mathrm{mm})$ & $\mathrm{F}_{\mathrm{H}}(\mathrm{kN})$ & $\Delta(\mathrm{mm})$ & $\mathrm{F}_{\mathrm{U}}(\mathrm{kN})$ & $\Delta(\mathrm{mm})$ \\
\hline SH-L & 357 & 3.8 & 67 & 0.95 & 125 & 2.86 & 156 & 6.44 \\
\hline SM-H & 486 & 5.2 & 125 & 0.72 & 230 & 2.62 & 289 & 4.87 \\
\hline SL-H & 477 & 5.1 & 142 & 0.50 & 320 & 2.11 & 400 & 7.03 \\
\hline
\end{tabular}

As the comparison between experimental and FE results demonstrates in Figure 4.17, a good agreement exists between the load-deformation pattern of experimental test and FE model. 


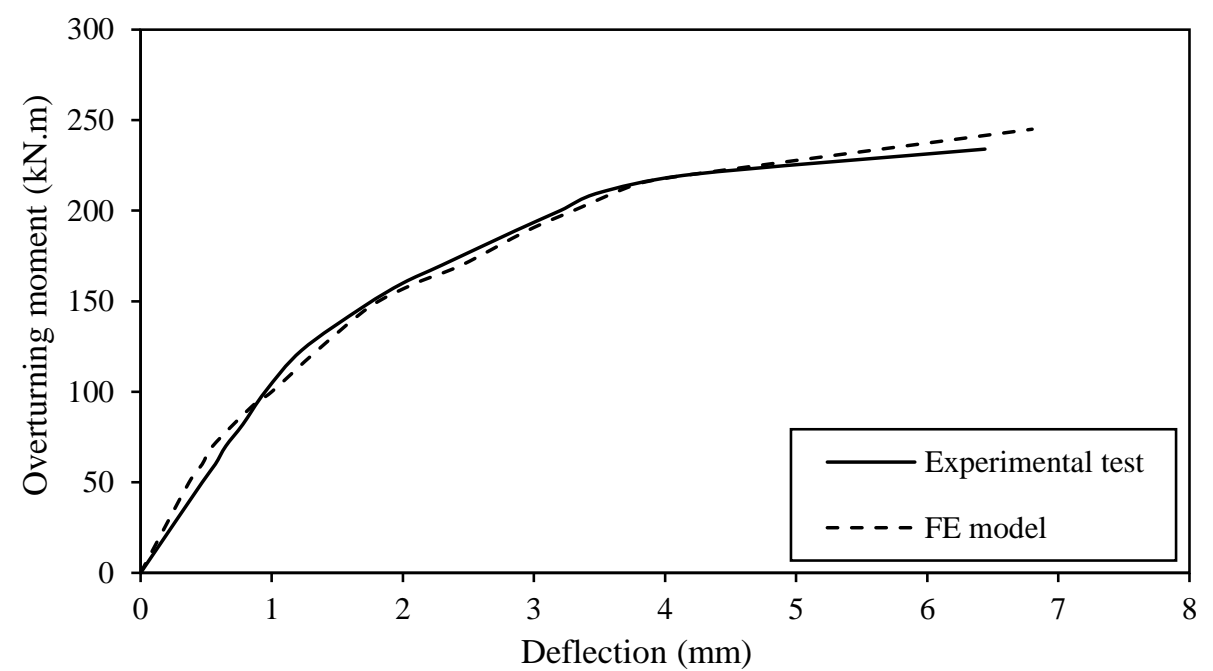

(a)

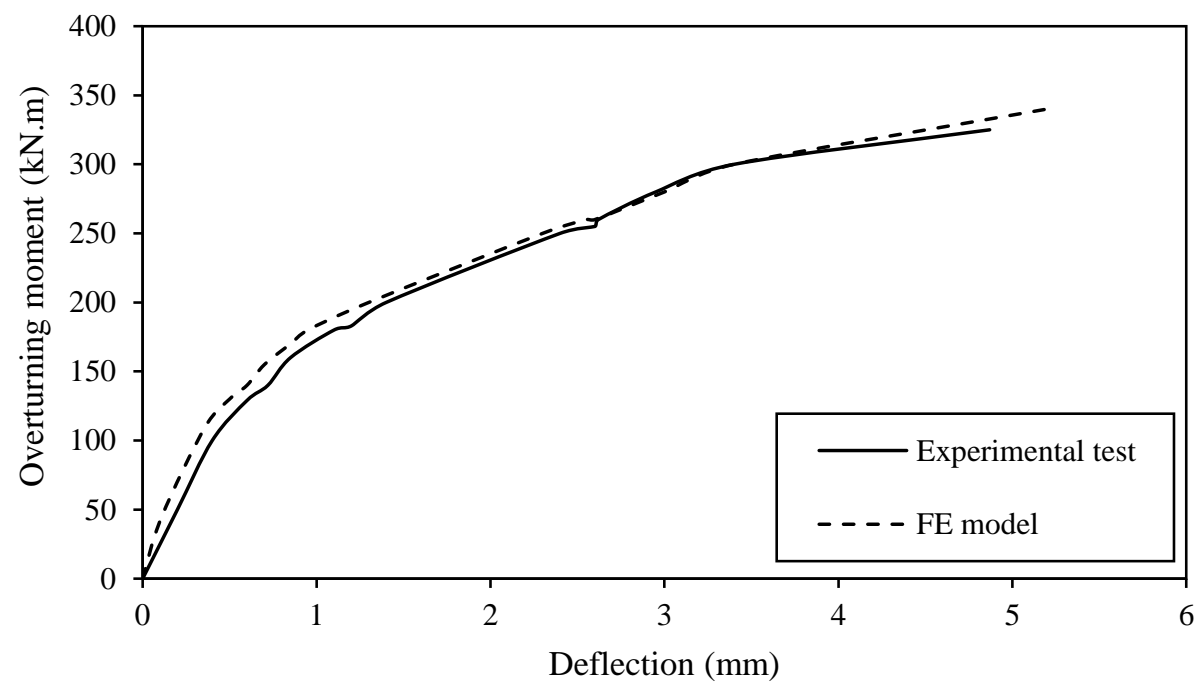

(b)

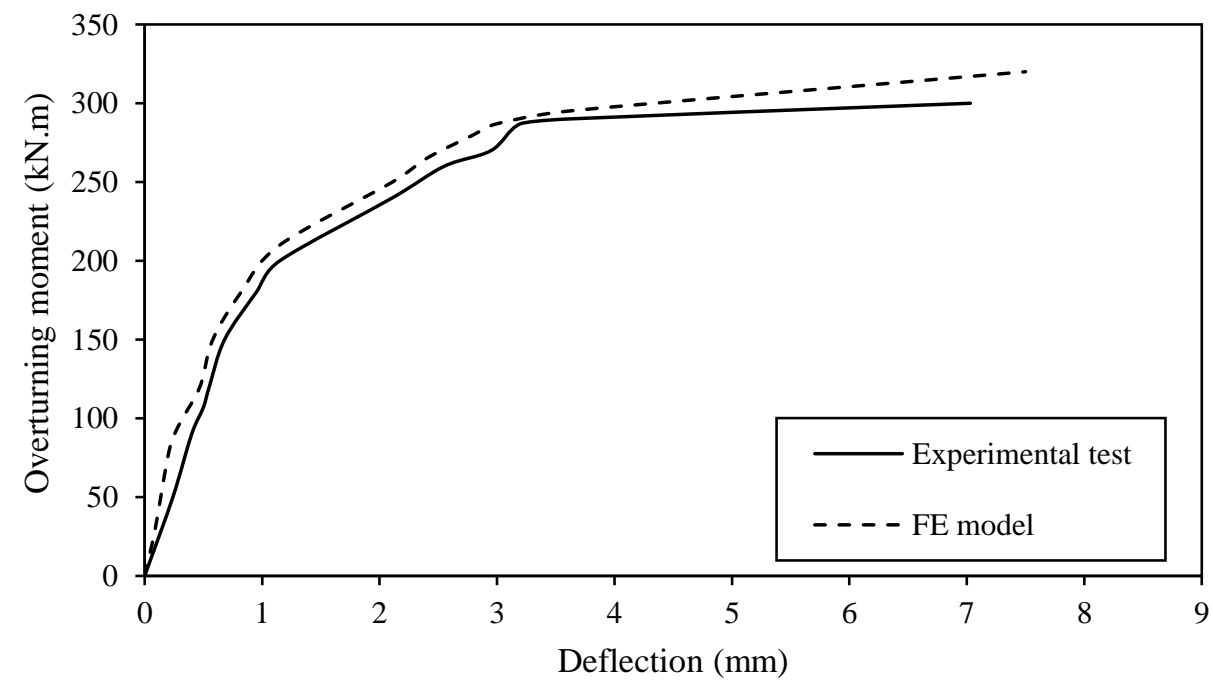

(c)

Figure 4.17 Experimental versus FE results for walls: a) SH-L, b) SM-H, c) SL-H 
Crack pattern of wall SH-L including the location of first crack and flexural cracks is shown in Figure 4.18. As shown in Figure 4.18, the initial flexural crack corresponding to overturning moment of $92 \mathrm{kN} . \mathrm{m}$ (lateral load of $61 \mathrm{kN}$ ) appears at the right bottom fibre of the wall when the flexural stress reaches to the modulus of rapture of 4.47 $\mathrm{MPa}$. By increasing the lateral load, successive cracking are distributed in constant moment region and moved up towards the top of the wall until the wall no longer can put up with more lateral load due to convergence failure.

All in all, the obtained results indicates that FE model will results in reliable results and capable of presenting an appropriate load-displacement graph, and consequently appraising the maximum shear wall lateral strength.

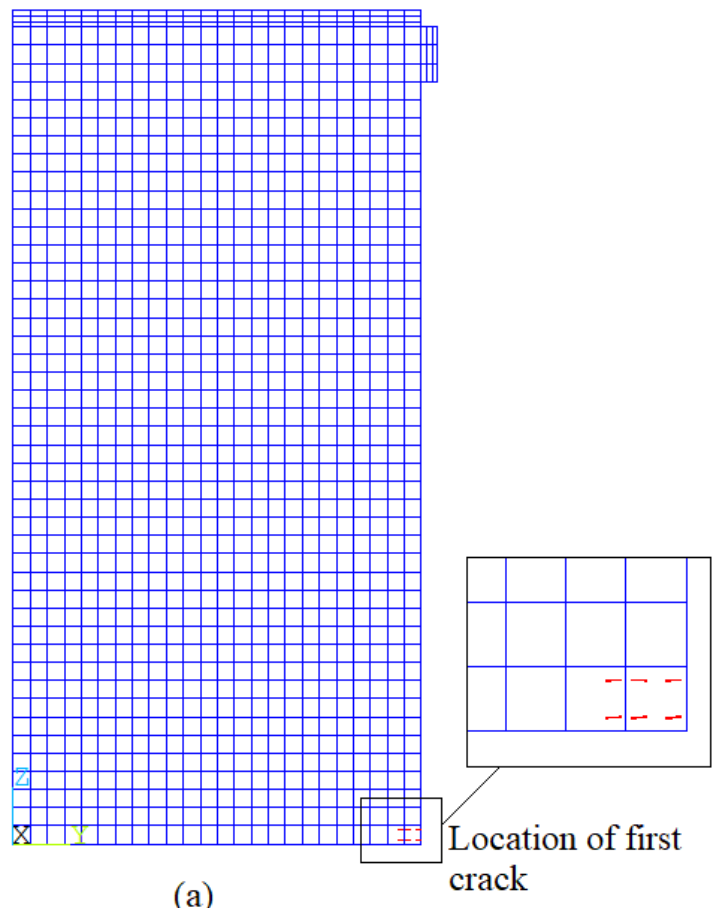

(a)

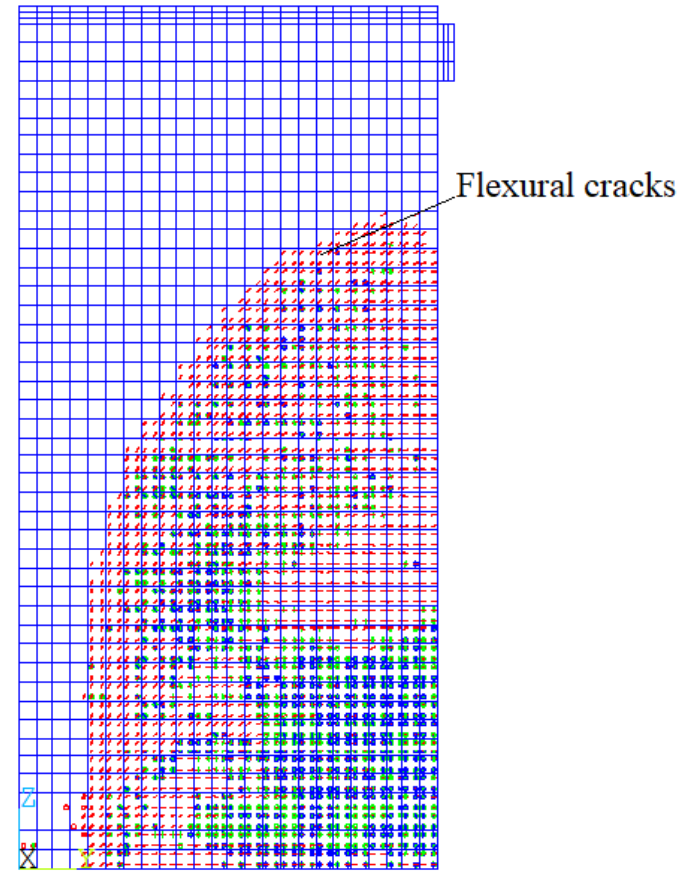

(b)

Figure 4.18 Crack pattern on the wall type SH-L; a) Initiation of flexural cracking, b) Crack pattern at ultimate stage

\subsubsection{Parametric study on shear transfer coefficient effect}

As discussed in section 4.5, various inputs are needed to implement in ANSYS program for element SOLID65 including elastic modulus, ultimate uniaxial compressive strength, 
ultimate uniaxial tensile strength, Poisson's ratio and shear transfer coefficient. Shear transfer coefficient for both open and closed crack is employed to introduce the failure model. The shear transfer coefficient $\beta_{t}$ is employed to represent the shear reduction factor for those subsequent loads which trigger sliding (shear) across the crack face. The crack face conditions are represented by the shear transfer coefficient for open cracks $\beta_{t}$. For smooth crack the value of $\beta_{t}$ is 0.0 (complete loos of shear transfer), and for rough crack this value is 1.0 (no loss of shear transfer). While the crack closes, all compressive stresses normal to the crack plane are transferred across the crack and only shear transfer coefficient for a closed crack $\left(\beta_{c}\right)$ is introduced (ANSYS, 2004).

In past decades, a variety of studies have been done to investigate the shear transfer coefficient effect on the FE results. Bangash, 1989; Hemmaty, 1998; Huyse, Hemmaty and L.Vandewalle, 1994 applied a range between 0.05 to 0.25 in the finite element models of concrete beams and bridge decks. Kachlakev et al (2001) performed a number of analytical studies to evaluate the shear transfer coefficient effect. They performed finite element method to model the reinforced concrete beam and bridge decks by assuming $\beta_{t}$ within the range of 0.05 to 0.25 , and the convergence problem occurred while the shear transfer coefficient for the open crack $\left(\beta_{t}\right)$ is less than 0.2. A number of studies have been performed by Kachlakev, T. Miller, Yim and Chansawat, 2001; Stehle, 2002; Wolanski, 2004; Dere, 2011 which assumed the shear transfer coefficient for closed crack $\left(\beta_{c}\right)$ is equal to 1.0 .

In order to investigate the effect of shear transfer coefficient on nonlinear response of FE model, wall type SH-L is considered and three shear transfer coefficients for open and closed cracks are assumed including 0.5 and 1.0 (Dere, Y., 2011) in model (A), 0.3 and 1.0 (Wolanski, A J., 2004) in model (B), and 0.35 and 0.65 (Tavakkoli, I., 2017) in model (C), respectively. 


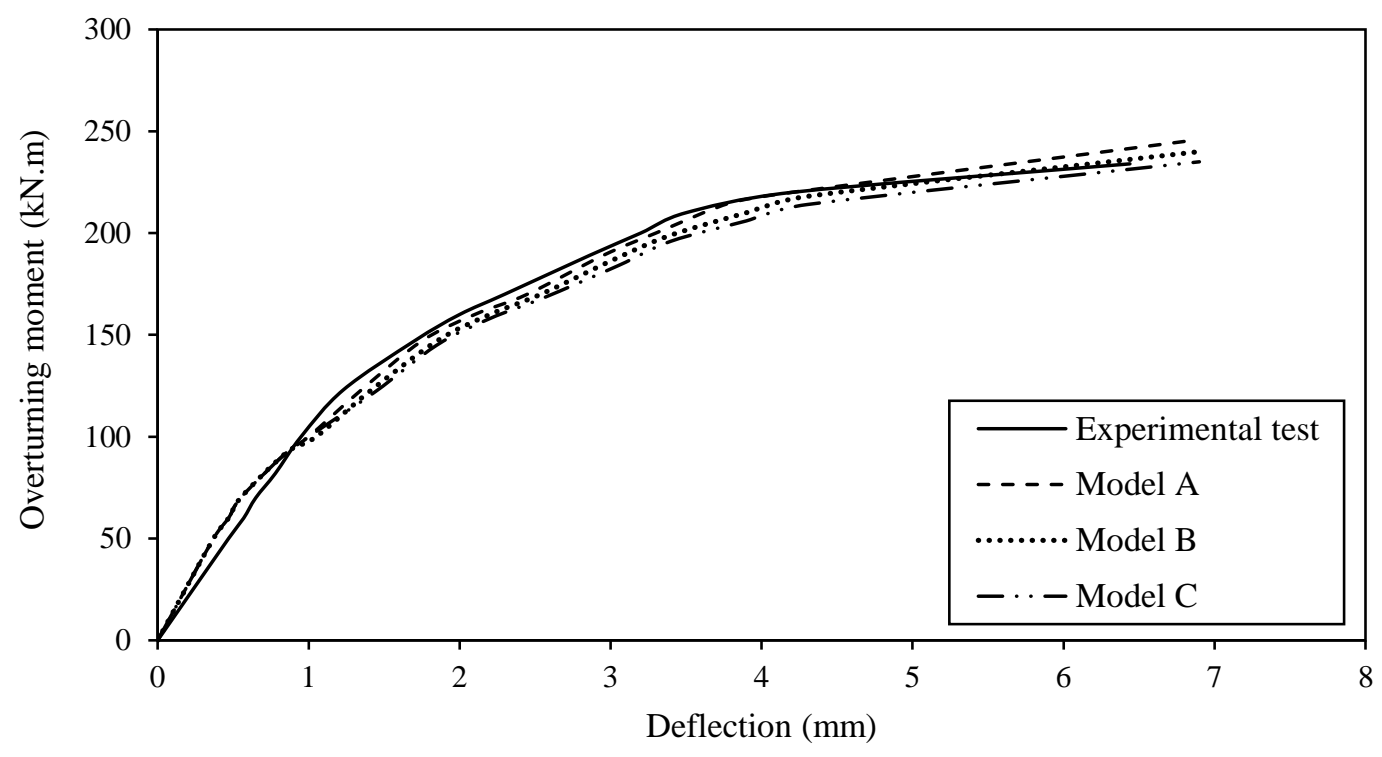

Figure 4.19 Deflection comparison between experimental test and models A, B and C

Figure 4.19 is a plot of the resulting the overturning moment versus the maximum displacement at top of the wall. As Figure shows, although there is no significant difference between these three analyses, Analysis (A) shows more realistic behavior and better performance in meeting the convergence problems.

\subsection{Summary}

In this chapter, the finite element method using the computer software ANSYS was introduced. The type of elements used in ANSYS software including SOLID65, LINK8, SPRING, FLUID 30 and FLUID 80 were presented in this chapter. Furthermore, the finite element formulation of SOLID65 element in linear state before and after cracking, as well as fluid elements formulation were presented. Next, the nonlinear static and dynamic equations applied in seismic analysis of reinforced concrete tanks and the solution method for these equations were addressed.

The material properties and numerical models of stress-strain response for both concrete and steel, were provided in this chapter. Then, the elastomeric bearing pads and seismic cables properties which are used to calculate the spring stiffness were presented. Finally, the proposed 
finite element technique in RC tank modeling was validated by comparing the results to experimental test results. For this purpose, two beams and three shear walls were considered from experimental tests. The comparison results verified the accuracy of proposed FE method in RC tank modeling. 


\section{CHAPTER 5}

\section{NONLINEAR BEHAVIOR OF CONCRETE CIRCULAR TANKS UNDER PUSH-OVER ANALYSIS AND SEISMIC RESPONSE FACTORS}

\subsection{Introduction}

In this study, the nonlinear behavior of concrete tank under the seismic loading is investigated by applying the nonlinear FE analysis or push-over analysis. The purpose of pushover analysis is investigating R-value specified in this study. This chapter will address the push-over analysis, developing the push-over curve, and determining the seismic response factors corresponding to push-over curves.

First part of this chapter focuses on conducting the push-over analysis by employing the ground-supported circular tanks. The RC tanks modeled are designed based on the requirements of ACI371R-08, ASCE/SEI 7-2010 and ACI 350.3-06. These RC tanks are simulated by finite element model and the push-over analysis is exerted on each finite element model. Then, the push-over curves are developed by withdrawing the load-deformation results. To find out the effective yield displacement $\left(\Delta_{\mathrm{y}}\right)$, ultimate base shear capacity $\left(\mathrm{V}_{\max }\right)$ and maximum lateral deflection $\left(\Delta_{\max }\right)$, a mathematical procedure should be used. According to this mathematical procedure, the bilinear approximation relationship is employed on the pushover curves.

Next, the methods used to define the seismic response factors including over-strength and ductility factors will be discussed. Then, the results of push-over analysis and the calculated seismic response factors will be presented.

\subsection{Nonlinear static response of circular tank (Pushover analysis)}

The main purpose of performing the pushover analysis is forming the pushover curve for the liquid storage tanks. Through the pushover curve, some significant information including 
maximum developed base shear, maximum deformation prior to collapse and maximum available ductility of the structure are obtained.

In this method, to simulate real loading system, the axial gravity load initially should be applied to the structural model. Then, the structural model is exposed to the lateral load incrementally based on the defined load pattern similar to the force or deformations produced in the structure during the earthquake. After that, the lateral load is increased until the structure collapses; it means that the displacement at controlling point reaches to a certain target.

\subsection{Tanks configuration and material properties}

\subsubsection{Design of circular tanks based on code requirements}

In this section, the procedure design of circular ground supported tanks is briefly described. For the purpose of the tank design, the dead load including the tank weight, stored water and earthquake load are considered. The circular tanks are designed based on ACI 35006 (2006) for the load combination including hydrostatic and hydrodynamic loads. The hydrodynamic forces are calculated considering the tanks are located in high seismic zone with $\mathrm{S}_{\mathrm{S}}=160 \%$ and $\mathrm{S}_{1}=60 \% . \mathrm{R}_{\mathrm{i}}$ is taken 2.0 and 3.25 for the fixed, hinged and flexible base, respectively. The following load combinations are taken for the design procedure:

$\mathrm{U}_{1}=1.4(\mathrm{D}+\mathrm{F})$

$\mathrm{U}_{2}=1.2(\mathrm{D}+\mathrm{F})+1.0 \mathrm{EQ}$

In this study, various tank configurations will be designed and analyzed using the proposed finite element method. The parametric study is performed using push-over analysis to investigate the effect of concrete strength and shear transfer coefficient as discussed in Chapter 4, on the R factor values. For this purpose, two different groups namely A and B are categorized based on the strength of concrete including 30MPa and 40Mpa, respectively. For each group design, different wall heights $\left(\mathrm{H}_{\mathrm{w}}\right)$ are considered as $3.25 \mathrm{~m}, 6.5 \mathrm{~m}$, and $9.6 \mathrm{~m}$ corresponding to water depths $\left(\mathrm{H}_{\mathrm{L}}\right)$ equal to $3 \mathrm{~m}, 6 \mathrm{~m}$, and $9 \mathrm{~m}$, respectively. Tank diameters (D) 
of 40,30 and $20 \mathrm{~m}$ are considered for tanks, and the wall thickness $\left(\mathrm{t}_{\mathrm{w}}\right)$ is varying for different tanks. Since the tank support conditions affect the tank response, fixed, hinged and flexible support are investigated. For design of the tank wall, the internal forces along the tank wall are calculated by performing the linear finite element analysis corresponding both hydrostatic and hydrodynamic pressures. The tank walls are designed based on the maximum design forces including hoop force, bending moment and shear force; however, the shear stresses are not so critical.

Wall thicknesses are required to determine as per the design requirements for all load combinations including eccentric loads and any lateral or other loads. In strength design approach, environmental durability factor $\left(\mathrm{S}_{\mathrm{d}}\right)$ is defined and utilized in order to control reinforcement stresses and crack widths. When it comes to ground supported reinforced concrete tanks, durability and long-term service life are the main design factors. The environmental durability factor is utilized so as to lower the effective stress for loads in service condition (acceptable cracking control range) (ACI 350M-06, 2006).

According to ACI 350-06 (2006), these tanks are designed based on two load combination defined as $\left(\mathrm{S}_{\mathrm{d}} \times 1.4 \mathrm{HS}\right)$ and $(1.2 \mathrm{HS}+\mathrm{EQ})$, where EQ is the total earthquake force including $\mathrm{P}_{\mathrm{i}}, \mathrm{P}_{\mathrm{w}}, \mathrm{P}_{\mathrm{c}}$ and $\mathrm{P}_{\mathrm{VL}}, \mathrm{HS}$ is hydrostatic force and $\mathrm{S}_{\mathrm{d}}$ is called environmental durability factor. Horizontal and vertical reinforcement distribution along the tank wall is assumed uniform.

The detailed calculation based on code for design of the wall reinforcement is presented in Appendix C. The tank dimension, reinforcement ratios and support condition are shown in Table 5.1.

In this table, the tank types are representative of different type of FE models. For instance, tank type A-F3-40 refers to tank in group A where F refers to fixed base, and number 3 and 40 shows the liquid height, and tank diameter, respectively. 
Table 5.1 Summary of tank dimensions and reinforcement ratio

\begin{tabular}{|c|c|c|c|c|c|c|c|}
\hline & Tank Type & $\begin{array}{c}\text { Tank } \\
\text { height } \\
\mathrm{H}_{\mathrm{w}}(\mathrm{m})\end{array}$ & $\begin{array}{l}\text { Liquid } \\
\text { height } \\
\mathrm{H}_{\mathrm{L}}(\mathrm{m})\end{array}$ & $\begin{array}{c}\text { Tank } \\
\text { diameter } \\
\mathrm{D}(\mathrm{mm})\end{array}$ & $\begin{array}{c}\text { Wall } \\
\text { thickness } \\
\mathrm{t}_{\mathrm{w}}(\mathrm{mm})\end{array}$ & $\begin{array}{c}\text { Vertical } \\
\text { reinforcement } \\
\text { ratio on each } \\
\text { face }(\rho) \%\end{array}$ & $\begin{array}{l}\text { Horizontal } \\
\text { reinforcement } \\
\text { ratio on each } \\
\text { face }(\rho) \%\end{array}$ \\
\hline \multirow{15}{*}{$\begin{array}{c}\text { Group A } \\
\left(\boldsymbol{f}_{c}^{\prime}=30 \mathrm{MPa}\right)\end{array}$} & A-F3-40 & 3.25 & 3.0 & \multirow{3}{*}{40} & 400 & 0.60 & 0.60 \\
\hline & A-F6-40 & 6.5 & 6.0 & & 400 & 0.70 & 0.60 \\
\hline & A-F9-40 & 9.6 & 9.0 & & 470 & 0.94 & 1.18 \\
\hline & A-F3-30 & 3.25 & 3.0 & \multirow{3}{*}{30} & 400 & 0.60 & 0.60 \\
\hline & A-F6-30 & 6.5 & 6.0 & & 400 & 0.60 & 0.60 \\
\hline & A-F9-30 & 9.6 & 9.0 & & 470 & 0.81 & 0.97 \\
\hline & A-F3-20 & 3.25 & 3.0 & \multirow{3}{*}{20} & 300 & 0.56 & 0.56 \\
\hline & A-F6-20 & 6.5 & 6.0 & & 300 & 0.73 & 0.57 \\
\hline & A-F9-20 & 9.6 & 9.0 & & 400 & 0.74 & 0.84 \\
\hline & A-H3-40 & 3.25 & 3.0 & \multirow{3}{*}{40} & 400 & 0.60 & 0.60 \\
\hline & A-H6-40 & 6.5 & 6.0 & & 400 & 0.60 & 1.01 \\
\hline & A-H9-40 & 9.6 & 9.0 & & 500 & 0.62 & 1.42 \\
\hline & A-FL3-40 & 3.25 & 3.0 & \multirow{3}{*}{40} & 250 & 0.53 & 1.05 \\
\hline & A-FL6-40 & 6.5 & 6.0 & & 300 & 0.60 & 1.49 \\
\hline & A-FL9-40 & 9.6 & 9.0 & & 400 & 0.60 & 1.70 \\
\hline \multirow{3}{*}{$\begin{array}{c}\text { Group B } \\
\left(\boldsymbol{f}_{c}^{\prime}=40 \mathrm{MPa}\right)\end{array}$} & B-F3-40 & 3.25 & 3.0 & \multirow{3}{*}{40} & 400 & 0.67 & 0.67 \\
\hline & B-F6-40 & 6.5 & 6.0 & & 400 & 0.70 & 0.67 \\
\hline & B-F9-40 & 9.6 & 9.0 & & 450 & 1.03 & 1.25 \\
\hline
\end{tabular}

The material properties of theses tanks are included both linear elastic and nonlinear material properties. The compression strength of concert $\left(f_{c}^{\prime}\right)$ and yield strength of reinforcement $\left(f_{y}\right)$ are taken 30,40 and $400 \mathrm{MPa}$, respectively. The elastic modulus of concrete and steel are considered as 24.65, 28.46 and $200 \mathrm{GPa}$, respectively. To study the nonlinear response of the structure, the materials nonlinearity should be considered as well. As explained in Chapter 4, the proposed Carrasquillo et. al (1981) method is used as a mathematical simulation to generate the concrete stress-strain curve. The mathematical model to simulate 
the stress-strain curve of reinforcement is an elastic-perfectly-plastic curve with yield strength $\left(f_{y}\right)$ of $400 \mathrm{MPa}$.

\subsubsection{Load pattern on tank walls}

As discussed in Chapter 3, according to ACI 650.3-06 (2006), the horizontal hydrostatic and hydrodynamic are applied uniformly and circumferentially based on the actual cosine distribution on the tank wall, respectively. Based on the cosine distribution, the maximum load is applied at $\theta=0$, and minimum load appears at $\theta=90$ degrees. For the nonlinear FE push-over analysis, the circular tanks presented in Table 5.1 are modeled using FE computer program, ANSYS. In the next step, the nonlinear push-over finite element analysis is performed on the structure under actual loads. In the first loading step, the axial gravity load including the weight of tank and stored liquid is applied to the structure, and then the hydrodynamic loads are applied in mush finer load steps on the tank wall. In push-over analysis, the lateral loading is gradually increased until the structure reaches to collapse

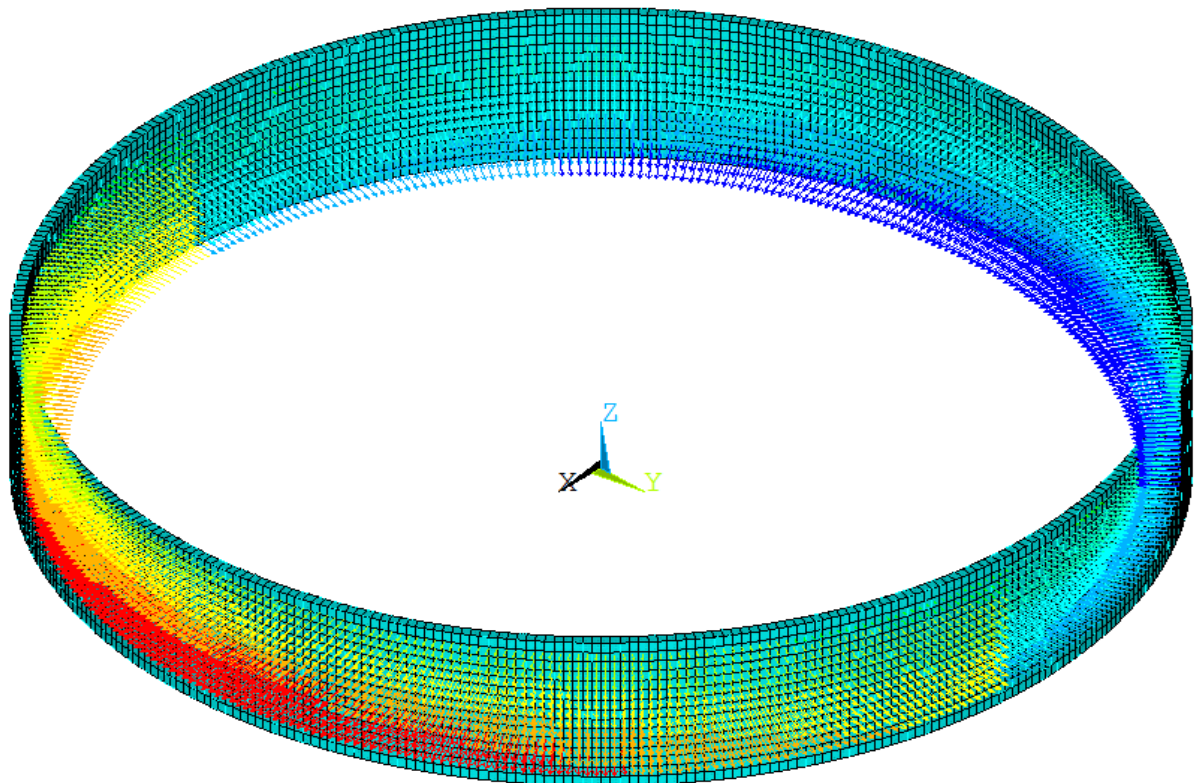

Figure 5.1 Hydrodynamic load distribution on finite element model 
condition. A typical tank model representing the actual hydrodynamic pressure is shown in Figure 5.1.

In ANSYS, the loading is applied to the structure until the analysis terminate due to the convergence errors. Since element SOLID65 is employed as a nonlinear element in modeling the structure, the convergence is so sensitive to the analysis. To avoid the convergence problem, at the beginning of the analysis, an optimum value for number of sub-step is chose, and let program changes automatically based on the number of nonlinear iterations performed at each load step. Employing element SOLID65 causes a significant convergence problems in the nonlinear solution due to the immoderate cracking. To overcome this problem, several attempts are required to perform by adjusting the number of sub-steps and changing the convergence tolerance.

\subsection{Mesh Sensitivity analysis}

Mesh density relationship to accuracy and cost has been always a disputable topic in finite element simulation studies. Selecting big elements causes inaccurate results, and small elements make computing time longer. To investigate the effect of the mesh size on the structure convergence, and determine the optimum number of elements, a sensitivity study is carried out on the results of the FE analysis. This sensitivity is employed for Tank A-F6-40. Four different mesh sizes are taken as $0.4 \mathrm{~m} \times 0.4 \mathrm{~m}, 0.32 \mathrm{~m} \times 0.2 \mathrm{~m}, 0.28 \mathrm{~m} \times 0.2 \mathrm{~m}, 0.22 \mathrm{~m}$ x $0.2 \mathrm{~m}$ and they considered as Model-S1, Model-S2, Model-S3, Model-S4, respectively. Table 5.2 and Figure 5.2 represent the sensitivity results. Model-S1 is a very coarse model with 4992 elements and represents the lower bound for the number of elements in the FE model. ModelS4 is a very fine model with 34080 elements which represents the upper bound for the number of elements. 
Table 5.2 Sensitivity analysis results on four different mesh size

\begin{tabular}{|c|c|c|c|c|}
\hline Model No. & $\begin{array}{c}\text { Number of } \\
\text { elements }\end{array}$ & $\begin{array}{c}\text { Number of } \\
\text { nodes }\end{array}$ & $\mathrm{V}_{\max }(\mathrm{KN})$ & $\begin{array}{c}\text { Max Displacement } \\
(\mathrm{mm})\end{array}$ \\
\hline Model-S1 & 4992 & 10608 & 73280 & 157 \\
\hline Model-S2 & 15680 & 24696 & 72820 & 160 \\
\hline Model-S3 & 20608 & 32256 & 71460 & 159 \\
\hline Model-S4 & 34080 & 52824 & 68950 & 131 \\
\hline
\end{tabular}

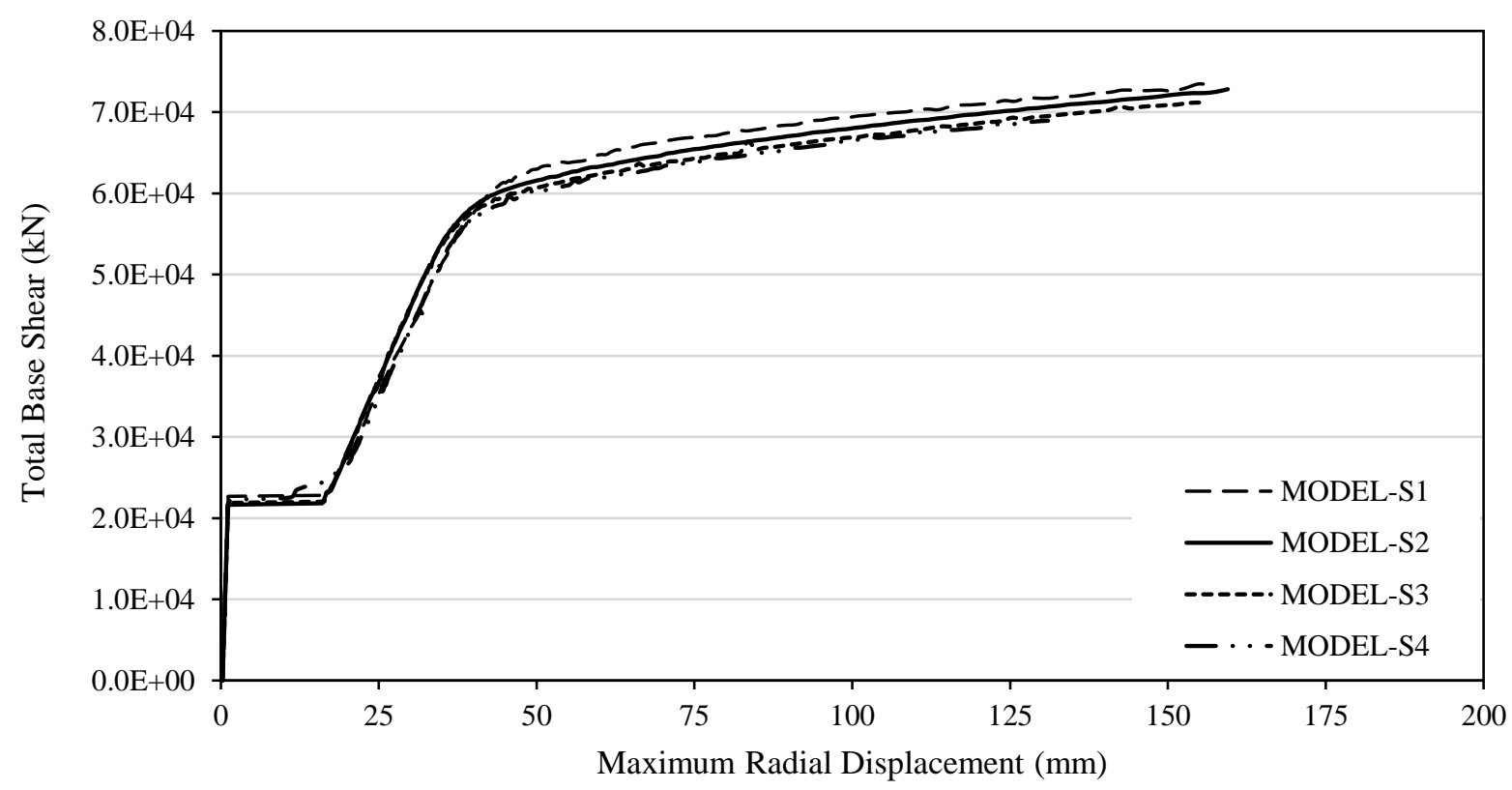

Figure 5.2 Results of mesh sensitivity analysis on four FE models

Various parameters such as mesh size, geometry of the structure and number of time steps have effect on the convergence of the system. Shown results in Figure 5.2 indicate that the selected element size does not affect the results significantly. However, it is proved that selecting smaller mesh size results in better results, but in ANSYS it leads to poor convergence. As a result, mesh discretization employed in Model-S2 is considered as the optimum model for this study. 


\subsection{Quantification of Structure Seismic Response Factors}

FEMA P-695 introduces a methodology for validation of building system performance and response parameters used in seismic design. The recommended methodology provides a rational basis for establishing global seismic performance factors (SPFs), including the response modification coefficient (R), and the system over-strength factor $\left(\Omega_{0}\right)$. Currently, building codes and standards use the seismic performance factors in accordance with linear methods of analysis to estimate strength and deformation demands on seismic-force-resisting systems; but as a matter of fact, these systems are responding in the nonlinear range. Initially, R factors were introduced in the ATC-3-06 report (1978), and their values have become fundamentally critical in the specification of design seismic loading. After that, the number of structural systems addressed in seismic codes has increased dramatically, and the 2003 edition of the National Earthquake Hazards Reduction Program (NEHRP) Recommended Provisions for Seismic Regulations for New Buildings and Other Structures (NEHRP Recommended Provisions), includes more than 75 individual systems, each having a somewhat arbitrarily assigned $\mathrm{R}$ factor.

The aim of FEMA-P 695 methodology is determining appropriate seismic performance factors for the design of seismic-force-resisting systems. When the parameters are properly implemented in the seismic design process, it will result in equivalent safety against collapse in an earthquake, comparable to the inherent safety against collapse intended by current seismic codes. This methodology is also applicable for design of non-building structures, and retrofit of seismic-force-resisting systems in existing buildings. The seismic performance factors used in this methodology will be explained and illustrated in Figure 5.3 defining seismic response factors in terms of the inelastic response (pushover curve analysis) of the seismicforce-resisting systems. 


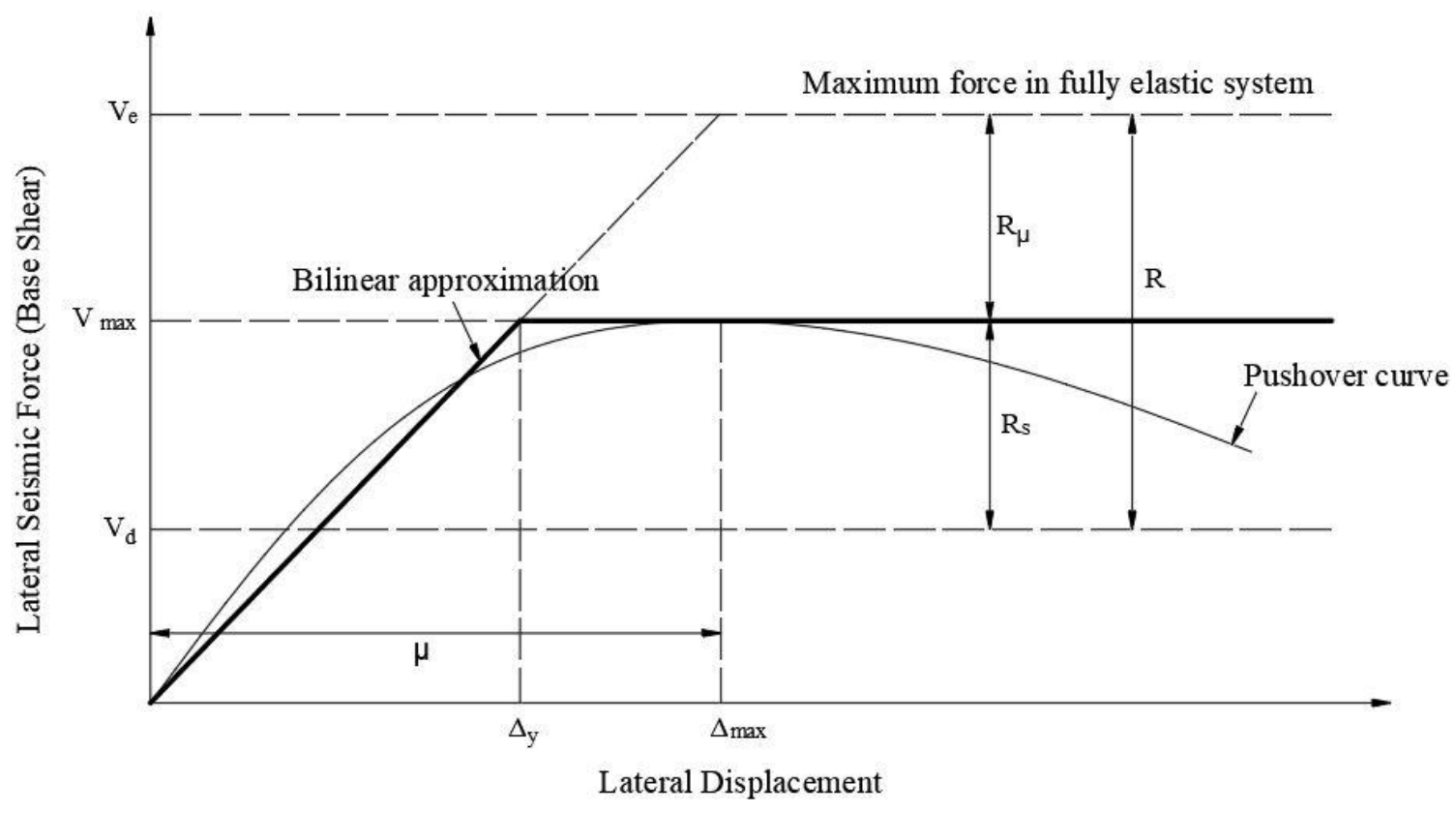

Figure 5.3 Definition of seismic response factors on a typical pushover curve

In Figure 5.3, $\mathrm{V}_{\max }$ represents the maximum base shear developed in actual nonlinear structures (prior to stiffness reduction), and the term $V_{d}$ is the seismic base shear required for design according to a pertinent code. The term $\mathrm{V}_{\mathrm{e}}$ shows the maximum base shear in an equivalent entirely linear-elastic structure. The term $\left(\Omega_{0}\right)$ is over-strength factor, and $\left(R_{\mu}\right)$ is the ductility factor. The $\mathrm{R}$ factor is the ratio of the force level to the design base shear:

$R=\frac{V_{e}}{V_{d}}$

and, ductility factor $\left(R_{\mu}\right)$ is the ratio of the force level to the maximum base shear of fullyyielded system.

$R_{\mu}=\frac{V_{e}}{V_{\max }}$

In Figure 5.3, $\Delta y$ represents effective yield displacement, and $\Delta_{\max }$ shows the maximum displacement prior to onset of stiffness reduction. 


\subsubsection{Response Modification Factor (R)}

A complete literature review on the subject of response modification factor was presented in Chapter 2 of this proposal. The value of R proposed by ATC (1995) is calculated by Equation (5.5):

$R=R_{S} R_{\mu} R_{R}$

Two first terms are over-strength factor $(R s)$ and ductility factor $\left(R_{\mu}\right)$ which will be discussed in the following. The redundancy factor $\left(R_{R}\right)$ is a factor of structural redundancy. In accordance with ATC 19 (1995), response modification factor must be reduced for structural systems with low level of redundancy. It also proposes draft values for redundancy factor depending on the lines of vertical seismic framing. The proposed draft redundancy factor for a system with two lines of vertical seismic framing is equal to 0.71 . Due to the low redundancy of the RC structure, this value is selected for the R factor calculation in this research.

\subsubsection{Over-strength Factor $\left(\mathrm{R}_{\mathrm{s}}\right)$}

Difference between the actual strength and code-design strength of the structure is defined as the over-strength factor. The over-strength factor is the ratio of the maximum base shear of fully-yielded system to the design base shear:

$R_{s}=\frac{V_{\max }}{V_{d}}$

where $\mathrm{V}_{\max }$ is maximum base shear when base shear ends up at a peak value at the beginning of the stiffness reduction and consequently the base shear starts to diminish, and $\mathrm{V}_{\mathrm{d}}$ is design seismic base shear. The general equation to calculate the total base shear encountered in the seismic force is $\mathrm{V}=\mathrm{C}_{\mathrm{s}} \mathrm{W}$. According to ACI 350.3-06, this equation is modified by replacing gravity load (W) with four effective weights including the effective weight of the tank wall, roof and the impulsive and convective component of the liquid weight, and the term $\mathrm{C}_{\mathrm{s}}$ is replaced with period-dependent seismic response coefficients including $\mathrm{C}_{\mathrm{i}}$ and $\mathrm{C}_{\mathrm{C}}$. As the 
impulsive and convective components are not in a same phase, the square-root sum of the squares is employed to combine these components. The following equation (Eq. 5.7) is exerted to calculate the base shear due to seismic forces:

$V=\sqrt{\left(P_{i}+P_{w}+P_{r}\right)^{2}+P_{c}^{2}}$

where $P_{i}, P_{w}, P_{r}$ and $P_{c}$ are defined as seismic forces which are defined in Chapter3.

\subsubsection{Ductility Reduction Factor $\left(\mathrm{R}_{\mu}\right)$}

Newmark and Hall (1982) proposed several formulas to calculate the ductility reduction factor $\left(R_{\mu}\right)$. These formulas represent that ductility reduction factor depends on fundamental period $(T)$ of the structure and displacement ductility $(\mu)$.

$R_{\mu}=1$

$\mathrm{T}($ period $)<0.03 \mathrm{sec}$

$R_{\mu}=\sqrt{2 \mu-1} \quad 0.12 \mathrm{sec}<\mathrm{T}($ period $)<0.5 \mathrm{sec}$

$R_{\mu}=\mu$

$1 \mathrm{sec}<\mathrm{T}($ period $)$

where the term displacement ductility factor $(\mu)$ is calculated by:

$\mu=\Delta_{\max } / \Delta_{y}$

In these relationships, ductility factor is presented in the form of a piecewise function and does not include soil type effects.

Krawinkler and Nassar (1992) presented a formula for SDOF system on rock or stiff soil depending on the fundamental period of the structure $(T)$, displacement ductility $(\mu)$, and strain hardening $\operatorname{ratio}(\alpha)$.

$R_{\mu}=[c(\mu-1)+1]^{1 / c}$

where $\mathrm{c}$ is calculated by Equation (5.13):

$c(T, \alpha)=\frac{T^{a}}{1+T^{a}}+\frac{b}{T}$

where $\mathrm{a}$ and $\mathrm{b}$ are regression parameters. The following Table 5.3 suggested by Krawinkler shows different values of $\mathrm{a}$ and $\mathrm{b}$ according to various values of $\alpha$. 
Table 5.3 Values of $\mathrm{a}$ and $\mathrm{b}$ according to strain hardening ration $(\alpha)$

\begin{tabular}{|c|c|c|}
\hline $\boldsymbol{\alpha}$ & $\mathrm{a}$ & $\mathrm{b}$ \\
\hline $0 \%$ & 1.00 & 0.42 \\
\hline $2 \%$ & 1.00 & 0.37 \\
\hline $10 \%$ & 0.80 & 0.29 \\
\hline
\end{tabular}

Miranda and Bertero (1994) introduced a relationship for ductility reduction factor depending on displacement ductility $(\mu)$, fundamental period( $(T)$, predominant period of the ground motion $\left(T_{g}\right)$ and site characteristics.

$R_{\mu}=(\mu-1 / \varphi)+1$

where $\varphi$ for rock site is obtained by Equation (5.15):

$\varphi=1+\frac{1}{10 T-\mu T}-\frac{1}{2 T} e^{-1.5(\ln (T)-0.6)^{2}}$

Figure 5.4 shows a comparison between "Newmark and Hall", "Krawinkler" and "Miranda and Bertero" for ductility factor of 3 to conclude that which relationship is more conservative for this study.

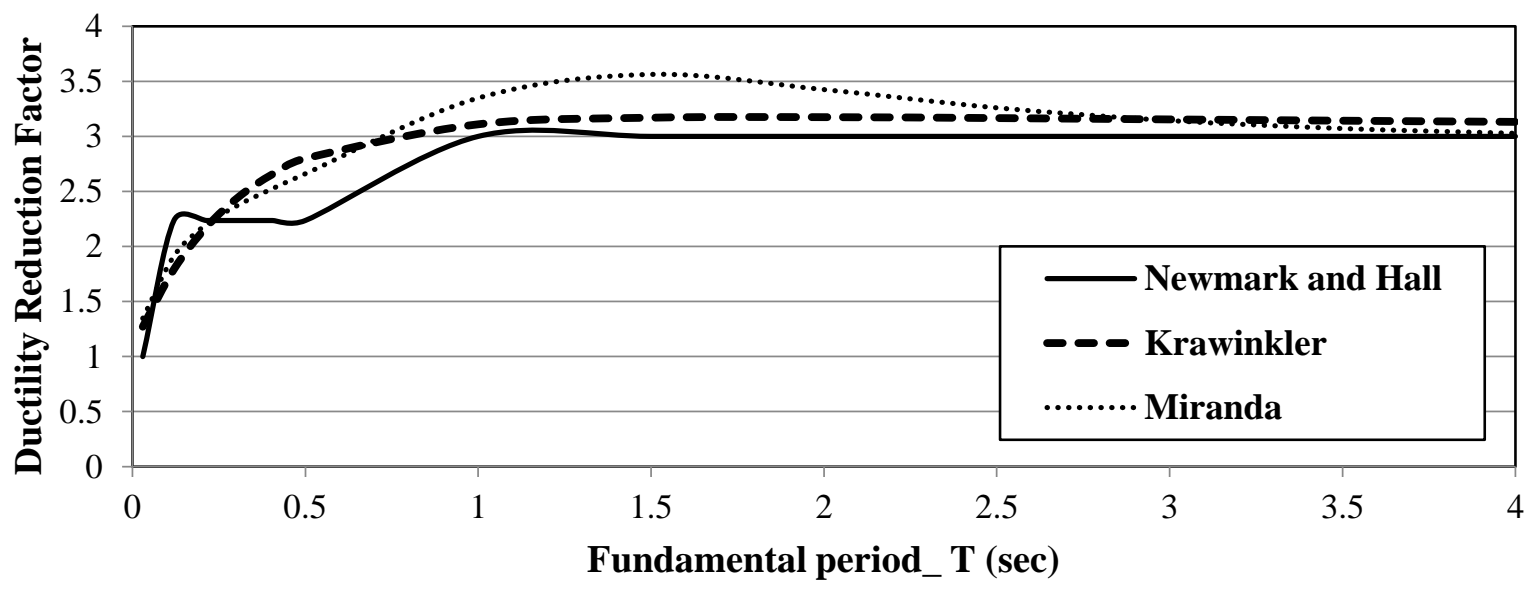

Figure 5.4 Comparison of ductility reduction factor between "Newmark", "Krawinkler", and Miranda assuming ductility factor $(\mu)$ of 3 .

Figure 5.4 shows that all three method result in equal values of ductility reduction factor $\left(\boldsymbol{R}_{\boldsymbol{\mu}}\right)$. Since the result of Newmark and Hall formula represents a conservative lower 
bound, using this relationship is more reasonable for essential infrastructure such as containing liquid storage facilities.

\subsection{Interpretation of push-over curve}

FEMA 273 strategy is employed in this study to perform the static nonlinear analysis. At first step, the gravity load and hydrostatic pressure due to stored water is applied to the FE models, and then the hydrodynamic pressure according to load pattern scribed in section 5.3.2 is applied and increased gradually.

The results of static nonlinear analysis are clarified in this section. The full nonlinear base shear deformation response of the tank is shown in the following Figures. In all diagrams, the results of finite element analysis in fully elastic system are shown by dashed line. There are different behaviors captured within the push-over analysis including the initial crack, yielding of reinforcement, tensile strength limit leading to crack and leakage of the tank wall, etc. For tank A-F3-40 (Figure 5.5), point A shows the initial cracking corresponding to the total base shear of $9880 \mathrm{kN}$. Figure 5.6 shows the location of the first crack appearing at the base of the tank. Tensile stress at theta $\theta=0$ of the tank wall reaches the modulus of rapture at this point. 


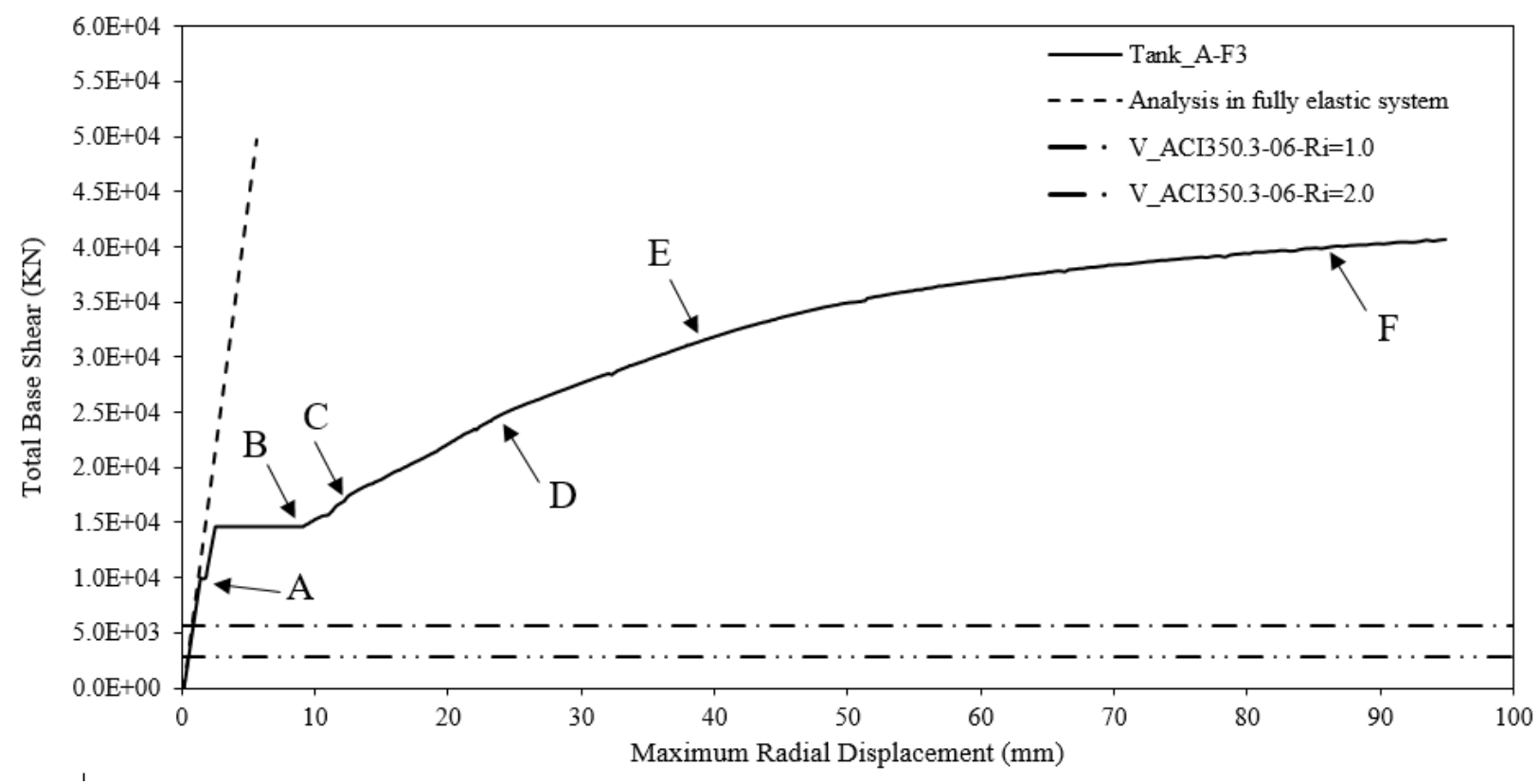

Figure 5.5 Load-deflection curve; Tank A-F3-40

As per the diagram, the tank wall is in linear elastic stage under the base shear of 5670 $\mathrm{kN}$ according to $\mathrm{ACI} 350.3-06\left(\mathrm{R}_{\mathrm{i}}=1.0\right)$. At point $\mathrm{B}$ (Figure 5.5), numerous cracks suddenly appear and propagate on the tank wall. Figure 5.7 shows the hoop strain distribution on the tank wall corresponding to point $\mathrm{B}$, at which the max hoop strain is beyond the cracking strain $\left(\varepsilon^{c k}\right)$. At this point, tensile stress develops in the entire wall section where the tank wall is subjected to compressive hydrodynamic pressure. Therefore, through the thickness wall crack due to tensile stress.

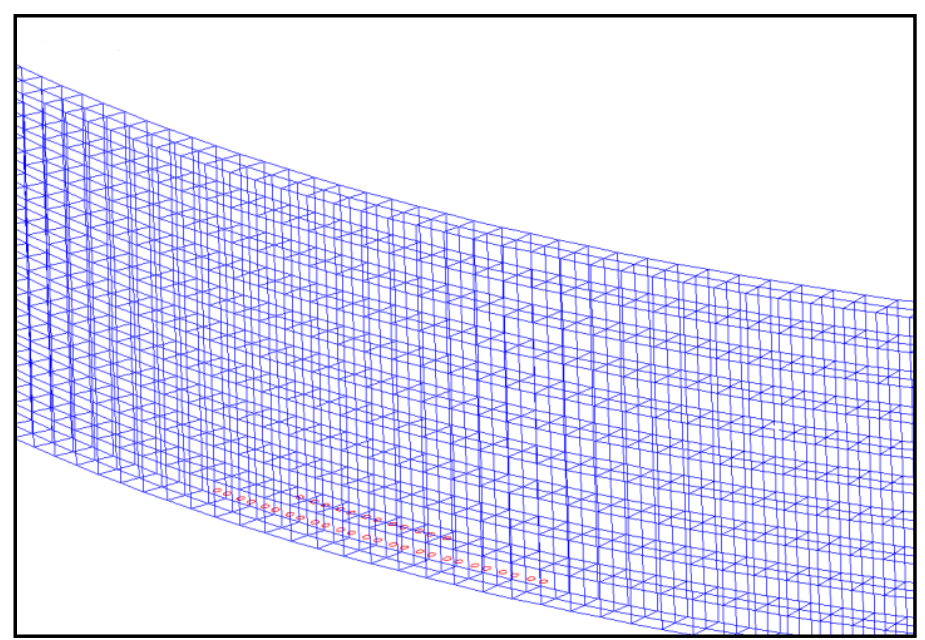

Figure 5.6 Initial cracking pattern on the tank wall in FE model; Tank A-F3-40 

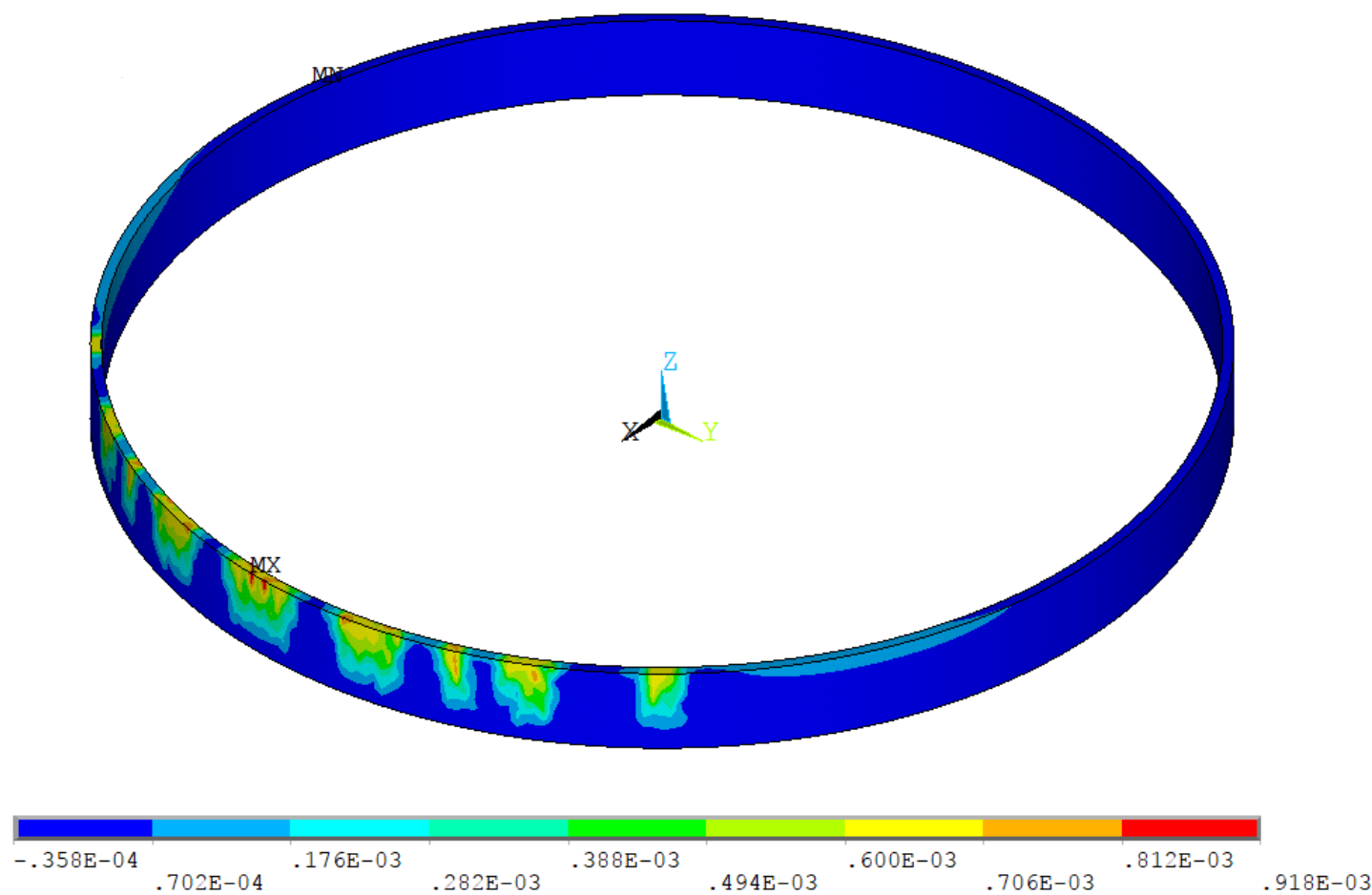

Figure 5.7 Contour hoop strain on the tank wall for FE model (Corresponding to point B); Tank A-F3-40

At point $\mathrm{C}$, the reinforcement starts to yield at total base shear of $17320 \mathrm{kN}$. By gradually increasing the lateral hydrodynamic pressure on the tank wall, the axial strain of reinforcement increases which is followed by consecutive cracking of the concrete wall. For example, at points $\mathrm{D}, \mathrm{E}$, and F, the rebar axial strains are equal to $0.006,0.012$ and 0.027 which are three, six and 14 times the yield strain of reinforcement $\left(\varepsilon_{\mathrm{y}}=0.002\right)$, respectively. Although, the FE tank model can support further loading beyond point B until push-over analysis stops due to convergence failure, in reality, the structure fails at point B due to extensive cracking caused by hoop stress and leakage.

Tank A-F6-40 (Figure 5.8), point A on the diagram is when the first crack develops at a base shear of $8092 \mathrm{kN}$ and the tensile stress at theta $\theta=0$ of the tank wall reaches the modulus of rapture. The tank wall is in linear elastic stage under the base shear of $13238 \mathrm{kN}$ as per ACI350.3-06 (Ri=1.0). At point B (Figure 5.8), numerous cracks suddenly appear and develop on the tank wall. Figure 5.9 shows the crack pattern appearing on the tank wall at point B. Figure 5.10 shows the hoop strain distribution on the tank wall corresponding to point B. 
Point $\mathrm{C}$ is when the reinforcement yields at total base shear of $22725 \mathrm{kN}$. At points $\mathrm{D}, \mathrm{E}$, and F, the rebar axial strains are equal to $0.006,0.012$ and 0.027 which is three, six, and 14 times the yield strain of reinforcement $\left(\varepsilon_{y}=0.002\right)$, respectively.

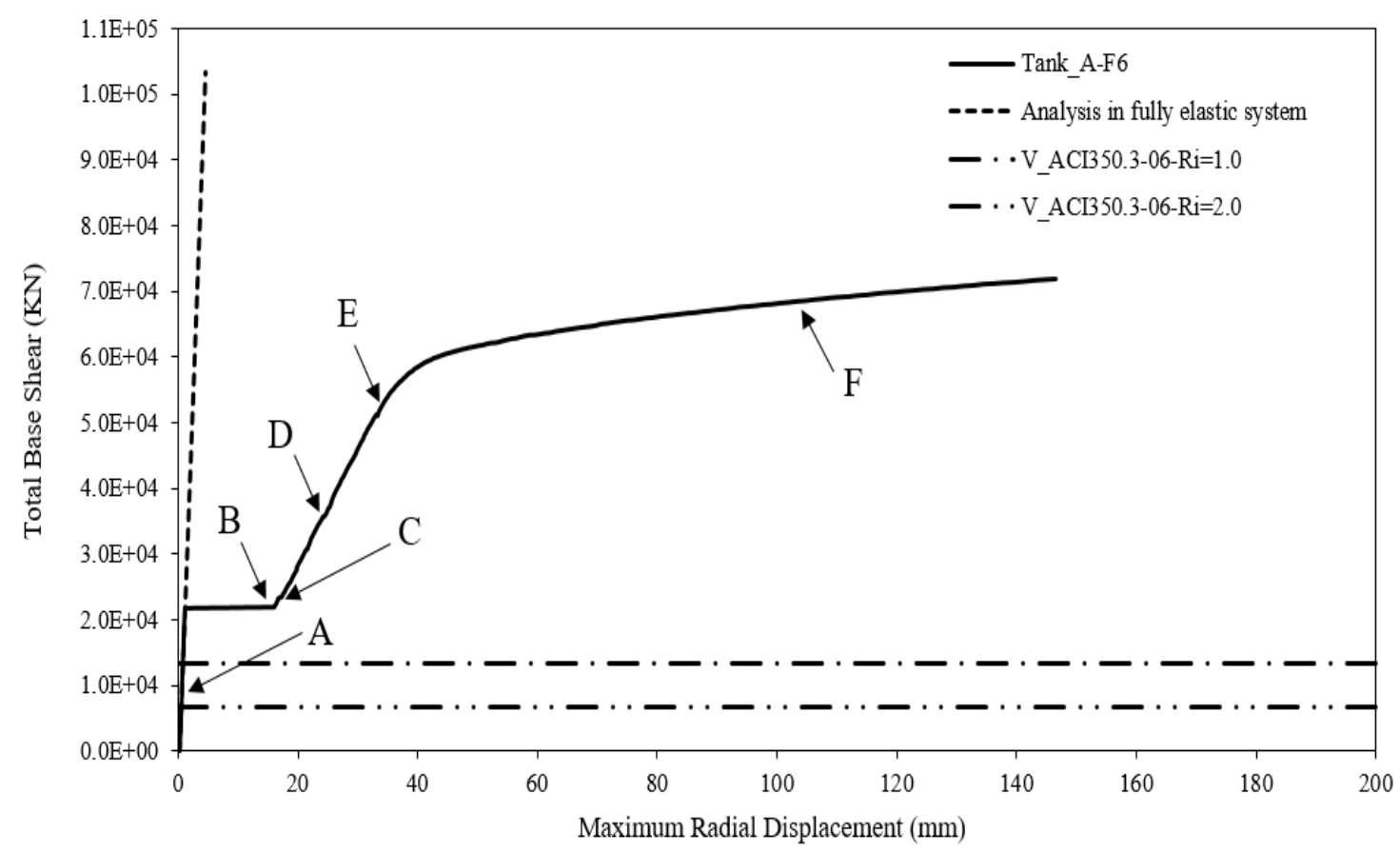

Figure 5.8 Load-deflection curve; Tank A-F6-40

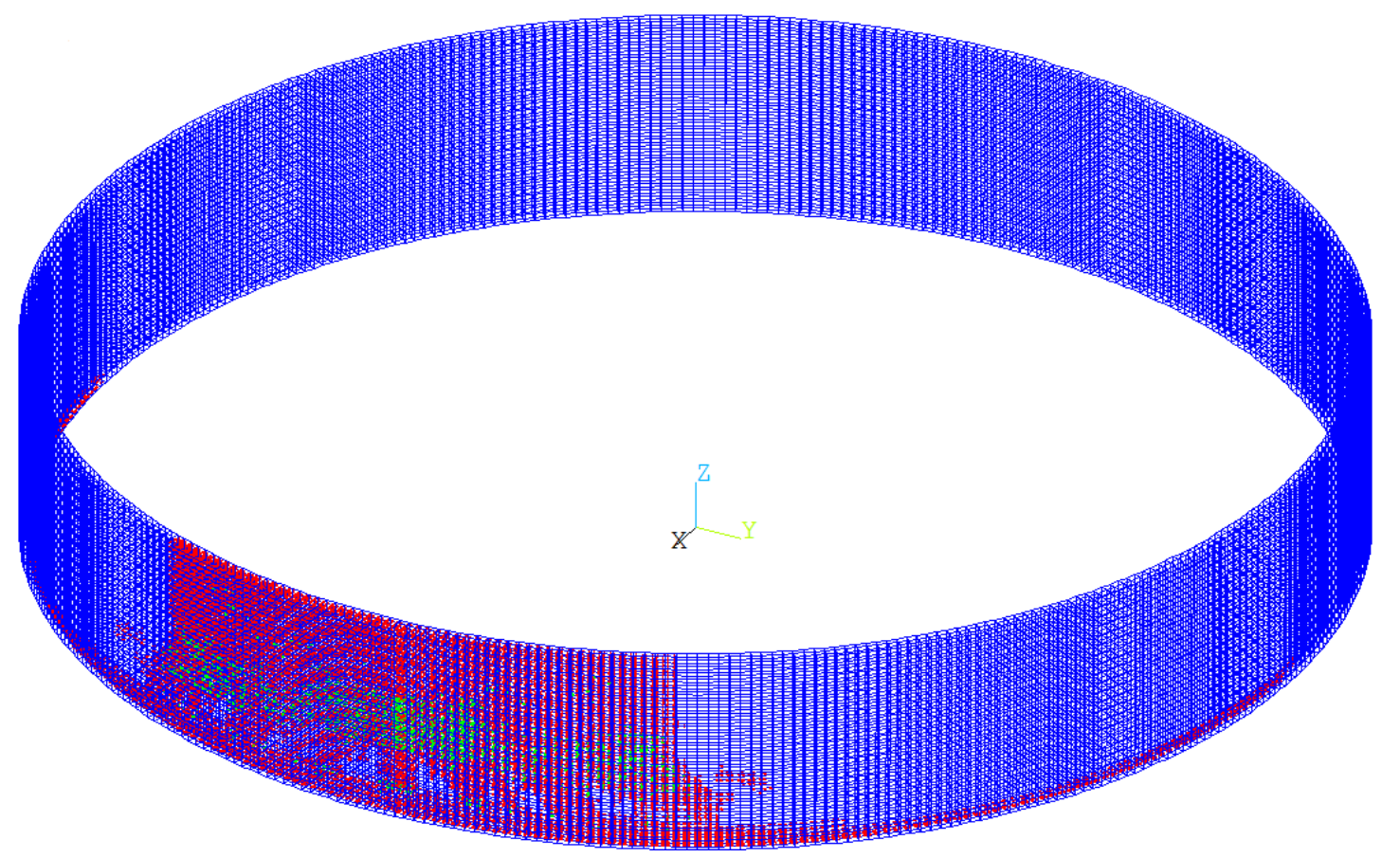

Figure 5.9 Cracking pattern on the tank wall in FE model (Corresponding to point B); Tank A-F6-40 

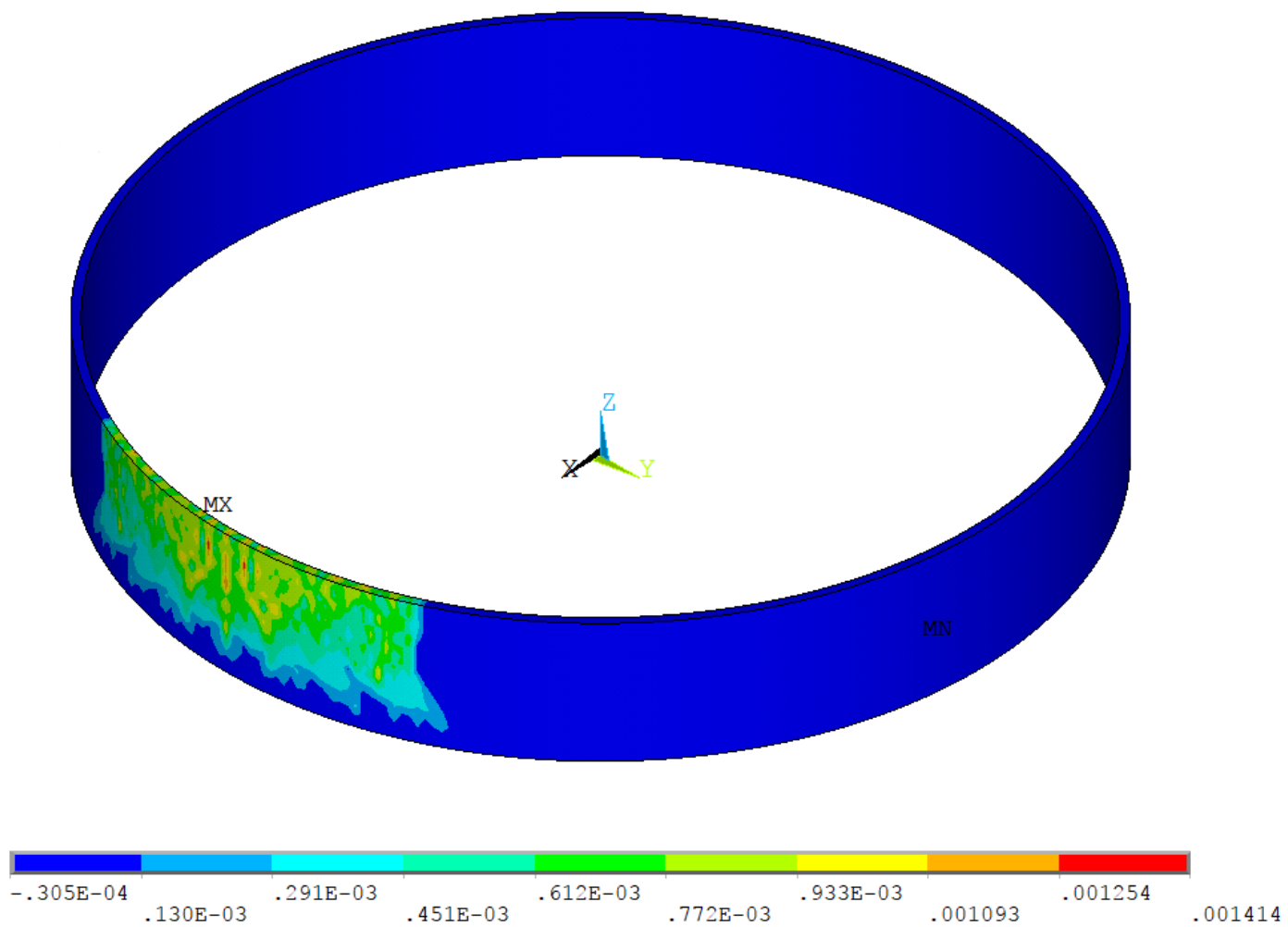

Figure 5.10 Contour hoop strain on the tank wall for FE model (Corresponding to point B); Tank A-F6-40

Tank A-F9-40 (Figure 5.11), the first crack develops at Point A at a base shear of 4657 $\mathrm{kN}$. As shown, the tank wall is in linear elastic stage below the base shear of $27988 \mathrm{kN}$ as per ACI350.3-06 $(\mathrm{Ri}=1.0)$. As shown in Figure 5.11 the maximum hoop strain at point $\mathrm{B}$, more than cracking strain, showing the tensile stress has reached the modulus of rupture and consequently cracks develop on the wall. 


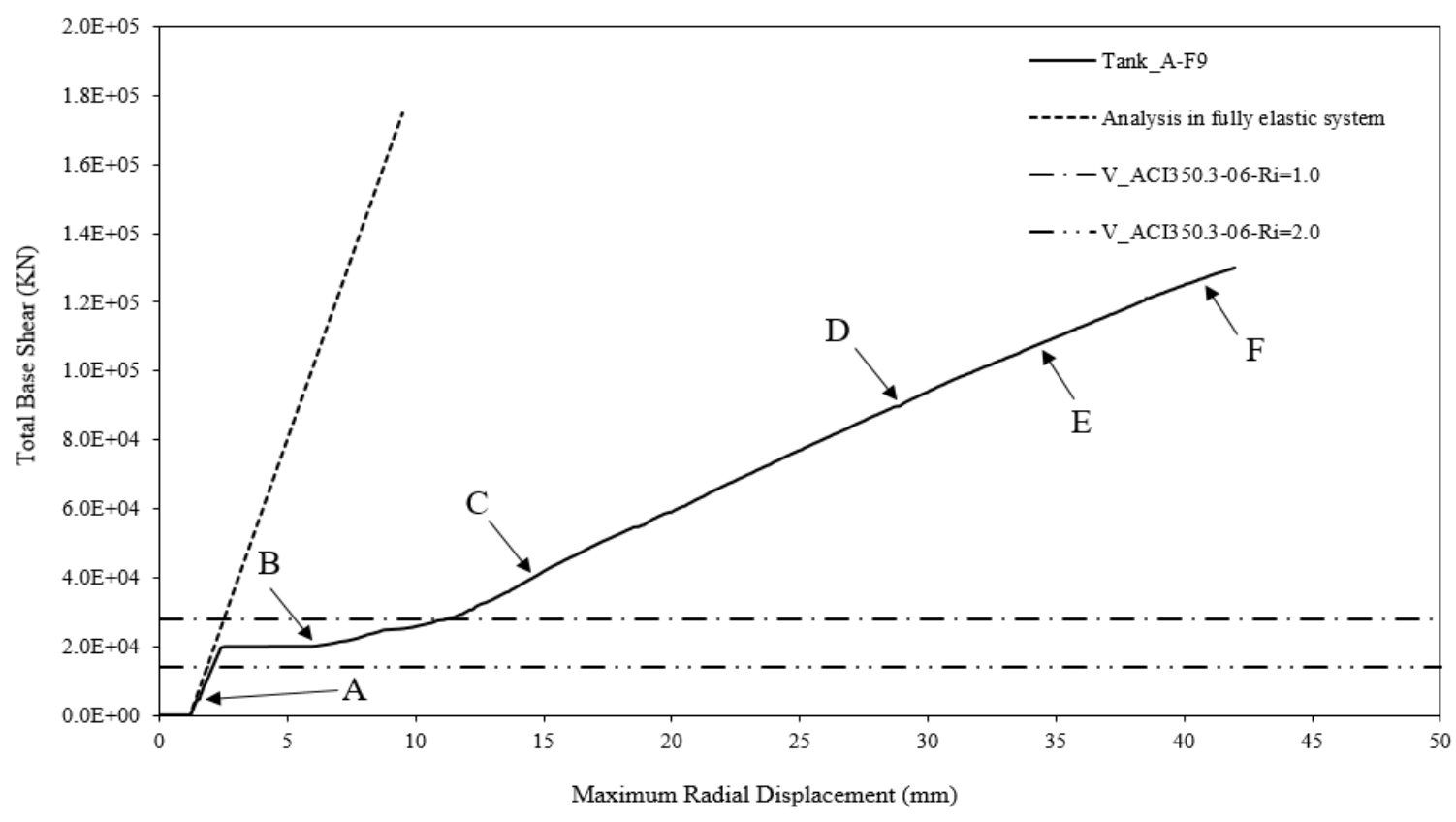

Figure 5.11 Load-deflection curve; Tank A-F9-40

The reinforcement yields at a base shear of $48720 \mathrm{kN}$ as demonstrated by Point C. At points $\mathrm{D}, \mathrm{E}$, and $\mathrm{F}$, the rebar axial strains are equal to $0.006,0.008$ and 0.012 which is three, four and six times more than the yield strain of reinforcement $\left(\varepsilon_{\mathrm{y}}=0.002\right)$, respectively.

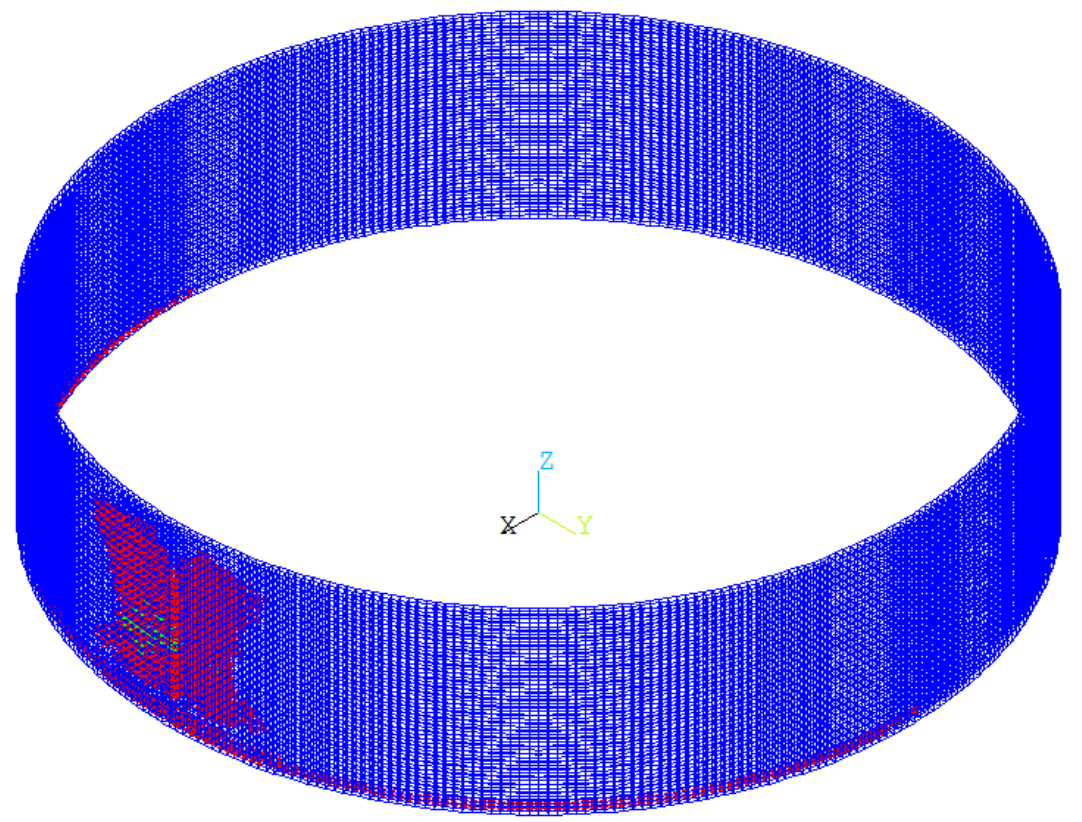

Figure 5.12 Cracking pattern on the tank wall in FE model (Corresponding to point B); Tank A-F9-40 

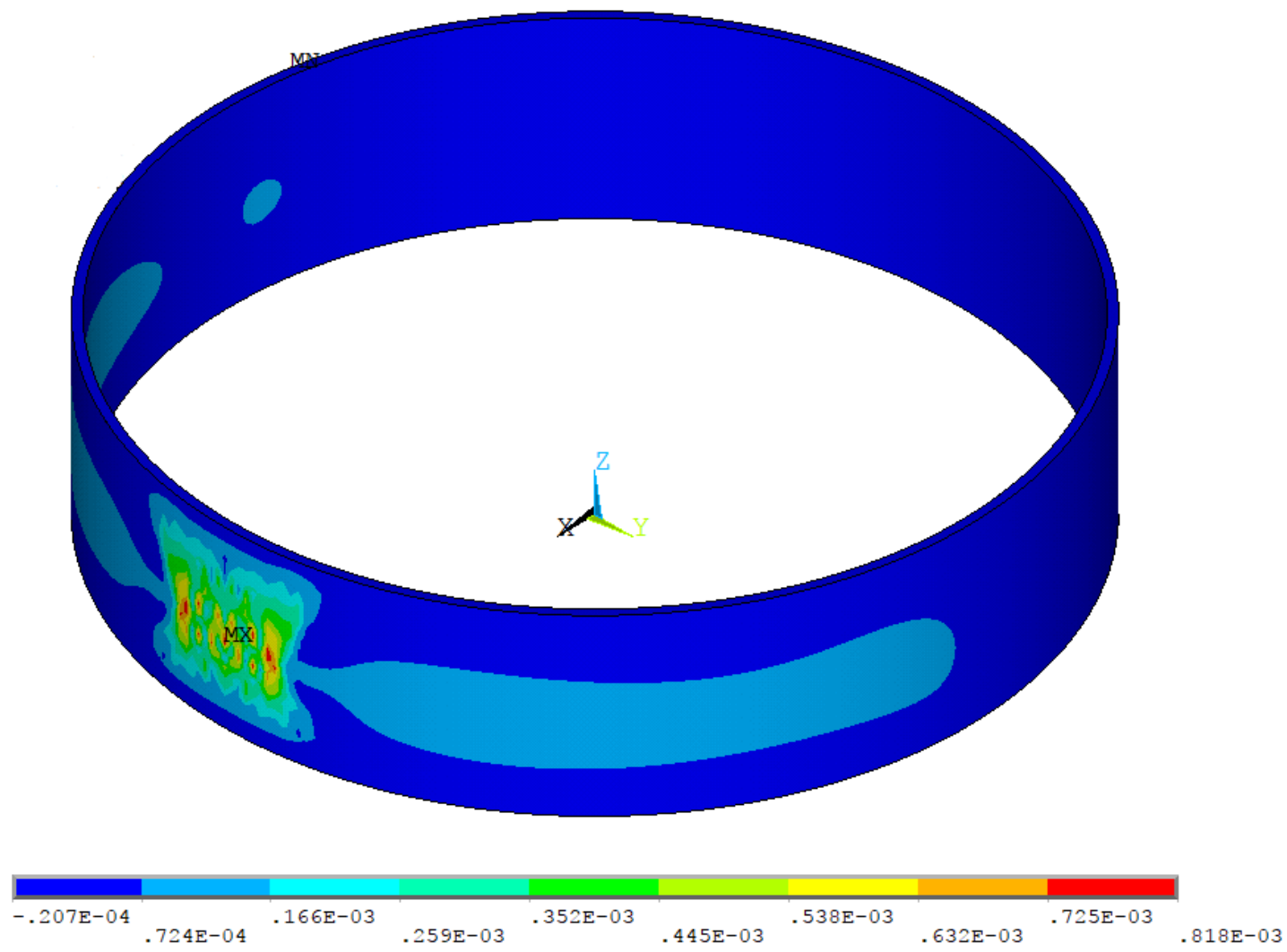

Figure 5.13 Contour hoop strain on the tank wall for FE model (Corresponding to point B); Tank A-F9-40

\subsection{Finite element results of pushover analysis}

The results of FE push-over analysis are illustrated based on the development of total tank base shear corresponding to maximum lateral displacement at each step. The push-over curves for a constant $40 \mathrm{~m}$ diameter tank with varying tank heights of $3.25,6.5$, and $9.6 \mathrm{~m}$ is shown in Figure 5.14. The solid line in these figures show the push-over diagram and the dotted and double dotted lines show the total base shear with constant $R_{i}$ of 1 and 2 respectively based on ACI350.3-06. As shown in Figure 5.14 for FE model tank A-F9-40, the design seismic base shear crosses the push-over curve but for the two other tanks with the same diameter and different heights, the tank wall behavior is elastic (linear) under $\mathrm{R}_{\mathrm{i}}=1.0$. 
a)

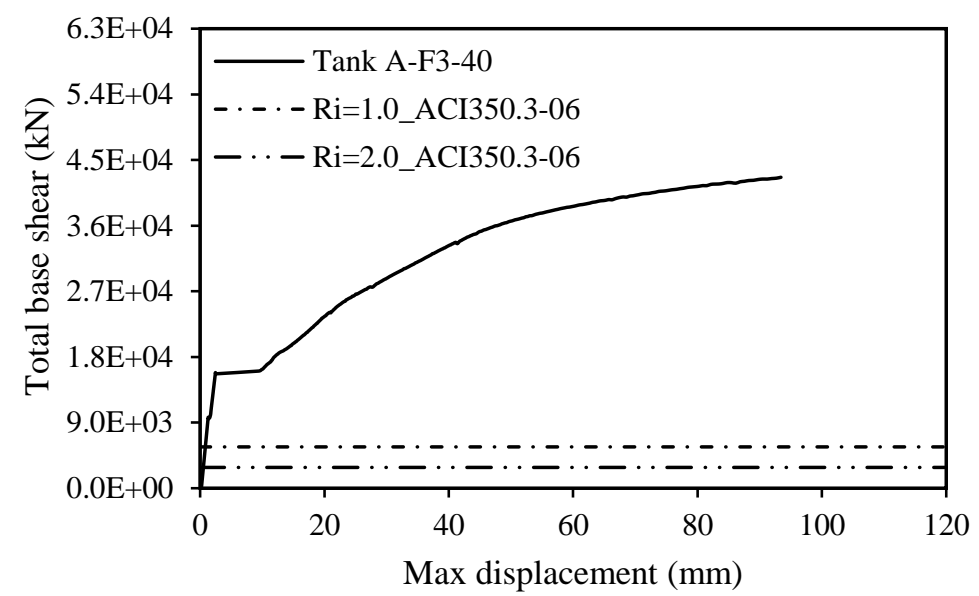

b)

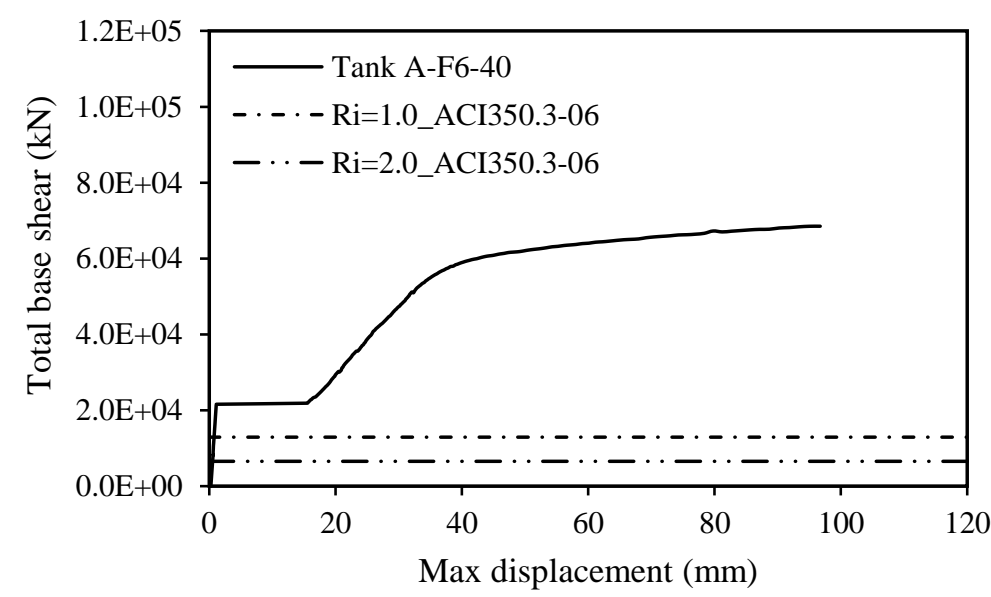

c)

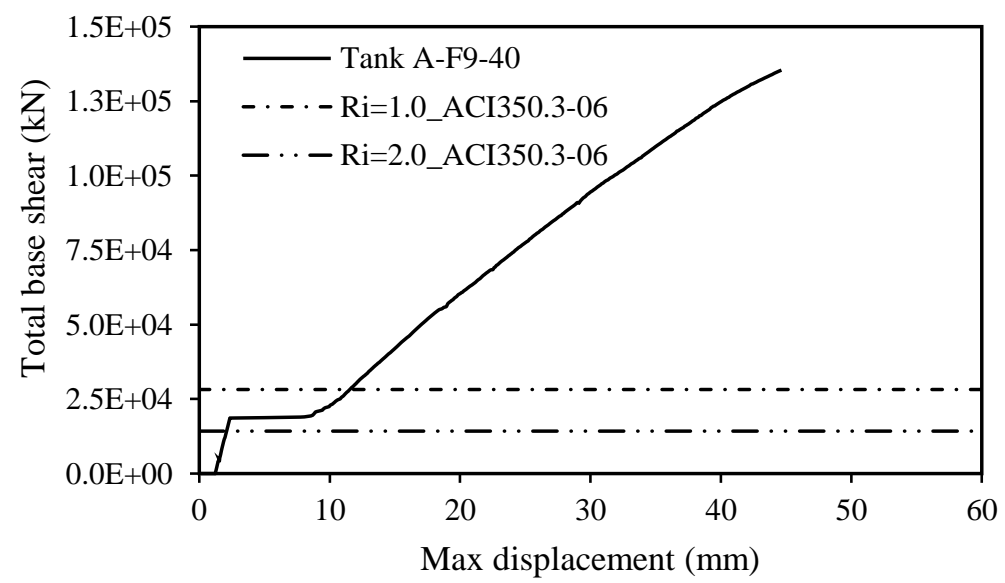

Figure 5.14 Load-deflection response; a) Tank A-F3-40, b) Tank A-F6-40, c) Tank A-F9-40 
Figure 5.15 shows push-over analysis results for tanks with a constant $30 \mathrm{~m}$ diameter with the 3.25, 6.5 and $9.6 \mathrm{~m}$ heights.

a)
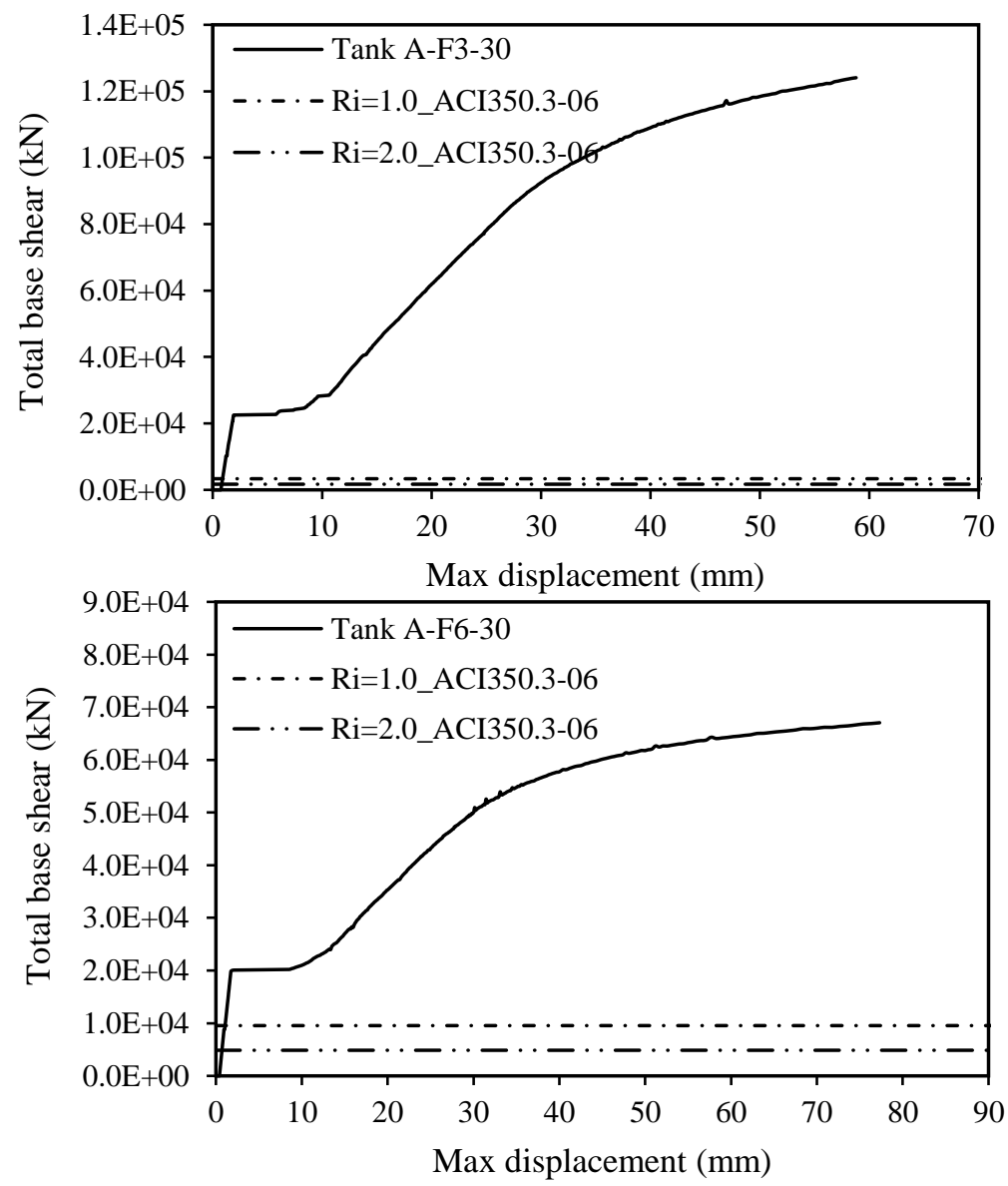

c)

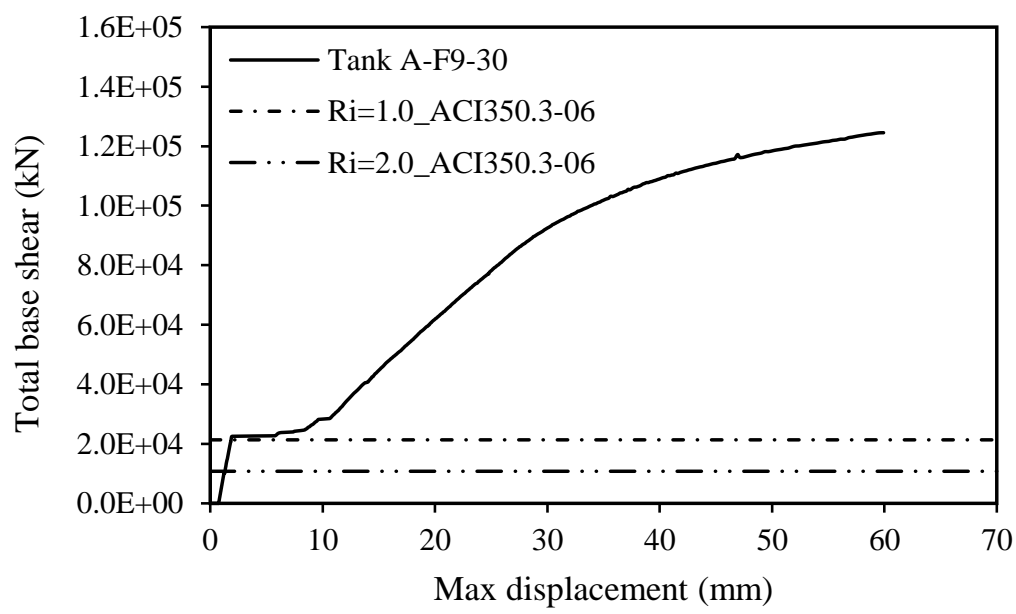

Figure 5.15 Load-deflection response; a) Tank A-F3-30, b) Tank A-F6-30, c) Tank A-F9-30 
Figure 5.16 demonstrates FE push-over results for $20 \mathrm{~m}$ diameter tanks with the same three different wall heights. As per these figures, by decreasing the diameter of the tanks, the difference between $V_{\max }$ and $\mathrm{V}_{\mathrm{d}}$ increases meaning that the over-strength factor is increasing. Also, by decreasing the tank diameter, the design base shear reduces as well.

a)
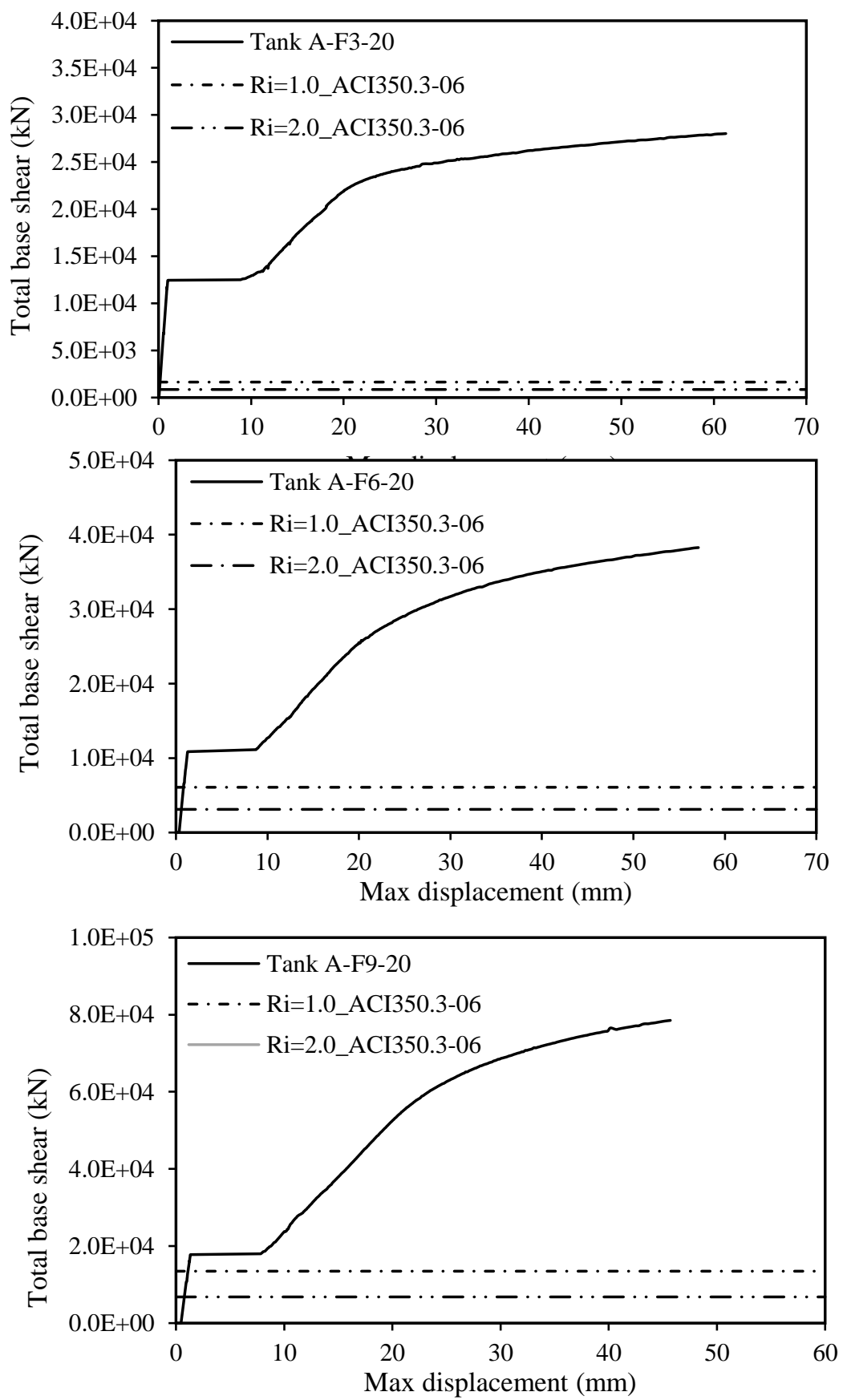

Figure 5.16 Load-deflection response; a) Tank A-F3-20, b) Tank A-F6-20, c) Tank A-F9-20 
Figure 5.17 shows the push-over curve for hinged-base condition. Although the design base shear value is identical for both hinged and fixed base tanks, $\mathrm{V}_{\max }$ is lower in hinged based condition.

a)

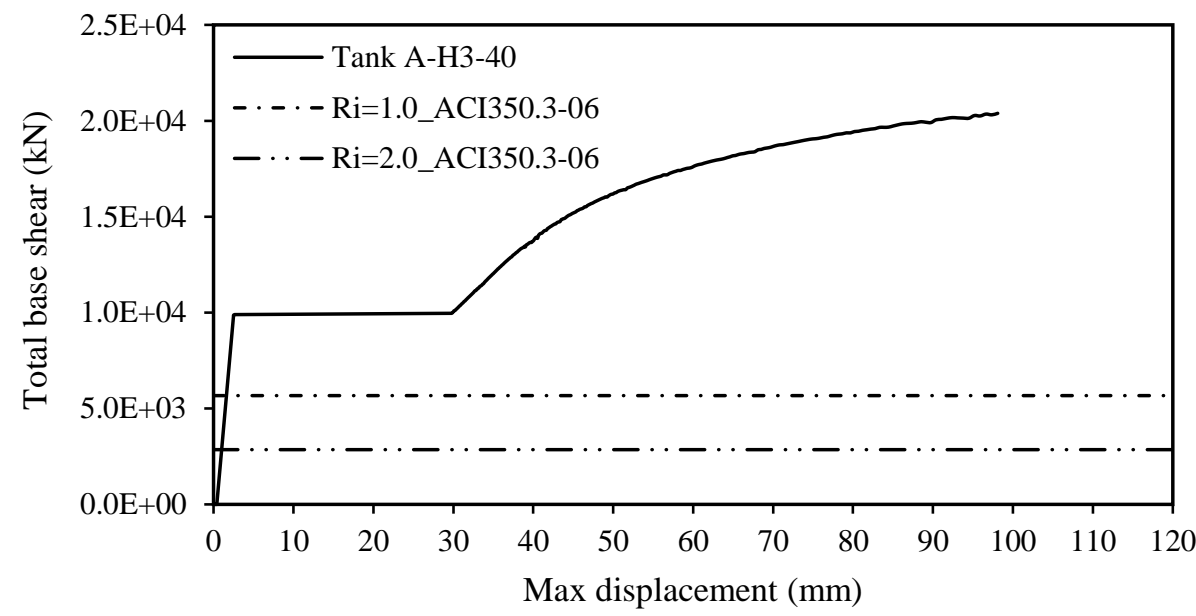

b)

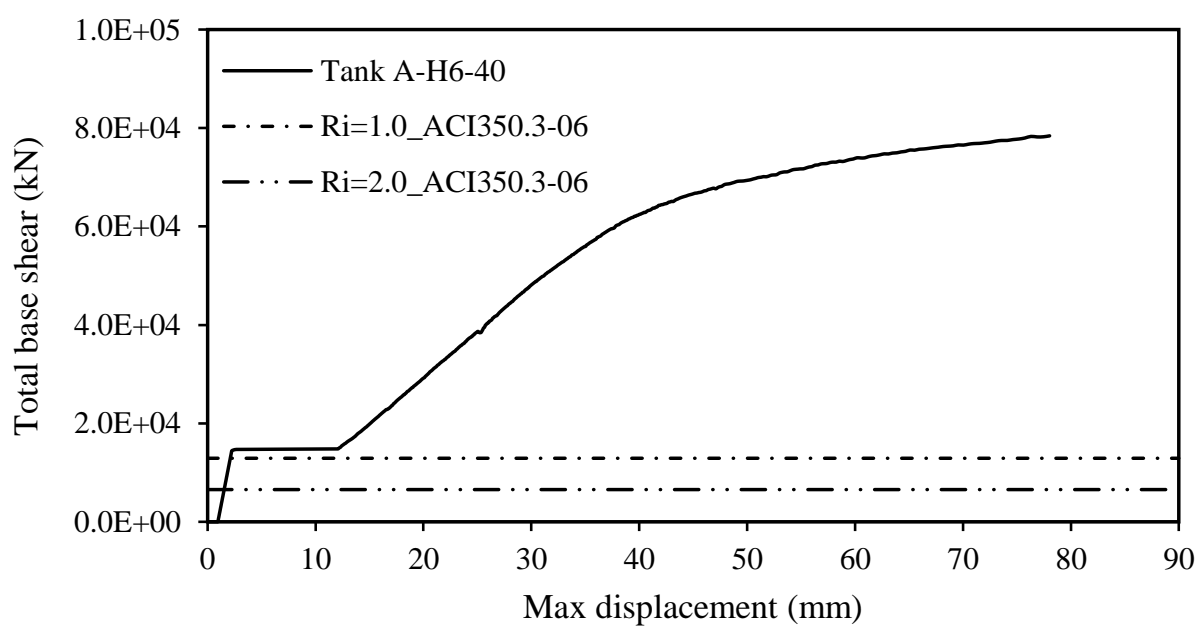

c)

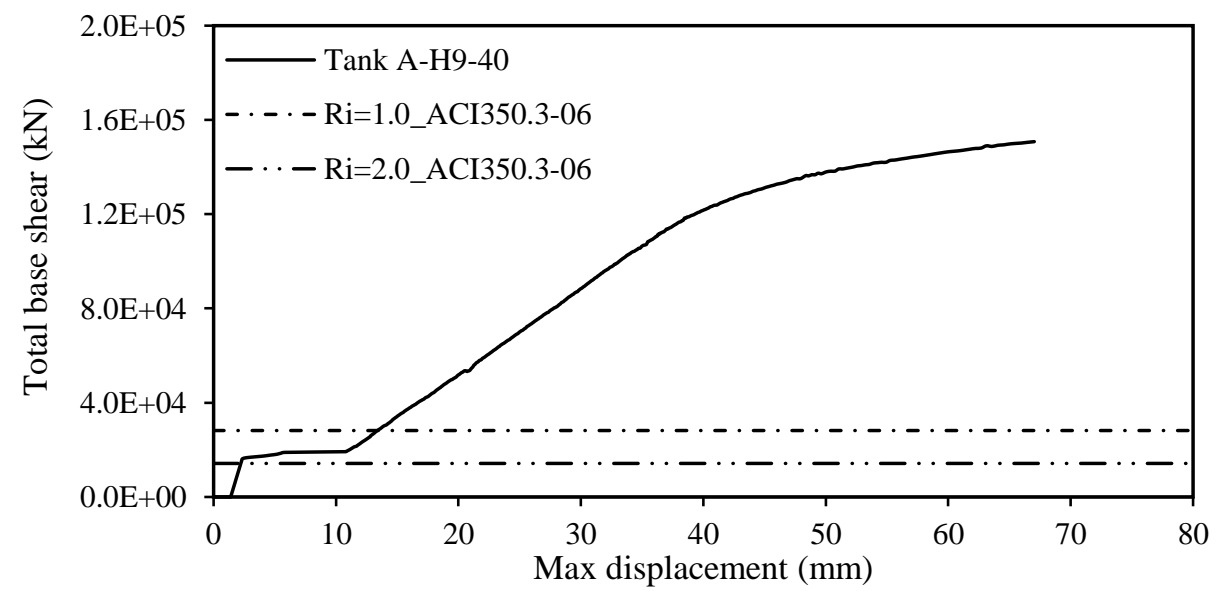

Figure 5.17 Load-deflection response; a) Tank A-H3-40, b) Tank A-H6-40, c) Tank A-H9-40 
Figure 5.18 shows the push-over curve for flexible base condition.

a)

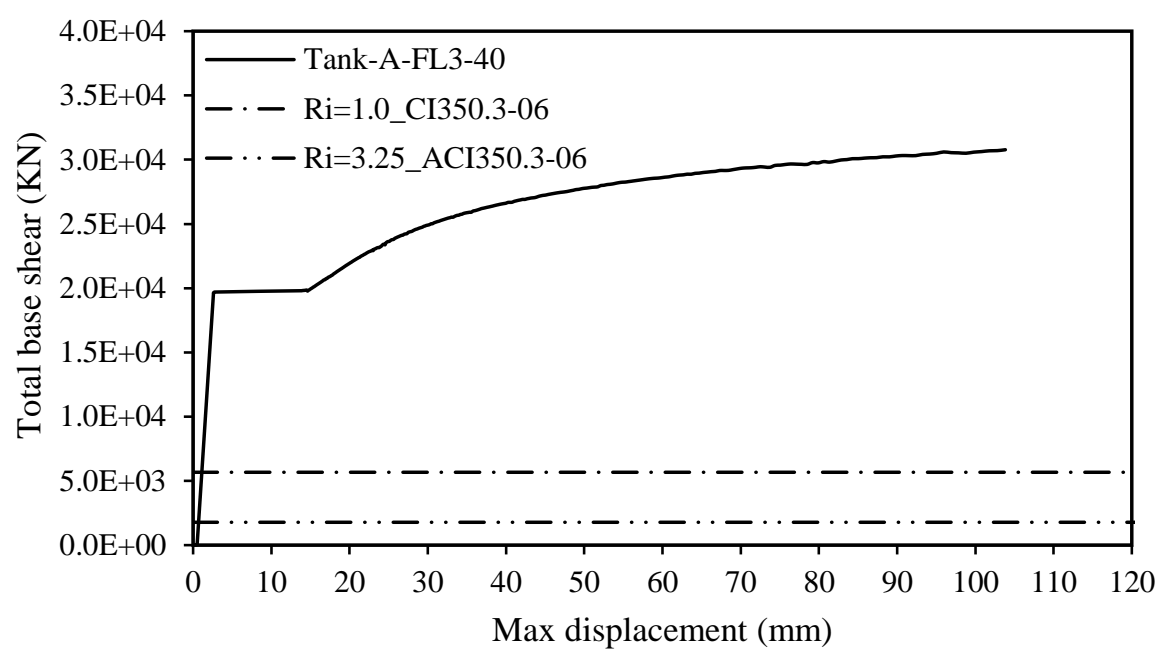

b)
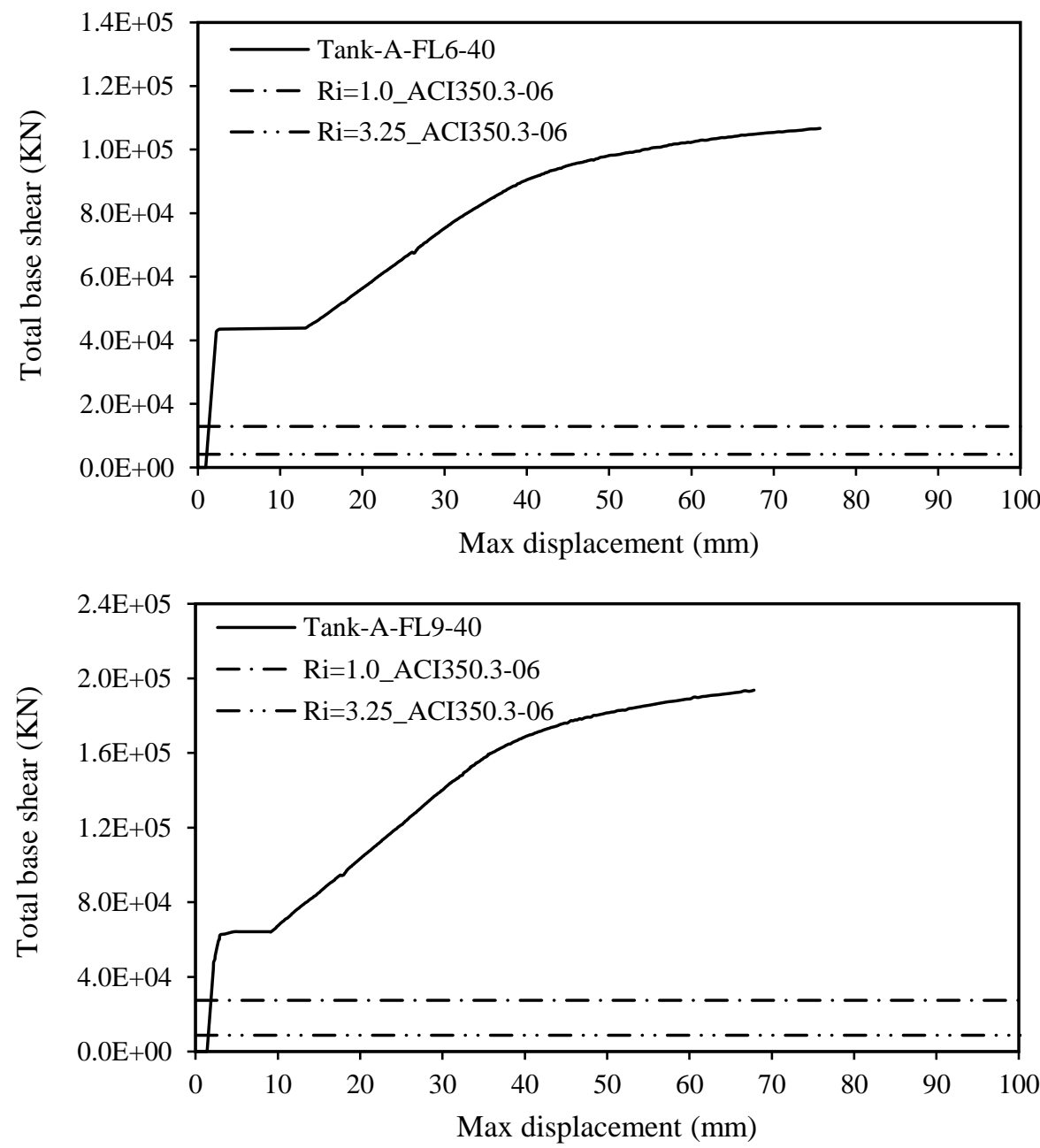

Figure 5.18 Load-deflection response; a) Tank A-FL3-40, b) Tank A-FL6-40, c) Tank A-FL9-40

Each graph includes the push-over curve for two groups A and B with concrete compressive strength of 30 and $40 \mathrm{MPa}$ respectively. The dash-line shows the results for the 
fully-elastic as shown in the figures. Although, as per Figure 5.19, the design base shear is equal for both tank types, tanks with higher compressive strength leads to a higher $\mathrm{V}_{\max }$ value.

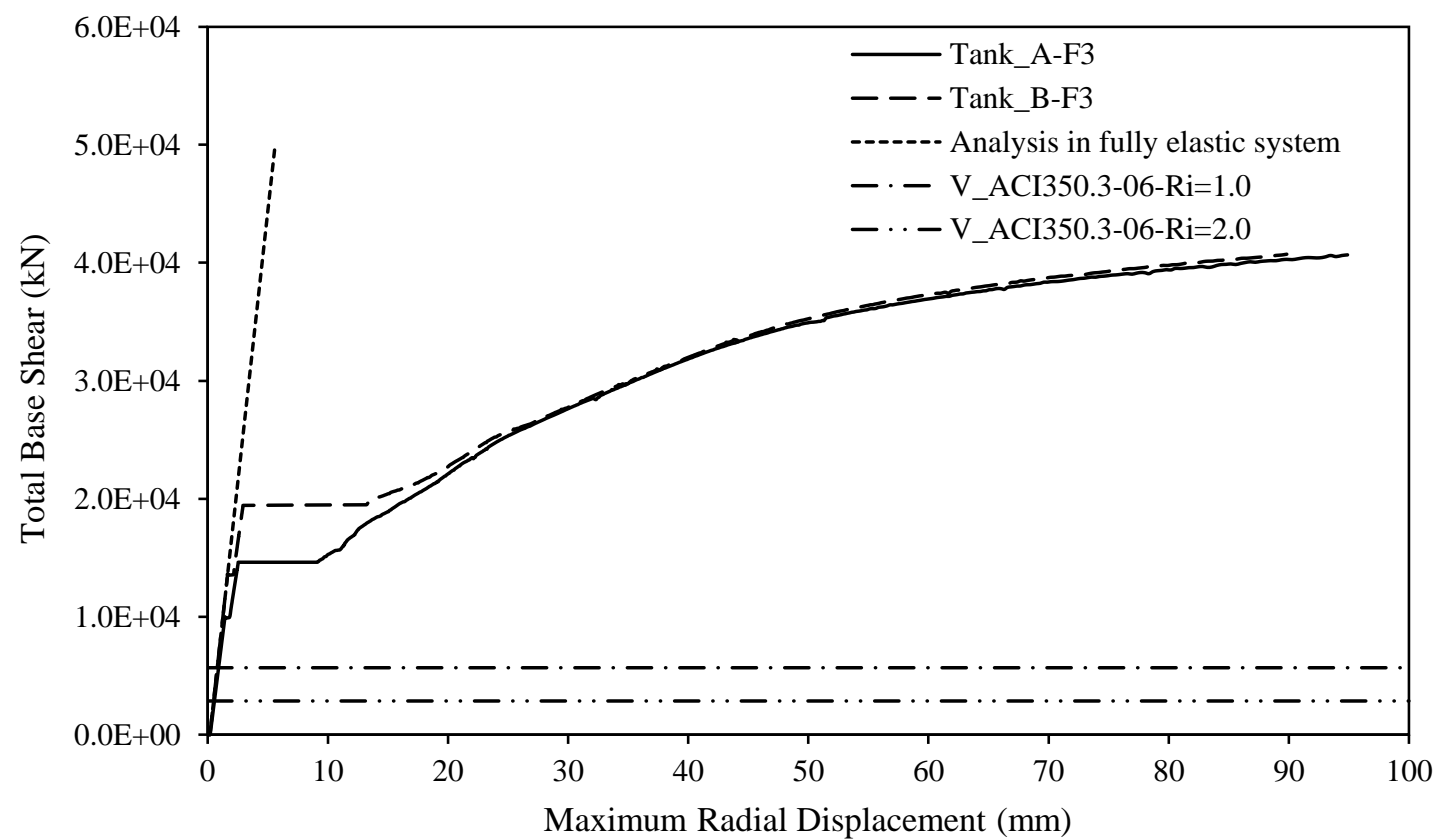

(a)

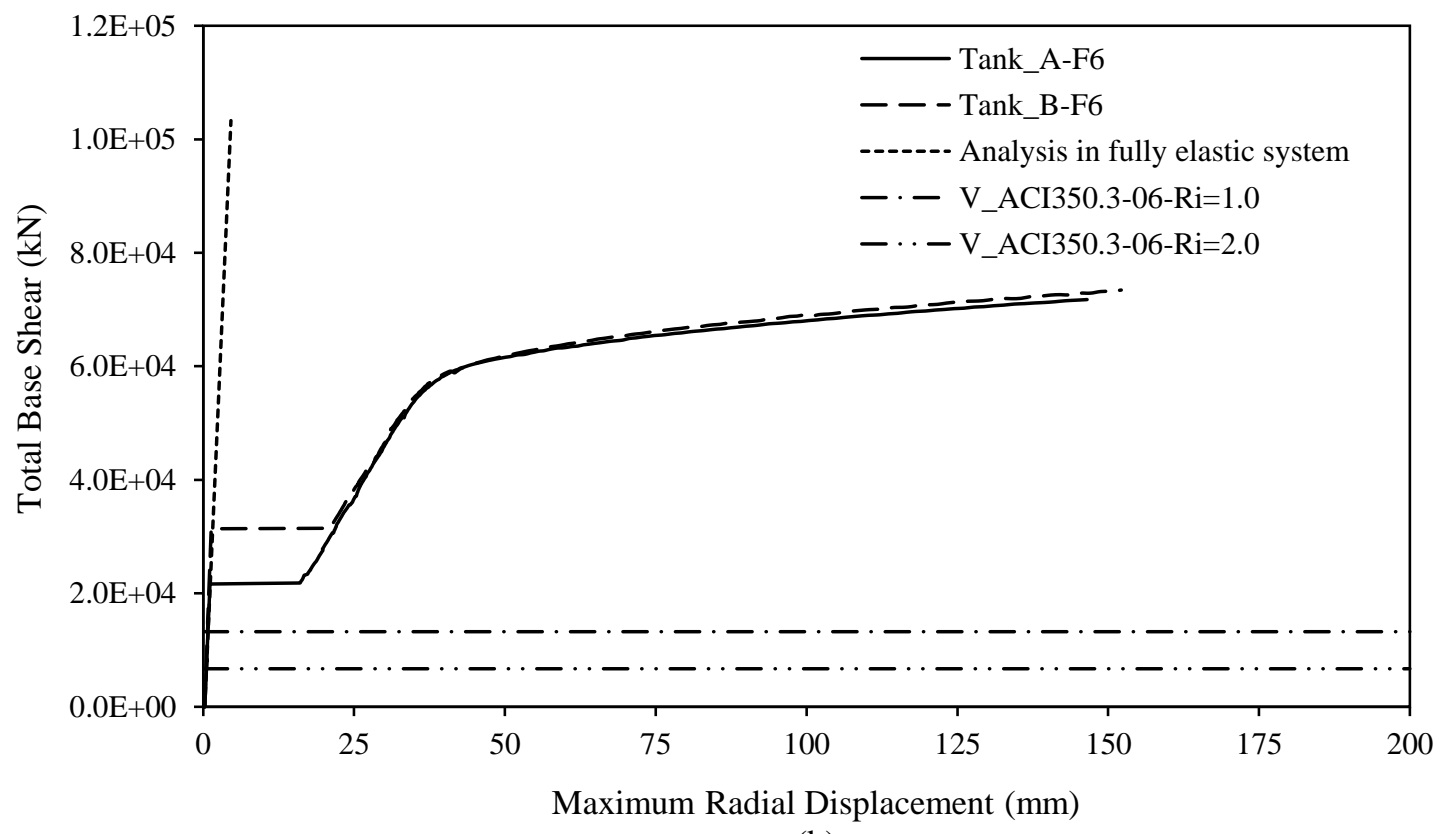

(b) 


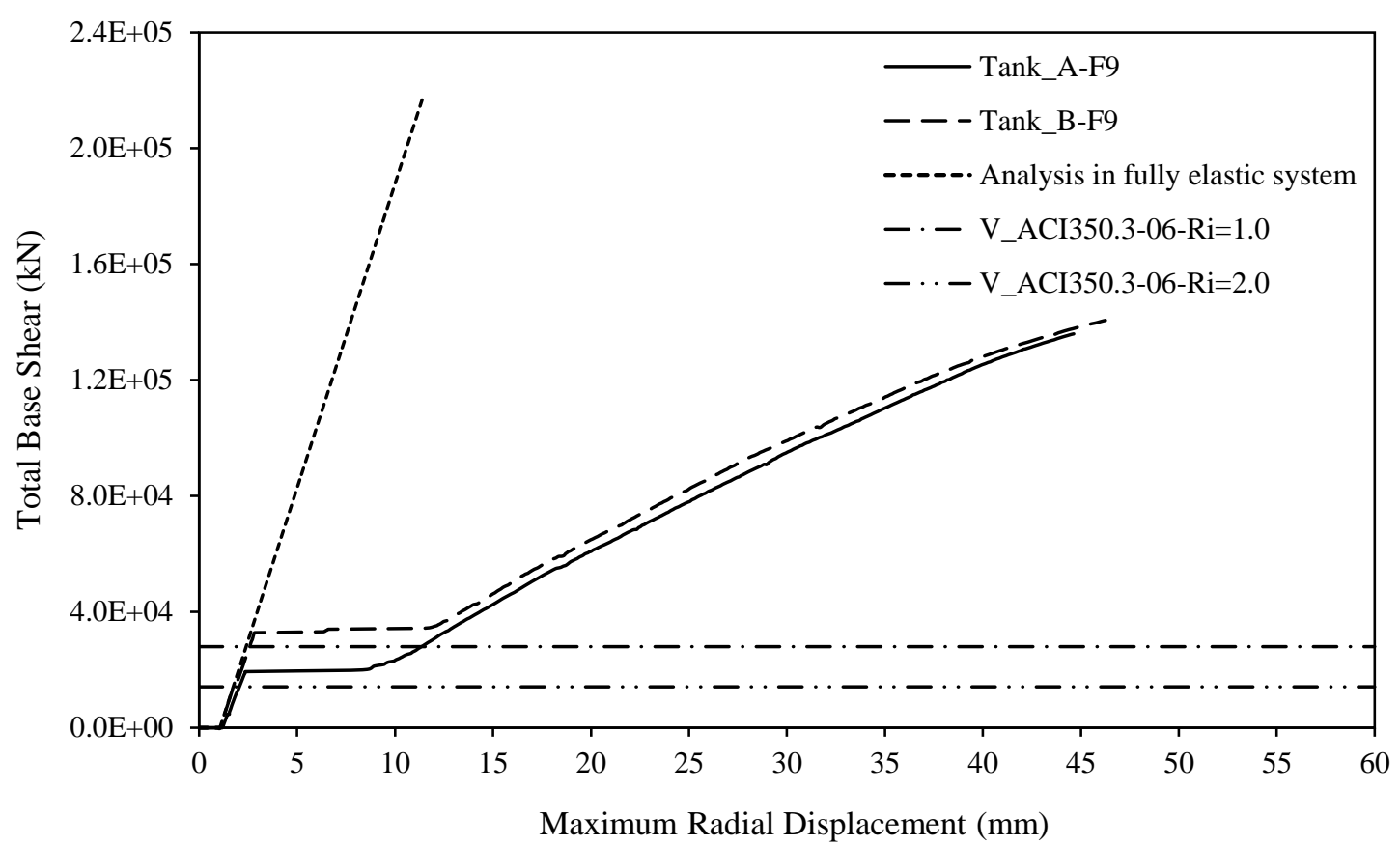

(c)

Figure 5.19 Comparing Load-deflection curves for two Groups A and B; (a) Tank F3-40, (b) Tank F6-40, (c) Tank F9-40

\subsection{Calculation of seismic response factors}

Pushover curves are employed to extract the valuable seismic response characteristics such as maximum shear capacity $\left(\mathrm{V}_{\max }\right)$, maximum displacement $\left(\mathrm{U}_{\max }\right)$, structure ductility $(\mu)$, effective yield displacement, and so on. The pushover curves were developed for all type of tanks designed here. Pushover curves do not display the distinct maximum displacement due to material nonlinearity; especially in RC structure due to cracking and crushing of concrete material. Therefore, interpretation of pushover were employed in section 5.7 to take out the practical and meaningful information from these curves.

Seismic design criteria of some RC structures such as building, or elevated water tanks are based on life safety and prevention of collapse. However, in design of RC groundsupported tanks, the serviceability limits such as leakage are to be met. The response modification factor $(\mathrm{R})$ in this study is calculated based on two major components including 
the over-strength and ductility factor, considering the leakage as the limit state. As the nonlinear response of the structure is governed by controlling concrete cracking, in design of liquid containing structures, the over-strength factor is attributed to response modification factor more than ductility; hence, the ductility might be assumed as unity.

In this study, defining the exact maximum drift of ground supported $\mathrm{RC}$ tank wall is not practical. Studies by Sadjadi (2009) showed that the leakage triggers at the time that the reinforcement yields. Therefore, in this study, the maximum practical displacement of the RC tanks is established based on the serviceability limits including cracking and leakage. Then, the maximum total base shear is obtained corresponding to the maximum displacement. Consequently, response modification factor $(\mathrm{R})$ is calculated using Equation (5.5). In the next section, the effect of tank size, base fixity and compressive concrete strength on the response modification factor will be investigated.

\subsubsection{Effect of tank dimension}

This section discusses the effect of tank's height and diameter on the response modification factor. Tanks are simulated with three different diameters, 20, 30 and $40 \mathrm{~m}$ and three different heights: $3.25,6.5$, and $9.6 \mathrm{~m}$.

Table 5.4 demonstrates the results of nine different tank models with the abovementioned dimensions. As shown in the matrix, at a constant diameter, by increasing the height of the tank, the total base shear at which the reinforcement starts to yield $\left(\mathrm{V}_{\mathrm{y}}\right)$ and the tensile cracking stress $\left(\mathrm{V}_{\mathrm{cr}}\right)$ both increase. 
Table 5.4 Summary of response modification factor for fixed and hinged base tanks

\begin{tabular}{|c|c|c|c|c|c|c|c|c|c|}
\hline $\begin{array}{c}\text { Tank } \\
\text { type }\end{array}$ & $\begin{array}{c}\mathrm{H}_{\mathrm{W}} \\
(\mathrm{m})\end{array}$ & $\begin{array}{c}\mathrm{H}_{\mathrm{L}} \\
(\mathrm{m})\end{array}$ & $\mathrm{D}(\mathrm{m})$ & $\mathrm{D} / \mathrm{H}_{\mathrm{L}}$ & $\mathrm{R}_{\mathrm{S}}$ & $\begin{array}{c}\mathrm{V}_{\mathrm{cr}} \\
(\mathrm{kN})\end{array}$ & $\mathrm{V}_{\mathrm{y}}(\mathrm{kN})$ & $\mathrm{R} \mu$ & $\mathrm{R}_{\mathrm{i}}$ \\
\hline A-F3-40 & 3.25 & 3.0 & 40 & 13.33 & 2.84 & 16065 & 17299 & 1.11 & 3.16 \\
\hline A-F6-40 & 6.5 & 6.0 & 40 & 6.67 & 1.76 & 21863 & 22724 & 1.02 & 1.79 \\
\hline A-F9-40 & 9.6 & 9.0 & 40 & 4.44 & 1.35 & 22438 & 47480 & 1.14 & 1.54 \\
\hline A-F3-30 & 3.25 & 3.0 & 30 & 10.34 & 5.08 & 16818 & 17051 & 1.12 & 5.69 \\
\hline A-F6-30 & 6.5 & 6.0 & 30 & 5.08 & 2.12 & 20210 & 20460 & 1.01 & 2.14 \\
\hline A-F9-30 & 9.6 & 9.0 & 30 & 3.37 & 1.22 & 22701 & 38482 & 1.16 & 1.42 \\
\hline A-F3-20 & 3.25 & 3.0 & 20 & 7.14 & 7.69 & 12503 & 12612 & 1.01 & 7.76 \\
\hline A-F6-20 & 6.5 & 6.0 & 20 & 3.45 & 2.08 & 11132 & 12665 & 1.18 & 2.47 \\
\hline A-F9-20 & 9.6 & 9.0 & 20 & 2.30 & 1.56 & 17978 & 25668 & 1.12 & 1.84 \\
\hline
\end{tabular}

Table 5.4 and Figure 5.20 shows that in a constant diameter, tanks with lower heights show higher over strength factors. When tanks are designed based on ultimate hoop force and moment of the wall section, the required reinforcement area is calculated to be lower that the minimum area of reinforcement. This can cause immediate failure as soon as a crack occurs without any warning. These tanks are designed with minimum reinforcement $\left(\mathrm{A}_{\mathrm{s}, \mathrm{min}}\right)$ as per shrinkage and temperature requirements. Consequently, it is expected to have higher over strength factors for lower tanks compared to taller tanks. On the other hand, when the diameter is decreased while the height is kept constant, the overestimate factor increases.

As shown in Figures 5.20 and 5.21, increasing $\mathrm{D} / \mathrm{H}_{\mathrm{L}}$ ratio with a constant height, reduces the response modification factor. Therefore, the lower the size (volume) of the tank, the over strength factor and consequently R factor will be higher. The ductility factor does not show a constant trend for a conclusion to be made. 


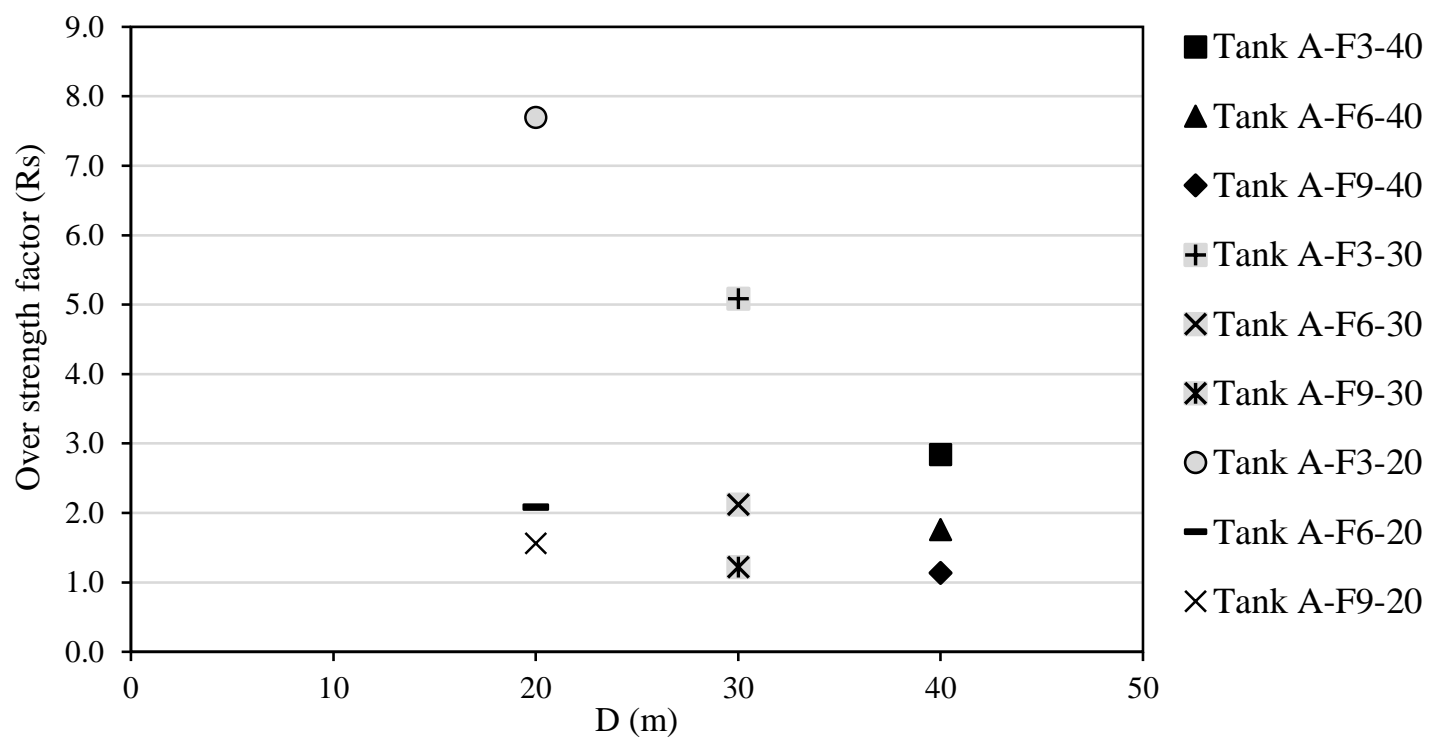

Figure 5.21 Effect of tank dimension on over-strength factor $\left(\mathrm{R}_{\mathrm{S}}\right)$

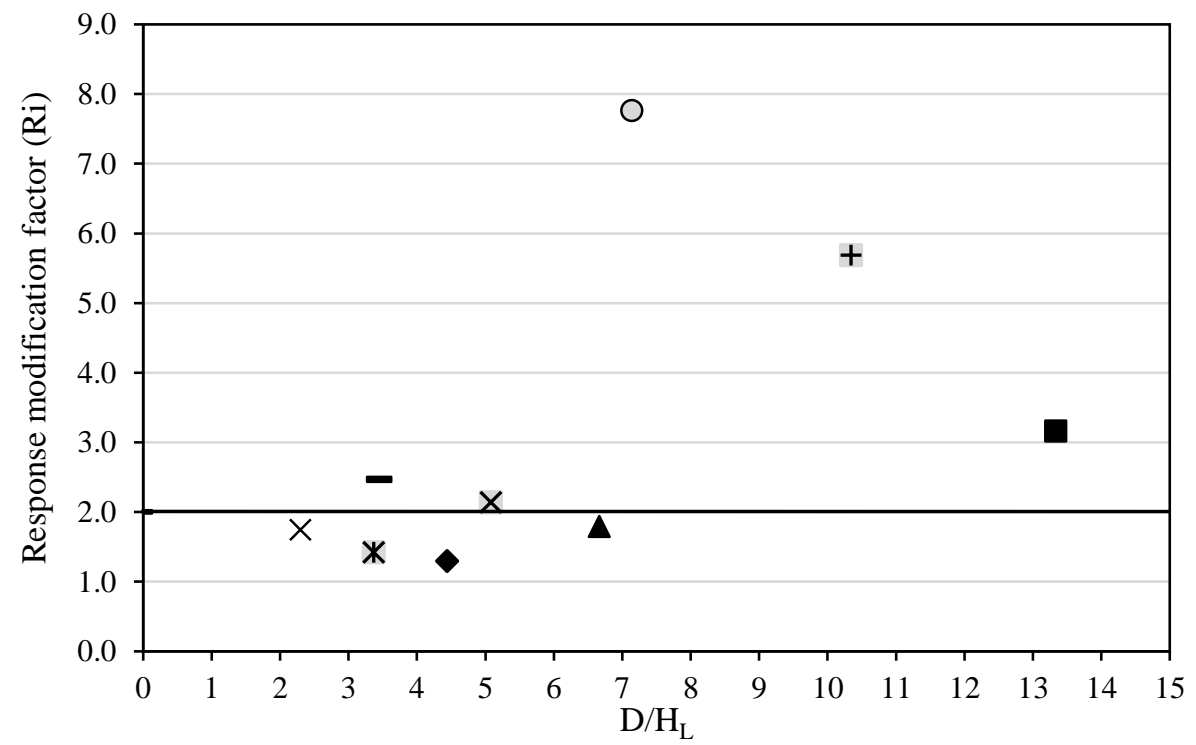

Tank A-F3-40

$\Delta$ Tank A-F6-40

- Tank A-F9-40

+ Tank A-F3-30

XTank A-F6-30

* Tank A-F9-30

OTank A-F3-20

-Tank A-F6-20

$\times$ Tank A-F9-20

- $\mathrm{Ri}=2.0 \_$ACI350.3-06

Figure 5.20 Effect of $\mathrm{D} / \mathrm{H}_{\mathrm{L}}$ on response modification factor $\left(\mathrm{R}_{\mathrm{i}}\right)$

\subsubsection{Effect of base fixity}

According to ACI350.3-06, response modification factor for fixed, hinged, and flexible base tanks are considered to be $R_{i}=2.0$ and 3.25, respectively, and applied load combination on the tank wall for both fixed and hinged tanks is identical, but for flexible tanks is lower. However, the ratio of horizontal reinforcement for the hinged base tanks is higher than those 
for fixed base condition and the total ratio of reinforcement is higher for fixed base tanks (As shown in Table 5.5). Based on the results shown in Table 5.5, summary of response modification factor for fixed, hinged, and flexible tanks, the flexible base tanks establish a higher total base shear at which the reinforcement yields and concrete stress reaches to tensile stress $\left(f_{t}\right)$.

Table 5.5 Summary of response modification factor for fixed and hinged base tanks

\begin{tabular}{|c|c|c|c|c|c|c|c|c|c|}
\hline Tank type & $\begin{array}{c}\text { Base } \\
\text { Condition }\end{array}$ & $\begin{array}{c}\mathrm{H}_{\mathrm{w}} \\
(\mathrm{m})\end{array}$ & $\begin{array}{c}\mathrm{H}_{\mathrm{L}} \\
(\mathrm{m})\end{array}$ & $\begin{array}{c}\mathrm{D} \\
(\mathrm{m})\end{array}$ & $\mathrm{R}_{\mathrm{S}}$ & $\mathrm{V}_{\mathrm{cr}}(\mathrm{kN})$ & $\begin{array}{c}\mathrm{V}_{\mathrm{y}} \\
(\mathrm{kN})\end{array}$ & $\mathrm{R} \mu$ & $\mathrm{R}_{\mathrm{i}}$ \\
\hline A-F3-40 & Fixed & 3.25 & 3.0 & 40 & 2.84 & 16065 & 17299 & 1.11 & 3.16 \\
\hline A-H3-40 & Hinged & 3.25 & 3.0 & 40 & 2.09 & 9962 & 11859 & 1.01 & 2.11 \\
\hline A-FL3-40 & Flexible & 3.25 & 3.0 & 40 & 4.09 & 19800 & 24120 & 1.16 & 5.04 \\
\hline A-F6-40 & Fixed & 6.5 & 6.0 & 40 & 1.76 & 21863 & 22724 & 1.02 & 1.79 \\
\hline A-H6-40 & Hinged & 6.5 & 6.0 & 40 & 1.55 & 14811 & 21101 & 1.07 & 1.66 \\
\hline A-FL6-40 & Flexible & 6.5 & 6.0 & 40 & 3.86 & 43840 & 50100 & 1.09 & 4.22 \\
\hline A-F9-40 & Fixed & 9.6 & 9.0 & 40 & 1.35 & 22438 & 47480 & 1.14 & 1.54 \\
\hline A-H9-40 & Hinged & 9.6 & 9.0 & 40 & 1.23 & 17478 & 45055 & 1.12 & 1.38 \\
\hline A-FL9-40 & Flexible & 9.6 & 9.0 & 40 & 2.71 & 64230 & 78246 & 1.41 & 3.81 \\
\hline
\end{tabular}

Table 5.5, Figures 5.22 and 5.23 show $\mathrm{D} / \mathrm{H}_{\mathrm{L}}$ ratio versus over-strength and response modification factors. As Table 5.5 demonstrates the over-strength factor $\left(\mathrm{R}_{\mathrm{S}}\right)$ of flexible base tanks are larger than the fixed and hinged base tanks. As expected, the response modification factor is larger for flexible base tanks in comparison to the fixed and hinged base tanks. 


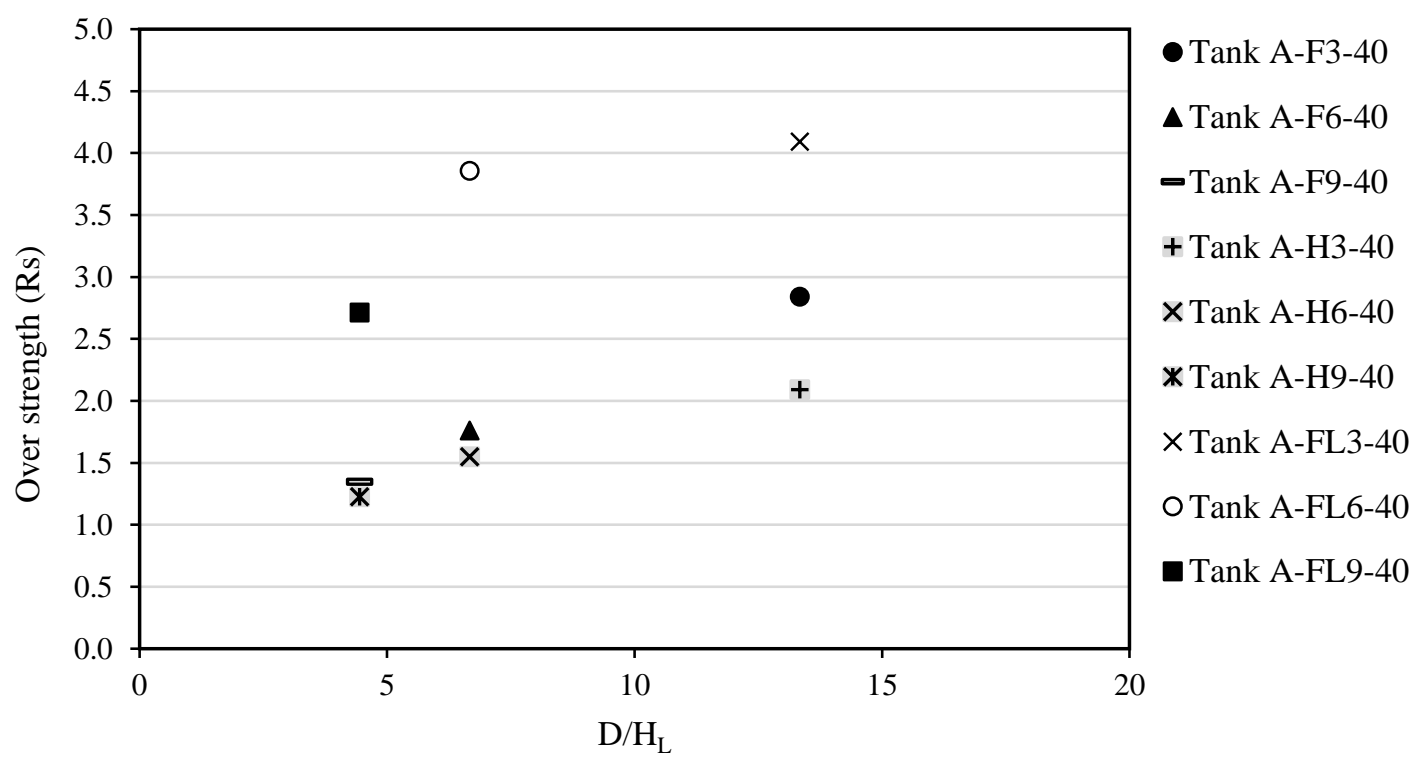

Figure 5.22 Effect of $\mathrm{D} / \mathrm{H}_{\mathrm{L}}$ on over-strength factor (Rs)

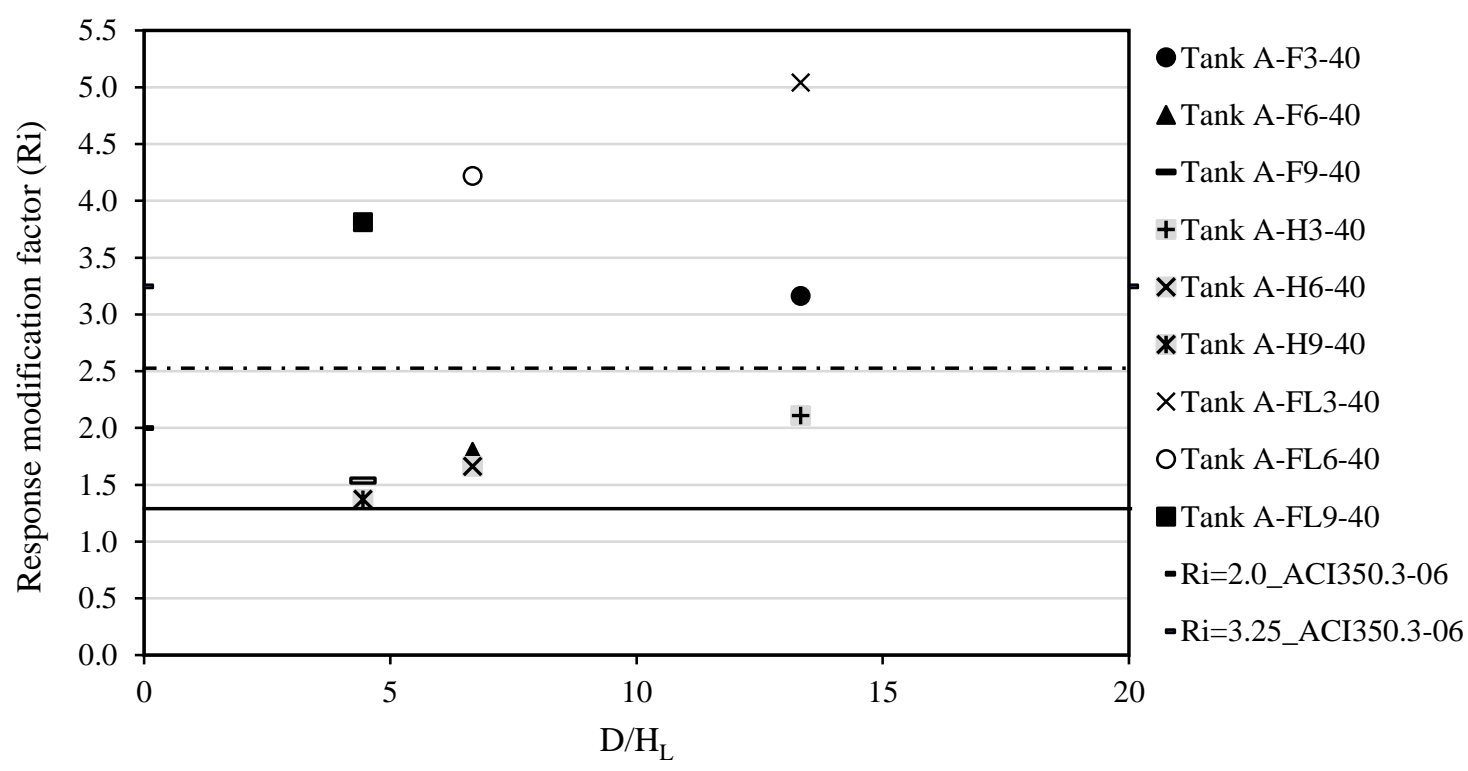

Figure 5.23 Effect of $\mathrm{D} / \mathrm{H}_{\mathrm{L}}$ on response modification factor $\left(\mathrm{R}_{\mathrm{s}}\right)$

\subsubsection{Effect of concrete strength $\left(f_{c}{ }^{\prime}\right)$}

As per previous studies (Uang (1991) and Whittaker et al. (1999), parameters such as material strength, strain hardening, minimum reinforcement, safety margins (load factors and combination) used in the design process influences over-strength factor. Elnashai and Mwafy (2002) showed that the seismic response of structures is affected by the over-strength factor, and the higher values of over-strength factor could provide more resistance of the structure against collapse. The fundamental period of structure depends on frequency of impulsive mode 
of vibration of the tank. Changing the tank dimension, elastic modulus and density of concrete influences the structure frequency. Hence, increasing compressive concrete strength induces increasing the tank frequency and decreasing the fundamental period of the structure. Table 5.6 shows the summary of response modification factor for two groups of A and B where the values of concrete strength are 30 and $40 \mathrm{MPa}$ for group $\mathrm{A}$ and $\mathrm{B}$, respectively.

Table 5.6 Summary of response modification factor for two groups of A and B

\begin{tabular}{|c|c|c|c|c|c|c|c|c|c|c|}
\hline $\begin{array}{c}\text { Tank } \\
\text { type }\end{array}$ & $\begin{array}{c}\mathrm{H}_{\mathrm{w}} \\
(\mathrm{m})\end{array}$ & $\begin{array}{c}\mathrm{H}_{\mathrm{L}} \\
(\mathrm{m})\end{array}$ & $\begin{array}{c}\mathrm{f}_{\mathrm{c}} \\
(\mathrm{MPa})\end{array}$ & $\mathrm{D}(\mathrm{m})$ & $\mathrm{T}_{\mathrm{i}}$ & $\mathrm{R}_{\mathrm{S}}$ & $\begin{array}{c}\mathrm{V}_{\mathrm{cr}} \\
(\mathrm{kN})\end{array}$ & $\begin{array}{c}\mathrm{V}_{\mathrm{y}} \\
(\mathrm{kN})\end{array}$ & $\mathrm{R} \mu$ & $\mathrm{R}_{\mathrm{i}}$ \\
\hline A-F3-40 & 3.25 & 3.0 & 30 & 40 & 0.038 & 2.84 & 16065 & 17299 & 1.11 & 3.16 \\
\hline B-F3-40 & 3.25 & 3.0 & 40 & 40 & 0.036 & 3.44 & 19486 & 19628 & 1.01 & 3.46 \\
\hline A-F6-40 & 6.5 & 6.0 & 30 & 40 & 0.068 & 1.76 & 21863 & 22724 & 1.02 & 1.79 \\
\hline B-F6-40 & 6.5 & 6.0 & 40 & 40 & 0.064 & 2.44 & 31455 & 32537 & 1.03 & 2.51 \\
\hline A-F9-40 & 9.6 & 9.0 & 30 & 40 & 0.086 & 1.35 & 22438 & 47480 & 1.14 & 1.54 \\
\hline B-F9-40 & 9.6 & 9.0 & 40 & 40 & 0.082 & 1.74 & 33144 & 48736 & 1.24 & 2.17 \\
\hline
\end{tabular}

As Table 5.6 represents, the total base shear at which the reinforcements yields $\left(V_{y}\right)$ and concrete stress reaching the cracking strength $\left(\mathrm{V}_{\mathrm{cr}}\right)$ increases by increasing the compressive concrete strength $\left(f_{c}^{\prime}\right)$. This table also shows that increasing the concrete compressive strength $\left(f_{c}^{\prime}\right)$ increases the tank frequency and decreases the fundamental period of the tank. Figures 5.24 and 5.25 show the effect of compressive strength $\left(f_{c}\right)$ on the over strength $\left(\mathrm{R}_{\mathrm{s}}\right)$ and response modification factor $\left(\mathrm{R}_{\mathrm{i}}\right)$, respectively. 


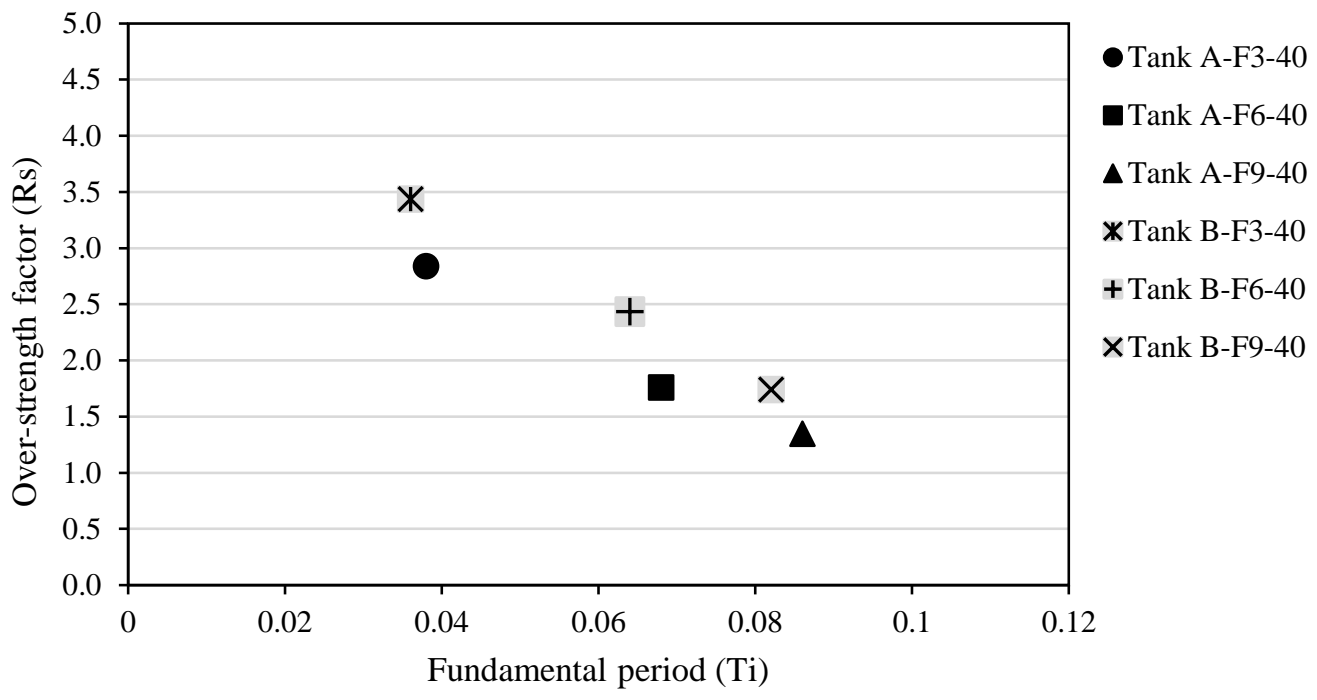

Figure 5.24 Effect of fundamental period on over-strength factor (Rs)

As Equation 5.6 shows, the over-strength factor $\left(\mathrm{R}_{\mathrm{S}}\right)$ varies by changing the maximum base shear $\left(\mathrm{V}_{\max }\right)$ since the design base shear $\left(\mathrm{V}_{\mathrm{d}}\right)$ is constant for both group $\mathrm{A}$ and $\mathrm{B}$. As Figures 5.24 and 5.25 indicate, increasing the concrete compressive strength $\left(f_{c}^{\prime}\right)$ increases the over-strength and response modification factors.

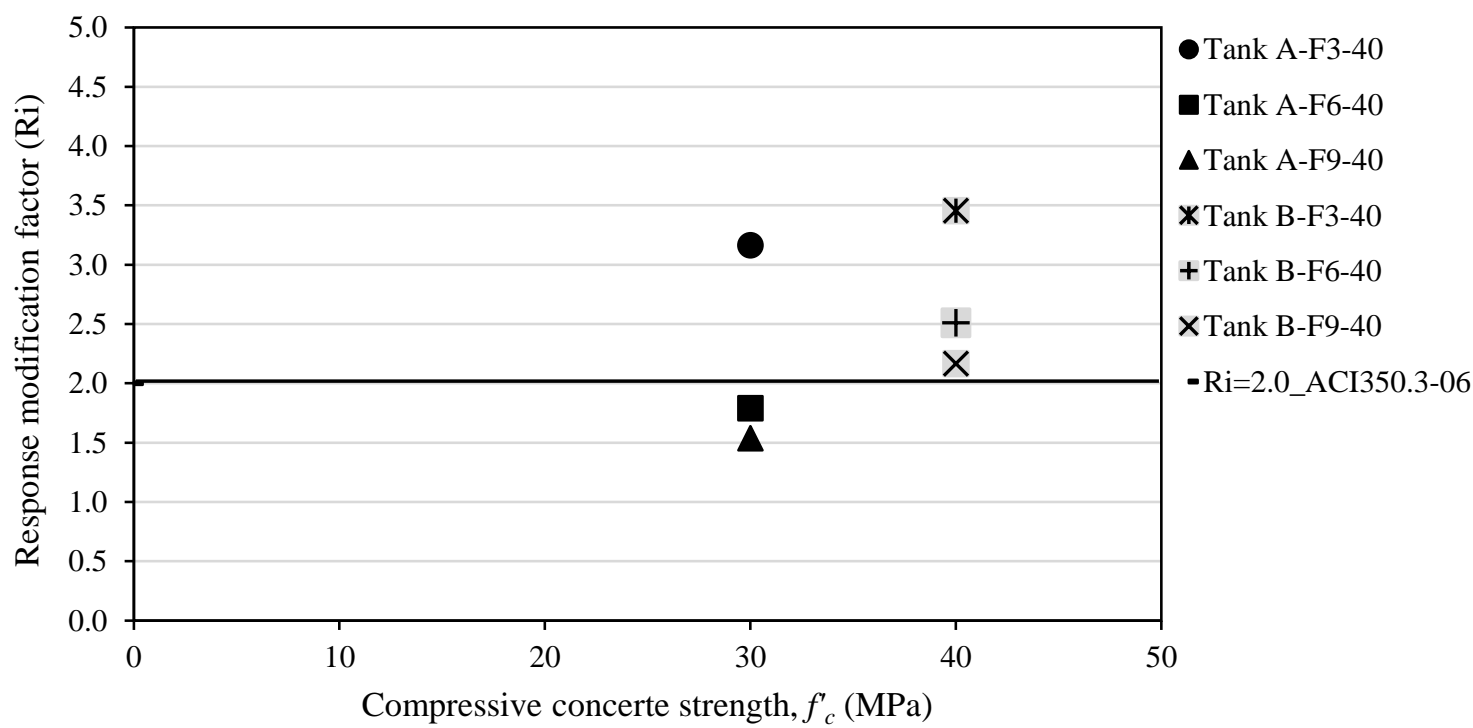

Figure 5.25 Effect of fundamental period on response modification factor (Rs) 


\subsection{Summary}

The purpose of this chapter is investigating the nonlinear response of structure by applying the nonlinear static analysis (Pushover analysis). For this reason, various tanks considering different tank dimension, base fixity, and concrete strength are designed and analyzed by applying the seismic pressure distribution according to standard ACI350.3-06. The pushover curves are developed, and seismic performance factors are calculated and discussed

According to the results of FE analysis, the flexible base tanks shows the higher total base shear at which the reinforcement yields in comparison to the fixed and hinged base tanks. So, higher over-strength and response modification factor is expected for the flexible base tanks. In addition, the over-strength factor of smaller tanks is higher than the one in larger tanks. It is expected because the smaller tanks are designed based on the minimum reinforcement $\left(\mathrm{A}_{\mathrm{s}, \mathrm{min}}\right)$ as per shrinkage and temperature requirements.

Furthermore, increasing the concrete compressive strength boosts the tank frequency and decrease the fundamental period of the structure. Consequently, the over-strength and response modification factor are increased by enhancing the concrete compressive strength. 


\section{CHAPTER 6 \\ TIME HISTORY ANALYSIS}

\subsection{Introduction}

In this chapter, the simulated ground supported circular tank by finite element method will be analyzed and studied subjected to time history. For dynamic analysis, two general methods including Modal Superposition and Direct Integration (Transient) are employed. The transient technique is more applicable and appropriate for the nonlinear analysis of structures. In time history method, seismic loads are applied through an array of lateral accelerations and the structural response will be calculated at small time steps through equilibrium of forces. In this study, different earthquake motions including Northridge (1994), El-Centro (1940), and San-Francisco (1957) earthquake records are used to investigate the effect of seismic frequency content on the nonlinear response of the structure. The proposed method considered both impulsive and convective response of the liquid tank. Linear free surface boundary condition is applied to simulate the sloshing behavior.

In past decades, various methods such as average acceleration, Newmark method, central difference, etc. have been developed to solve the equation of motion by employing the explicit and implicit approaches. In an implicit method, several iterations are required to get the solution leading to numerical instability and convergence issue, and consequently, nonlinearities may not be handled very well. In addition, the analysis progress may stop by encountering the singularities due to the matrix inversion in the calculation. However, the explicit method involves none of these deficiencies. ANSYS program employs the most accurate solver called modified-Newmark technique. This chapter shows the nonlinear response of circular tanks under different earthquake motions. 


\subsection{Verification of numerical model}

To verify the proposed finite element method prior to the time-history analysis, a modal analysis of the tank is carried out and the obtained FE results are compared with those reported in Moslemi (2011) and recalculated here analytically. The modal response and natural frequency are attained by employing the analytical methods and finite element technique for both impulsive and convective modes. Housner (1963) proposed a method to calculate the natural frequency of the fundamental sloshing mode. The tank is modeled assuming rigid wall boundary condition.

Veletsos and Shivakumar (1997) proposed an analytical solution to calculate the fundamental impulsive frequency of the liquid containing tank by employing the following equations:

$\omega_{i}=C_{I} \frac{1}{H_{l}} \sqrt{1000 E_{c} \frac{g}{\gamma_{c}}}$

$C_{I}=C_{w} \sqrt{\frac{t_{w}}{10 R}}$

$T_{i}=\frac{2 \pi}{\omega_{i}}=\frac{1}{f_{i}}$

where,

$H_{l}:$ depth of stored liquid (m)

$E_{c}:$ modulus of elasticity of concrete $(\mathrm{MPa})$

$g:$ acceleration due to gravity $\left(9.807 \mathrm{~m} / \mathrm{s}^{2}\right)$

$\gamma_{c}:$ density of concrete $\left(\mathrm{kN} / \mathrm{m}^{3}\right)$

$\omega_{i}$ : circular frequency of the fundamental impulsive mode of vibration $(\mathrm{rad} / \mathrm{s})$

$f_{i}$ : natural frequency of the fundamental impulsive mode of vibration $(\mathrm{Hz})$

$C_{I}$ and $C_{w}$ are coefficients for determining the fundamental frequency of the tank-liquid system, and $C_{w}$ can be calculated as follows: 
For $\frac{\mathrm{D}}{\mathrm{H}_{1}}>0.667$

$C_{W}=9.375 \times 10^{-2}+0.2039\left(\frac{H_{l}}{D}\right)-0.1034\left(\frac{H_{l}}{D}\right)^{2}-0.1253\left(\frac{H_{l}}{D}\right)^{3}+0.1267\left(\frac{H_{l}}{D}\right)^{4}-$

$3.186 \times 10^{-2}\left(\frac{H_{l}}{D}\right)^{5}$

where $t_{w}$ is average wall thickness, $D$ is inside diameter of tank, and $R$ is inside radius of the tank. $C_{w}$ can be determined from Figure 6.1, alternatively.

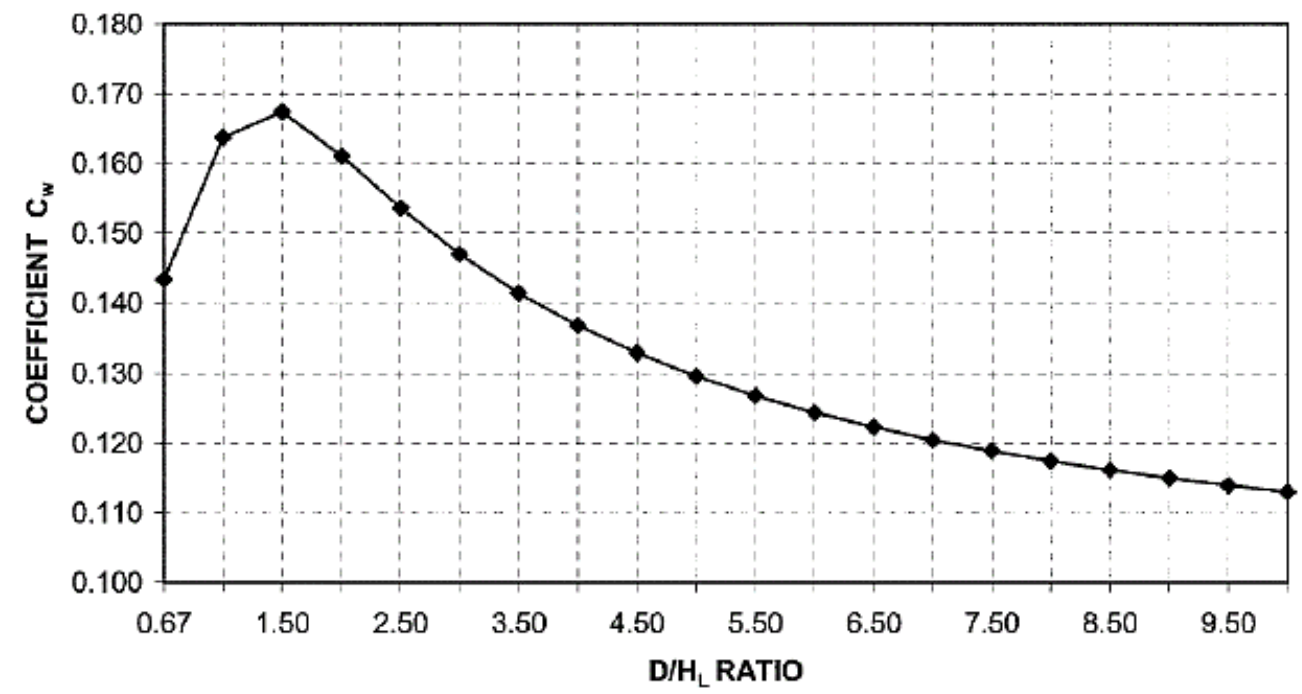

Figure 6.1 Coefficient $C_{w}$ for ground-supported circular tanks (Adopted from ACI350.3-06)

Both analytical solutions developed by Housner (1963) and Veletsos and Shivakumar (1997) are employed in ACI 350.3-06 to obtain the dynamic properties of liquid containing structures. The fundamental convective frequency of the liquid containing tank proposed by ACI 350.3-06 is calculated by the following equations:

$$
\begin{aligned}
& \omega_{c}=\frac{\lambda}{\sqrt{D}} \\
& \lambda=\sqrt{3.68 g \tanh \left[3.68\left(\frac{H_{l}}{D}\right)\right]} \\
& T_{c}=\frac{2 \pi}{\omega_{c}}=\left(\frac{2 \pi}{\lambda}\right) \sqrt{D}=\frac{1}{f_{c}}
\end{aligned}
$$


where, $\omega_{c}$ is the circular frequency of oscillation of the first (convective) mode of sloshing $(\mathrm{rad} / \mathrm{s})$.

As explained before, tank with rigid wall boundary condition is needed to be modeled for the Housner's method. Due to singularity in the solution process of FE analysis, the tank cannot be modeled as infinitely rigid. So, the tank is modeled relatively rigid by increasing the concrete elastic modulus for solid elements. For finite element model, a tank with a diameter of $34 \mathrm{~m}$ and thickness of $500 \mathrm{~mm}$ is modeled. The heights of tank wall and liquid are 12 and $11 \mathrm{~m}$, respectively. Since the wall is assumed to be rigid, the elastic modulus of concrete is considered as ten times that of normal concrete $24.86 \mathrm{GPa}$.

The modal results corresponding to the fixed tank are shown in Table 6.1 and Figure 6.2. Veletsos (1984) proposed the sloshing profile for the first convective mode of cylindrical tanks as represented in Figure 6.2.

Table 6.1 Modal analysis results for a ground-supported rigid tank model

\begin{tabular}{|c|c|c|c|c|c|}
\hline \multicolumn{2}{|c|}{ Mode } & \multicolumn{4}{c|}{ Frequency (Hz) } \\
\hline $\begin{array}{c}\text { Mode } \\
\text { Number }\end{array}$ & Type & FE & Moslemi (2011) & ACI 350.3-06 & Housner (1963) \\
\hline 1 & Convective & 0.149 & 0.149 & 0.149 & 0.149 \\
\hline 1 & Impulsive & 11.04 & 30.53 & 12.46 & 36.00 \\
\hline
\end{tabular}

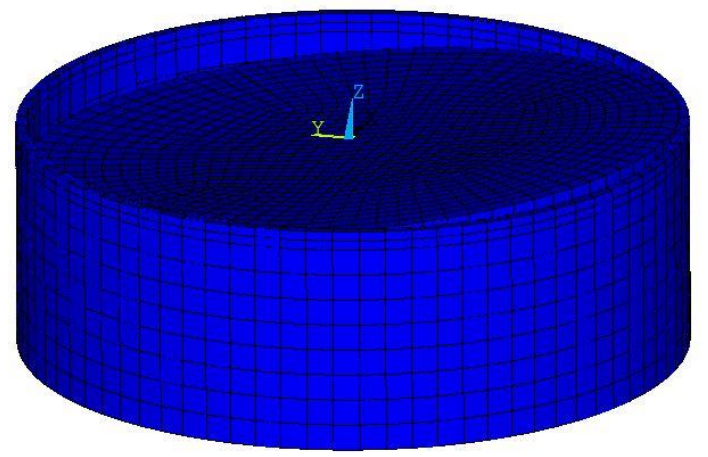

(a)

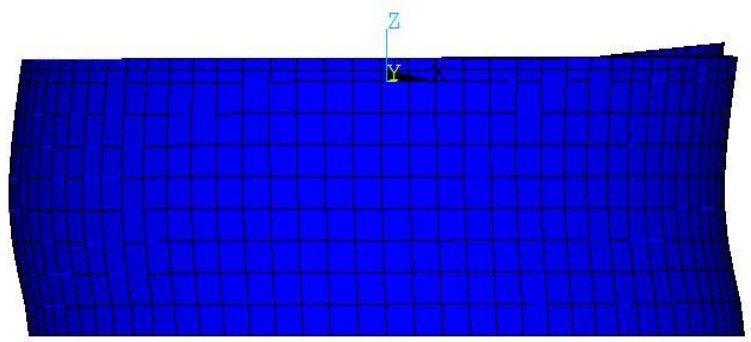

(b) 


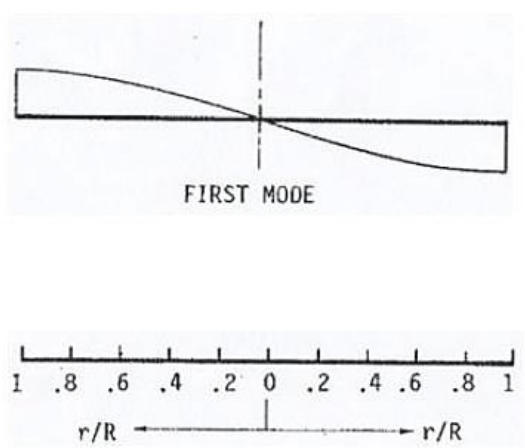

(c)

Figure 6.2 Mode shapes of cylindrical ground-supported tank; a) First convective mode (FE), b) First impulsive mode (FE), c) First convective mode (adapted from Veletsos (1984))

For further verification, the analytical solution proposed by Haroun and Housner (1981A) is employed and the results of FE analysis are compared to those of analytical solution. According to the Haroun's study, the analytical impulsive pressure for a rigid cylindrical tank can be calculated by the following equation (Eq. 6.8):

$p_{1}(R, \phi, z, t)=-\frac{2 \rho_{l} \ddot{u}_{0}(t)}{H_{l}} \sum_{i=1}^{\infty} \frac{(-1)^{i+1} I_{1}\left(\alpha_{i} R\right)}{\alpha_{i}^{2} I_{1}^{\prime}\left(\alpha_{i} R\right)} \cos \left(\alpha_{i} Z\right) \cos (\phi)$

and,

$\alpha_{i}=\frac{(2 i-1) \pi}{2 H_{l}}$

where, $R, \phi, z$ are tank's radial, circumferential and axial coordinates, respectively. $\rho_{l}$ is liquid mass density, $H_{l}$ is liquid depth, $\ddot{u}_{0}(t)$ is horizontal ground acceleration, and $I_{l}$ is modified Bessel function of the first kind of order one and $I_{1}^{\prime}$ is its derivative. In Equation 6.8, more series terms can be considered to get more precise results. In this study, using the first fifteen terms of the series provides an accurate estimation.

For comparison purposes, a fixed circular tank with a diameter of $36 \mathrm{~m}$ and thickness of $300 \mathrm{~mm}$ is modeled. Tank wall and liquid heights are 5.5 and $5.0 \mathrm{~m}$, respectively. The FE model is assumed as zero damping and both rigid and flexible wall condition are studied. Moreover, the tank is assumed to be anchored to the rigid ground. 
To obtain the time history response of the tank, the horizontal component of El-Centro earthquake (1940) scaled to the peak ground acceleration of $0.4 \mathrm{~g}$ is applied to the tank. To verify the FE model, the hydrodynamic pressure distribution on the wall at $(r=R$ and $\phi=0)$ for the analytical solution and FE model for both rigid and flexible walls are shown in Figure 6.3. As shown in the figure, the flexible tank reveals higher impulsive pressure in comparison to the rigid tank.

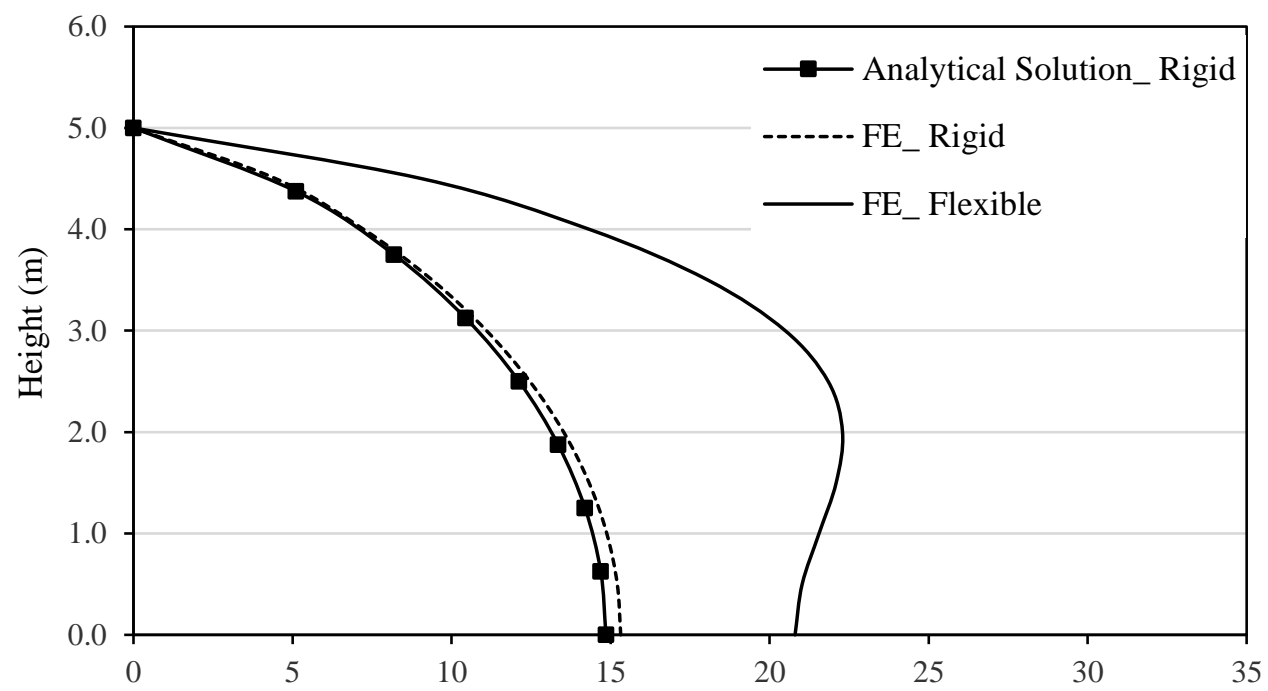

Figure 6.3 Impulsive hydrodynamic pressure distribution on the tank wall under horizontal excitation; Haroun's study, FE results

Figure 6.4 shows the comparison of results between the FE model and analytical solution for impulsive pressure at the tank base at $(\mathrm{r}=\mathrm{R}, \phi=0$, and $\mathrm{z}=0)$.

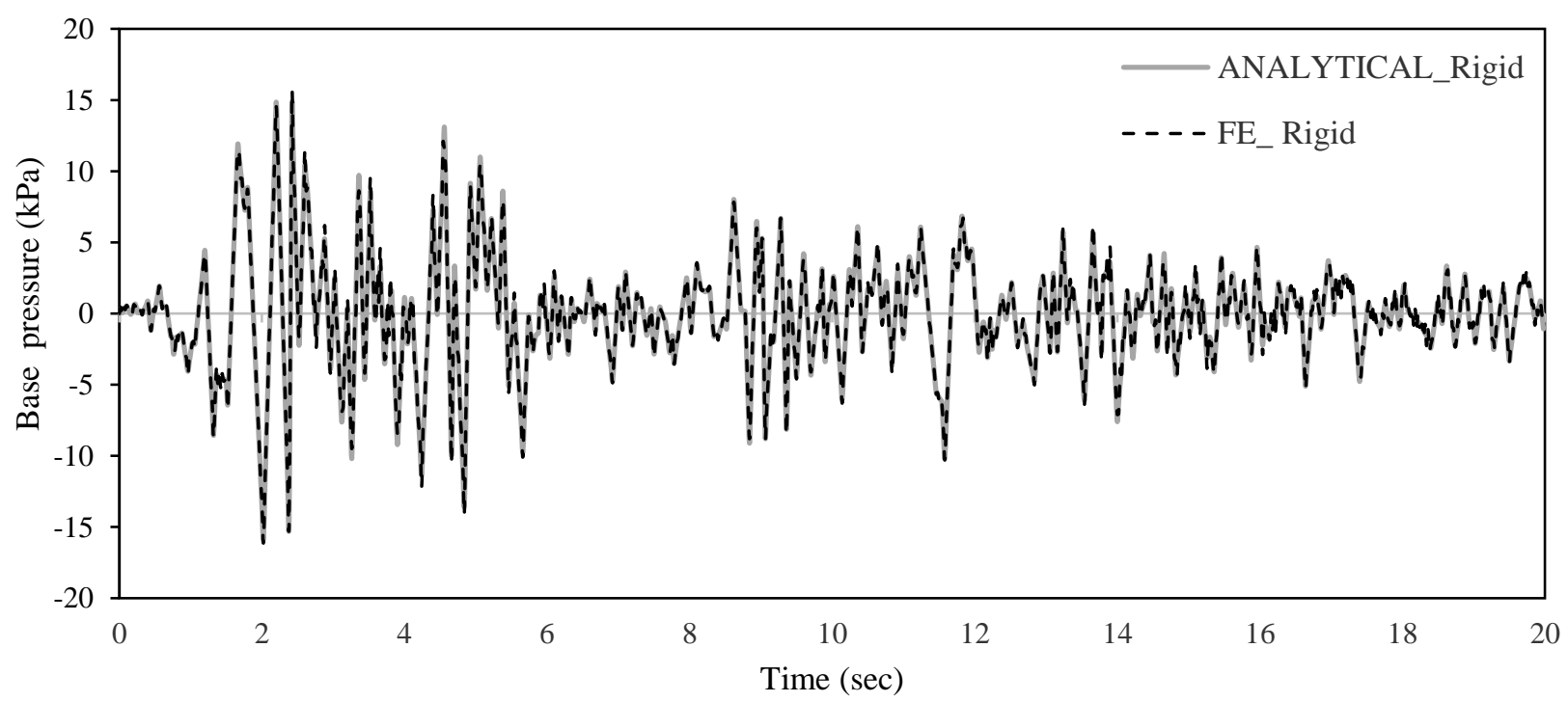

Figure 6.4 Time history impulsive pressure at the base ( $\mathrm{r}=\mathrm{R}, \phi=0, \mathrm{z}=0)$ 
According to Table 6.1, Figures 6.3 and 6.4, an ideal agreement between the FE and analytical results is observed. This verifies that the proposed FE model can be employed for the modeling of the liquid containing structures in this study.

Next, the accuracy of hydrodynamic pressure distribution on the wall is investigated by comparing the estimated FE hydrodynamic pressure with the one recommended by ACI 350.3-06. In ACI calculations, response modification factor, and mapped spectral acceleration $\left(\mathrm{S}_{\mathrm{S}}\right.$ and $\left.\mathrm{S}_{1}\right)$ are assumed to be $1.0,1.5 \mathrm{~g}$ and $0.6 \mathrm{~g}$, respectively. In addition, the damping ratios of impulsive and convective components are considered as $5 \%$ and $0.5 \%$, respectively. Figure 6.5 shows the hydrodynamic pressure distribution over the height of the tank for both flexible and rigid tank models.

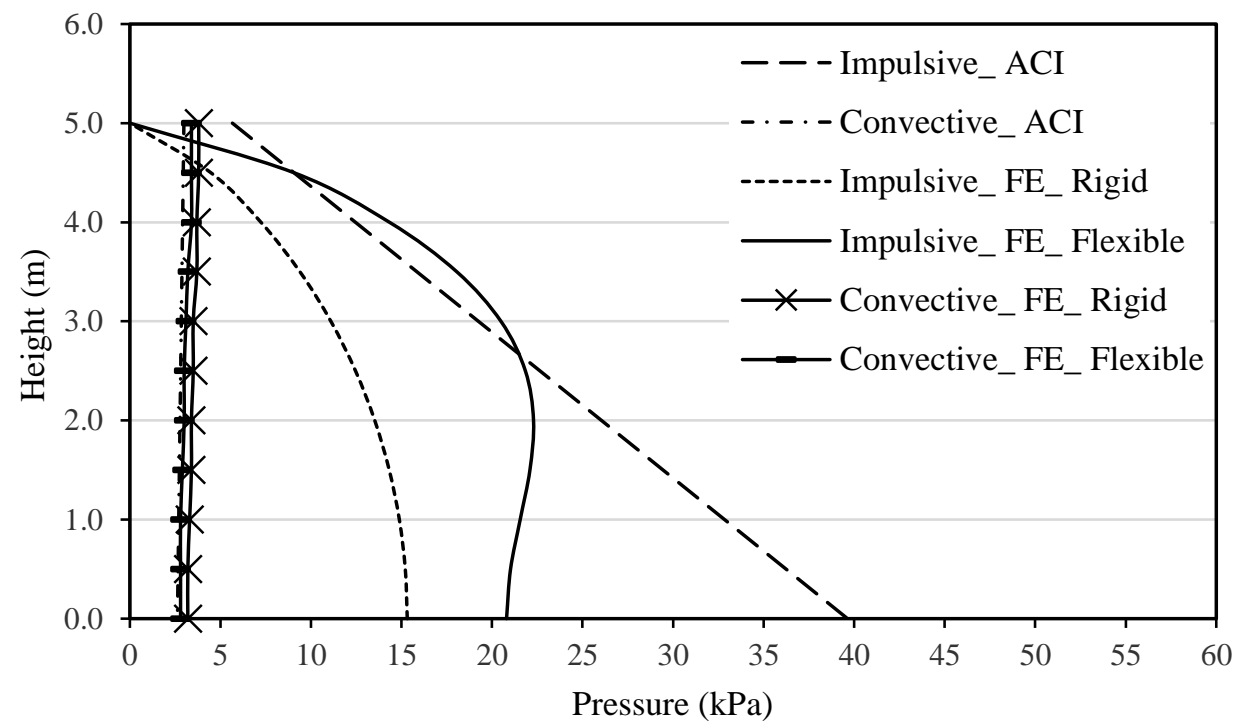

Figure 6.5 Hydrodynamic pressure distribution on the wall

As results in Figure 6.5 display, ACI 350.3-06 has some deficiencies in hydrodynamic pressure calculation. First, the impulsive pressure distribution proposed by ACI is not in a full agreement with FE results. ACI employs a linear distribution function to calculate the hydrodynamic pressure over the tank wall, and the impulsive pressure value is maximum at the base. Next, based on ACI, the pressure distribution on the tank wall is the same for both 
rigid and flexible walls, as well as fixed and hinged bases. As shown in Figure 6.5, the FE convective pressure is compatible with the values suggested by ACI, and furthermore the wall flexibility does not show a significant effect on the convective pressure.

To examine the effect of base fixity on the hydrodynamic pressure on the tank wall, the FE model with three different base fixities (fixed, hinged and flexible) is subjected to the horizontal component of El-Centro earthquake and the results are shown in Figure 6.6.

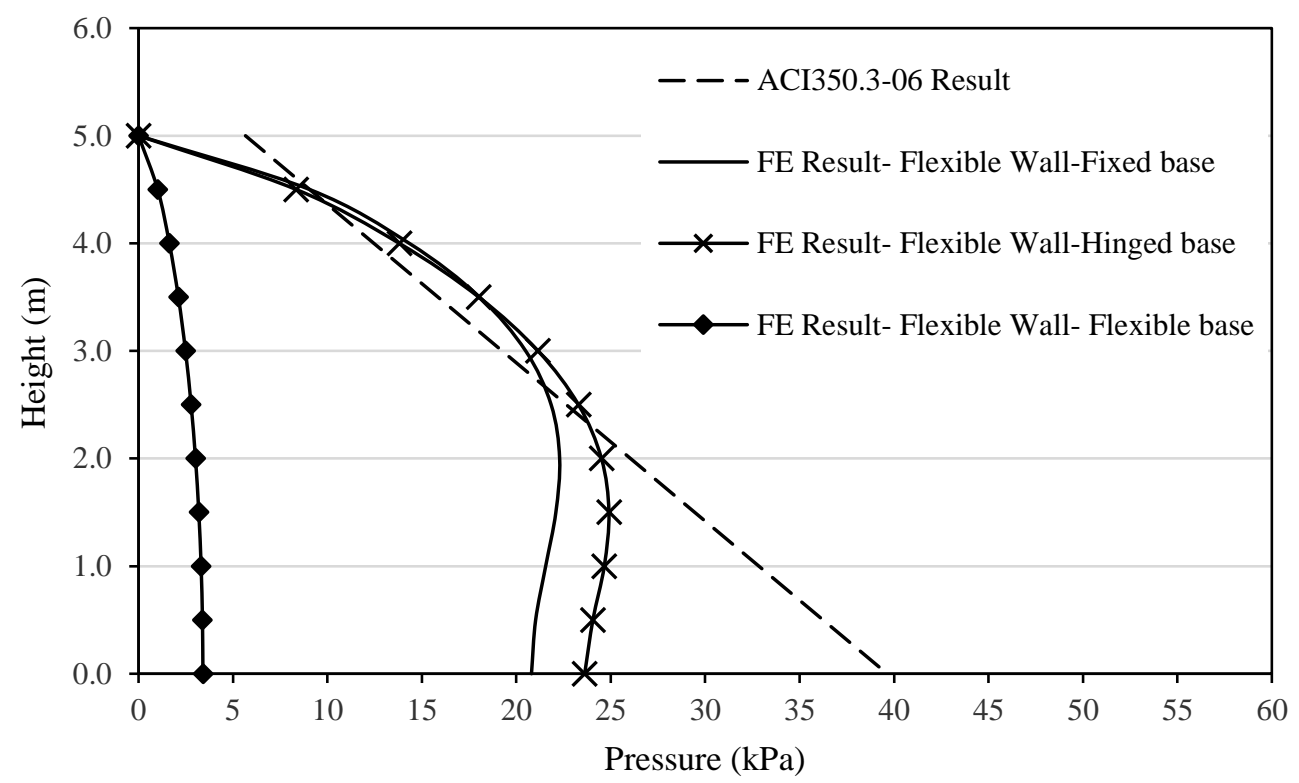

Figure 6.6 Impulsive hydrodynamic pressure distribution on the flexible tank wall for different base fixities

As Figure 6.6 displays, the impulsive pressure is amplified in the hinged base tank compared to the fixed one. However, ACI gives the same pressure value for both fixed and hinged base tanks. As a result, higher response values (internal forces and moments) are expected for the hinged base tanks near the mid-height of the wall due to higher hydrodynamic pressure (Moslemi, 2011). It can be concluded that the impulsive pressure at the base is overestimated by around $90 \%$ and $68 \%$ by ACI for the fixed and hinged tanks, respectively. As obvious from the figure, the impulsive pressure at the base is significantly higher in nonflexible base compared to the flexible base. Kianoush and Ghaemmaghami (2011) and 
Moslemi (2011) showed that impulsive and convective fundamental frequencies of such structures had significant difference and that the peak values of their impulsive and convective components of response did not happen at the same time. As a result, the dynamic response of the structure is usually assumed to be dominated by the impulsive component due to its higher contribution in total response and the big time lag between impulsive and convective peaks. In addition, they proved that the impulsive response did not change significantly considering the combined effect of vertical and horizontal seismic motions.

Based on the obtained results and previous studies, since the convective component has no significant effect on the total structural response, only the impulsive component of response is considered in the time-history analysis of the tanks in this study.

\subsection{Effect of earthquake frequency content on the dynamic behavior of circular ground supported tanks}

In this section, the dynamic behavior of ground supported LCS considering the effect of earthquake frequency content is investigated. For this purpose, three different seismic motions with different frequency content properties: Northridge (1994), El-Centro (1940), and SanFrancisco (1957) are applied to the FE models and time history response are attained. In this study, only the first 10 seconds of the records are used in time history analysis.

In this study, first the El-Centro record is scaled in such way that its peak ground acceleration reaches to $0.4 \mathrm{~g}$ in the horizontal direction where $\mathrm{g}$ is the ground acceleration and equals to $9.807 \mathrm{~m} / \mathrm{sec} 2$. Then, two other records are required to be scaled in such a way that all of them have the same value of Power index (Pa) (Housner, 1975).

To scale earthquake motions and intensity of motions, different indices have been suggested such as Arias intensity (Arias 1970), Power index (Housner 1975), and Spectrum intensity (Housner 1952), etc. The Power index is one of the most proper indices used for 
scaling the earthquake records. According to Housner's study (1975), characterizing the seismic motions by employing parameters basically corresponding to the shaking amplitude such as peak ground acceleration is not a reliable measure by itself. The exact representation of the earthquake record is not guaranteed by a single peak on an accelerogram. Housner (1975) defined a seismic intensity measurement by considering the average rate of buildup of the total energy per unit mass input to the structure. Housner proposed the Power index as the following equation (Eq. 6.10):

$P_{a}=\frac{E(D)}{D}=\frac{1}{D} \int_{t_{0}}^{t_{0}+D} a(t)^{2} d t$

where, $E(D)$ is the total energy input during time $D, D$ is the "significant duration" of the earthquake, $t_{0}$ is the time at the beginning of the strong shaking phase, and $a(t)$ is the base acceleration. As shown in Equation (6.10), the integral of the squared ground acceleration is proportional to the total input energy. It explains the average value of the squared acceleration over the significant interval between $t_{0}$ and $t_{0}+D$ representing the strong portion of the motion. Arias (1970) proposed an intensity includes the sum of the energies dissipated per unit of mass by a population of damped oscillators of all natural frequencies. The Arias intensity $(A I)$ equation can be calculated by Equation 6.11:

$A I=\frac{\pi}{2 g} \int_{0}^{t_{r}} a(t)^{2} d t$

where, $t_{r}$ is the total duration of the ground motion and $g$ is the acceleration due to gravity. In this study, the significant duration of motion proposed by Trifunac and Brady (1975) is used. The significant duration is defined as the interval between instants $t_{5}$ and $t_{95}$ at which 5\% and $95 \%$ of the total integral in Equation 6.11 is obtained. The significant duration is employed to take the whole accelerogram properties and define a continuous time interval during which the shaking may be considered as strong. Consequently, the seismic power can be calculated by the following equation (Eq. 6.12): 
$P_{a}=\frac{1}{t_{95}-t_{5}} \int_{t_{5}}^{t_{95}} a(t)^{2} d t$

The Arias intensity versus time for all earthquake records are indicated in Figure 6.7 and the properties of these scaled records are shown in Table 6.2.

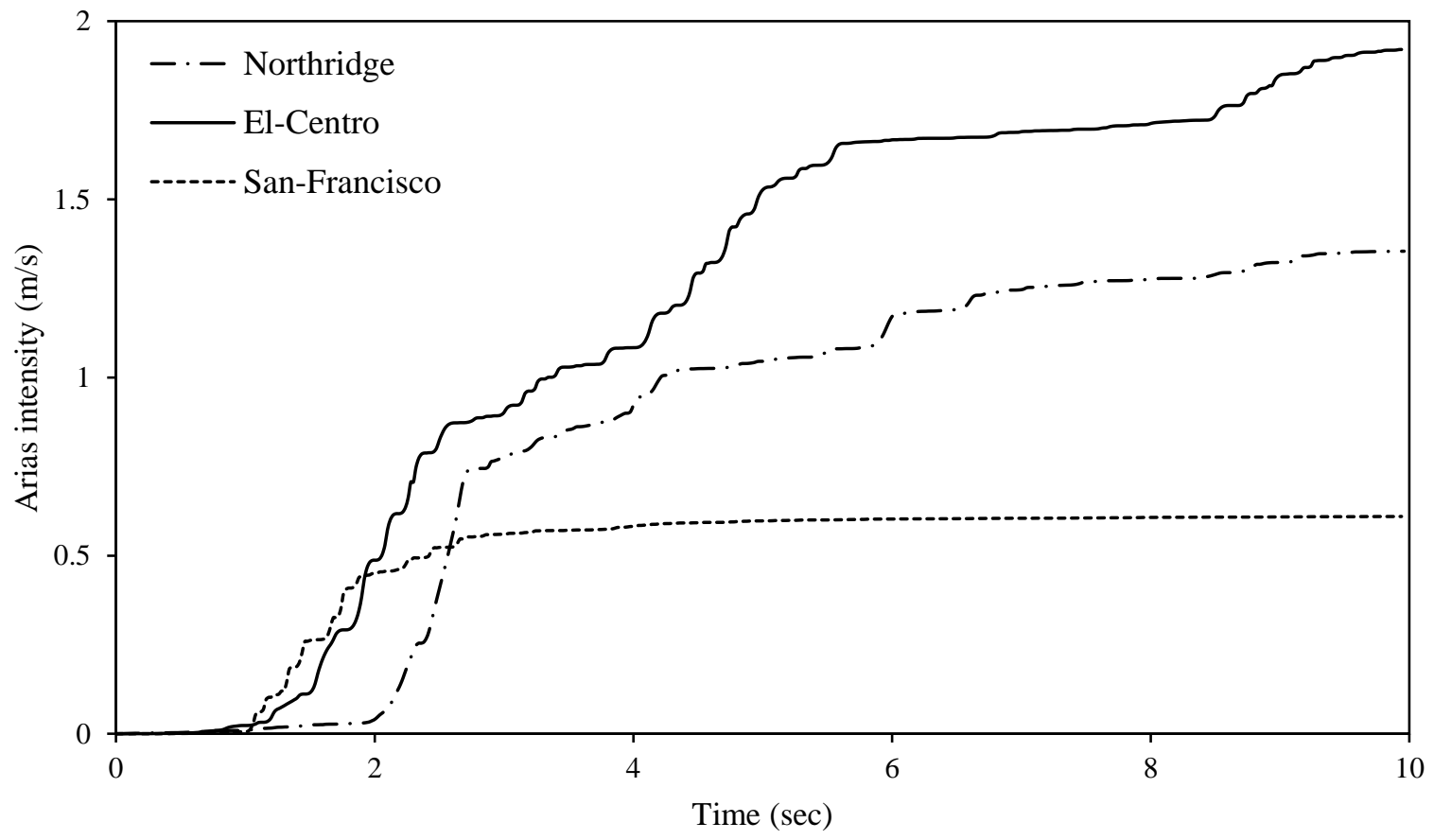

Figure 6.7 Arias Intensity versus time of the earthquake records (Adopted from Seismosoft, 2016)

Table 6.2 Characteristics of ground motions

\begin{tabular}{|c|c|c|c|c|c|c|c|}
\hline Earthquake & $\mathrm{t}_{5}(\mathrm{~s})$ & $\mathrm{t}_{95}(\mathrm{~s})$ & $\mathrm{D}(\mathrm{s})$ & $\begin{array}{c}\mathrm{P}_{\mathrm{a}} \\
\left(\mathrm{m}^{2} / \mathrm{s}^{4}\right)\end{array}$ & $\begin{array}{c}\text { PGA } \\
(\mathrm{g})\end{array}$ & $\begin{array}{c}\text { PGV } \\
(\mathrm{m} / \mathrm{s})\end{array}$ & Frequency \\
\hline Northridge & 2.12 & 9.14 & 7.02 & 1.12 & 0.885 & 1.734 & Low \\
\hline El-Centro & 1.63 & 13.25 & 11.62 & 1.13 & 0.318 & 0.366 & Intermediate \\
\hline San-Francisco & 1.18 & 4.15 & 2.97 & 1.13 & 0.111 & 0.045 & High \\
\hline
\end{tabular}

As shown in Figure 6.7, the initial slope of these three curves in the significant interval (D) verifies that all scaled records have the same level of Power. Moreover, the scaled seismic records are shown in Figure 6.8. 


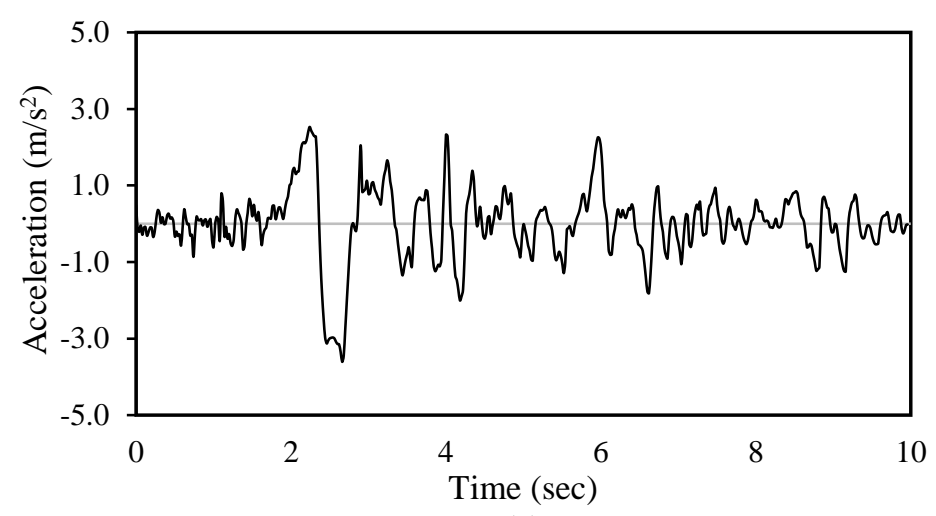

(a)

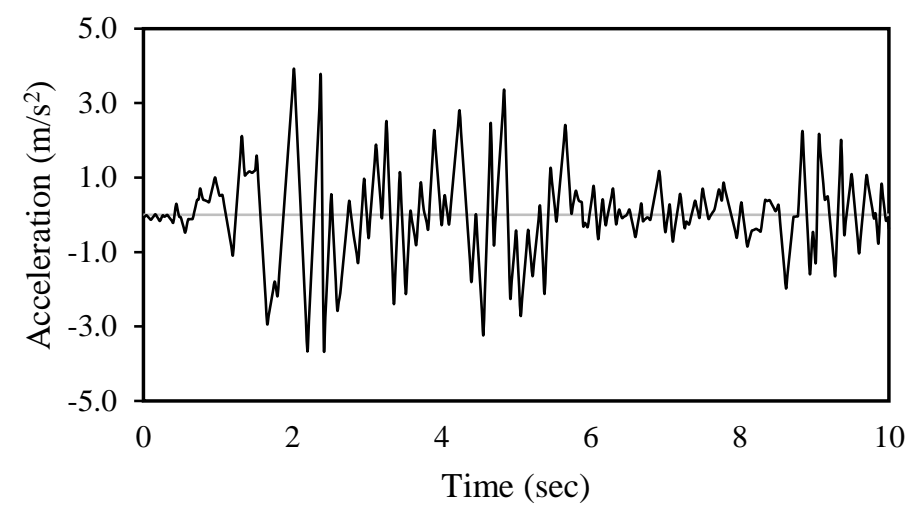

(b)

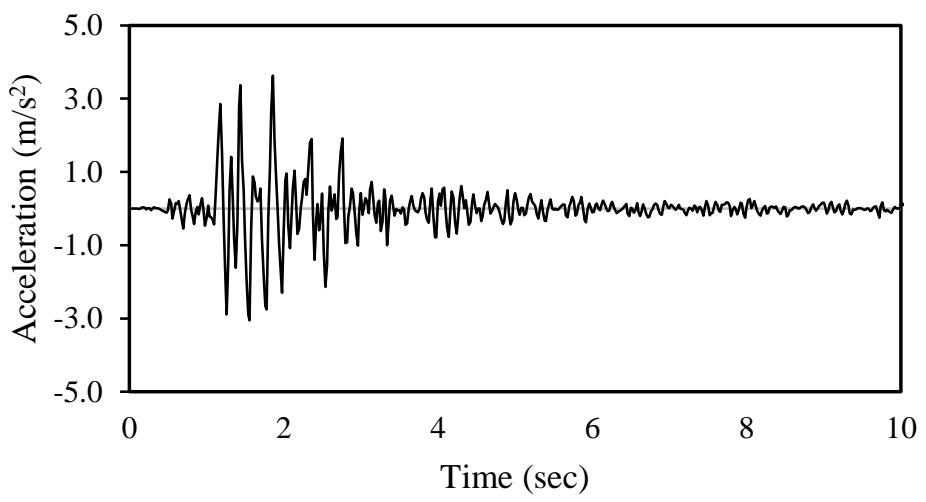

(c)

Figure 6.8 Scaled seismic records (horizontal component): a) 1994 Northridge, b) 1940 El-Centro, c) 1957 San-Francisco

The frequency content of earthquake records can be identified by the ratio of peak ground acceleration (PGA) to peak ground velocity (PGV). Seismic records are classified into three frequency categories: low, intermediate and high based on this ratio. When the ratio of PGA/PGV is less than 0.8 , between 0.8 and 1.2 , and more than 1.2 , the record is classified as low, intermediate and high frequency, respectively (Ghaemmaghami, 2010). As per this definition, San-Francisco has high-frequency content, while El-Centro and Northridge have intermediate and low-frequency contents, respectively.

For this section, two fixed base circular tanks with constant diameter of $40 \mathrm{~m}$ and thickness of $400 \mathrm{~mm}$ are modeled. Tank $3 \mathrm{~F}$ is simulated with wall height of $3.25 \mathrm{~m}$, liquid height of $3 \mathrm{~m}$ and Tank $6 \mathrm{~F}$ is $6.5 \mathrm{~m}$ tall with liquid height of $6 \mathrm{~m}$. Tank models (3F and $6 \mathrm{~F}$ ) are subjected to three scaled seismic records shown in Figure 6.8. In this study, only the 
impulsive component of response is investigated and the effect of convective term is ignored due to its negligible effect on the overall dynamic behavior of the tanks. Figure 6.9 shows the total base shear response of the tank $3 \mathrm{~F}$ subjected to scaled seismic records.

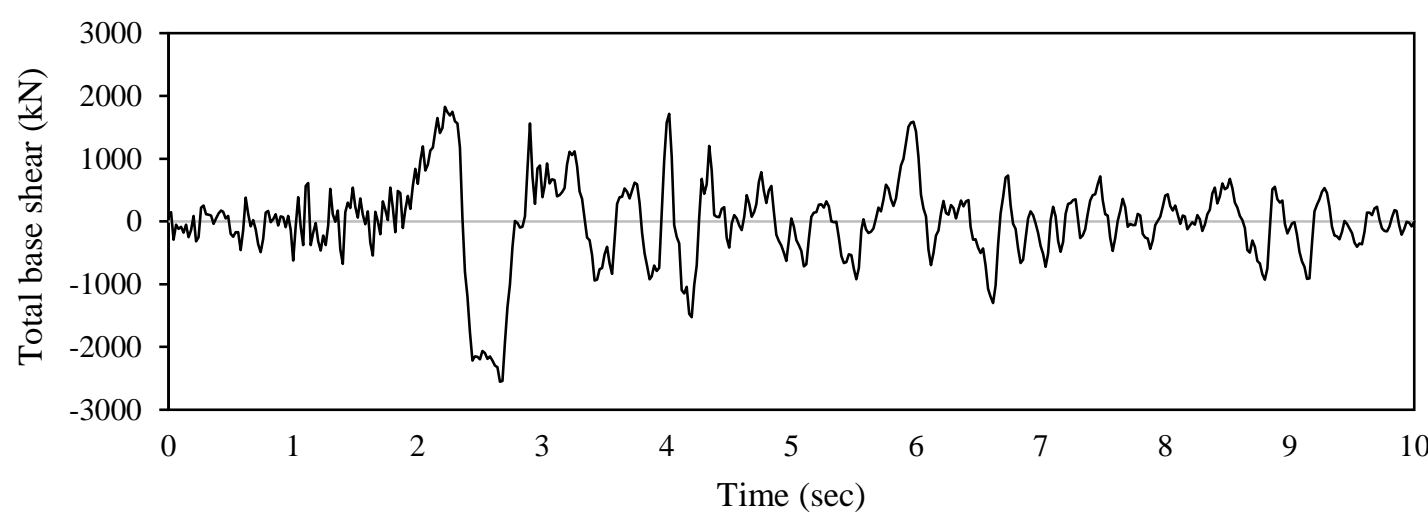

(a)

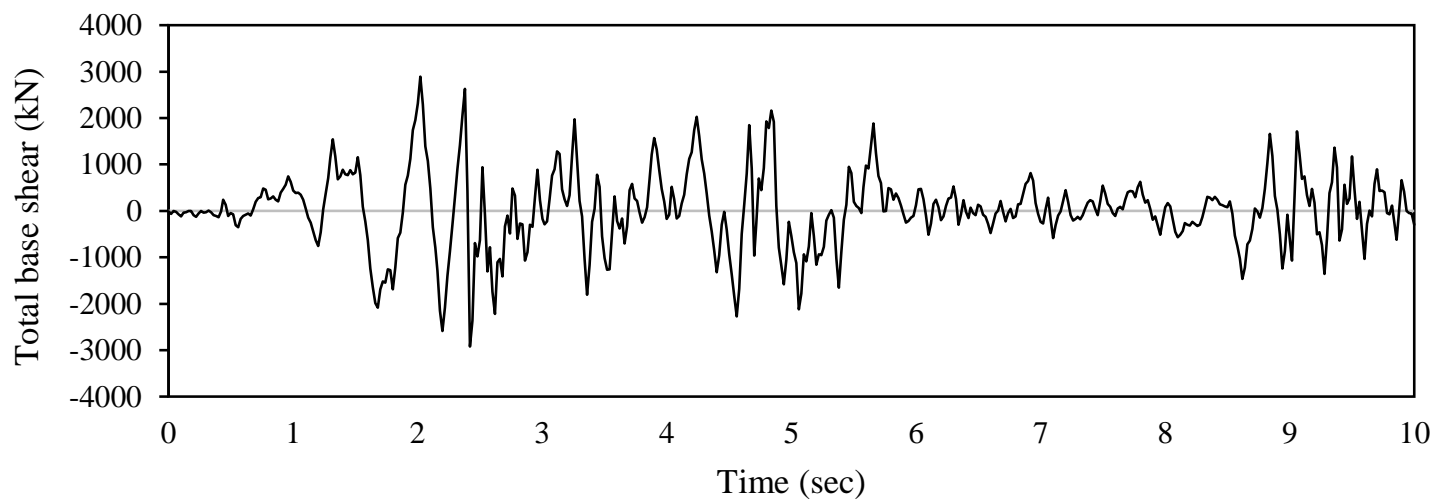

(b)

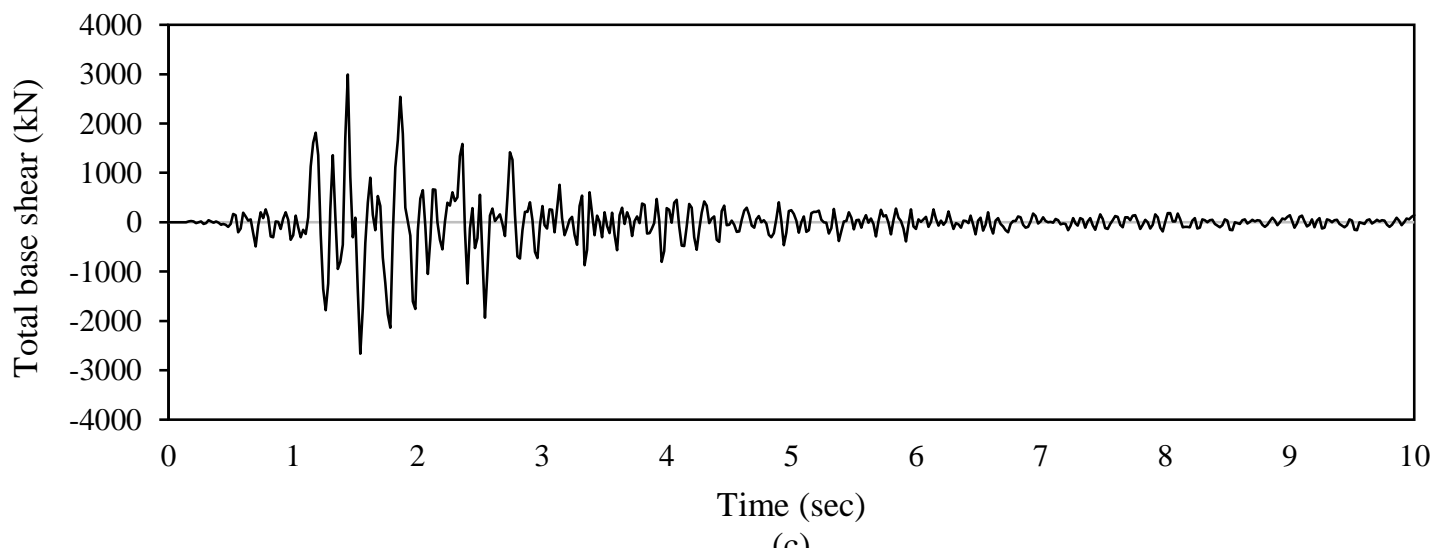

(c)

Figure 6.9 Time history of base shear response of the tank $3 \mathrm{~F}$ under different seismic motions; a) Northridge, b) El-Centro, c) San-Francisco 
In order to compare the FE results, the obtained peak finite element base shear values for three different records are normalized with respect to the highest response as presented in Figure 6.10.

(a)

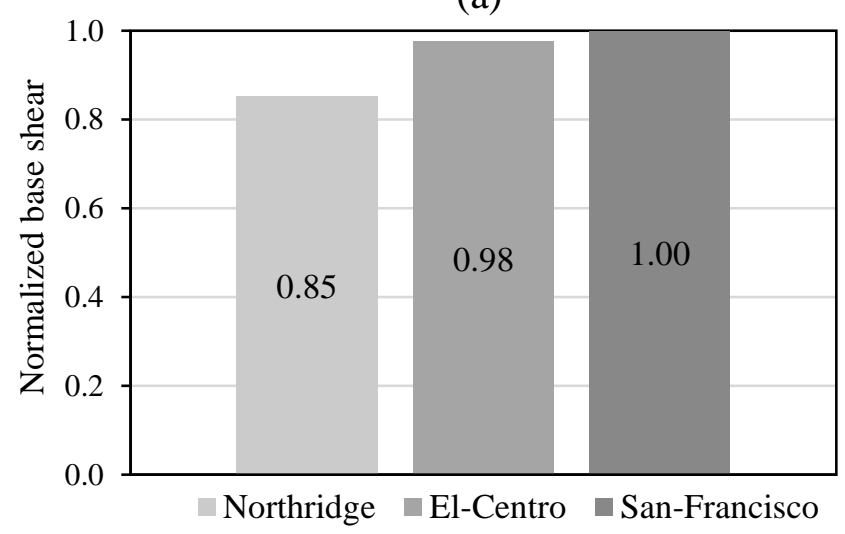

(b)

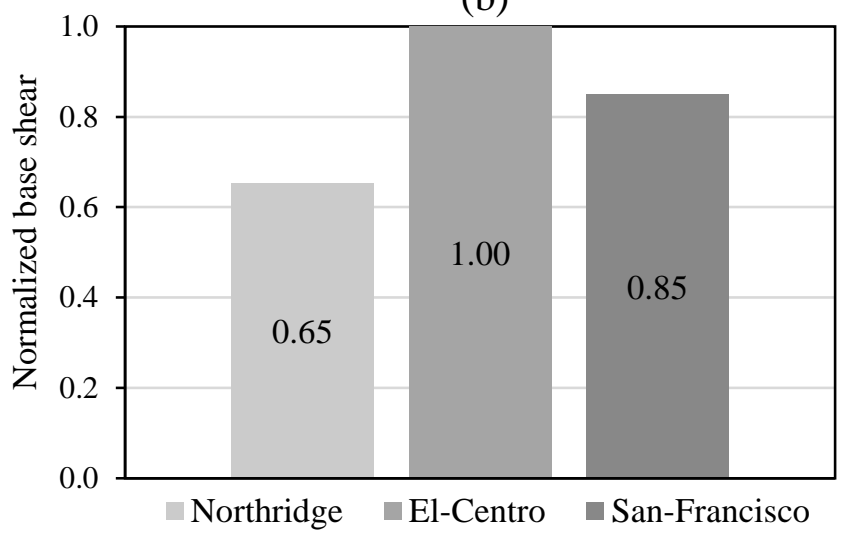

Figure 6.10 Normalized peak base shear corresponding to FE responses;

a) Tank $3 \mathrm{~F}, \mathrm{~b})$ Tank $6 \mathrm{~F}$

As per Figure 6.10-a, the highest response value for Tank 3F is obtained based on San Francisco earthquake which has the highest frequency content among all other records. In addition, the lowest response corresponds to the low frequency content record of Northridge. As shown in Figure 6.10-b, for Tank 6F, the response due to El-Centro with intermediate frequency content results in a higher total base shear compared to other three records. The results also show that Northridge with low frequency content shows the lower response value for both tank models. It is shown that the earthquake frequency content causes the base shear values to raise for both $3 \mathrm{~F}$ and $6 \mathrm{~F}$ tanks by $18 \%$ and $54 \%$ respectively. Consequently, the earthquake frequency content causes a substantial increment in time-domain peak response values. This result depends on similarity between frequency of structure and earthquake motion. 


\subsection{Tanks configurations and material properties}

\subsubsection{Design of concrete tank wall}

Seismic design of liquid-containing concrete structures is performed based on ACI 350.3-06 and ASCE/SEI 7-10. For design purposes, the effects of dead load, liquid weight, and seismic load are considered. Tank prototypes with various dimensions and base fixity conditions (flexible and nonflexible) are taken into consideration in this chapter.

According to ASCE/SEI 7-10, soil classification and site seismicity govern the response spectrum to be considered for design. As mentioned before, three different seismic motions are considered for time history analysis purpose. In this study, prototypes are designed for a high level of seismicity. In this study, the mapped spectral accelerations $\left(\mathrm{S}_{\mathrm{S}}\right.$ and $\left.\mathrm{S}_{1}\right)$ for Imperial Valley location are selected as $1.5 \mathrm{~g}$ and $0.6 \mathrm{~g}$, respectively as per ASCE/SEI 7-10. Moreover, a hard rock site classified as site class " $\mathrm{A}$ " is assumed for all models. The corresponding design response spectrum and definition of design spectral parameters are presented in Chapter3. Figure 6.11 indicates the design response spectrum based on the design spectral acceleration parameters for Imperial Valley location.

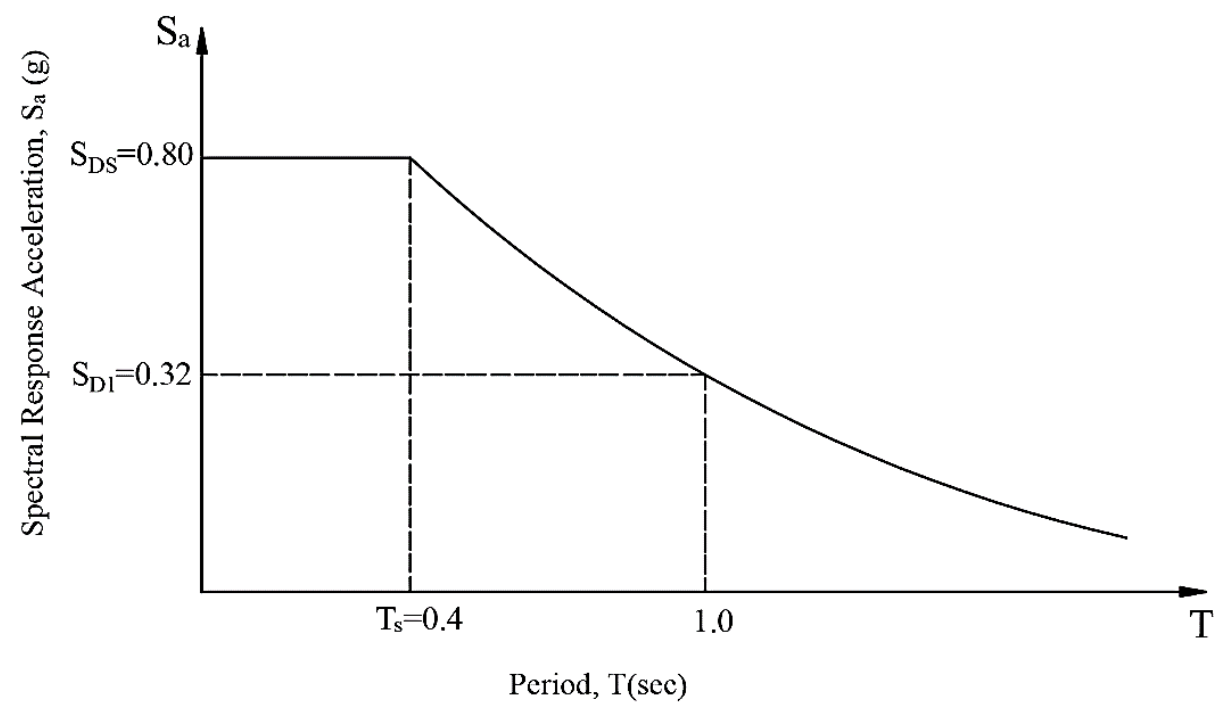

Figure 6.11 Design spectral response acceleration for Imperial Valley 
In order to obtain the strength and serviceability of the structure; first, the hydrostatic and hydrodynamic forces calculated as per ACI 350.3-06 are applied to the tank, and the design forces and bending moments are calculated using a linear static finite element analysis. Tank walls are then designed based on the provisions of ACI 350-06. In this chapter, all tanks are assumed to have a constant diameter of 40m. However, different wall heights: $3.25,6.5$ and 9m and liquid heights: 3, 6 and 9m are considered. According to ACI 350.3-06, the response modification factor for impulsive component $\left(\mathrm{R}_{\mathrm{i}}\right)$ is equal to 2.0 and 3.25 for nonflexible and anchored flexible base conditions, respectively. The detailed calculation of forces and moments and tank design for both flexible and nonflexible base tanks are shown in Appendices A and C, respectively. According to ACI 350.3-06, the flexible support is only used in tanks with prestressed walls. It should be noted that the purpose for considering normal reinforced concrete tanks with the flexible base condition in this study is only to see how differently they respond in comparison to non-flexible tanks under seismic loading.

As discussed in previous chapters, the seismic design of tanks is affected by the response modification factor $(\mathrm{R})$ defined in the code. Hafez (2012) proved that the reinforcement ratio affects the $\mathrm{R}$ factor value. Accordingly, each tank is designed with different values of $\mathrm{R}_{\mathrm{i}}$ ranging from 1 to 4 , and based on the maximum forces. All prototypes dimensions and properties including the reinforcement ratio are summarized in Table 6.3. In order to classify the models, each prototype is named specifically; as for example, in Tank 6F-R1; 6 refers to the liquid height which is $6.0 \mathrm{~m}, \mathrm{~F}$ refers to the fixed base condition, and R1 refers to $\mathrm{R}$ equal to 1 . 
Table 6.3 Summary of tank dimensions and reinforcement ratios based on the seismic design

\begin{tabular}{|c|c|c|c|c|c|c|}
\hline Tank Type & $\begin{array}{c}\text { Base } \\
\text { condition }\end{array}$ & $\begin{array}{c}\text { Wall } \\
\text { height (m) } \\
\mathrm{H}_{\mathrm{W}}\end{array}$ & $\begin{array}{c}\text { Liquid } \\
\text { height }(m) \\
\mathrm{H}_{\mathrm{L}}\end{array}$ & $\begin{array}{c}\text { Wall } \\
\text { thickness } \\
\mathrm{t}_{\mathrm{w}}(\mathrm{mm})\end{array}$ & $\begin{array}{c}\text { Vertical } \\
\text { reinforcement } \\
\text { ratio on each } \\
\text { face }(\rho) \%\end{array}$ & $\begin{array}{l}\text { Horizontal } \\
\text { reinforcement } \\
\text { ratio on each } \\
\text { face }(\rho) \%\end{array}$ \\
\hline 3F-R1 & \multirow{12}{*}{ Fixed } & \multirow{4}{*}{3.25} & \multirow{4}{*}{3.0} & 400 & 0.60 & 0.60 \\
\hline 3F-R2 & & & & 400 & 0.60 & 0.60 \\
\hline 3F-R3 & & & & 300 & 0.57 & 0.57 \\
\hline 3F-R4 & & & & 250 & 0.62 & 0.54 \\
\hline 6F-R1 & & \multirow{4}{*}{6.50} & \multirow{4}{*}{6.0} & 420 & 0.62 & 0.68 \\
\hline 6F-R2 & & & & 400 & 0.70 & 0.60 \\
\hline 6F-R3 & & & & 400 & 0.70 & 0.72 \\
\hline 6F-R4 & & & & 350 & 0.94 & 0.82 \\
\hline 9F-R1 & & \multirow{4}{*}{9.60} & \multirow{4}{*}{9.0} & 620 & 0.63 & 0.90 \\
\hline 9F-R2 & & & & 470 & 0.94 & 1.18 \\
\hline 9F-R3 & & & & 450 & 1.03 & 1.23 \\
\hline 9F-R4 & & & & 430 & 1.14 & 1.29 \\
\hline 3H-R1 & \multirow{12}{*}{ Hinged } & \multirow{4}{*}{3.25} & \multirow{4}{*}{3.0} & 400 & 0.60 & 0.60 \\
\hline $3 \mathrm{H}-\mathrm{R} 2$ & & & & 400 & 0.60 & 0.60 \\
\hline 3H-R3 & & & & 300 & 0.57 & 0.57 \\
\hline 3H-R4 & & & & 250 & 0.54 & 0.61 \\
\hline 6H-R1 & & \multirow{4}{*}{6.50} & \multirow{4}{*}{6.0} & 400 & 0.60 & 2.44 \\
\hline $6 \mathrm{H}-\mathrm{R} 2$ & & & & 400 & 0.60 & 1.01 \\
\hline 6H-R3 & & & & 400 & 0.60 & 1.01 \\
\hline 6H-R4 & & & & 350 & 0.58 & 1.15 \\
\hline 9H-R1 & & \multirow{4}{*}{9.60} & \multirow{4}{*}{9.0} & 600 & 0.63 & 1.18 \\
\hline 9H-R2 & & & & 500 & 0.62 & 1.42 \\
\hline 9H-R3 & & & & 450 & 0.61 & 1.57 \\
\hline 9H-R4 & & & & 450 & 0.61 & 1.57 \\
\hline 3FL-R3.25 & \multirow{9}{*}{ Flexible } & \multirow{3}{*}{3.25} & \multirow{3}{*}{3.0} & 250 & 0.53 & 1.05 \\
\hline 3FL-R4 & & & & 250 & 0.52 & 1.03 \\
\hline 3FL-R5 & & & & 250 & 0.50 & 1.01 \\
\hline 6FL-R3.25 & & \multirow{3}{*}{6.50} & \multirow{3}{*}{6.0} & 300 & 0.60 & 1.49 \\
\hline 6FL-R4 & & & & 300 & 0.60 & 1.48 \\
\hline 6FL-R5 & & & & 300 & 0.57 & 1.45 \\
\hline 9FL-R3.25 & & \multirow{3}{*}{9.60} & \multirow{3}{*}{9.0} & 400 & 0.60 & 1.70 \\
\hline 9FL-R4 & & & & 400 & 0.60 & 1.67 \\
\hline 9FL-R5 & & & & 400 & 0.59 & 1.64 \\
\hline
\end{tabular}

After designing wall tanks sections, the entire tank-liquid system is modeled in finite element software, ANSYS. As explained in Chapter 4, to perform the nonlinear analysis, the mathematical simulation proposed by Carrasquillo et al. (1981) is used to generate the concrete stress-strain curve. Moreover, the material properties are considered as follows: the compressive strength of concrete $\left(f_{c}^{\prime}\right)$ and yield strength of reinforcement $\left(f_{y}\right)$ are 30 and $400 \mathrm{MPa}$, 
respectively, moreover the modulus of elasticity of concrete $\left(E_{c}\right)$ and reinforcement $\left(E_{s}\right)$ are taken as 26 and $200 \mathrm{GPa}$, respectively. As described in Chapter 4, for time-history dynamic analysis, the general "Rayleigh" damping is employed to evaluate the damping properties of the RC tanks.

For this study, both nonflexible (fixed and hinged) and flexible base tanks are considered. In the finite element model, restraining the movement and rotation in the desired direction defines the tank support condition for the fixed and hinged bases. For flexible condition, springs are employed to model the effect of seismic cables and bearing pads. The linear stiffness of seismic cables and elastomeric bearing pad in both tangential and radial directions can be calculated as described in Chapter 4. The seismic cables and elastomeric bearing pad properties are shown in Table 6.4 and support stiffness calculation and detailed calculation of forces are described in Appendix D.

Table 6.4 Seismic cable and elastometic bearing pad details for flexible base tanks (Hafez, 2012)

\begin{tabular}{|c|c|c|c|c|c|c|}
\hline \multirow{2}{*}{ Tank Type } & \multicolumn{3}{|c|}{ Seismic cables } & \multicolumn{3}{c|}{ Elastomeric bearing pad } \\
\cline { 2 - 7 } & $\begin{array}{c}\text { Strand size } \\
(\mathrm{mm})\end{array}$ & $\begin{array}{c}\text { Spacing } \\
(\mathrm{m})\end{array}$ & $\begin{array}{c}\text { Elastic } \\
\text { modulus } \\
(\mathrm{GPa})\end{array}$ & $\begin{array}{c}\text { Width } \\
(\mathrm{mm})\end{array}$ & $\begin{array}{c}\text { Thickness } \\
(\mathrm{mm})\end{array}$ & $\begin{array}{c}\text { Shear } \\
\text { modulus } \\
(\mathrm{MPa})\end{array}$ \\
\hline 3FL & 15 & 5.0 & 200 & 250 & 25.4 & 0.345 \\
\hline 6FL & 15 & 2.0 & 200 & 300 & 25.4 & 0.345 \\
\hline 9FL & 15 & 0.9 & 200 & 400 & 25.4 & 0.345 \\
\hline
\end{tabular}

\subsubsection{Applying earthquake ground motions}

In order to eliminate the effect of earthquake intensity, the seismic accelerations are required to be normalized. In normalization process, first the ground acceleration data are divided by the peak seismic ground acceleration, then the acceleration data are maximized or minimized to reach a single PGA. The calibration is performed to create an elastic spectral response similar to design spectrum given in the code. The pseudo-acceleration response 
spectra with adjusted PGAs for El-Centro record corresponding to the different tank wall hieghts $(3.25,6.5$, and 9.6m) are shown in Figure 6.12.

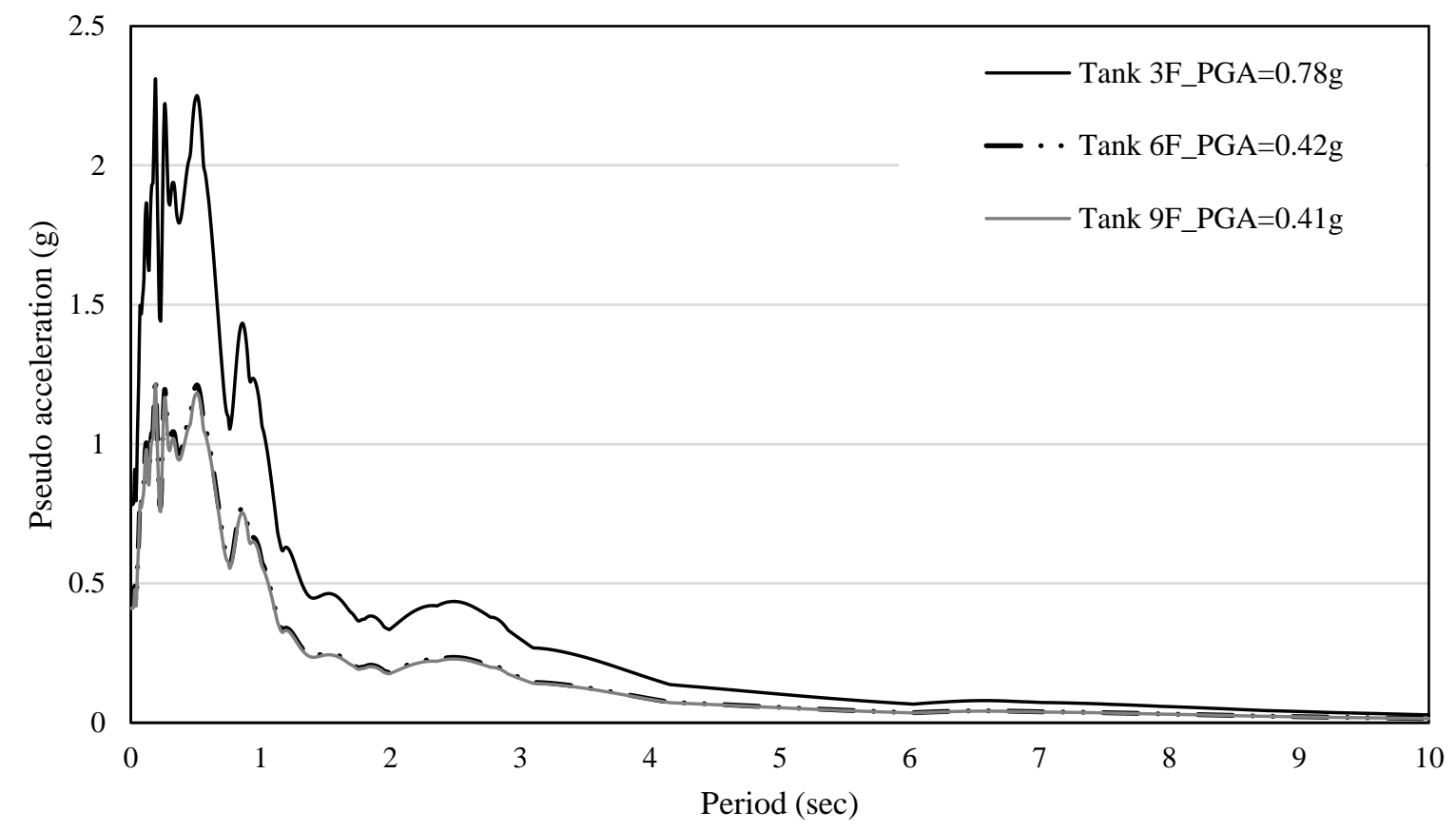

Figure 6.12 Pseudo acceleration response spectra for El-Centro

As shown in Figure 6.12, the El-Centro record is required to be scaled up and down during the calibration process. To balance the differences between the seismic records including the magnitude, frequency content, PGA and PGV, design spectral acceleration, and fundamental period of structure, the normalization procedure is performed. Table 6.5 displays the normalized record set for two seismic records (El-Centro and San-Francisco), tank sizes and base fixity. 
Table 6.5 Normalized earthquake records

\begin{tabular}{|c|c|c|c|c|c|c|}
\hline \multirow[b]{2}{*}{ Record } & \multicolumn{2}{|c|}{ Original } & \multirow{2}{*}{$\begin{array}{c}\text { Base } \\
\text { Condition }\end{array}$} & \multirow{2}{*}{$\begin{array}{l}\text { Tank } \\
\text { Height } \\
\text { (m) }\end{array}$} & \multicolumn{2}{|c|}{ Calibrated } \\
\hline & $\begin{array}{c}\text { PGA } \\
(\mathrm{g})\end{array}$ & $\begin{array}{l}\mathrm{PGV} \\
(\mathrm{cm} / \mathrm{s})\end{array}$ & & & $\begin{array}{c}\text { PGA } \\
(\mathrm{g})\end{array}$ & $\begin{array}{l}\mathrm{PGV} \\
(\mathrm{cm} / \mathrm{s})\end{array}$ \\
\hline \multirow{6}{*}{ El-Centro } & \multirow{6}{*}{0.318} & \multirow{6}{*}{36.60} & \multirow{3}{*}{ Nonflexible } & 3.25 & 0.78 & 89.66 \\
\hline & & & & 6.50 & 0.42 & 48.28 \\
\hline & & & & 9.60 & 0.41 & 47.12 \\
\hline & & & \multirow{3}{*}{ Flexible } & 3.25 & 0.36 & 20.70 \\
\hline & & & & 6.50 & 0.34 & 19.54 \\
\hline & & & & 9.60 & 0.32 & 18.40 \\
\hline \multirow{6}{*}{ San-Francisco } & \multirow{6}{*}{0.111} & \multirow{6}{*}{4.579} & \multirow{3}{*}{ Nonflexible } & 3.25 & 0.65 & 26.63 \\
\hline & & & & 6.50 & 0.46 & 18.85 \\
\hline & & & & 9.60 & 0.40 & 16.38 \\
\hline & & & \multirow{3}{*}{ Flexible } & 3.25 & 0.42 & 34.41 \\
\hline & & & & 6.50 & 0.45 & 36.87 \\
\hline & & & & 9.60 & 0.49 & 40.15 \\
\hline \multirow{6}{*}{ Northridge } & \multirow{6}{*}{0.885} & \multirow{6}{*}{173.4} & \multirow{3}{*}{ Nonflexible } & 3.25 & 0.80 & 156.30 \\
\hline & & & & 6.50 & 0.72 & 140.70 \\
\hline & & & & 9.60 & 0.70 & 136.80 \\
\hline & & & \multirow{3}{*}{ Flexible } & 3.25 & 0.59 & 115.30 \\
\hline & & & & 6.50 & 0.61 & 119.21 \\
\hline & & & & 9.60 & 0.60 & 117.26 \\
\hline
\end{tabular}

\subsection{Results of time-history FE analysis}

This section presents the nonlinear time-history analysis results of flexible and nonflexible base conditions. In addition, the R-values currently being used in practice is verified against the results of FE analysis.

As previously discussed, the crack width usually controls the design of tank walls. Previous studies on the seismic behavior of liquid containing structures have shown that in most cases cracking and leakage starts as soon as the reinforcement yields (Sadjadi 2009). Since the earthquake load is of transient nature being applied in a very short period of time, the reinforcement stress could reach the yield strength at certain locations without the structural integrity of the tank being compromised. Hence, the R-value should be estimated at first reinforcement yielding in case of an earthquake excitation.

Tanks 3, 6 and 9 (3, 6, and 9 tall, respectively) are designed under hydrostatic and hydrodynamic loading for different $\mathrm{R}$-values. The maximum reinforcement stress is 
determined in the tanks under horizontal hydrostatic plus hydrodynamic pressure. The reinforcement yield stress (corresponding to the yield strain of $\varepsilon_{y}=0.002$ ) is then used to determine the corresponding R-value.

Figures 6.13 to 6.15 demonstrate the R-values assumed in tank design versus the corresponding total strain of rebar in the tanks under all El-Centro, San-Francisco, and Northridge records. Three base fixity conditions are considered in this analysis; Fixed, Hinged, and Flexible.

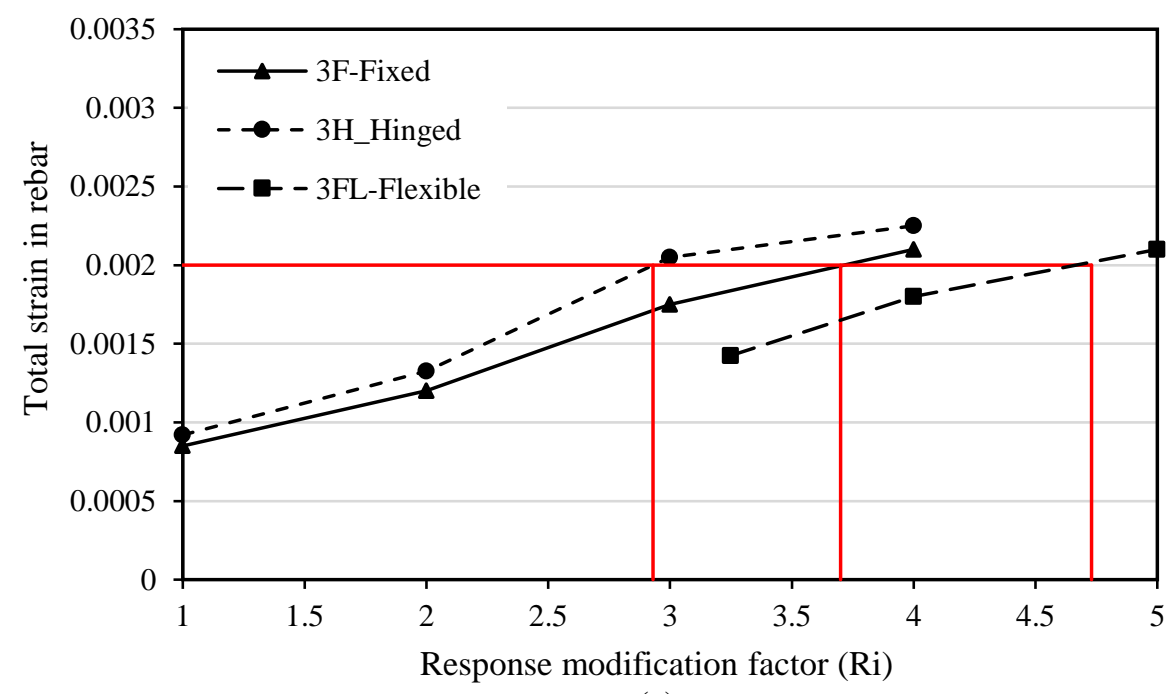

(a)

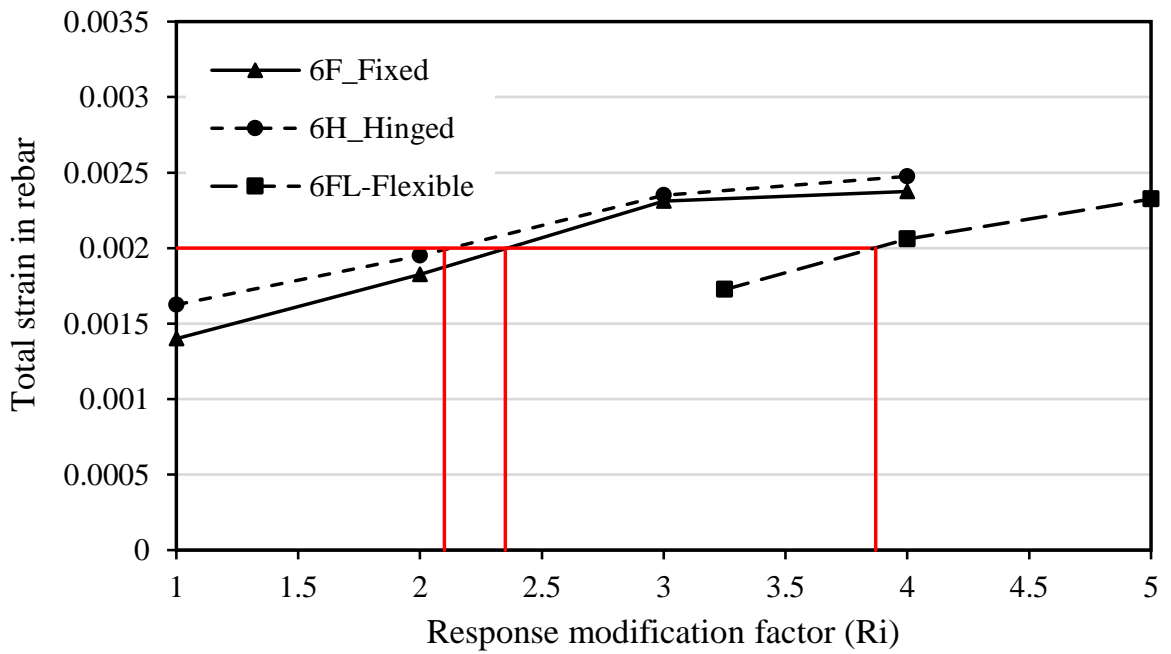

(b) 


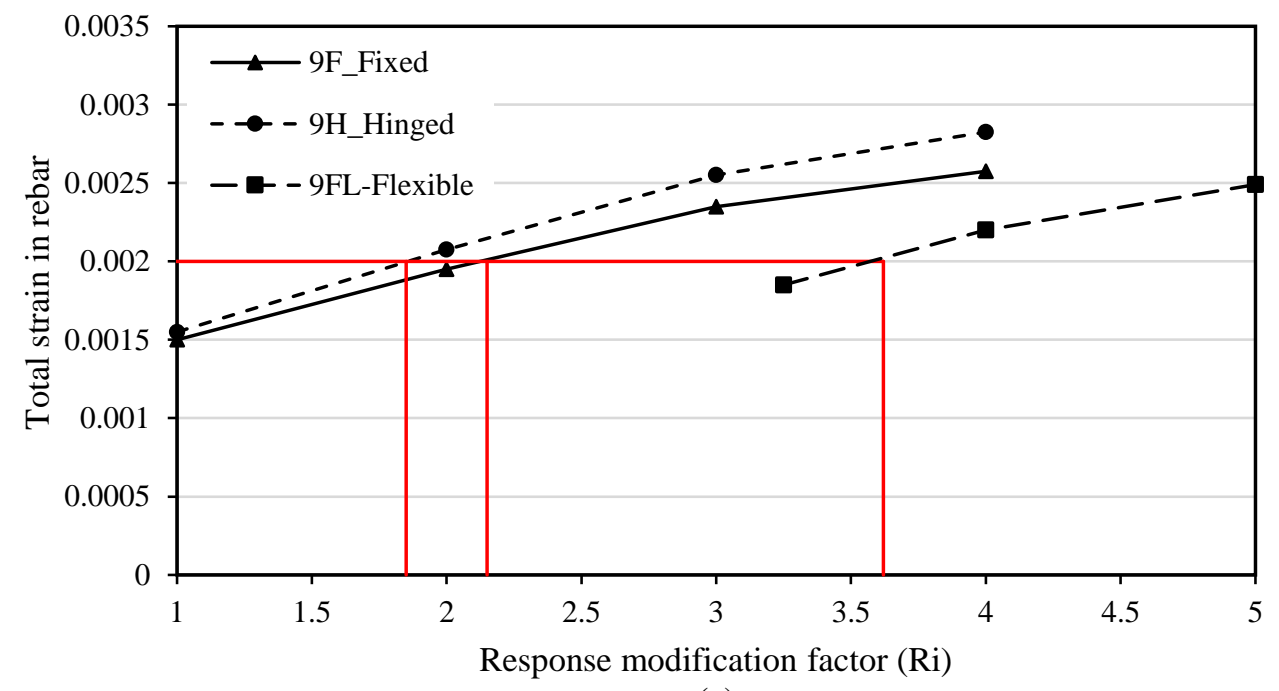

(c)

Figure 6.13 Effect of reinforcement strain on response modification factor under ElCentro record; a) $\mathrm{H}=3.25 \mathrm{~m}$, b) $\mathrm{H}=6.5 \mathrm{~m}$, c) $\mathrm{H}=9.6 \mathrm{~m}$

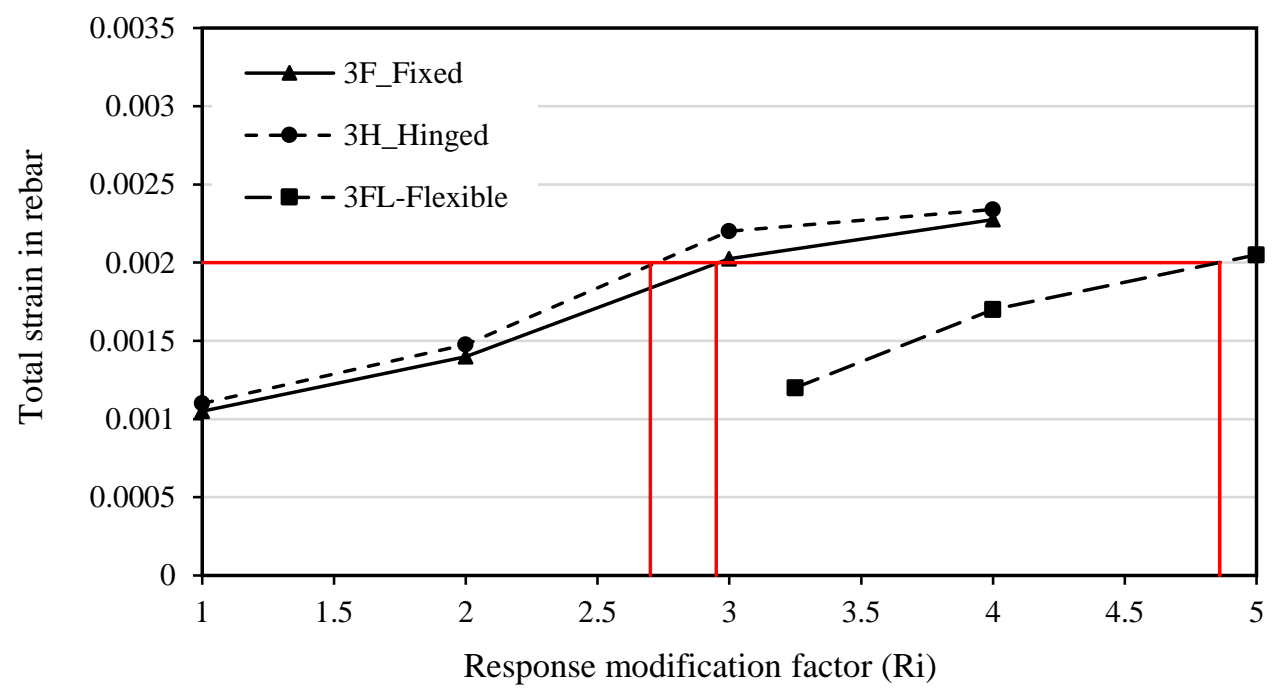

(a)

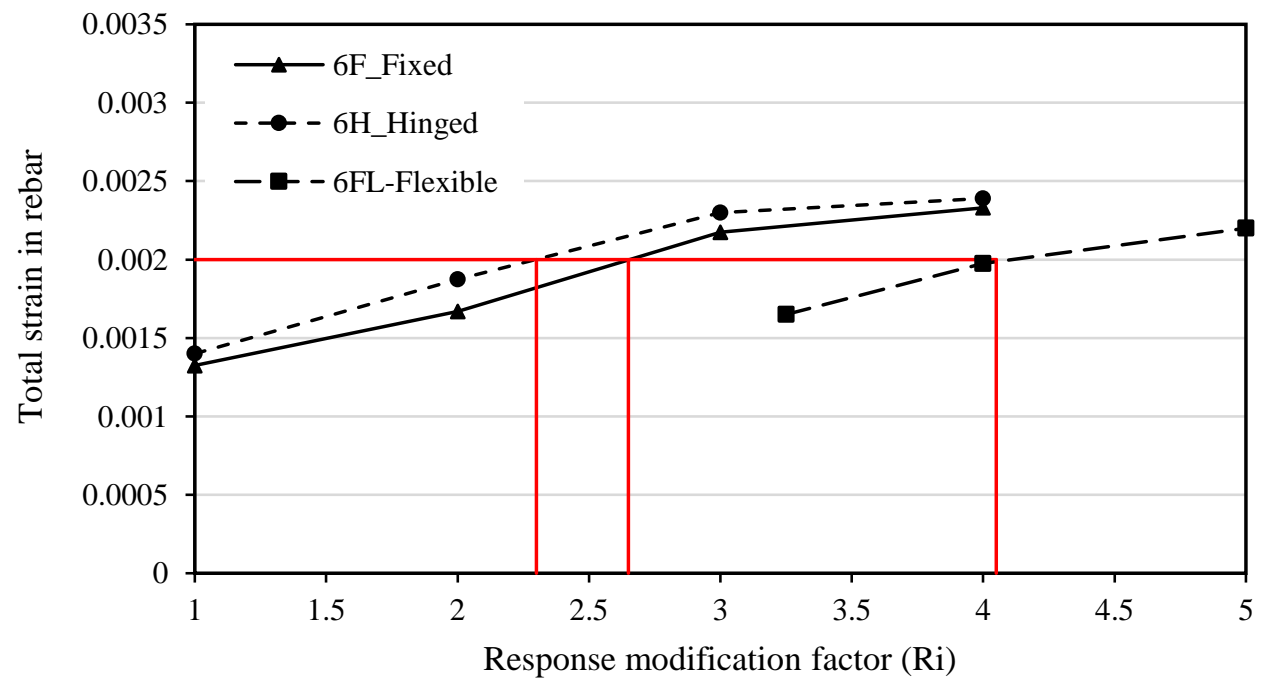

(b) 


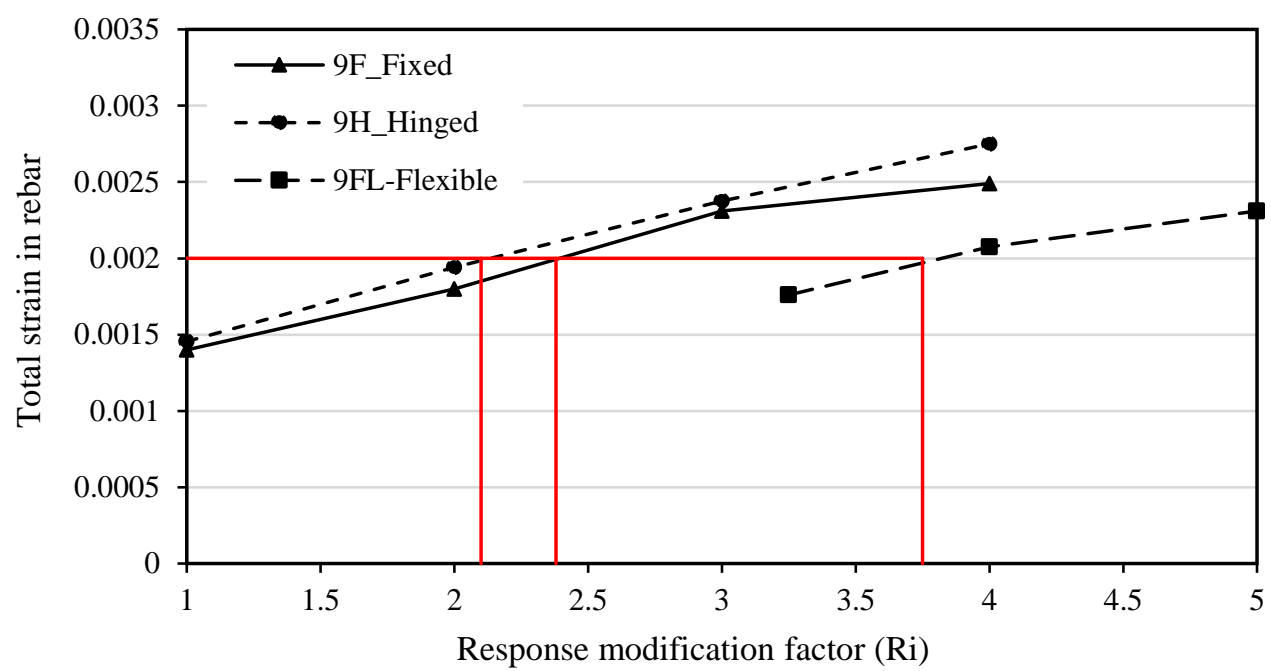

(c)

Figure 6.14 Effect of reinforcement strain on response modification factor under SanFrancisco record; a) $\mathrm{H}=3.25 \mathrm{~m}, \mathrm{~b}$ ) $\mathrm{H}=6.5 \mathrm{~m}, \mathrm{c}) \mathrm{H}=9.6 \mathrm{~m}$

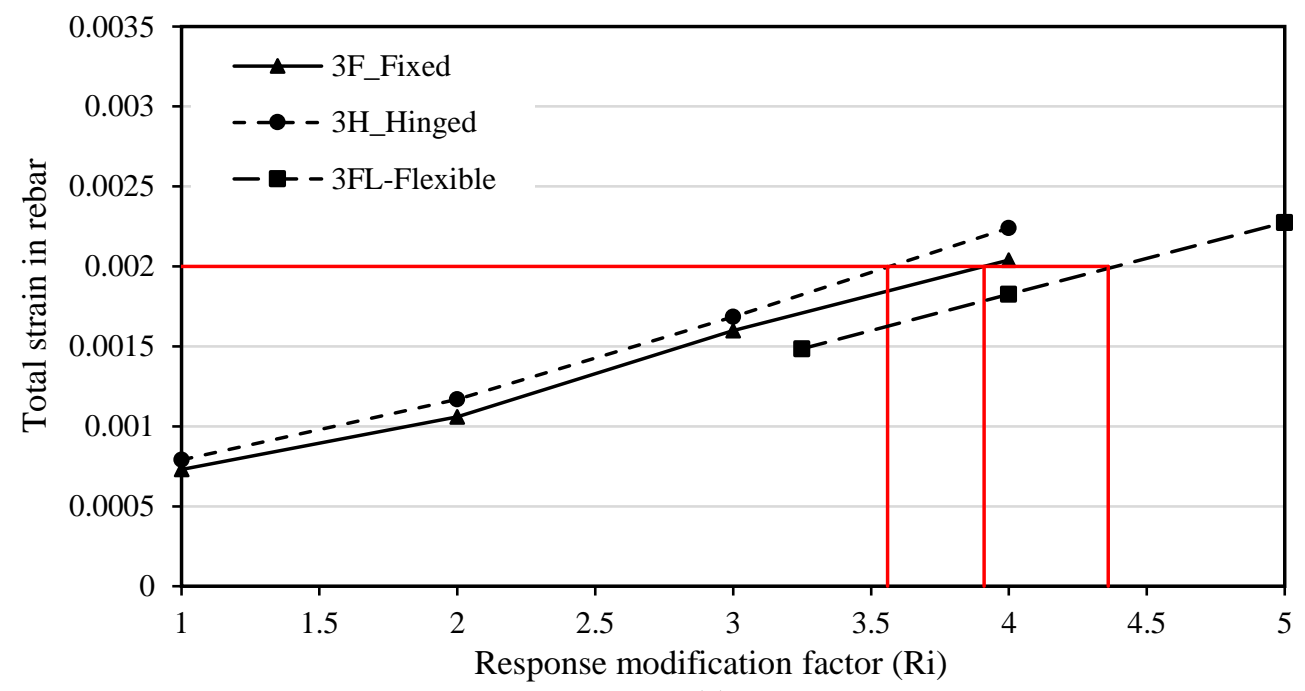

(a)

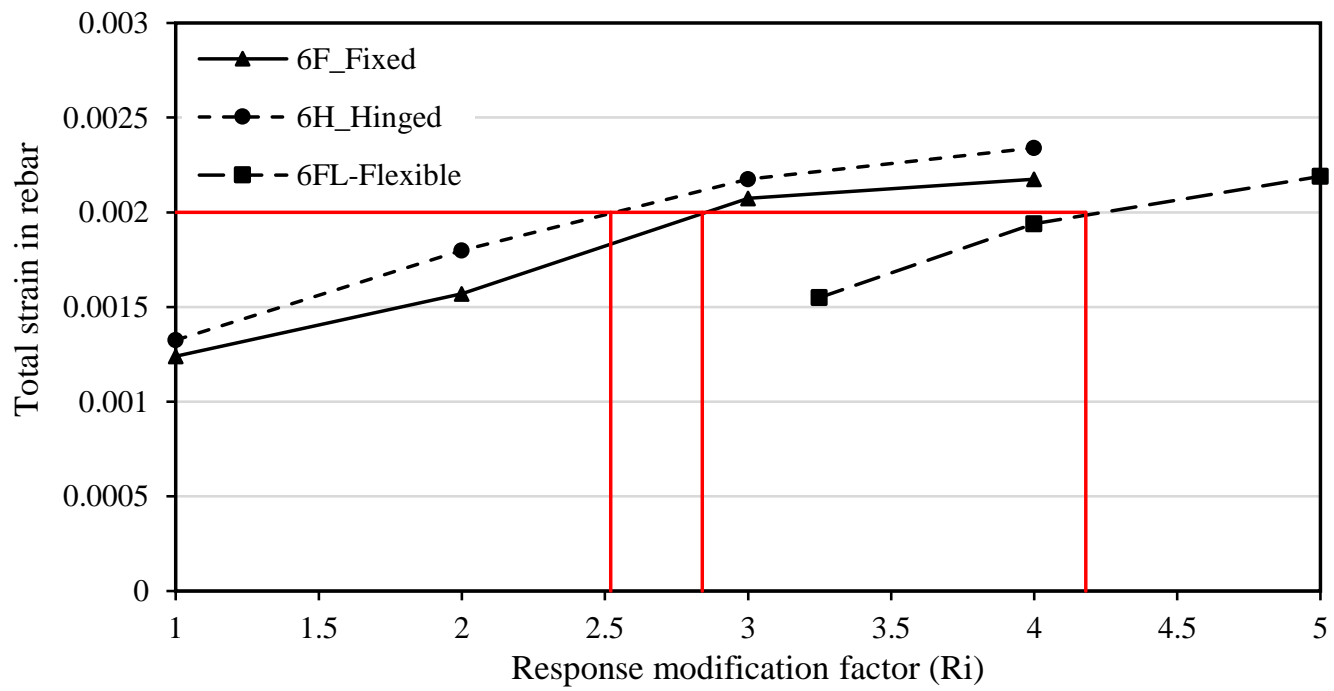

(b) 


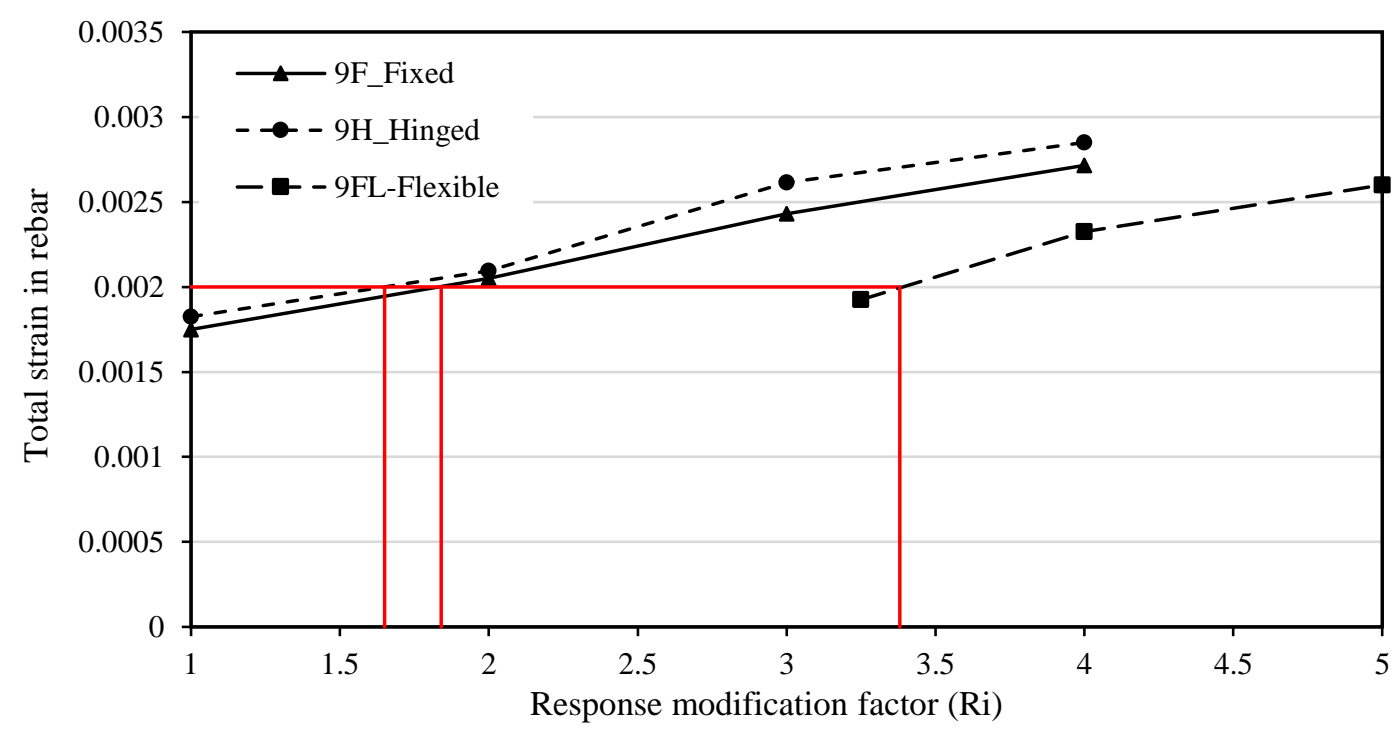

(c)

Figure 6.15 Effect of reinforcement strain on response modification factor under Northridge record; a) $\mathrm{H}=3.25 \mathrm{~m}, \mathrm{~b}) \mathrm{H}=6.5 \mathrm{~m}, \mathrm{c}) \mathrm{H}=9.6 \mathrm{~m}$

The R-values corresponding to the first reinforcement yield is summarized in Table 6.6 for nonflexible and flexible base tanks.

Table 6.6 Response modification factors from FE analysis

\begin{tabular}{|c|c|c|c|c|c|c|}
\hline Tank Type & $\begin{array}{c}\text { Tank } \\
\text { Height (m) }\end{array}$ & $\begin{array}{c}\text { Liquid } \\
\text { Height (m) }\end{array}$ & $\begin{array}{c}\text { Wall } \\
\text { Thickness } \\
\left(\mathrm{t}_{\mathrm{w}}\right)\end{array}$ & $\begin{array}{c}\text { Base } \\
\text { Condition }\end{array}$ & Record & $\mathrm{R}_{\mathrm{i}}$ \\
\hline $3 \mathrm{~F}$ & 3.25 & 3.0 & 300 & \multirow{3}{*}{ Fixed } & \multirow{9}{*}{ El-Centro } & 3.70 \\
\hline $6 \mathrm{~F}$ & 6.50 & 6.0 & 400 & & & 2.35 \\
\hline $9 \mathrm{~F}$ & 9.60 & 9.0 & 470 & & & 2.15 \\
\hline $3 \mathrm{H}$ & 3.25 & 3.0 & 400 & \multirow{3}{*}{ Hinged } & & 2.93 \\
\hline $6 \mathrm{H}$ & 6.50 & 6.0 & 400 & & & 2.10 \\
\hline $9 \mathrm{H}$ & 9.60 & 9.0 & 500 & & & 1.85 \\
\hline $3 \mathrm{FL}$ & 3.25 & 3.0 & 250 & \multirow{3}{*}{ Flexible } & & 4.73 \\
\hline $6 \mathrm{FL}$ & 6.50 & 6.0 & 300 & & & 3.87 \\
\hline 9FL & 9.60 & 9.0 & 400 & & & 3.62 \\
\hline $3 \mathrm{~F}$ & 3.25 & 3.0 & 300 & \multirow{3}{*}{ Fixed } & \multirow{9}{*}{ San-Francisco } & 2.95 \\
\hline $6 \mathrm{~F}$ & 6.50 & 6.0 & 400 & & & 2.65 \\
\hline $9 \mathrm{~F}$ & $\begin{array}{l}9.60 \\
\end{array}$ & 9.0 & 470 & & & 2.38 \\
\hline $3 \mathrm{H}$ & 3.25 & 3.0 & 400 & \multirow{3}{*}{ Hinged } & & 2.70 \\
\hline $6 \mathrm{H}$ & 6.50 & 6.0 & 400 & & & 2.30 \\
\hline $9 \mathrm{H}$ & 9.60 & 9.0 & 500 & & & 2.10 \\
\hline $3 \mathrm{FL}$ & 3.25 & 3.0 & 250 & \multirow{3}{*}{ Flexible } & & 4.86 \\
\hline $6 \mathrm{FL}$ & 6.50 & 6.0 & 300 & & & 4.05 \\
\hline 9FL & 9.60 & 9.0 & 400 & & & 3.75 \\
\hline
\end{tabular}




\begin{tabular}{|c|c|c|c|c|c|c|}
\hline $3 \mathrm{~F}$ & 3.25 & 3.0 & 300 & \multirow{3}{*}{ Fixed } & \multirow{9}{*}{ Northridge } & 3.91 \\
\hline $6 \mathrm{~F}$ & 6.50 & 6.0 & 400 & & & 2.84 \\
\hline $9 \mathrm{~F}$ & 9.60 & 9.0 & 470 & & & 1.84 \\
\hline $3 \mathrm{H}$ & 3.25 & 3.0 & 400 & \multirow{3}{*}{ Hinged } & & 3.56 \\
\hline $6 \mathrm{H}$ & 6.50 & 6.0 & 400 & & & 2.52 \\
\hline $9 \mathrm{H}$ & 9.60 & 9.0 & 500 & & & 1.65 \\
\hline $3 \mathrm{FL}$ & 3.25 & 3.0 & 250 & \multirow{3}{*}{ Flexible } & & 4.36 \\
\hline $6 \mathrm{FL}$ & 6.50 & 6.0 & 300 & & & 4.18 \\
\hline 9FL & 9.60 & 9.0 & 400 & & & 3.38 \\
\hline
\end{tabular}

As per the results presented in Table 6.6, in flexible tanks, the reinforcement yields at higher assigned R-values in comparison to the fixed and hinged base tanks. Based on the timehistory analysis, the obtained results of Tank 3F (Fixed) and 3H (Hinged) are compatible with the results of Kianoush and Ghaemmaghami (2011). They proved that higher frequency earthquakes result in higher impulsive response in shallower tank models. In this study, Tank 3 can be categorized as a shallow tank and the total base shear of Tanks 3F, 3H, and 3FL is greater due to San-Francisco high frequency content earthquake compared to the other seismic records. As expected, R-values of fixed, hinged, and flexible base tanks with $3.25 \mathrm{~m}$ height under San-Francisco is lower than El-Centro and Northridge. This is only observed in the shallow tank (Tank 3); whereas, the intermediate frequency content amplified the response of Tank 6 and 9, and assigned R-values of these three tanks are lower under El-Centro earthquake in comparison to Northridge and San-Francisco earthquakes.

To show the effect of tank size on the R-value for nonflexible and flexible base tank supports, the R-values versus different $\left(\mathrm{D} / \mathrm{H}_{\mathrm{L}}\right)$ are presented in Figure 6.16. 


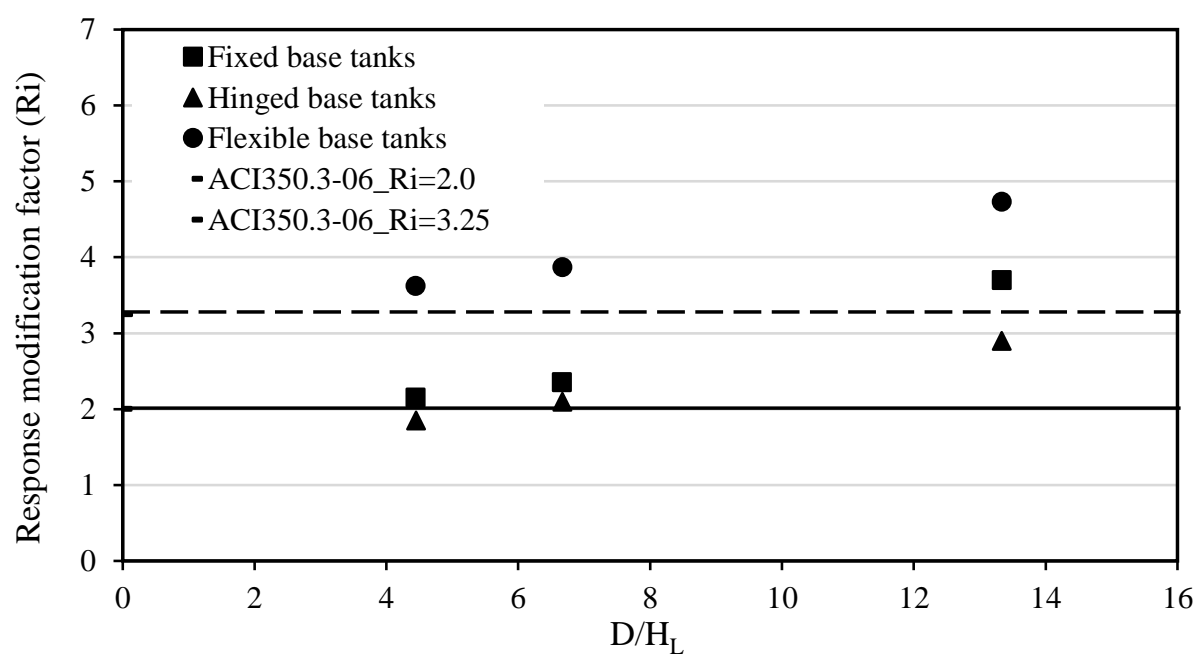

(a)

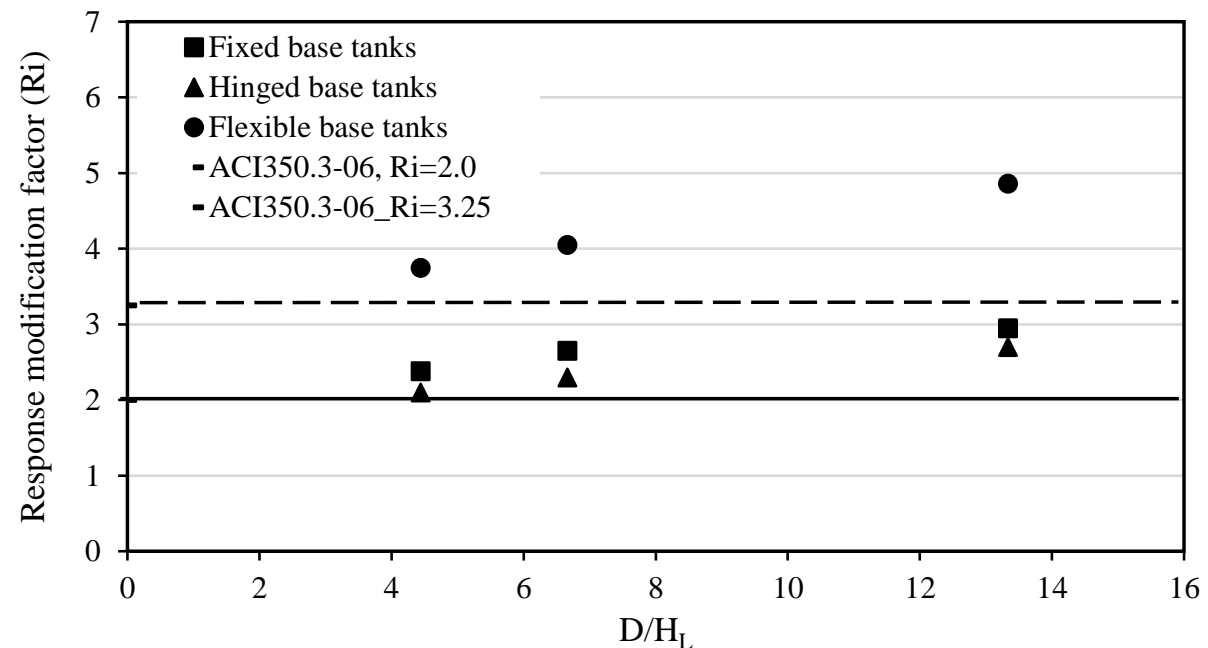

(b)

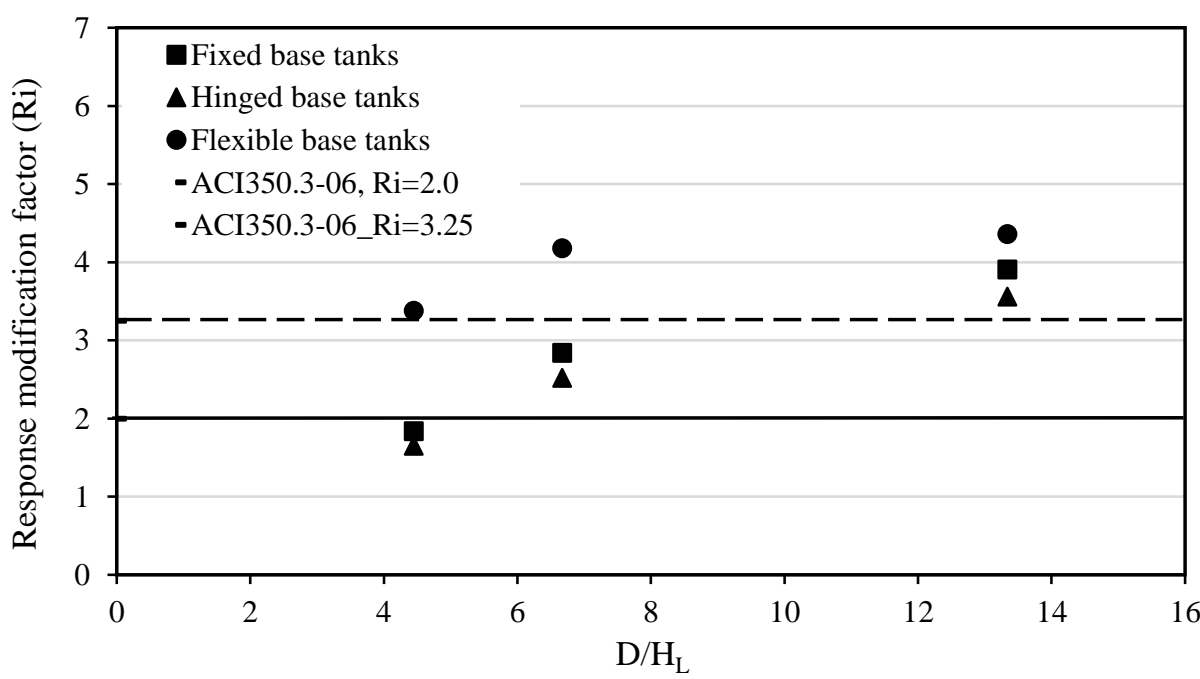

(c)

Figure 6.16 Effect of tank dimension and base fixity on response modification factor; a) El-Centro, b) San-Francisco, c) Northridge 
Comparing the dynamic response of tanks with different base fixity conditions has shown that hinged tanks develop higher structural response values than fixed and flexible tanks. In addition, impulsive pressure is proven to be larger in walls of the hinged tanks. However, fixed tanks show larger maximum values for base shear and moment.

As shown in Figure 6.16, R-values depend on tank dimensions and base fixity. In fact, higher R-value could be assigned to flexible base tanks in comparison to fixed and hinged base tanks, because the flexible base tanks develop the first yield of reinforcement at higher load compared to the fixed and hinged base. In addition, it is concluded that decreasing the tank wall height in constant diameter tank (i.e. larger $\mathrm{D} / \mathrm{H}_{\mathrm{L}}$ ratios) leads to higher $\mathrm{R}$-value for all cases (fixed and hinged). The effect of earthquake frequency content on dynamic behavior of fixed, hinged, and flexible base tanks are shown in Figure 6.17 using three different ground motions having different frequency content characteristics.

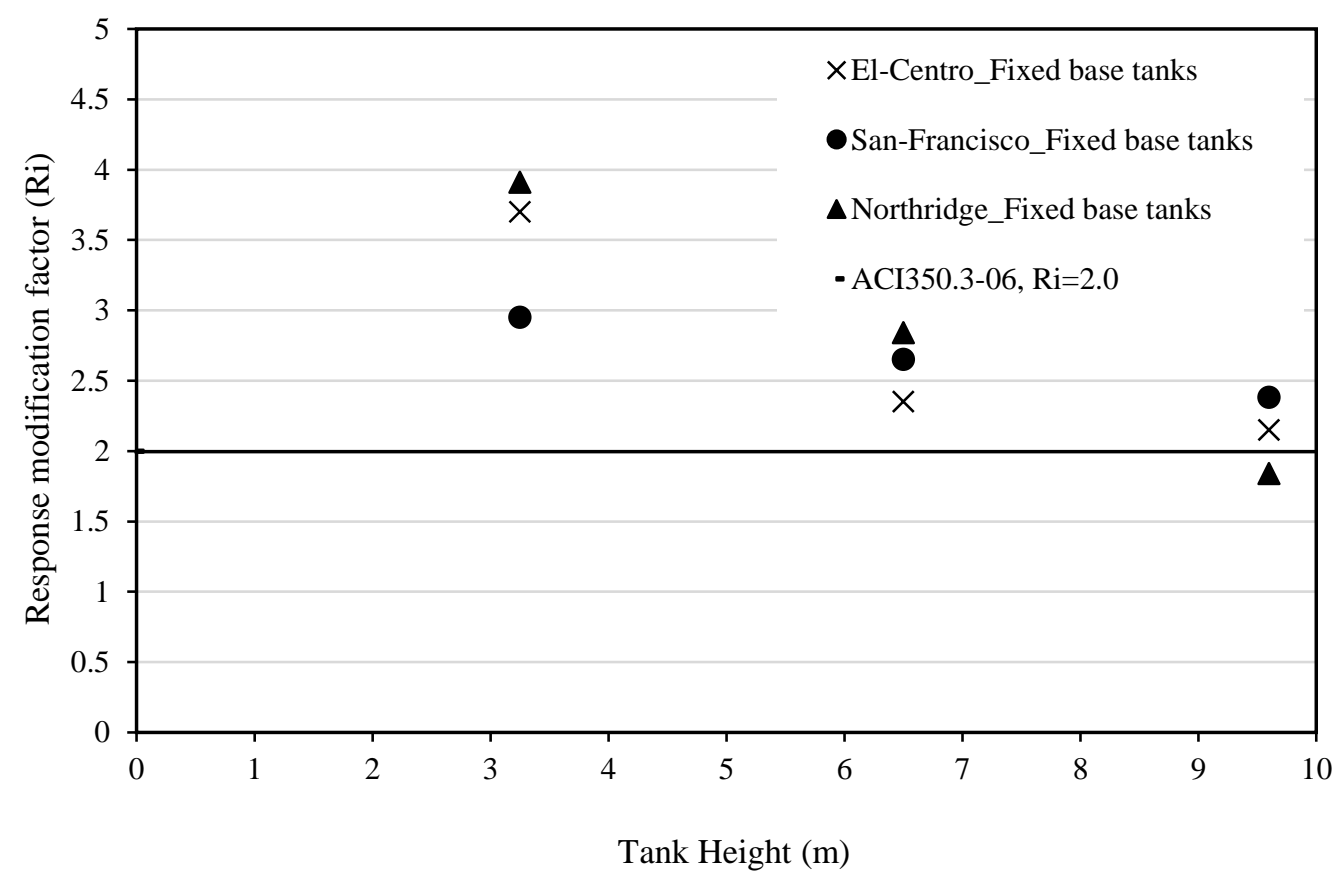

(a) 


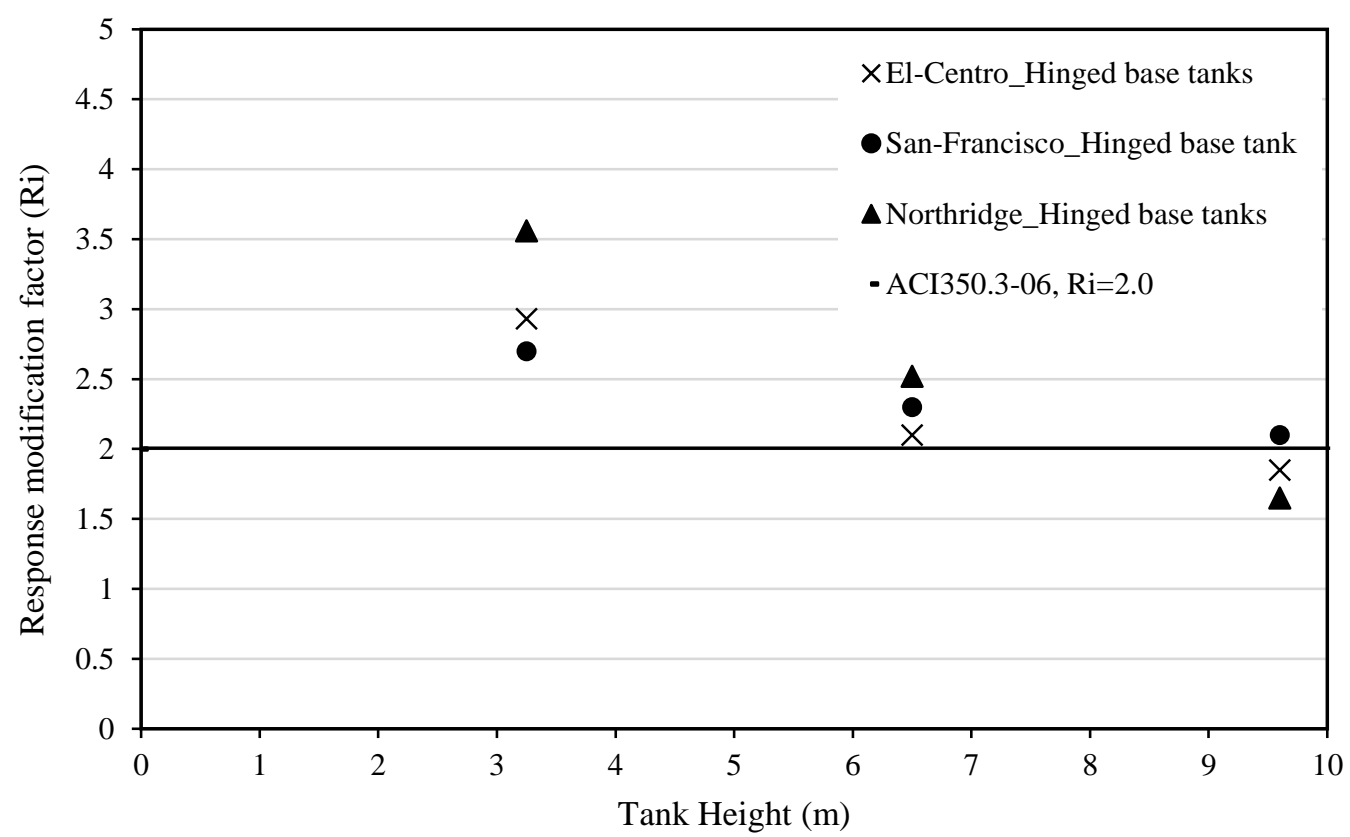

(b)

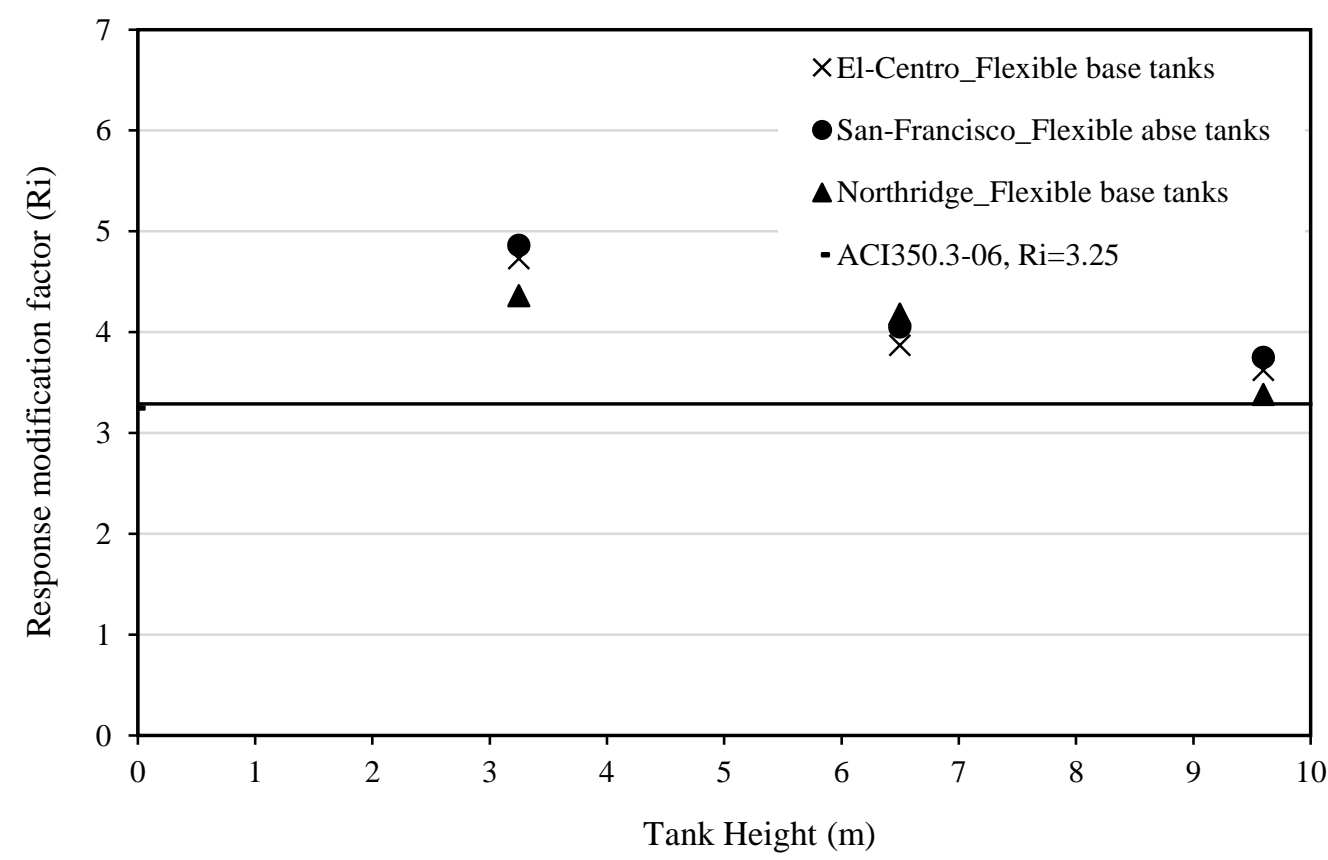

(c)

Figure 6.17 Effect of seismic frequency content on response modification factor; a) Fixed base, b) Hinged base, c) Flexible base

The chosen earthquake records have high to low frequency contents. It is found that the earthquake frequency content has different effects on the dynamic response of tanks due to the similarity between the characteristics of the tanks and earthquake record; as a result, it affects the R-value. As shown in Figure 6.17, Tank 3 (shallow tank), results in lower R-value 
under San-Francisco (high frequency content) among the other seismic records. On the other hand, Northridge (low frequency content) amplifies the dynamic pressure on Tank 9 (tall tank) and leads to lower R-value among other earthquake records. As observed in Figure 6.17, Rvalue of Tank 6 (medium tank) is lower for El-Centro (intermediate frequency content) among other seismic records as a result of amplification of the dynamic response value. However, this should be considered that the results could also depend on the size and dynamic characteristics of the tank and therefore a firm conclusion cannot be made. In order to be able draw a final conclusion, a large number of ground motions should be applied to tank with different dimensions and characteristics but due to time limitations we could not proceed any further in this research.

As the obtained results show, by considering all frequency contents, the average of Rvalue for Tank 3, 6, and 9 equals to 3.29, 2.46, and 1.99 for non-flexible and flexible tanks (fixed, hinged, and flexible), respectively. On the other hand, the average of R-values for ElCentro equal to $2.73,2.30$, and 4.07 for fixed, hinged, and flexible base tanks, respectively. In addition, this average values for San-Francisco equal to 2.66, 2.37, and 4.22 for fixed, hinged, and flexible base tanks, respectively. As the results show, the average of R-values for Northridge equal to $2.86,2.58$, and 3.97 for fixed, hinged, and flexible base tanks, respectively. Despite of the fact that $\mathrm{R}_{\mathrm{i}}$-value is equal to 2.0 and 3.25 for all non-flexible and flexible tanks, this study proved that the R-values depend on the tank relative dimensions, base fixity conditions, and earthquake frequency and considering a single R-Value is not, in fact, a valid hypothesis.

\subsection{Summary}

In this study, a finite element method was introduced which was used for the time-history analysis to study the effect of different parameters including the tank dimension, base fixity and ground motion characteristics on the R-value. A full tank was considered which the inside 
liquid was modeled using 3D fluid finite elements. First, the capability of proposed finite element method was shown. Modal analysis was carried out on a fixed rigid tank and the obtained response quantities were verified by comparing the FE results with those obtained by the analytical solution proposed by Housner (1963), Veletsos and Shivakumar (1997), and ACI 350.3-06.

Moreover, it was shown that the dynamic behavior of the tanks was affected dominantly by the impulsive component rather than the convective component. Also, the impulsive proponent of the response is related to flexibility of the tank walls and has to be considered in seismic design. Next, the effect of earthquake frequency content on the seismic behavior of ground-supported tanks was investigated by performing time-history FE analysis on the tanks of the two size tanks employing three different records. The obtained results showed that the intermediate frequency record led to a higher impulsive response and total base shear. Unlike the intermediate frequency earthquake, the high-frequency record resulted in the highest impulsive response for the shallow tanks.

For the purpose of parametric study, different tank sizes with various base fixity conditions were chosen and designed based on ACI350.3-06 and 350.3R-06, the FE timehistory analysis was performed using three different records with different earthquake frequency contents. It was found that flexible base tanks led to higher R-values rather than fixed and hinged base tanks. And based on the tank size (shallow or tall), the R-values are affected by the seismic frequency content which it depends on the tank geometry and seismic characteristics. As shown, the influence of wall flexibility, fixity and earthquake features are not considered on R-Values in ACI350.3-06. In other words, the ACI interpretation for the hydrodynamic pressure values for both rigid and flexible are the same as well as hinged and fixed based tanks leading to more conservative values for rigid tanks. It was further concluded 
that current practice offered more conservative $\mathrm{R}$ factors for nonflexible and flexible base (fixed, hinged, and flexible) tanks. This has to be further investigated in liquid tanks design. In addition, the results of the nonlinear static analysis (push-over) discussed in Chapter 5 and nonlinear dynamic analysis (time-history) presented here are in good agreement. 


\section{CHAPTER 7 \\ SUMMARY, CONCLUSIONS AND RECOMMENDATIONS}

\subsection{Summary}

Liquid containing structures are designed to safely withstand the hydrostatic and hydrodynamic loadings based on strength and serviceability criteria to control crack development and leakage. Seismic design is performed with forces smaller than the elastic response so that the structure safely survives the earthquake by considering the effect of the Rvalues.

The nonlinear behavior of at-grade, open top, circular RC tanks were studied employing two methods of analysis including non-linear static (push-over) and non-linear dynamic (timehistory). The Finite Element computer program ANSYS was used for performing the analysis. The ground-supported water tanks are built in various dimensions, base fixities and concrete material properties. This research investigates the influence of these parameters on the dynamic behavior of the tank.

A comprehensive literature review of at-grade water tanks was presented in order to better understand the seismic behaviour of these structures. The proposed FE model and its ability to accurately simulate the reinforced concrete behavior was verified with experimental test results.

The methodology developed by FEMA 273 in order to perform push-over analysis was utilized to develop pushover curves and determine the seismic response factor. In order to investigate the effect of tank capacity, three different liquid heights $(3 \mathrm{~m}, 6 \mathrm{~m}$, and $9 \mathrm{~m})$ and three tank diameters $(20 \mathrm{~m}, 30 \mathrm{~m}$ and $40 \mathrm{~m})$ were investigated. These tanks were simulated with two different base fixity conditions (fixed and hinged) and two different values for concrete compressive strength (30 $\mathrm{MPa}$ and $40 \mathrm{MPa}$ ) in order to determine the influence of fixity 
condition and compressive strength. Hydrostatic and hydrodynamic load distribution was defined based on ACI 350.3-06 and accuracy of load distribution on the FE tank wall was validated with some analytical solutions. In pushover analysis a total of 18 prototype tanks were designed based on ACI 350 for high seismic zone with a response modification factor of 2.

Pushover analyses were conducted on 3D finite element models developed based on tank design. Seismic response factors including over-strength, ductility and response modification factors were calculated based on the developed push-over curves. The effect of tank capacity, base fixity and concrete strength on seismic response factor were discussed.

In this study, a finite element method was introduced for the time-history analysis in order to study the effect of tank dimension, base fixity and ground motion characteristics on the Rvalue. A full tank was simulated with liquid modeled using 3D fluid finite elements. The capability of proposed finite element method was shown using modal analysis on a fixed rigid tank and the obtained response quantities were verified by comparing the FE results with analytical solutions proposed by previous researchers.

It was also shown that the dynamic behavior of the tanks was affected dominantly by the impulsive component rather than the convective component. Next, the effect of earthquake frequency content on the seismic behavior of ground-supported tanks was investigated by performing time-history FE analysis on the tanks of the two size tanks employing three different records. For the purpose of parametric study, different tank sizes with various base fixity conditions were chosen and designed. The FE time-history analysis was performed using three different records with different earthquake frequency contents. In this study, there are some assumptions and limitations such as there is no sliding or uplift in the tanks at the base and that the soil-structure interaction effect is ignored. The wall thickness is assumed uniform with open top tanks. The fluid is defined as incompressible and inviscid material. 


\subsection{Conclusions}

The following conclusion are drawn based on the results of this study regarding the dynamic behavior of circular ground-supported tanks:

1. The response (base shear and moment) is overestimated in the code procedure. This is caused by impulsive and convective masses and other simplifications and assumptions that have been used and implicated in this procedure.

2. Tank wall flexibility affects the hydrodynamic pressure in liquid containing structures and its effect cannot be neglected in hydrodynamic pressure calculations.

3. The finite element method was proven to be capable in predicting/simulating the nonlinear behavior of reinforced concrete by comparing its results with experimental studies on RC beams and walls.

4. Comparisons in between analytical solutions and FE results of liquid tanks demonstrated the capability of the proposed FE method to simulate LCS's. Fluid domain behavior was simulated quite accurately by defining the appropriate fluidstructure interface along with coupling of structural motion with fluid pressure.

5. A variety of fluid-structure interaction problems such as wall flexibility, sloshing motion, damping properties of fluid domain and individual effects of impulsive and convective terms in a 3D could be effectively modeled using the proposed method.

6. An increase in the tank size could lead to a proportionally larger total base shear values where reinforcement yields and concrete tensile stress is reached according to the nonlinear pushover FE analysis.

7. As per the nonlinear pushover analysis results, shallower tanks with minimum reinforcement ratios $\left(A_{s, \min }-\right.$ shrinkage \& temperature reinforcement $)$ showed higher response modification factors ( $\mathrm{R}_{\mathrm{i}}$-values) and over-strength factors. 
8. Nonlinear push-over FE analysis demonstrated that first reinforcement yield happens earlier in hinged based tanks compared to fixed base tanks at lower loads. In other words, hinged tanks show less resistance compared to fixed base tanks.

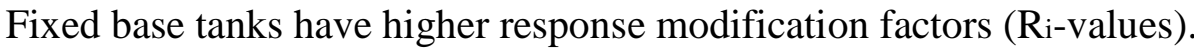

9. The over-strength and response modification factors show a relationship with concretes compressive strength while base shear is not affected by changed in the concrete strength as shown in pushover FE results.

10. The over-strength factor is attributed to R-factor in ground-supported LCS more than ductility factor and the nonlinear response of the structure is governed by controlling concrete cracking. In this study, the ductility factor does not show a constant trend.

11. There is an inverse relationship between tank size and over-strength factor. Increasing tank size results in decreasing the over-strength and R-factors.

12. According to push-over analysis, the proposed R-factors are in the range of 3.16 to $7.76,1.79$ to 2.47 , and 1.54 to 1.84 for the low, medium, and tall tanks, respectively.

13. For fixed and hinged base tanks, the proposed R-factor varies from 3.16 to 1.54 and 2.11 to 1.38 by increasing the tank size, respectively. Moreover, the proposed Rfactor ranges from 5.04 to 3.81 for flexible base tanks.

14. Impulsive component of response significantly increases by inclusion of wall flexibility but the convective component is almost independent of the wall flexibility proponent. Also, wall flexibility has a rather insignificant influence on the sloshing height of the tank liquid.

15. Influence of wall flexibility and base condition is not appropriately taken into account in ACI 350.3-06 standard. In other words, the ACI interpretation for the 
hydrodynamic pressure values for both rigid and flexible tanks are the same as well as hinged and fixed based tanks leading to more conservative values for rigid tanks.

16. Generally, ACI 350.3-06 (2006) procedure results in a rather conservative estimation more noticeably in rigid tanks (both shallow and tall). Linear vertical distribution of the hydrodynamic pressure proposed by the code leads to overly conservative values near the base of the tank.

17. Comparing the dynamic response of tanks with different base fixity conditions has shown that hinged tanks develop higher structural response values than fixed base tanks. In addition, impulsive pressure is proven to be larger in walls of the hinged tanks. However, fixed tanks show larger maximum values for base shear and moment. Hinged tanks show larger impulsive pressure and lower response modification factors (Ri-Values) based on the nonlinear FE time-history analysis.

18. Seismic response of ground supported tanks and transient response values are influenced by earthquake frequency content. This study showed that similarity in between frequency characteristics of the tank system and the earthquake record could have a significant effect on the response values. In this case, San-Franscisco (high frequency), El-Centro (intermediate frequency) and Northridge (low frequency) showed the highest total base shear for shallow, medium and tall tanks respectively.

19. As per time history analysis, the average value of "Ri" for fixed base tanks are equal to $3.52,2.61$, and 2.12 for low, medium, and tall tanks, respectively. The average of "Ri" for hinged base tanks are equal to 3.06, 2.31, and 1.87 for low, medium, and tall tanks, respectively, and average of "Ri" for flexible base tanks are equal to $4.65,4.03$, and 3.58 for low, medium, and tall tanks, respectively. 


\subsection{Recommendations for future research programs}

Based on some aspects of this research, some recommendations for further research on seismic behavior of circular reinforced concrete tanks are summarized as follows:

1. Further parametric studies with tank roof configuration, earthquake excitations, construction methods and materials such as pre-stressed including normal, composite steel-shotcrete and wire-wound precast concrete could be carried out.

2. Soil-Structure Interaction could have a noticeable effect on the seismic response of the ground-supported tanks which could be introduced into the finite element model in a future study.

3. An experimental study would improve the understanding of the seismic response of the at-grade tanks.

4. The effect of vertical earthquake component to be considered on the dynamic behavior of liquid containing structures.

5. Passive energy dissipation systems such as seismic isolators or energy dissipaters and their influence on the linear and nonlinear dynamic behavior of liquid containing structures with different base fixities and tank capacities could be used.

6. The effect of sloshing behavior on LCS and convective response modification factor $(\mathrm{Rc})$ can be further investigated to validate the Rc-values as per current practice.

7. Development of design charts and clear guidelines to determine the most efficient wall thickness, reinforcement, and prestressing for ground-supported LCS based on existing conditions could be of benefit to designers. 
APPENDIX A

EARTHQUAKE DESIGN LOADS AND LOAD DISTRIBUTION OF GROUND-SUPPORTED NONFLEXIBLE-BASE CIRCULAR TANK 


\section{Design of Circular Tank Type 2.1 or 2.2}

\section{Earthquake Design Loads and Load Distribution}

Reference:

Seismic Design of Liquid-Containing Concrete Structures (ACI350.3R-06) and Commentary (350.3R-06)

\section{A.1 Design Data}

$\begin{array}{ll}\mathrm{D}=\mathbf{4 0 . 0} & \mathrm{m} \\ \mathrm{H}_{\mathrm{w}}=\mathbf{6 . 5} & \mathrm{m} \\ \mathrm{H}_{\mathrm{L}}=\mathbf{6 . 0} & \mathrm{m} \\ \mathrm{t}_{\mathrm{w}}=\mathbf{4 0 0} & \mathrm{mm} \\ \mathrm{H}_{\mathrm{w}}(\min )=6.44 & \mathrm{~m}\end{array}$

Freeboard> Freeboard allowance (okay)

$\mathrm{g}_{\mathrm{L}}=\mathbf{9 . 8} \quad \mathrm{kN} / \mathrm{m}^{3}$

$\mathrm{g}_{\mathrm{c}}=\mathbf{2 3 . 6} \quad \mathrm{kN} / \mathrm{m}^{3}$

$\rho_{\mathrm{L}}=\mathbf{1 . 0} \quad \mathrm{kN} . \mathrm{s}^{2} / \mathrm{m}^{4}$

$\rho_{\mathrm{c}}=\mathbf{2 . 4} \quad \mathrm{kN} \cdot \mathrm{s}^{2} / \mathrm{m}^{4}$

$\mathrm{f}_{\mathrm{c}}^{\prime}=\mathbf{3 0} \quad \mathrm{MPa}$

$\mathrm{E}_{\mathrm{c}}=\mathbf{2 4 6 4 8} \quad \mathrm{MPa}$

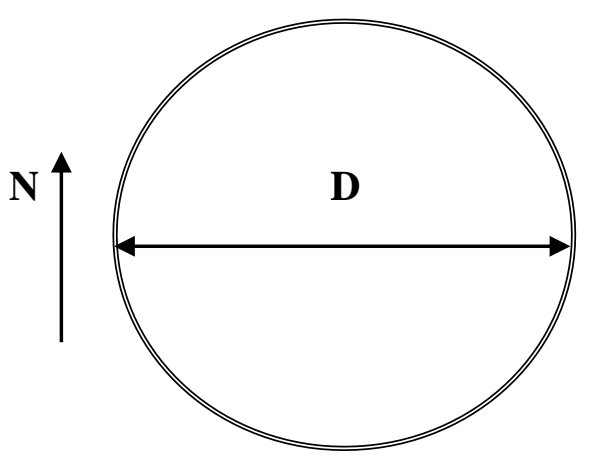

Plan

$\mathrm{S}_{\mathrm{S}}=\mathbf{1 5 0 \%} \quad \mathrm{g}$

$\mathrm{S}_{1}=60 \% \quad \mathrm{~g}$

$\mathrm{F}_{\mathrm{a}}=\mathbf{0 . 8}$

$\mathrm{F}_{\mathrm{v}}=\mathbf{0 . 8}$

$\mathrm{I}=\mathbf{1 . 0}$

Type of structure is Fixed or hinged

$\mathrm{R}_{\mathrm{i}}=\mathbf{2 . 0}$

$\mathrm{R}_{\mathrm{c}}=\mathbf{1 . 0}$

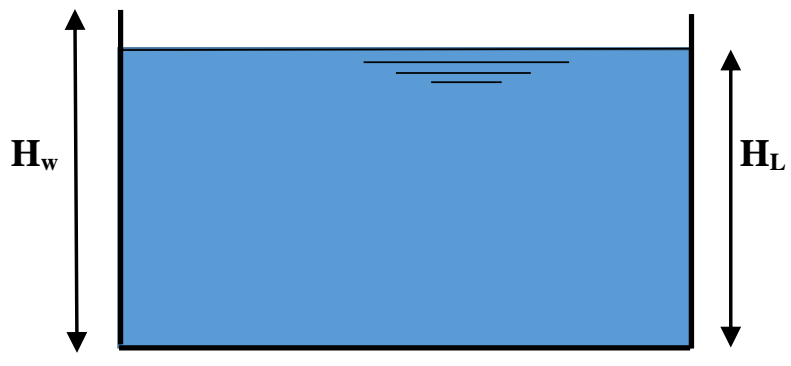

Section 


\section{A.2 Dynamic Model}

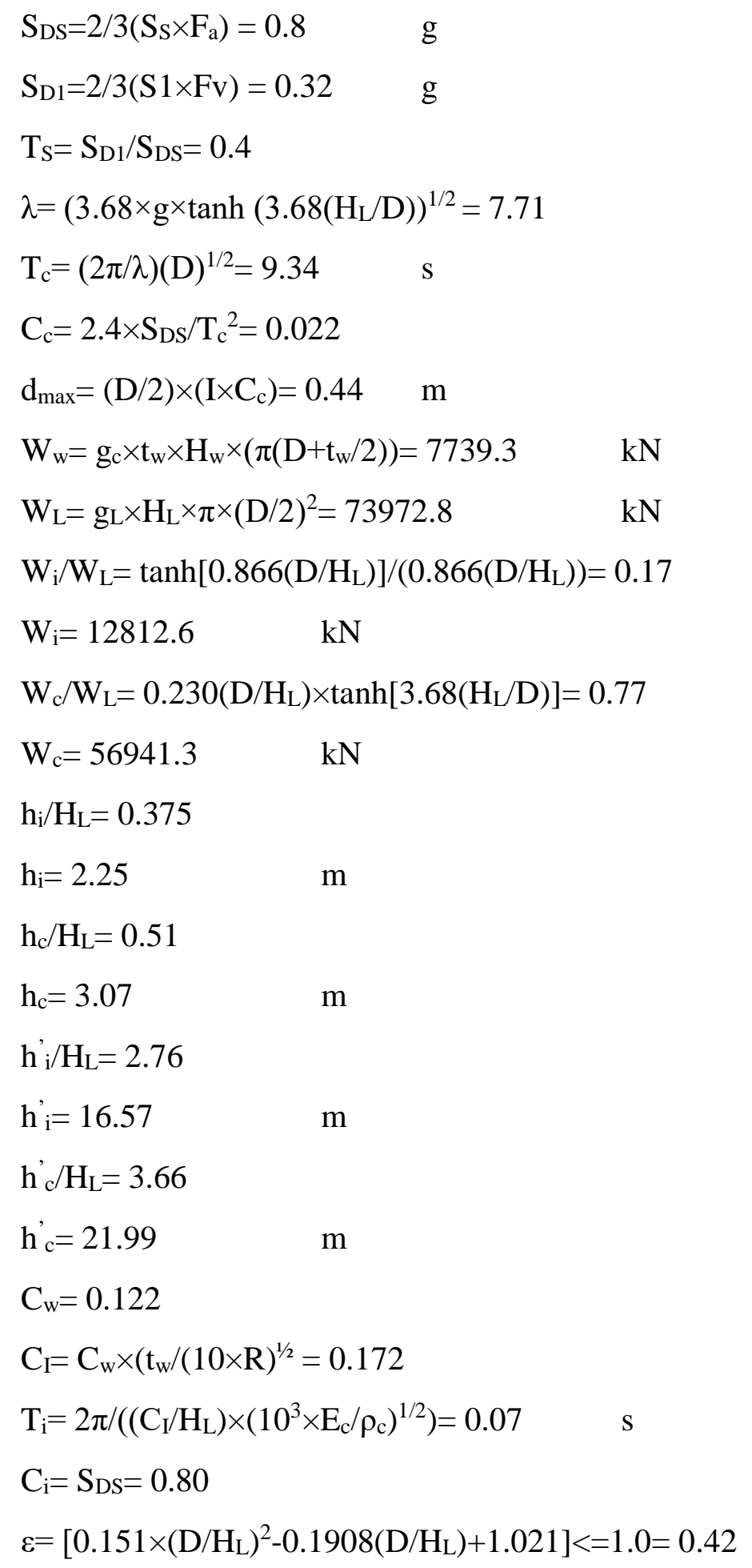




\section{A.3 Earthquake Design Loads}

\section{A.3.1 Dynamic Lateral Forces}

$\mathrm{P}_{\mathrm{w}}=\mathrm{IC}_{\mathrm{i}} \times\left[\varepsilon \mathrm{W}_{\mathrm{w}} / \mathrm{R}_{\mathrm{i}}\right]=1300.5 \quad \mathrm{kN}$

$\mathrm{P}_{\mathrm{i}}=\mathrm{IC}_{\mathrm{i}} \times\left[\mathrm{W}_{\mathrm{i}} / \mathrm{R}_{\mathrm{i}}\right]=5125.0 \quad \mathrm{kN}$

$\mathrm{P}_{\mathrm{c}}=\mathrm{IC}_{\mathrm{c}} \times\left[\mathrm{W}_{\mathrm{c}} / \mathrm{R}_{\mathrm{c}}\right]=1253.1 \quad \mathrm{kN}$

\section{A.3.2 Total base shear}

$\mathrm{V}=\left(\left(\mathrm{P}_{\mathrm{i}}+\mathrm{P}_{\mathrm{w}}+\mathrm{P}_{\mathrm{r}}\right)^{2}+\mathrm{P}_{\mathrm{c}}{ }^{2}\right)^{1 / 2}=6546.6 \quad \mathrm{kN}$

\section{A.3.3 Bending moment on the entire tank cross section (EBP)}

$$
\begin{array}{ll}
M_{w}=P_{w} \times h_{w}=4226.8 & k N . m \\
M_{i}=P_{i} \times h_{i}=11531.3 & k N . m \\
M_{c}=P_{c} \times h_{c}=3852.0 & \text { kN.m }
\end{array}
$$

$\mathrm{M}_{\mathrm{h}}=\left(\left(\mathrm{M}_{\mathrm{i}}+\mathrm{M}_{\mathrm{w}}+\mathrm{M}_{\mathrm{r}}\right)^{2}+\mathrm{M}_{\mathrm{c}}{ }^{2}\right)^{1 / 2}=16222.1 \quad \mathrm{kN} . \mathrm{m}$

\section{A.3.4 Overturning moment at the base of the tank (IBP)}

$$
\begin{aligned}
& M_{\mathrm{i}}^{\prime}=\mathrm{P}_{\mathrm{i}} \times \mathrm{h}_{\mathrm{i}}^{\prime}=84923.6 \quad \mathrm{kN} \cdot \mathrm{m} \\
& \mathrm{M}_{\mathrm{c}}^{\prime}=\mathrm{P}_{\mathrm{c}} \times \mathrm{h}_{\mathrm{c}}^{\prime}=27552.2 \quad \mathrm{kN} \cdot \mathrm{m} \\
& \mathrm{M}_{0}=\left(\left(\mathrm{M}_{\mathrm{i}}+\mathrm{M}_{\mathrm{w}}+\mathrm{M}_{\mathrm{r}}\right)^{2}+\mathrm{M}_{\mathrm{c}}{ }^{2}\right)^{1 / 2}=93310.8 \quad \mathrm{kN} \cdot \mathrm{m}
\end{aligned}
$$

$$
\begin{aligned}
& \text { A.3.5 Vertical acceleration } \\
& \mathrm{T}_{\mathrm{v}}=2 \pi\left[\left(\mathrm{g}_{\mathrm{L}} \times \mathrm{D} \times \mathrm{H}_{\mathrm{L}}{ }^{2}\right) /\left(24 \times \mathrm{g} \times \mathrm{t}_{\mathrm{w} \times} \mathrm{E}_{\mathrm{c}}\right)\right]^{1 / 2}=0.05 \quad \mathrm{~s} \\
& \mathrm{C}_{\mathrm{t}}=\mathrm{S}_{\mathrm{DS}}=0.80 \\
& \mathrm{~b}=2 / 3=0.67 \\
& \ddot{U}=\mathrm{C}_{\mathrm{t}} \mathrm{I}\left[\mathrm{b} / \mathrm{R}_{\mathrm{i}}\right]>=0.2 \mathrm{~S}_{\mathrm{DS}}=0.267 \\
& \mathrm{P}_{\mathrm{hL}}=\ddot{U} \mathrm{q}_{\mathrm{hL}}=15.69
\end{aligned}
$$




\section{A.4 Earthquake Load Distribution}

\section{A.4.1 Seismic Forces}

1- Hydrostatic force, $\mathrm{P}_{\mathrm{h}}=7061.0 \quad \mathrm{kN}$

2-Vertical acceleration effect, $\ddot{U} \times \mathrm{P}_{\mathrm{h}}=1882.9 \quad \mathrm{kN}$

3- Impulsive force, $\mathrm{P}_{\mathrm{i}} / 2=2562.5 \quad \mathrm{kN}$

4- Convective force, $\mathrm{P}_{\mathrm{c}} / 2=626.6 \quad \mathrm{kN}$

5- Wall inertia force, $\mathrm{P}_{\mathrm{w}} / 2=650.3 \quad \mathrm{kN}$

- Max. static shear force in wall=7061.0 kN/m

- Max. seismic shear force in wall $=3776.2 \quad \mathrm{kN} / \mathrm{m}$

- Max. static bending moment in wall $=14122.08 \quad \mathrm{kN} . \mathrm{m} / \mathrm{m}$

- Max. seismic bending moment in wall $=8942.6 \quad \mathrm{kN} . \mathrm{m} / \mathrm{m}$

\section{A.4.2 Seismic Pressures}

1- Hydrostatic pressures, $\mathrm{P}_{\mathrm{h}}=176.5 \quad \mathrm{kN} / \mathrm{m}$

2-Vertical acceleration effect, $\ddot{U} \times \mathrm{P}_{\mathrm{h}}=47.1 \quad \mathrm{kN} / \mathrm{m}$

3- Impulsive pressures, $\mathrm{p}_{\mathrm{i}}=\left(2 \mathrm{P}_{\mathrm{i}} / 2\right) /(\pi \mathrm{R})=81.5 \quad \mathrm{kN} / \mathrm{m}$

4- Convective pressures, $p_{c}=(16 \mathrm{Pc} / 2) /(9 \pi \mathrm{R})=17.7 \quad \mathrm{kN} / \mathrm{m}$

5- Wall inertia force, $\mathrm{p}_{\mathrm{w}}=\left(\mathrm{P}_{\mathrm{w}} / 2\right) /(\pi \mathrm{R})=10.3 \quad \mathrm{kN} / \mathrm{m}$ 


\section{A.5 Earthquake Load Distribution along tank wall at $\theta=0$}

\begin{tabular}{|c|c|c|c|c|c|c|}
\cline { 2 - 7 } \multicolumn{1}{c|}{} & Static & \multicolumn{5}{c|}{ Seismic } \\
\hline $\mathbf{y}$ & $\mathbf{H S}$ & $\ddot{\mathbf{U}}_{\mathbf{x q}} \mathbf{\text { hy }}$ & $\mathbf{P i}_{\mathbf{y}}$ & $\mathbf{P}_{\mathbf{c y}}$ & $\mathbf{P}_{\mathbf{w y}}$ & $\mathbf{H D}$ \\
\hline $\mathbf{6 . 5 0}$ & 0 & 0 & 0 & 0 & 1.59 & 1.6 \\
\hline $\mathbf{6 . 0}$ & 0 & 0 & 3.40 & 3.17 & 1.59 & 5.9 \\
\hline $\mathbf{5 . 0}$ & 9.81 & 2.62 & 6.79 & 3.10 & 1.59 & 9.3 \\
\hline $\mathbf{4 . 0}$ & 19.61 & 5.23 & 10.19 & 3.03 & 1.59 & 13.2 \\
\hline $\mathbf{3 . 0}$ & 29.42 & 7.85 & 13.59 & 2.95 & 1.59 & 17.3 \\
\hline $\mathbf{2 . 0}$ & 39.23 & 10.46 & 16.99 & 2.88 & 1.59 & 21.5 \\
\hline $\mathbf{1 . 0}$ & 49.04 & 13.08 & 20.38 & 2.81 & 1.59 & 25.7 \\
\hline $\mathbf{0 . 0}$ & 58.84 & 15.69 & 23.78 & 2.74 & 1.59 & 30.0 \\
\hline
\end{tabular}

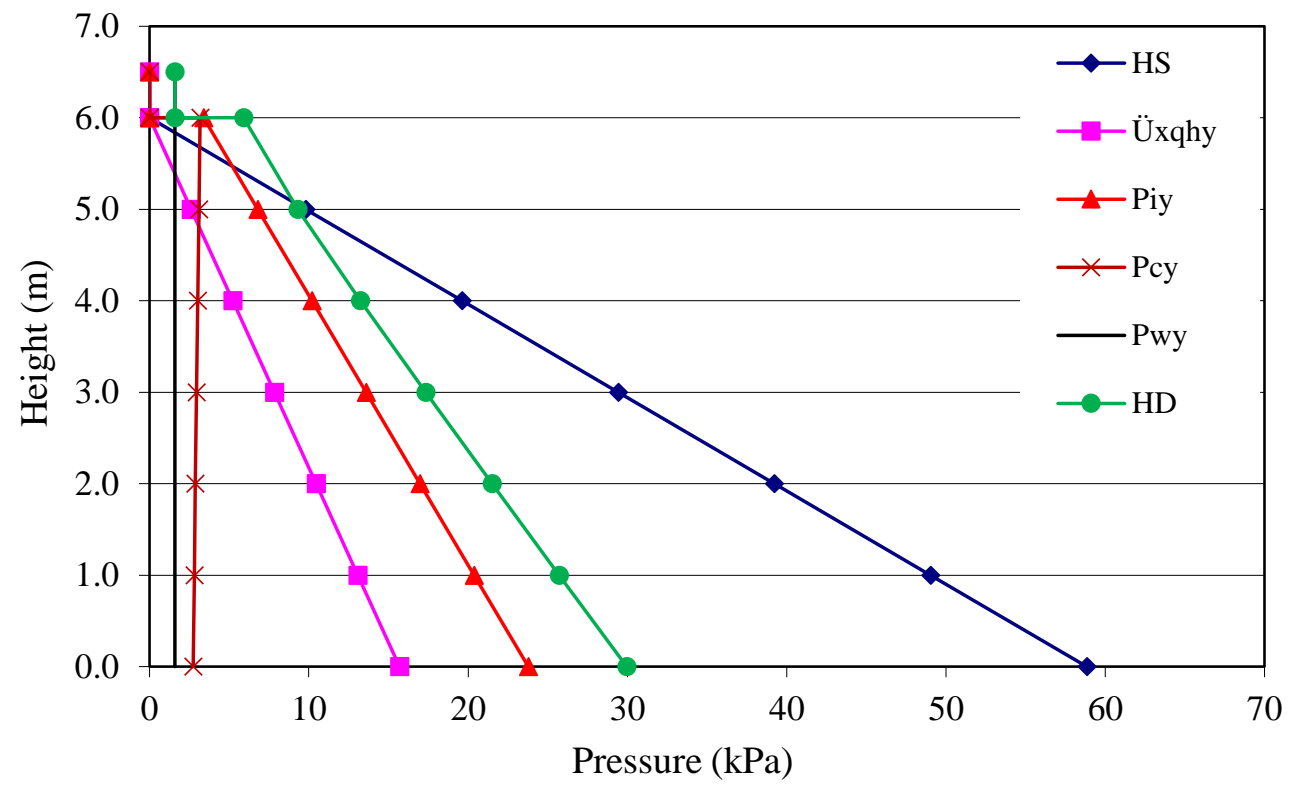




\section{APPENDIX B}

ANALYTICAL SOLUTION OF CYLINDRICAL TANK UNDER HYDROSTATIC LOADING 
Reference:

Theory plates and shells ( $2^{\text {nd }}$ edition) proposed by S.Timoshenko and S.Woinowsky-Krieger (1976)

\section{B.1 Geometry and material properties of the cylindrical shell}

Radius of cylinder: $\mathrm{a}=20 \mathrm{~m}$

Thickness of cylinder: $\mathrm{h}=0.4 \mathrm{~m}$

Height of tank wall: $\mathrm{d}=6.0 \mathrm{~m}$

Section modulus for 1-meter shell length (circumferential):

$\mathrm{S}_{\mathrm{s}}=\left(\frac{1}{6}\right)(1)\left(\mathrm{h}^{2}\right)=0.027 \frac{1}{\mathrm{~m}} \mathrm{~m}^{3}$

Poisson's ratio: $v=0.2$

Elastic modulus: $\mathrm{E}=26000 \mathrm{MPa}$

Specific density of fluid: $\gamma=1000 \mathrm{~kg} / \mathrm{m}^{3} . \mathrm{g}$

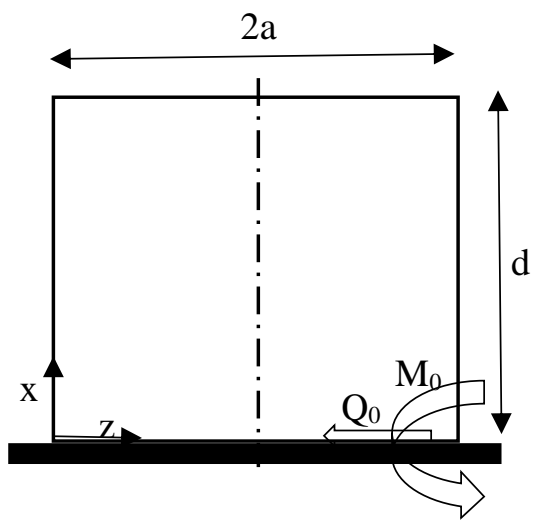

\section{B.2 Analytical functions}

\section{B.2.1 Calculate tank deflection}

$$
\begin{aligned}
& D=\frac{E h^{3}}{12\left(1-v^{2}\right)}=139.78 \\
& \beta=\sqrt[4]{\frac{E h}{4 a^{2} D}}=0.46 \\
& \varphi(\beta x)=e^{-\beta x}(\cos \beta x+\sin \beta x) \\
& \psi(\beta x)=e^{-\beta x}(\cos \beta x-\sin \beta x) \\
& \theta(\beta x)=e^{-\beta x}(\cos \beta x) \\
& \xi(\beta x)=e^{-\beta x}(\sin \beta x) \\
& w(x)=-\frac{\gamma a^{2} d}{E h}\left\{1-\frac{x}{d}-\theta(x)-\left(1-\frac{1}{\beta d}\right) \xi(x)\right\}
\end{aligned}
$$




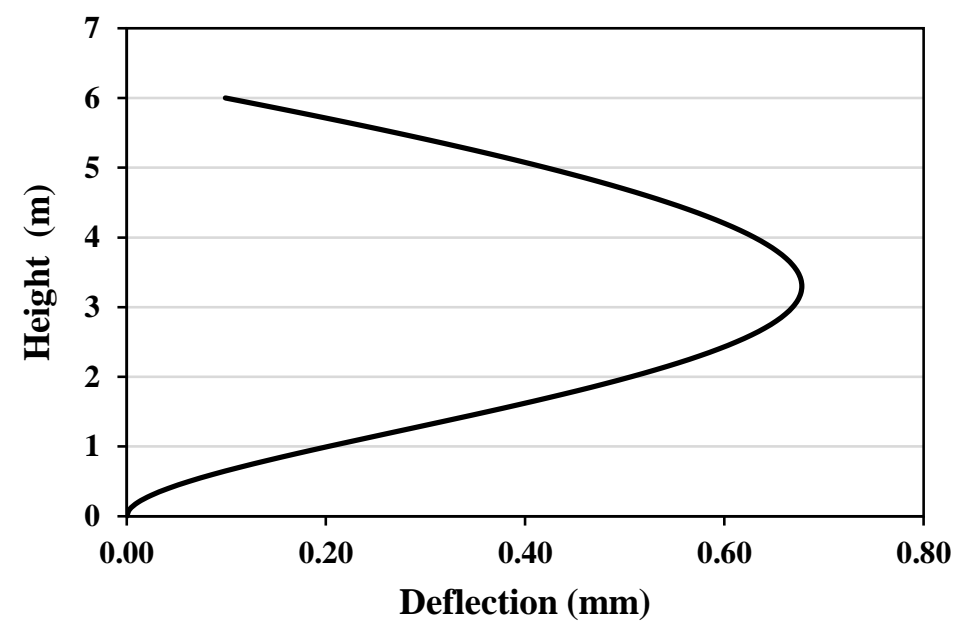

Figure B.1 Radial deflection under uniform hydrostatic pressure

\section{B.2.2 Calculate maximum shear and moment at the tank base}

Max moment: $\mathrm{M}_{0}=\left(1-\frac{1}{\beta \mathrm{d}}\right) \frac{\gamma \mathrm{adh}}{\sqrt{12\left(1-v^{2}\right)}}=-104.6 \quad \mathrm{KN} \cdot \mathrm{m} / \mathrm{m}$

Max shear: $Q_{0}=-\frac{\gamma a d h}{\sqrt{12\left(1-v^{2}\right)}}\left(2 \beta-\frac{1}{d}\right)=88.5 \quad \mathrm{KN} / \mathrm{m}$

\section{B.2.3 Calculate force and stress in the cylindrical shell}

Hoop force: $\mathrm{N}_{\varphi}(\mathrm{x})=\frac{-\mathrm{Eh}}{\mathrm{a}} \mathrm{w}(\mathrm{x})$

Bending moment: $\mathrm{M}_{\mathrm{x}}(\mathrm{x})=\frac{\text { yadh }}{\sqrt{12\left(1-v^{2}\right)}}\left[-\xi(\mathrm{x})+\left(1-\frac{1}{\beta \mathrm{d}}\right) \theta(\mathrm{x})\right]$

$\mathrm{M}_{\varphi}(\mathrm{x})=v \mathrm{M}_{\mathrm{x}}(\mathrm{x})$

Shear force: $Q_{x}(x)=\frac{\gamma \operatorname{adh} \beta}{\sqrt{12\left(1-v^{2}\right)}}\left[\psi(x)+\left(1-\frac{1}{\beta d}\right) \psi(x)\right]$

Shear stress: $\tau_{X Z}=\frac{Q_{x}(x)}{h}$

Bending stress due to bending moment $\mathrm{M}_{\mathrm{x}}: \sigma_{\mathrm{x}}(\mathrm{x})=\frac{\mathrm{M}_{\mathrm{x}}(\mathrm{x})}{\mathrm{S}_{\mathrm{S}}}$

Hoop stress due to hoop force $\mathrm{N}_{\varphi}(\mathrm{x}): \sigma_{\varphi}(\mathrm{x})=\frac{\mathrm{N}_{\varphi}(\mathrm{x})}{\mathrm{h}}$ 


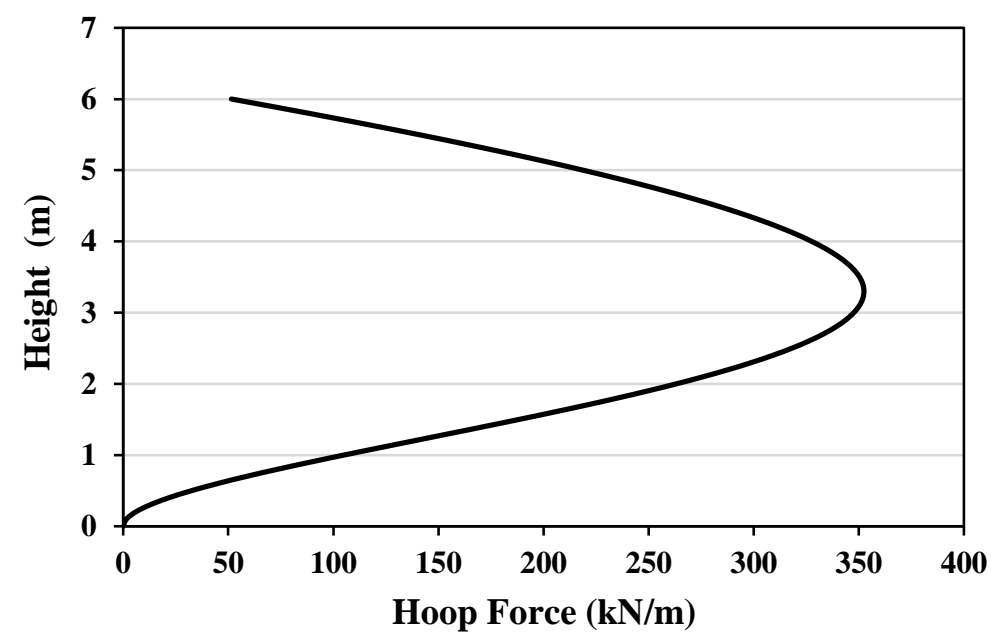

Figure B.2 Hoop force under uniform hydrostatic pressure

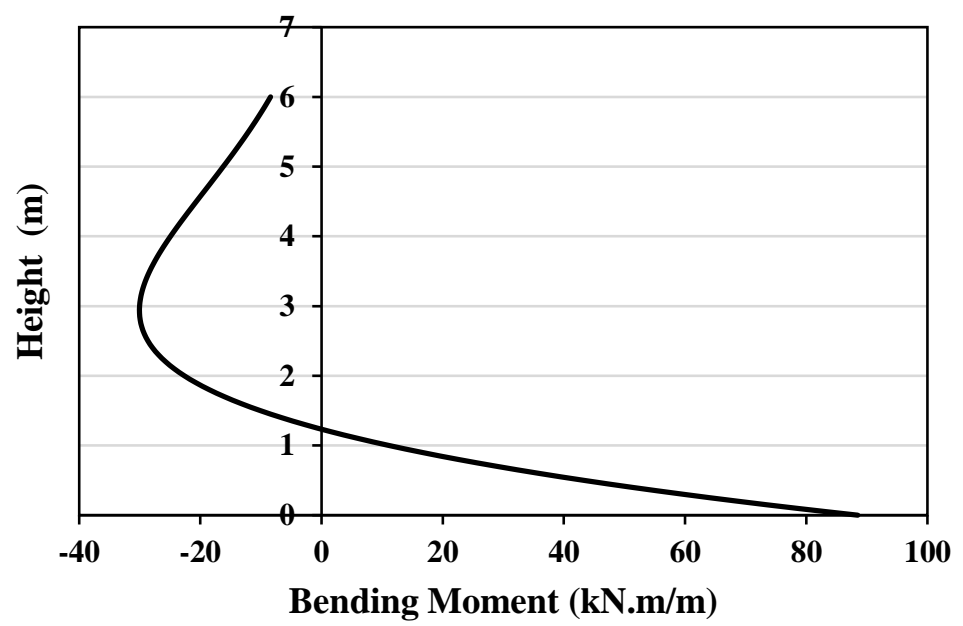

Figure B.3 Bending moment under uniform hydrostatic pressure

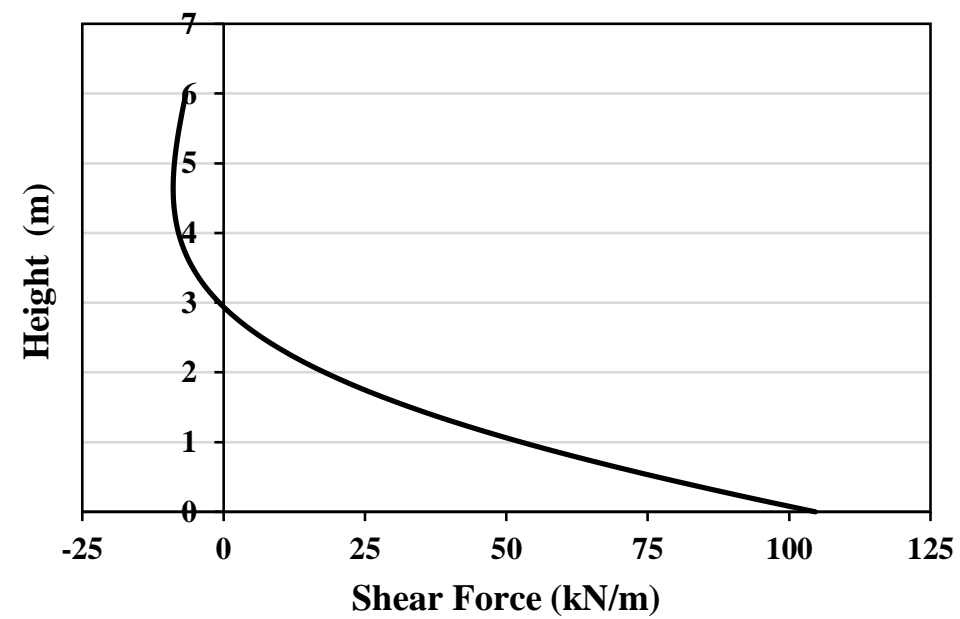

Figure B.4 Shear force under uniform hydrostatic pressure 


\begin{abstract}
APPENDIX C
DESIGN OF CONCRETE SECTION OF GROUNDSUPPORTED NONFLEXIBLE-BASE CIRCULAR TANK
\end{abstract}




\section{Design of Concrete Section of a Circular Tank}

Reference:

Seismic Design of Liquid-Containing Concrete Structures (ACI 350.3R-06) and Commentary (350.3R-06)

\section{C.1 Design Data}

$\begin{array}{ll}\mathrm{D}=\mathbf{4 0 . 0} & \mathrm{m} \\ \mathrm{t}_{\mathrm{w}}=\mathbf{4 0 0} & \mathrm{mm} \\ \mathrm{H}_{\text {Wall }}=\mathbf{6 . 5} & \mathrm{m} \\ \mathrm{H}_{\text {Liquid }}=\mathbf{6 . 0} & \mathrm{m}\end{array}$

$\mathrm{f}_{\mathrm{c}}^{\prime}=\mathbf{3 0} \quad \mathrm{MPa}$

$\mathrm{E}_{\mathrm{c}}=\mathbf{2 4 6 4 8} \mathrm{MPa}$

$\mathrm{F}_{\mathrm{y}}=\mathbf{4 0 0} \mathrm{MPa}$

Bar Size $=20 M$

- Max. Hoop force (Static): $\mathrm{N}_{\mathrm{f}}=\mathbf{3 3 1 . 6}$

- Max. Hoop force (Seismic): $\mathrm{N}_{\mathrm{E}}=\mathbf{2 0 8 . 9}$

- Max. Bending moment (Static): $\mathrm{M}_{\mathrm{f}}=\mathbf{6 3 . 0}$

- Max. Bending moment (Seismic): $\mathrm{M}_{\mathrm{E}}=\mathbf{3 6 . 5}$

- Max. Shear force in wall (Static): $V_{f}=87.9$

- Max. Shear force in wall (Seismic): $V_{E}=\mathbf{4 7 . 8}$

- Max. Hydrostatic pressure: $\mathrm{PHS}=\mathbf{5 8 . 8}$

- Max. Seismic pressure: $\mathrm{PEQ}=\mathbf{3 0 . 3}$
$\mathrm{kN} / \mathrm{m}$

$\mathrm{kN} / \mathrm{m}$

$\mathrm{kN} . \mathrm{m} / \mathrm{m}$

$\mathrm{kN} . \mathrm{m} / \mathrm{m}$

$\mathrm{kN} / \mathrm{m}$

$\mathrm{kN} / \mathrm{m}$

$\mathrm{kPa}$

$\mathrm{kPa}$ 


\section{C.2 Design of Concrete Section (Hoop reinforcement)}

Reference:

Code Requirements for Environmental Engineering Concrete Structures (ACI 350-01) and Commentary (ACI 350R-01) - 2003

\section{Strength Design Method}

$\underline{\text { Load due to fluid }}$
$\mathrm{N}_{\mathrm{f}}=331.6$
$\mathrm{kN} / \mathrm{m}$

\section{Load due to earthquake}

$$
\mathrm{N}_{\mathrm{E}}=208.9 \quad \mathrm{kN} / \mathrm{m}
$$

$\mathrm{f}_{\mathrm{c}}^{\prime}=30 \quad \mathrm{MPa}$

$\mathrm{f}_{\mathrm{y}}=400 \quad \mathrm{MPa}$

$\phi=0.9 \quad$ for flexure $\&$ axial tension

Concrete Cover $=50 \mathrm{~mm}$

Bar sizes $=20 \mathrm{~mm}$

Spacing between bars $\mathrm{S}=150 \mathrm{~mm}$

$\mathrm{t}_{\mathrm{w}}=400 \mathrm{~mm}$

$\mathrm{d}=340 \mathrm{~mm}$

$\mathrm{d}_{1}=140 \mathrm{~mm}$

$\mathrm{b}=1000 \mathrm{~mm}$

$\mathrm{d}_{\mathrm{c}}=60 \mathrm{~mm}$

$A_{s, \min }=0.25\left(f_{c}^{\prime}\right)^{2} \times f_{y} \times b \times d=1164 \mathrm{~mm}^{2} / \mathrm{m}$ (each side of the wall)

$\mathrm{A}_{\mathrm{s}, \min }=1.4 \mathrm{bw} \times \mathrm{d} / \mathrm{fy}=1190 \mathrm{~mm}^{2} / \mathrm{m} \quad$ (each side of the wall)

Ratio of $\mathrm{A}_{\mathrm{s}, \mathrm{min}}$ for shrinkage $=0.005$ both sides

$A_{s, \min }$ for shrinkage $=850 \mathrm{~mm}^{2} / \mathrm{m}$

$\mathrm{A}_{\mathrm{s}, \min }=850 \mathrm{~mm}^{2} / \mathrm{m}$ 

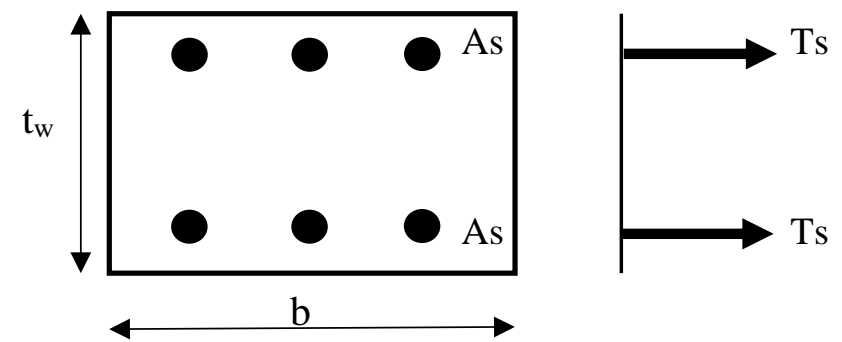

$\mathrm{N}_{\mathrm{u} 1}=1.4\left(\mathrm{~N}_{\mathrm{D}}+\mathrm{N}_{\mathrm{f}}\right)=464.2 \mathrm{kN} / \mathrm{m}$

$\mathrm{N}_{\mathrm{u} 2}=1.2 \mathrm{~N}_{\mathrm{D}}+1.2 \mathrm{~N}_{\mathrm{f}}+1.0 \mathrm{~N}_{\mathrm{E}}=606.8 \mathrm{kN} / \mathrm{m}$

Environmental exposure: Normal

Direct and hoop tensile stress in normal environmental exposures $>20000$ psi

$\mathrm{f}_{\mathrm{s}}=138 \mathrm{MPa}$

$\gamma=($ Factored load $) /($ Unfactored load $)=1.40$

$S_{d}=\left(\varphi \times f_{y}\right) /\left(\gamma \times f_{s}\right)=1.86$

$\mathrm{S}_{\mathrm{d} X ~} \mathrm{~N}_{\mathrm{u} 1}=865.4 \mathrm{kN} / \mathrm{m}$

$\mathrm{N}_{\mathrm{u}}=\operatorname{Max}\left(\mathrm{S}_{\mathrm{d}} \times \mathrm{N}_{\mathrm{u} 1} \& \mathrm{~N}_{\mathrm{u} 2}\right)=865.4 \mathrm{kN} / \mathrm{m}$

$\mathrm{S}_{\mathrm{d}} \mathrm{N}_{\mathrm{u}} \leq \varphi \mathrm{N}_{\mathrm{n}}$

$\mathrm{N}_{\mathrm{u}=} \varphi \mathrm{A}_{\mathrm{s}} \times \mathrm{f}_{\mathrm{y}} \quad \gg \mathrm{A}_{\mathrm{s}}=\mathrm{N}_{\mathrm{u}} / \varphi \mathrm{f}_{\mathrm{y}}$

$\mathrm{A}_{\mathrm{s}, \mathrm{req}} \mathrm{d}=1202$

$A_{s}=\max \left(A_{s, r e q ' d}, A_{s, \min }\right)=1202 \mathrm{~mm}^{2} / \mathrm{m} \quad($ each side of the wall $)$

\section{C.2.1 Control of Concrete Cracking}

$\mathrm{S}=150 \mathrm{~mm}$

$\mathrm{S}=5.9055 \mathrm{inch}$

$\beta=1.35$

$\mathrm{f}_{\mathrm{s}-\max }=30.633 \mathrm{ksi}$

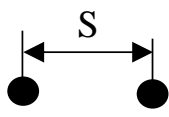

$20 \mathrm{ksi}<\mathrm{f}_{\mathrm{s}-\max }=320 / \beta\left(\mathrm{S}^{2}+25\right)^{1 / 2}<36 \mathrm{ksi} \quad>$ It is safe. 


\section{C.3 Design of Concrete Section (Vertical reinforcement)}

Reference:

Code Requirements for Environmental Engineering Concrete Structures (ACI 350-01) and Commentary (ACI 350R-01) - 2003.

\section{Strength Design Method}

Load due to fluid

$$
\begin{array}{ll}
\text { Mf }=63.0 & \mathrm{kN} / \mathrm{m} \\
\mathrm{Vf}=87.9 & \mathrm{kN} / \mathrm{m}
\end{array}
$$

\section{Load due to earthquake}

$$
\begin{array}{ll}
\mathrm{M}_{\mathrm{E}}=36.5 & \mathrm{kN} / \mathrm{m} \\
\mathrm{V}_{\mathrm{E}}=47.8 & \mathrm{kN} / \mathrm{m}
\end{array}
$$

$\mathrm{f}_{\mathrm{c}}^{\prime}=30 \quad \mathrm{MPa}$

$\mathrm{f}_{\mathrm{y}}=400 \mathrm{MPa}$

$\varphi=0.9 \quad$ Tension-controlled sections

Concrete Cover $=50 \quad \mathrm{~mm}$

Bar sizes $=20 \quad \mathrm{~mm}$

Spacing between bars $S=150 \mathrm{~mm}$

$\begin{array}{ll}\mathrm{t}_{\mathrm{w}}=400 & \mathrm{~mm} \\ \mathrm{~d}=340 & \mathrm{~mm} \\ \mathrm{~d}_{1}=140 & \mathrm{~mm} \\ \mathrm{~b}=1000 & \mathrm{~mm} \\ \mathrm{~d}_{\mathrm{c}}=60 & \mathrm{~mm}\end{array}$

$A_{s, \min }=0.25\left(f_{c}^{\prime}\right)^{2} \times f_{y} \times b \times d=1164 \mathrm{~mm}^{2} / \mathrm{m} \quad($ each side of the wall $)$

$\mathrm{A}_{\mathrm{s}, \min }=1.4 \mathrm{bw} \times \mathrm{d} / \mathrm{fy}=1190 \mathrm{~mm}^{2} / \mathrm{m} \quad$ (each side of the wall)

Ratio of $\mathrm{A}_{\mathrm{s}, \min }$ for shrinkage $=0.005$ both sides

$A_{s, \min }$ for shrinkage $=850 \mathrm{~mm}^{2} / \mathrm{m}$

$\mathrm{A}_{\mathrm{s}, \min }=850 \mathrm{~mm}^{2} / \mathrm{m}$ 
$\varphi \mathrm{M}_{\mathrm{n}} \geq \mathrm{S}_{\mathrm{d}} \mathrm{M}_{\mathrm{u}}$

$0.85 \mathrm{f}_{\mathrm{c}}$

$\mathrm{C}_{\mathrm{c}}=\mathrm{T}_{\mathrm{s}}$

$\mathrm{C}_{\mathrm{c}}=0.85 \times \mathrm{f}_{\mathrm{c}}^{\prime} \times \mathrm{a} \times \mathrm{b}$

$\varphi \mathrm{M}_{\mathrm{n}}=\varphi \times \mathrm{T}_{\mathrm{s}}(\mathrm{d}-\mathrm{a} / 2)$

$\mathrm{M}_{\mathrm{u} 1}=1.4\left(\mathrm{M}_{\mathrm{D}}+\mathrm{M}_{\mathrm{f}}\right)=88.3 \mathrm{kN} \cdot \mathrm{m} / \mathrm{m}$

$\mathrm{M}_{\mathrm{u} 2}=1.2 \mathrm{M}_{\mathrm{D}}+1.2 \mathrm{M}_{\mathrm{f}}+1.0 \mathrm{M}_{\mathrm{E}}=112.1 \mathrm{kN} \cdot \mathrm{m} / \mathrm{m}$

Environmental exposure: Normal

If $\mathrm{t}>406.4 \mathrm{~mm}, \beta=1.2$

If $\mathrm{t}<406.4 \mathrm{~mm}, \beta=1.35$

Direct and hoop tensile stress in normal environmental exposures >> $20000 \mathrm{psi}$

$\mathrm{f}_{\mathrm{s}}=138 \mathrm{MPa}$

$\gamma=($ Factored load $) /($ Unfactored load $)=1.40$

$S_{d}=\left(\varphi \times f_{y}\right) /\left(\gamma \times f_{s}\right)=1.86$

$\mathrm{S}_{\mathrm{d}} \times \mathrm{M}_{\mathrm{u} 1}=164.6 \mathrm{kN} \cdot \mathrm{m} / \mathrm{m}$

$\mathrm{M}_{\mathrm{u}}=\operatorname{Max}\left(\mathrm{S}_{\mathrm{d}} \times \mathrm{M}_{\mathrm{u} 1} \& \mathrm{M}_{\mathrm{u} 2}\right)=164.6 \mathrm{kN} \cdot \mathrm{m} / \mathrm{m}$

Solve quadratic equation to find "a":

$\varphi \mathrm{M}_{\mathrm{u}}=0.85 \times \mathrm{f}_{\mathrm{c}}^{\prime} \times \mathrm{a} \times \mathrm{b} \times(\mathrm{d}-\mathrm{a} / 2)$

$\mathrm{a}=21.8 \mathrm{~mm}$

If $\mathrm{f}_{\mathrm{c}}^{\prime}<30 \mathrm{MPa} \quad \gg>\beta_{1}=0.85$

If $\mathrm{f}_{\mathrm{c}}^{\prime}>30 \mathrm{MPa} \quad \gg>\beta_{1}=0.85-0.008\left(\mathrm{f}_{\mathrm{c}}{ }_{\mathrm{c}}-30\right) \geq 0.65$

$\beta_{1}=0.85$

$\mathrm{c}=\beta_{1} \times \mathrm{a}=25.6 \mathrm{~mm}$

$\mathrm{C}_{\mathrm{c}}=\mathrm{T}_{\mathrm{s}}=55.6 \mathrm{kN}$

$\mathrm{A}_{\mathrm{s}}=\mathrm{T}_{\mathrm{s}} / \mathrm{f}_{\mathrm{y}}=1389 \mathrm{~mm}^{2} / \mathrm{m}$

$\mathrm{A}_{\mathrm{s}}=\max \left(\mathrm{A}_{\mathrm{s}, \text { req'd }}, \mathrm{A}_{\mathrm{s}, \min }\right)=1389 \mathrm{~mm}^{2} / \mathrm{m} \quad($ each side of the wall $)$ 


\section{C.3.1 Check Shear Resistance}

$\mathrm{V}_{\mathrm{u} 1}=1.4\left(\mathrm{~V}_{\mathrm{D}}+\mathrm{V}_{\mathrm{f}}\right)=$

$\mathrm{V}_{\mathrm{u} 2}=1.2 \mathrm{~V}_{\mathrm{D}}+1.2 \mathrm{~V}_{\mathrm{f}}+1.0 \mathrm{~V}_{\mathrm{E}}=$

$\varphi=0.75$ Shear-controlled sections

Shear stress carried by shear reinforcement in normal environmental exposures $\gg>24000 \mathrm{psi}$

$\mathrm{f}_{\mathrm{s}}=166 \mathrm{MPa}$

$\gamma=($ Factored load $) /($ Unfactored load $)=1.40$

$S_{d}=\left(\varphi \times f_{y}\right) /\left(\gamma \times f_{s}\right)=1.29 \geq 1.0$

Shear stress carried by shear reinforcement: No

$\mathrm{S}_{\mathrm{d}}=1.0$

$\mathrm{S}_{\mathrm{d}} \times \mathrm{V}_{\mathrm{u} 1}=123.1 \mathrm{kN} / \mathrm{m}$

$\mathrm{V}_{\mathrm{u}}=\operatorname{Max}\left(\mathrm{S}_{\mathrm{d}} \times \mathrm{V}_{\mathrm{u} 1} \& \mathrm{~V}_{\mathrm{u} 2}\right)=153.3 \mathrm{kN} / \mathrm{m}$

$\varphi \mathrm{V}_{\mathrm{n}} \geq \mathrm{S}_{\mathrm{d}} \times \mathrm{V}_{\mathrm{u}}$

$\mathrm{V}_{\mathrm{n}}=\mathrm{V}_{\mathrm{c}}+\mathrm{V}_{\mathrm{s}}$

$\mathrm{V}_{\mathrm{s}}=0$

$\mathrm{V}_{\mathrm{c}} \leq 3.5\left(\mathrm{f}_{\mathrm{c}}\right)^{2} \times \mathrm{b}_{\mathrm{w}} \times \mathrm{d}$

$\left.V_{c}=\left[\left(f_{c}^{\prime}\right)^{2}+120 \rho_{w} \times(V u \times d) / M_{u}\right)\right] \times\left(b_{w} \times d / 7\right) \leq 0.3\left(f_{c}^{\prime}\right)^{2} \times b_{w} \times d$

$\rho_{\mathrm{w}}=0.0041$

$(\mathrm{Vu} \times \mathrm{d}) / \mathrm{M}_{\mathrm{u}}=0.3167 \leq 1.0$

$\mathrm{V}_{\mathrm{c}}=273.58 \mathrm{kN} / \mathrm{m}$

$\mathrm{V}_{\mathrm{c}, \min }=0.3\left(\mathrm{f}_{\mathrm{c}}^{\prime}\right)^{2} \times \mathrm{b}_{\mathrm{w}} \times \mathrm{d}=558.68 \mathrm{kN} / \mathrm{m}$

$\mathrm{V}_{\mathrm{c}}=273.58 \mathrm{kN} / \mathrm{m} \leq \mathrm{V}_{\mathrm{c}, \min }=558.68 \mathrm{kN} / \mathrm{m}$

$\varphi \mathrm{V}_{\mathrm{n}}=205.18 \geq \mathrm{V}_{\mathrm{u}}=153.3 \mathrm{kN} / \mathrm{m} \quad \gg \gg>$ It is safe.

\section{C.3.2 Control of Concrete Cracking}

$\mathrm{S}=150 \mathrm{~mm}$

$\mathrm{S}=5.9055 \mathrm{inch}$

$\beta=1.35$

$\mathrm{f}_{\mathrm{s}-\max }=30.633 \mathrm{ksi}$

$20 \mathrm{ksi}<\mathrm{f}_{\mathrm{s}-\max }=320 / \beta\left(\mathrm{S}^{2}+25\right)^{1 / 2}<36 \mathrm{ksi} \quad>>$ It is safe. 


\section{APPENDIX D}

EARTHQUAKE DESIGN LOADS AND LOAD DISTRIBUTION OF GROUND-SUPPORTED FLEXIBLE-BASE CIRCULAR TANK 
Design of Circular Tank Type 2.3 (1)

\section{Earthquake Design Loads and Load Distribution}

Reference:

Seismic Design of Liquid-Containing Concrete Structures (ACI350.3R-06) and Commentary (350.3R-06)

\section{D.1 Design Data}

$\mathrm{D}=\mathbf{4 0 . 0}$

$\mathrm{m}$

$\mathrm{H}_{\mathrm{w}}=\mathbf{6 . 5 0}$

$\mathrm{m}$

$H_{L}=\mathbf{6 . 0}$

$\mathrm{m}$

$\mathrm{t}_{\mathrm{w}}=\mathbf{3 0 0}$

$\mathrm{mm}$

$\mathrm{H}_{\mathrm{w}}(\min )=6.44$

$\mathrm{m}$

Freeboard $>$ Freeboard allowance (okay)

$\begin{array}{ll}\mathrm{g}_{\mathrm{L}}=\mathbf{9 . 8} & \mathrm{kN} / \mathrm{m}^{3} \\ \mathrm{~g}_{\mathrm{c}}=\mathbf{2 3 . 6} & \mathrm{kN} / \mathrm{m}^{3} \\ \rho_{\mathrm{L}}=\mathbf{1 . 0} & \mathrm{kN} \cdot \mathrm{s}^{2} / \mathrm{m}^{4} \\ \rho_{\mathrm{c}}=\mathbf{2 . 4} & \mathrm{kN} \cdot \mathrm{s}^{2} / \mathrm{m}^{4} \\ \mathrm{f}^{\prime} \mathrm{c}=\mathbf{3 0} & \mathrm{MPa}\end{array}$

$\mathrm{E}_{\mathrm{c}}=\mathbf{2 4 6 4 8} \quad \mathrm{MPa}$

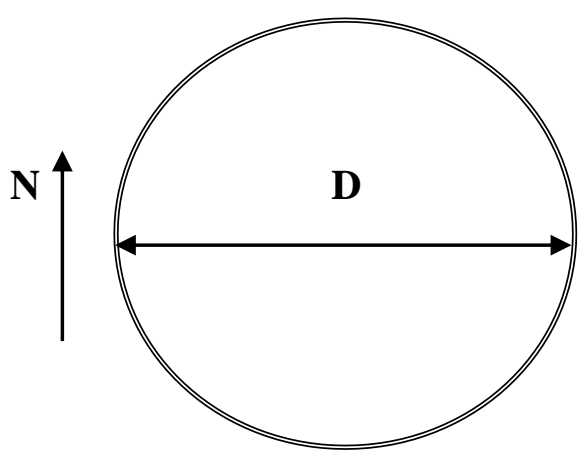

$\mathrm{S}_{\mathrm{S}}=\mathbf{1 5 0 \%} \quad \mathrm{g}$

$\mathrm{S}_{1}=60 \% \quad \mathrm{~g}$

$F_{a}=\mathbf{0 . 8}$

$F_{v}=\mathbf{0 . 8}$

$\mathrm{I}=\mathbf{1 . 0}$

g g

Type of structure is anchored, flexible base

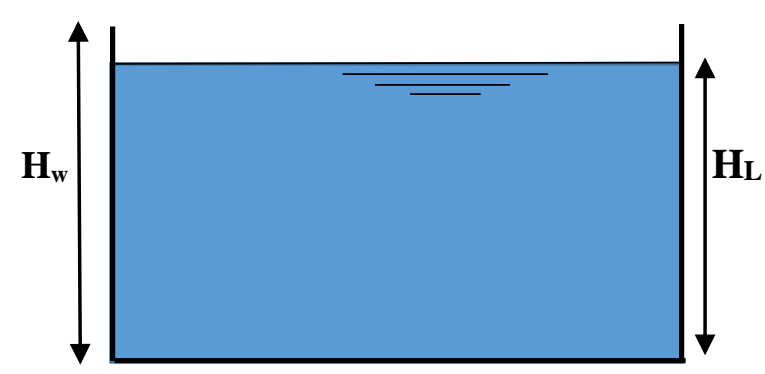

Section

$\mathrm{R}_{\mathrm{i}}=\mathbf{3 . 2 5}$

$\mathrm{R}_{\mathrm{c}}=\mathbf{1 . 0}$ 


\section{D.2 Dynamic Model}

$$
\begin{aligned}
& \mathrm{S}_{\mathrm{DS}}=2 / 3\left(\mathrm{~S}_{\mathrm{S}} \times \mathrm{F}_{\mathrm{a}}\right)=0.8 \quad \mathrm{~g} \\
& \mathrm{~S}_{\mathrm{D} 1}=2 / 3(\mathrm{~S} 1 \times \mathrm{Fv})=0.32 \quad \mathrm{~g} \\
& \mathrm{~T}_{\mathrm{S}}=\mathrm{S}_{\mathrm{D} 1} / \mathrm{S}_{\mathrm{DS}}=0.4 \\
& \lambda=\left(3.68 \times \mathrm{g} \times \tanh \left(3.68\left(\mathrm{H}_{\mathrm{L}} / \mathrm{D}\right)\right)^{1 / 2}=7.71\right. \\
& \mathrm{T}_{\mathrm{c}}=(2 \pi / \lambda)(\mathrm{D})^{1 / 2}=9.34 \quad \mathrm{~s} \\
& \mathrm{C}_{\mathrm{c}}=2.4 \times \mathrm{S}_{\mathrm{DS}} / \mathrm{T}_{\mathrm{c}}{ }^{2}=0.022 \\
& \mathrm{~d}_{\max }=(\mathrm{D} / 2) \times\left(\mathrm{I} \times \mathrm{C}_{\mathrm{c}}\right)=0.44 \quad \mathrm{~m} \\
& \mathrm{~W}_{\mathrm{w}}=\mathrm{g}_{\mathrm{c}} \times \mathrm{t}_{\mathrm{w}} \times \mathrm{H}_{\mathrm{w}} \times\left(\pi\left(\mathrm{D}+\mathrm{t}_{\mathrm{w}} / 2\right)\right)=5797.2 \quad \mathrm{kN} \\
& \mathrm{W}_{\mathrm{L}}=\mathrm{g}_{\mathrm{L}} \times \mathrm{H}_{\mathrm{L}} \times \pi \times(\mathrm{D} / 2)^{2}=73972.8 \quad \mathrm{kN} \\
& \mathrm{W}_{\mathrm{i}} / \mathrm{W}_{\mathrm{L}}=\tanh \left[0.866\left(\mathrm{D} / \mathrm{H}_{\mathrm{L}}\right)\right] /\left(0.866\left(\mathrm{D} / \mathrm{H}_{\mathrm{L}}\right)\right)=0.17 \\
& \mathrm{~W}_{\mathrm{i}}=12812.6 \quad \mathrm{kN} \\
& \mathrm{W}_{\mathrm{c}} / \mathrm{W}_{\mathrm{L}}=0.230\left(\mathrm{D} / \mathrm{H}_{\mathrm{L}}\right) \times \tanh \left[3.68\left(\mathrm{H}_{\mathrm{L}} / \mathrm{D}\right)\right]=0.77 \\
& \mathrm{~W}_{\mathrm{c}}=56941.3 \quad \mathrm{kN} \\
& h_{i} / H_{L}=0.375 \\
& \mathrm{~h}_{\mathrm{i}}=2.25 \quad \mathrm{~m} \\
& \mathrm{~h}_{\mathrm{c}} / \mathrm{H}_{\mathrm{L}}=0.51 \\
& \mathrm{~h}_{\mathrm{c}}=3.07 \quad \mathrm{~m} \\
& \mathrm{~h}_{\mathrm{i}}^{\prime} / \mathrm{H}_{\mathrm{L}}=2.76 \\
& \mathrm{~h}_{\mathrm{i}}^{\prime}=16.57 \quad \mathrm{~m} \\
& h^{\prime}{ }_{c} / H_{L}=3.66 \\
& \mathrm{~h}_{\mathrm{c}}^{\prime}=21.99 \quad \mathrm{~m} \\
& \mathrm{C}_{\mathrm{w}}=0.122 \\
& \mathrm{C}_{\mathrm{l}}=\mathrm{C}_{\mathrm{w}} \times\left(\mathrm{t}_{\mathrm{w}} /(10 \times \mathrm{R})^{1 / 2}=0.149\right.
\end{aligned}
$$


D.2.1 Calculate spring constant of the tank wall in Tank Type 2.3 (1)

$\begin{array}{ll}\mathrm{A}_{\mathrm{s}}=\mathbf{7 0 0} & \mathrm{mm} 2 \\ \mathrm{E}_{\mathrm{s}}=\mathbf{2 0 0 0 0 0} & \mathrm{MPa} \\ \alpha=\mathbf{4 5} & \text { degrees } \\ \mathrm{L}_{\mathrm{c}}=\mathbf{8 3 8} & \mathrm{mm} \\ \mathrm{S}_{\mathrm{s}}=\mathbf{2 0 0 0} & \mathrm{mm} \\ \mathrm{G}_{\mathrm{p}}=\mathbf{0 . 3 4 5} & \mathrm{MPa} \\ \mathrm{W}_{\mathrm{p}}=\mathbf{3 0 0} & \mathrm{mm} \\ \mathrm{L}_{\mathrm{p}}=\mathbf{1 0 0 0} & \mathrm{mm} \\ \mathrm{t}_{\mathrm{p}}=\mathbf{2 5 . 4} & \mathrm{mm} \\ \mathrm{S}_{\mathrm{p}}=\mathbf{1 0 0 0} & \mathrm{mm}\end{array}$

$\mathrm{K}_{\mathrm{a}}($ radial $)=8150 \quad \mathrm{~N} / \mathrm{m}$ per $\mathrm{m}$

$\mathrm{K}_{\mathrm{a}}($ tangential $)=49916 \quad \mathrm{~N} / \mathrm{m}$ per $\mathrm{m}$

$\mathrm{F}_{\max }=252.04 \quad \mathrm{kN} \quad(\max$ force per acting seismic cable)

$\mathrm{T}_{\mathrm{i}}=\left[8 \pi\left(\mathrm{W}_{\mathrm{w}}+\mathrm{W}_{\mathrm{r}}+\mathrm{W}_{\mathrm{i}}\right) /\left(\mathrm{g} \times \mathrm{D} \times \mathrm{K}_{\mathrm{a}}\right)\right]^{1 / 2}=0.1546 \quad \mathrm{~s}$

$\mathrm{C}_{\mathrm{i}}=\mathrm{S}_{\mathrm{DS}}=0.80$

$\varepsilon=\left[0.151 \times\left(\mathrm{D} / \mathrm{H}_{\mathrm{L}}\right)^{2}-0.1908\left(\mathrm{D} / \mathrm{H}_{\mathrm{L}}\right)+1.021\right]<=1.0=0.42$ 


\section{D.3 Earthquake Design Loads}

\section{D.3.1 Dynamic Lateral Forces}

$\mathrm{P}_{\mathrm{w}}=\mathrm{IC}_{\mathrm{i}} \times\left[\varepsilon \mathrm{W}_{\mathrm{w}} / \mathrm{R}_{\mathrm{i}}\right]=599.5 \quad \mathrm{kN}$

$\mathrm{P}_{\mathrm{i}}=\mathrm{IC}_{\mathrm{i}} \times\left[\mathrm{W}_{\mathrm{i}} / \mathrm{R}_{\mathrm{i}}\right]=3153.9 \quad \mathrm{kN}$

$\mathrm{P}_{\mathrm{c}}=\mathrm{IC}_{\mathrm{c}} \times\left[\mathrm{W}_{\mathrm{c}} / \mathrm{R}_{\mathrm{c}}\right]=1253.1 \quad \mathrm{kN}$

\section{D.3.2 Total base shear}

$\mathrm{V}=\left(\left(\mathrm{P}_{\mathrm{i}}+\mathrm{P}_{\mathrm{w}}+\mathrm{P}_{\mathrm{r}}\right)^{2}+\mathrm{P}_{\mathrm{c}}{ }^{2}\right)^{1 / 2}=3957.0 \quad \mathrm{kN}$

D.3.3 Bending moment on the entire tank cross section (EBP)

$\mathrm{M}_{\mathrm{w}}=\mathrm{P}_{\mathrm{w}} \times \mathrm{h}_{\mathrm{w}}=1948.4 \quad \mathrm{kN} \cdot \mathrm{m}$

$\mathrm{M}_{\mathrm{i}}=\mathrm{P}_{\mathrm{i}} \times \mathrm{h}_{\mathrm{i}}=7096.2 \quad \mathrm{kN} . \mathrm{m}$

$\mathrm{M}_{\mathrm{c}}=\mathrm{P}_{\mathrm{c}} \times \mathrm{h}_{\mathrm{c}}=3852.0 \quad \mathrm{kN} . \mathrm{m}$

$\mathrm{M}_{\mathrm{h}}=\left(\left(\mathrm{M}_{\mathrm{i}}+\mathrm{M}_{\mathrm{w}}+\mathrm{M}_{\mathrm{r}}\right)^{2}+\mathrm{M}_{\mathrm{c}}{ }^{2}\right)^{1 / 2}=9830.7 \mathrm{kN} \cdot \mathrm{m}$

D.3.4 Overturning moment at the base of the tank (IBP)

$\mathrm{M}_{\mathrm{i}}^{\prime}=\mathrm{P}_{\mathrm{i}} \times \mathrm{h}_{\mathrm{i}}^{\prime}=52260.7 \quad \mathrm{kN} . \mathrm{m}$

$\mathrm{M}_{\mathrm{c}}^{\prime}=\mathrm{P}_{\mathrm{c}} \times \mathrm{h}_{\mathrm{c}}^{\prime}=27552.2 \quad \mathrm{kN} \cdot \mathrm{m}$

$\mathrm{M}_{0}=\left(\left(\mathrm{M}_{\mathrm{i}}+\mathrm{M}_{\mathrm{w}}+\mathrm{M}_{\mathrm{r}}\right)^{2}+\mathrm{M}_{\mathrm{c}}{ }^{2}\right)^{1 / 2}=60809.1 \quad \mathrm{kN} . \mathrm{m}$

\section{D.3.5 Vertical acceleration}

$\mathrm{T}_{\mathrm{v}}=2 \pi\left[\left(\mathrm{g}_{\mathrm{L}} \times \mathrm{D} \times \mathrm{H}_{\mathrm{L}}^{2}\right) /\left(24 \times \mathrm{g} \times \mathrm{t}_{\mathrm{w} \times} \mathrm{E}_{\mathrm{c}}\right)\right]^{1 / 2}=0.06 \quad \mathrm{~s}$

$\mathrm{C}_{\mathrm{t}}=\mathrm{S}_{\mathrm{DS}}=0.80$

$b=2 / 3=0.67$

$\ddot{U}=\mathrm{C}_{\mathrm{t}} \mathrm{I}\left[\mathrm{b} / \mathrm{R}_{\mathrm{i}}\right]>=0.2 \mathrm{~S}_{\mathrm{DS}}=0.164$

$\mathrm{P}_{\mathrm{hL}}=\ddot{U} \mathrm{q}_{\mathrm{hL}}=9.66 \quad \mathrm{kPa}$ 


\section{D.4 Earthquake Load Distribution}

\section{D.4.1 Seismic Forces}

1- Hydrostatic force, $\mathrm{P}_{\mathrm{h}}=7061.0 \quad \mathrm{kN}$

2-Vertical acceleration effect, $\ddot{U} \times \mathrm{P}_{\mathrm{h}}=1158.7 \quad \mathrm{kN}$

3- Impulsive force, $\mathrm{P}_{\mathrm{i}} / 2=1576.9 \quad \mathrm{kN}$

4- Convective force, $\mathrm{P}_{\mathrm{c}} / 2=626.6 \quad \mathrm{kN}$

5- Wall inertia force, $\mathrm{P}_{\mathrm{w}} / 2=299.8 \quad \mathrm{kN}$

- Max. static shear force in wall=7061.0 kN/m

- Max. seismic shear force in wall $=2292.9 \quad \mathrm{kN} / \mathrm{m}$

- Max. static bending moment in wall $=14122.08 \quad \mathrm{kN} . \mathrm{m} / \mathrm{m}$

- Max. seismic bending moment in wall $=5434.3 \quad \mathrm{kN} . \mathrm{m} / \mathrm{m}$

\section{D.4.2 Seismic Pressures}

1- Hydrostatic pressures, $\mathrm{P}_{\mathrm{h}}=176.5 \quad \mathrm{kN} / \mathrm{m}$

2-Vertical acceleration effect, $\ddot{U} \times \mathrm{P}_{\mathrm{h}}=29.0 \quad \mathrm{kN} / \mathrm{m}$

3- Impulsive pressures, $\mathrm{p}_{\mathrm{i}}=\left(2 \mathrm{P}_{\mathrm{i}} / 2\right) /(\pi \mathrm{R})=50.2 \quad \mathrm{kN} / \mathrm{m}$

4- Convective pressures, $p_{c}=(16 \mathrm{Pc} / 2) /(9 \pi \mathrm{R})=17.7 \quad \mathrm{kN} / \mathrm{m}$

5- Wall inertia force, $\mathrm{p}_{\mathrm{w}}=\left(\mathrm{P}_{\mathrm{w}} / 2\right) /(\pi \mathrm{R})=4.8 \quad \mathrm{kN} / \mathrm{m}$ 
D.5 Earthquake Load Distribution along tank wall at $\theta=0$

\begin{tabular}{|c|c|c|c|c|c|c|}
\cline { 2 - 7 } \multicolumn{1}{c|}{} & Static & \multicolumn{6}{c|}{ Seismic } \\
\hline $\mathbf{y}$ & HS & $\ddot{U}_{\mathbf{x q}}$ & $\mathbf{P i}_{\mathbf{y}}$ & $\mathbf{P}_{\mathbf{c y}}$ & $\mathbf{P}_{\mathbf{w y}}$ & HD \\
\hline $\mathbf{6 . 5 0}$ & 0 & 0 & 0 & 0 & 0.73 & 0.7 \\
\hline $\mathbf{6 . 0}$ & 0 & 0 & 2.09 & 3.17 & 0.73 & 4.2 \\
\hline $\mathbf{5 . 0}$ & 9.81 & 1.61 & 4.18 & 3.10 & 0.73 & 6.0 \\
\hline $\mathbf{4 . 0}$ & 19.61 & 3.22 & 6.27 & 3.03 & 0.73 & 8.3 \\
\hline $\mathbf{3 . 0}$ & 29.42 & 4.83 & 8.36 & 2.95 & 0.73 & 10.7 \\
\hline $\mathbf{2 . 0}$ & 39.23 & 6.44 & 10.45 & 2.88 & 0.73 & 13.2 \\
\hline $\mathbf{1 . 0}$ & 49.04 & 8.05 & 12.54 & 2.81 & 0.73 & 15.8 \\
\hline $\mathbf{0 . 0}$ & 58.84 & 9.66 & 14.63 & 2.74 & 0.73 & 18.4 \\
\hline
\end{tabular}

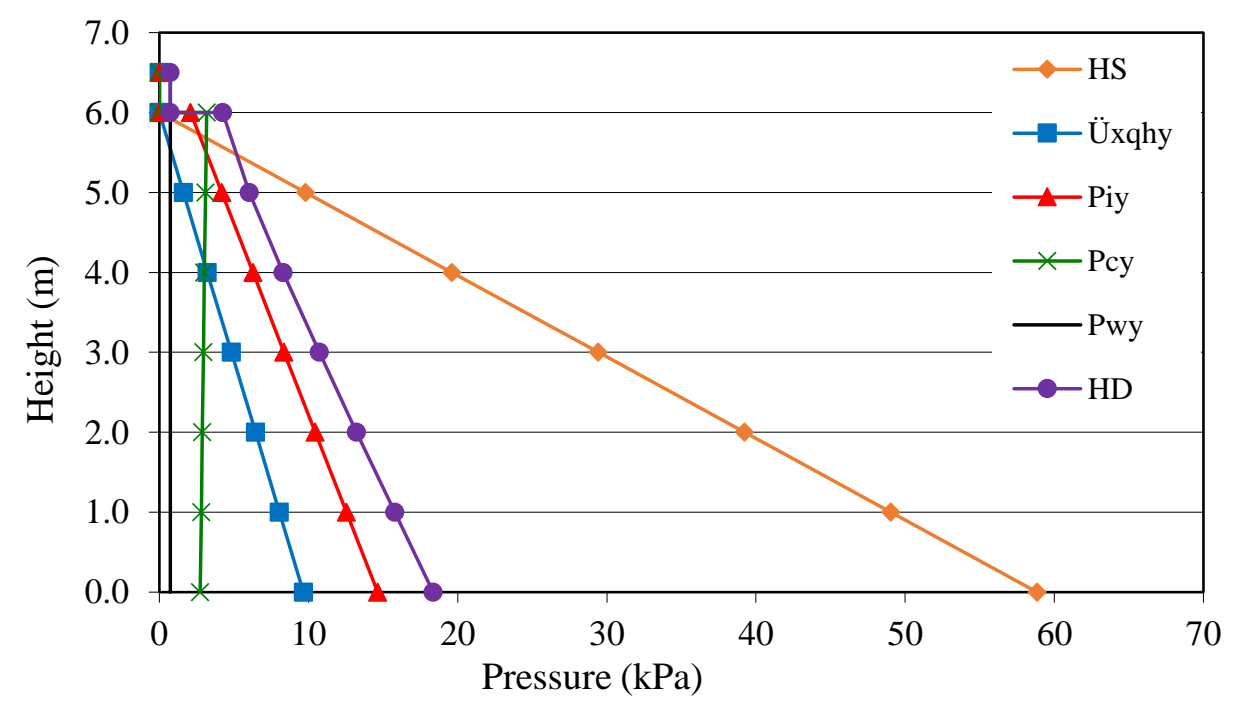




\section{APPENDIX E}

TEXT COMMAND FILES OF THE TANK'S PARAMETRIC MODEL AND THE POST-PROCESSOR ALGORITHMS IN PUSH-OVER ANALYSIS 


\section{E.1 Input file for the tank's parametric model}

The parameters defined for the tank's parametric model are defined as follows:

ri : Inner radius of the cylindrical tank (m)

hw : Height of the cylindrical tank (m)

$\mathrm{hl}$ : Height of liquid in the cylindrical tank (m)

tw : Thickness of the tank's wall (m)

Hi : Height above the base of the wall to the center of gravity of the impulsive lateral force for the case excluding base pressure $(\mathrm{m})$

Hc : Height above the base of the wall to the center of gravity of the convective lateral force for the case excluding base pressure (m)

Pim : Total lateral impulsive force $(\mathrm{N})$

Pc : Total lateral convective force $(\mathrm{N})$

PW : Lateral inertia force of the accelerating wall $(\mathrm{N})$

PHL : Total hydrostatic force occurring on diameter D of a circular tank (N)

AV : Rebar area in vertical direction (m2)

$\mathrm{AH}:$ Rebar area in hoop direction $\left(\mathrm{m}^{2}\right)$

Ec : Concrete modulus of elasticity $(\mathrm{Pa})$

nuc: Concrete Poisson's ratio

Es : Steel modulus of elasticity $(\mathrm{Pa})$

nus: Steel Poisson's ratio

fc : Concrete compressive strength $(\mathrm{Pa})$

fy: Yield strength of steel $(\mathrm{Pa})$

NHW: Number of mesh division in height of the tank's wall

NRI: Number of mesh division on one-quarter of the tank's circumference

Ntw: Number of mesh division in the tank's thickness 


\section{E.2 Text command file of the tank's parametric model}

Based on the parameters defined in section E.1, the text command file for the tank's parametric model is given as follows:

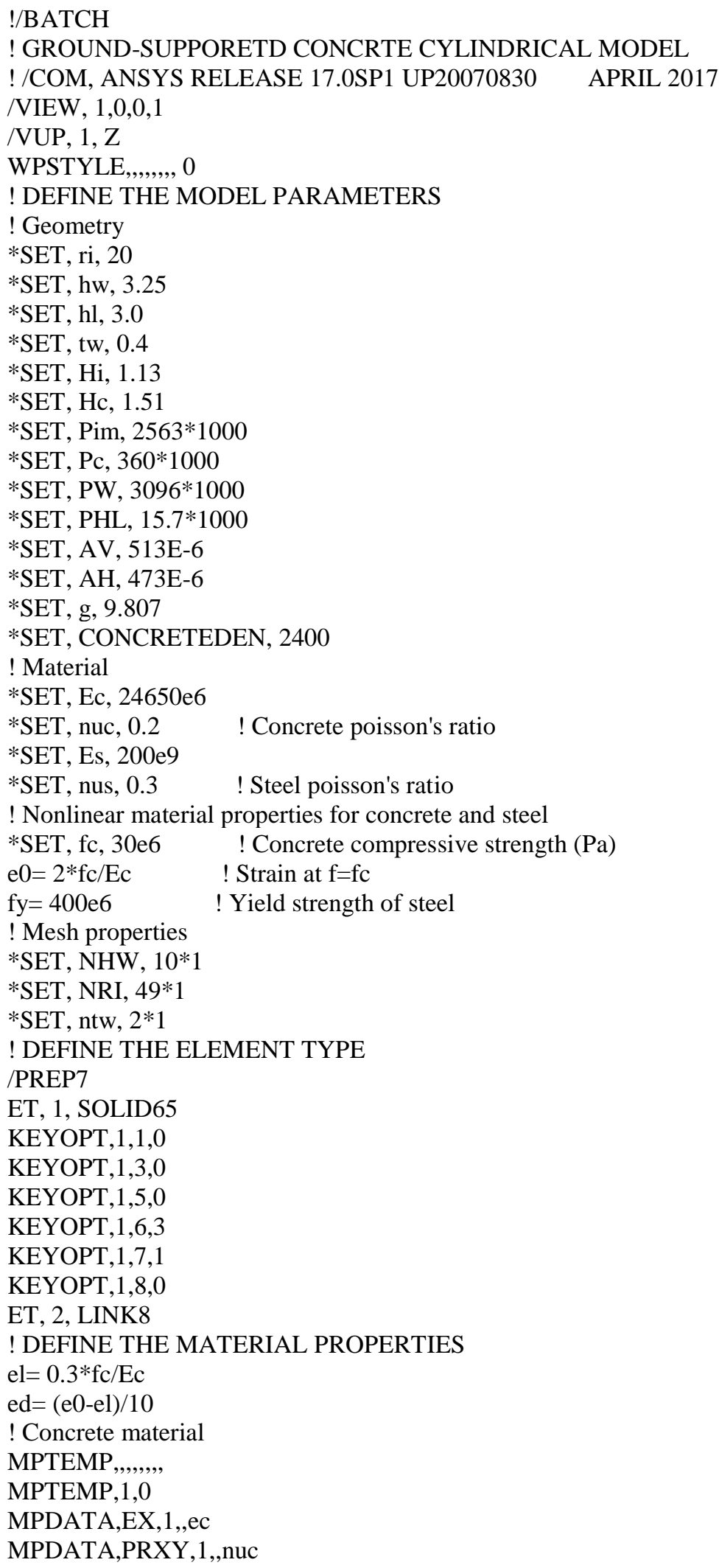


MP,Dens, 1,CONCRETEDEN

TB,CONC, $1,1,9$,

TBTEMP, 0

TBDATA, ,0.5,0.9,0.1*fc,-1,

TBDATA,,,0.6,,

TB,MISO, $1,1,11,0$

! Multi-linear isotropic hardening for concrete compression

TBTEMP, 0

! Steel material

MPTEMP,,,,,,,

MPTEMP, 1,0

MPDATA,EX,2,Es

MPDATA,PRXY,2,,nus

TB,BISO,2,1,2,

TBTEMP, 0

TBDATA,,fy, $0,,$,

!REALCONSTANT,MAT,RATIO1,THETA1,PHI,MAT,RATIO2,THETA2,PHI2

$\mathrm{R}, 1,,,,,$,

RMORE,,,,,,

RMORE, ,

! DEFINE THE REAL CONSTANT FOR REBAR ELEMENT

$\mathrm{R}, 2, \mathrm{Av}$

$\mathrm{R}, 3, \mathrm{AH}$

! NOTE: ALWAYS CHECK THE ORIENTATION OF REBARS

!1) PLOT CONTROLS_STYLE_SIZE AND SHAPE

!2) PLOT CONTROLS_DEVICE OPTION_VECTOR MODE

! CREATE THE HOLLOW CYLINDIR GEOMETRY

CYL4,0,0,ri, ,ri+tw, hw

! DIVIDE THE HOLLOW CYLINDER INTO FOUR PARTS USING WORK PLANES

FLST, $3,3,8$

FITEM,3, 1,0,0

FITEM, 3, 0,0,0

FITEM,3,0,0,1

WPLANE,-1,P51X

VSBW,

! VPLOT

FLST, 3,3,8

FITEM,3,0,1,0

FITEM,3,0,0,0

FITEM,3,0,0,1

WPLANE,-1,P51X

FLST,2,2,6,ORDE,2

FITEM, 2,2

FITEM,2,-3

VSBW,P51X

!!!!!!!!!!!!!!!!!!!! MESHING THE HOLLOW CYLINDER

Csys, 1

LOCAL, 111,1,0,0,0,0,0,0

! DEFINE A LOCAL COORDINATE SYSTEM ALLIGNED WITH

CYLINDRICAL CCORDINATE SYSTEM

!! ELEMENT AND MATERIAL TYPE

WPSTYLE,,,,,,,,0

TYPE, 1

MAT, 1

REAL, 1 !!!!! NOTE: ONLY FOR SOLID^\% ELEMENT

ESYS, $111 \quad$ ! SET ELEMENT COORDIANE SYSTEM AS THE PRE-DEFINED LOCAL

COORDINATE SYSTEM

SECNUM,

!! LINE DIVISIONS

FLST,5,8,4,ORDE,6

FITEM,5,17

FITEM,5,-20 
FITEM,5,26

FITEM,5,-27

FITEM,5,30

FITEM,5,-31

CM,_Y,LINE

LSEL, , , ,P51X

CM,_Y1,LINE

CMSEL,,_Y

LESIZE,_Y1, , NHw, , , , , ! IIVIDE THE HEIGHT OF TANK INTO NHW ELEMENTS

FLST, 5,8,4,ORDE, 5

FITEM,5,21

FITEM,5,-25

FITEM,5,28

FITEM,5,-29

FITEM,5,32

CM,_Y,LINE

LSEL, , , P51X

CM,_Y1,LINE

CMSEL,,_Y

LESIZE,_Y1, , ,Ntw, , , , ,

FLST, 5, 16,4,ORDE, 2

FITEM,5,1

FITEM,5,-16

CM,_Y,LINE

LSEL, , , ,P51X

CM,_Y1,LINE

CMSEL,,YY

LESIZE,_Y1, , ,2*nri, , , , , 0

! DIVIDE THE QUATER OF TANK PERIMETER INTO 2NRI ELEMENTS

!! re-orient the volume

VEORIENT,4,AREA, 18 ,

VEORIENT,6,AREA,27,

VEORIENT,1,AREA,13,

VEORIENT,5,AREA,23

!! MESH THE VOLUME

MSHAPE, $0,3 \mathrm{D}$

MSHKEY, 1

FLST, 5,4,6,ORDE, 3

FITEM,5,1

FITEM,5,4

FITEM,5,-6

$\mathrm{CM},, \mathrm{Y}, \mathrm{VOLU}$

VSEL, , , ,P51X

$\mathrm{CM}$,_Y1,VOLU

CHKMSH,'VOLU'

CMSEL,S,_Y

VMESH,_Y1

CMDELE,_Y

CMDELE,_Y1

CMDELE,_Y2

NumCmp, all

NumMrg,KP

NumMrg,Node

!!!!!!!!!!!!!!!!!! BOUNDARY CONDITION

!! ROTATE THE NODES IN CYLINDRICAL COORDINATES

CSYS, 1

NSEL, S, , ALL

NROTAT, ALL

ALLSEL

!! APLLY THE FIXED BOUNDARY CONDITION

NSEL, S, LOC, Z, 0 
/GO

D,ALL, , , , , ,UX,UY,UZ, , ,

ALLSEL, ALL

\section{E.3 Text command file of the solution and post-processing script}

The text command file of the nonlinear solution and post-processor is given below:

CSYS, 1

$\mathrm{pi}=\mathrm{ACOS}(-1)$

! Equation for dynamic pressure applied to the tank

![1.0] DEFINE THE PARAMETERS

$\mathrm{A}=10$

Num_Step_Sta $=10$

Num_Step_Dyn=2000

![2.0] DEFINE THE ARRAYS

*DIM,t_Sta,ARRAY,Num_Step_Sta

*DIM,t_Dyn,ARRAY,Num_Step_Dyn

*DIM,Rx_Sta,ARRAY,Num_Step_Sta

*DIM,Ry_Sta,ARRAY,Num_Step_Sta

*DIM,Rz_Sta,ARRAY,Num_Step_Sta

*DIM,Ux_Sta,ARRAY,Num_Step_Sta

*DIM,Ux_Dyn,ARRAY,Num_Step_Dyn

*DIM,Rx_Dyn,ARRAY,Num_Step_Dyn

*DIM,Ry_Dyn,ARRAY,Num_Step_Dyn

*DIM,Rz_Dyn,ARRAY,Num_Step_Dyn

! Filling out the time arrys

dt_Sta $=1.0 /$ Num_Step_Sta

dt_Dyn=1.0/Num_Step_Dyn

*DO,I,1,Num_Step_Sta

$\mathrm{t} \_\mathrm{Sta}(\mathrm{I})=(\mathrm{I}-1) * \mathrm{dt} \_\mathrm{Sta}+1.0$

*ENDDO

$\mathrm{t} \_\mathrm{Sta}(1,1)=1.0001$

*DO,I,1,Num_Step_Dyn

t_Dyn $(\mathrm{I})=2.0+(\mathrm{I}-1) * \mathrm{dt} \_$Dyn

*ENDDO

t_Dyn $(1,1)=2.0001$

![3.0] CREATING NODE/ELEMENT COMPONENTS AND LISTS

! CREAT COMPONENT INCLUDING DRY ELEMENTS

NSEL,S,LOC,Z,Hw,HL

ESLN,S,

CM,DRYELEM,ELEM

ALLSEL

! SELECT THE WET NODES AND ELEMENTS ON THE INTERIOR FACE OF THE CYLINDRICAL TANK

NSEL,S,LOC,X,ri ! SELECT THE NODES

ESLN,S ! SELECT THE ELEMENTS ATTACHED TO THE NODES

CMSEL,U,DRYELEM,ELEM

ESEL,U,TYPE,,2 ! UNSELECT LINK ELEMENTS

! STORING THE ELEMENT/NODE LISTS

*GET,NumSNode,NODE,,COUNT

*GET,NumSElem,ELEM,,COUNT

*DIM,LSNode,ARRAY,NumSNode

*DIM,LSElem,ARRAY,NumSElem

*DIM,XSElem,ARRAY,NumSElem

*DIM,YSElem,ARRAY,NumSElem

*DIM,ZSElem,ARRAY,NumSElem

*DIM,PN,ARRAY,NumSElem

*VGET,LSNode(1),NODE,,NLIST

*VGET,LSElem(1),ELEM,,ELIST

![4.0] GENERAL ANALYSIS SETUP 


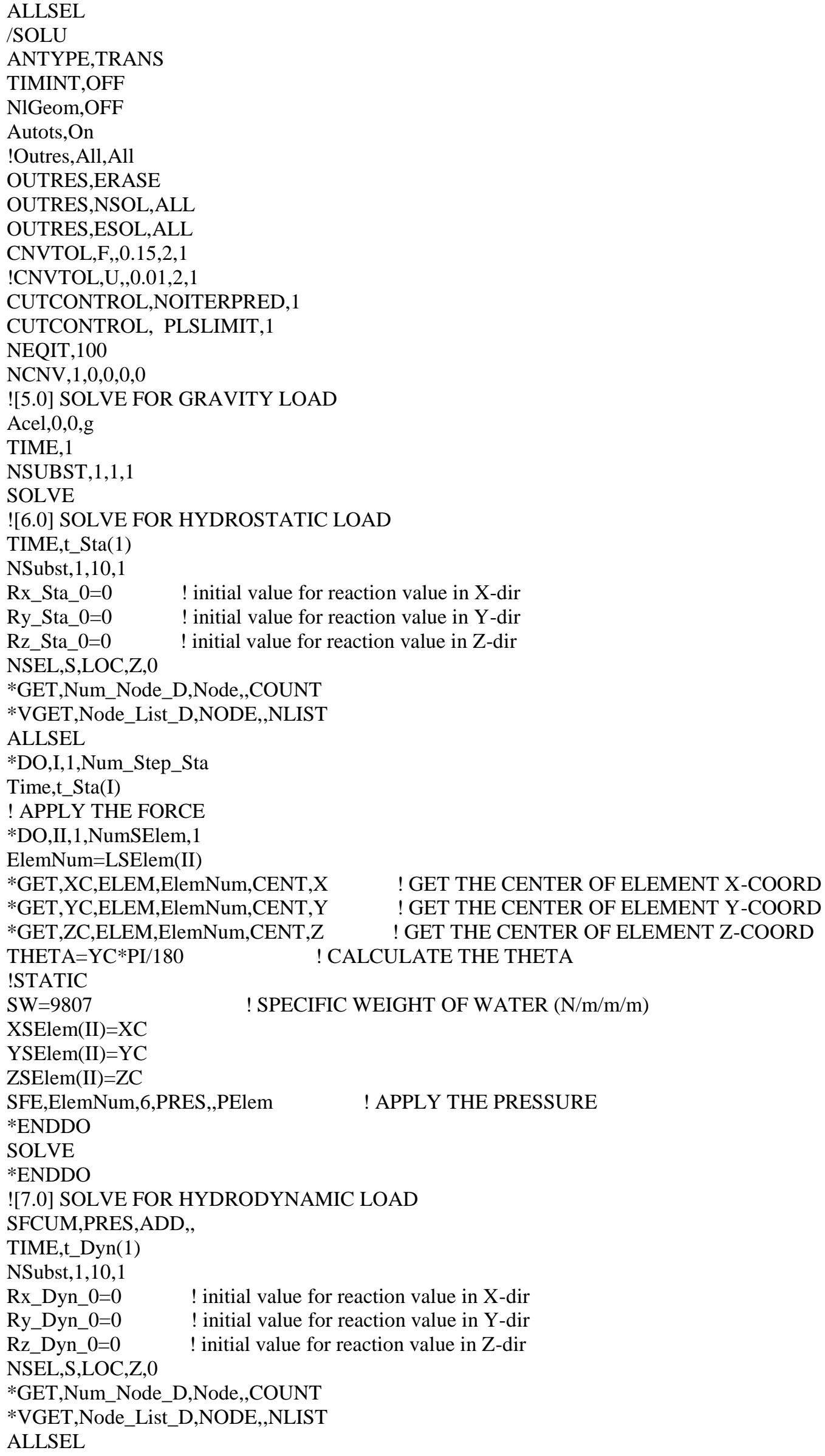


*DO,I,1,Num_Step_Dyn

Time,t_Dyn(I)

*DO,II,1,NumSElem, 1

ElemNum=LSElem(II)

*GET,XC,ELEM,ElemNum,CENT,X

*GET,YC,ELEM,ElemNum,CENT,Y

! GET THE CENTER OF ELEMENT X-COORD

*GET,ZC,ELEM,ElemNum,CENT,Z

THETA $=\mathrm{YC} * \mathrm{PI} / 180$

! GET THE CENTER OF ELEMENT Y-COORD

$\mathrm{XSElem}(\mathrm{II})=\mathrm{XC}$

! GET THE CENTER OF ELEMENT Z-COORD

YSElem $(\mathrm{II})=\mathrm{YC}$

ZSElem $(\mathrm{II})=\mathrm{ZC}$

SFE,ElemNum,6,PRES,,PElem

*ENDDO

SOLVE

*ENDDO 


\section{REFERENCES}

ACI committee 224, 2004, "Cracking of Concrete Members in Direct Tension (ACI 224.2R92)", American Concrete institute, Farmington Hills, MI, USA.

ACI committee 224, 2008, "Control of Cracking in Concrete Structures (ACI 224R-01)", American Concrete institute, Farmington Hills, MI, USA.

ACI 350.3-06, 2006. Seismic design of liquid-containing concrete structures (ACI 350.3-06) and commentary (350.3R-06). American Concrete Institute (ACI) Committee 350, Environmental Engineering Concrete Structures, Farmington Hills, MI, USA.

ACI Committee 350-01, 2001, "Code requirements for environmental engineering concrete structures (ACI 350-01) and commentary (ACI 350R-01)", American Concrete Institute, Farmington Hills, MI, U.S.A.

ACI Committee 350-06, 2006, "Code Requirements for Environmental Engineering Concrete Structures (ACI 350-06) and Commentary (ACI 350R-06)", American Concrete Institute, Farmington Hills, MI, U.S.A.

ACI 371R-08, 2017, Guide for the analysis, design and construction of elevated concrete and composite steel-concrete water storage tanks American Concrete Institute, ACI Committee 371, Farmington Hills, MI, USA.

ANSYS Inc. ANSYS help manual (Version 17.1), 2017. Global headquarters, Southpointe, 275 Technology drive, Canonsburg, PA 15317.

American Petroleum Institute, API 620, 2013, "Design and construction of large, welded, lowpressure storage tanks", American Petroleum Institute Standard, Washington D.C., U.S.A.

American Petroleum Institute, API 650, 2013, "Welded steel tanks for oil storage", American Petroleum Institute Standard, Washington D.C., U.S.A.

Arias, A., 1970, “A measure of earthquake intensity", Seismic Design for Nuclear Power Plants, MIT Press, Cambridge.

American Society of Civil Engineers (ASCE), 1980, "Structural analysis and design of nuclear 
plant facilities", ASCE Manuals and Reports on Engineering Practice No. 58, New York, New York.

American Society of Civil Engineers (ASCE), 2000, "Seismic analysis of safety-related nuclear and commentary", ASCE 4-98, Reston, VA.

American Society of Civil Engineering (ASCE), 2013. Minimum design loads for buildings and other structures, ASCE Standard ASCE/SEI 7-10.

ATC, 1978, Tentative Provisions for the Development of Seismic Regulations for buildings. ATC Report 3-06, Applied Technology Council, Redwood City, California.

ATC-19, 1995, Structural Response ModificFraiation Factors. ATC Report 19, Applied Technology Council, Redwood City, California.

American Water Works Association (AWWA), 1984 and 2011, "Welded steel tanks for water storage", AWWA D100, CO.

American Water Works Association (AWWA), 2013, "Wire and strand-wounded circular prestressed concrete water tanks", AWWA D110, Denver, CO.

American Water Works Association (AWWA), 2017, “Circular prestressed concrete water tanks with circumferential tendons", AWWA D115, Denver, CO.

Bangash, M. Y. H., 1989, "Concrete and Concrete Structures: NumericalModeling and Applications." Elsevier Science Publishers Ltd., London, England.

Brooms, Bengt B., and Lutz Leroy A., 1965, "Effect of Arrangement of Reinforcement on Crack Width and Spacing of Reinforced Concrete Members", ACI Jurnal, Proceedings V. 62, pp. 1395-1410.

BS 8007, 1987, "Code of practice for design of concrete structures for retaining aqueous liquids", British Standard Institution.

Burns, NH., Siess, CP., 1962, Load-deformation characteristics of beam-column connections in reinforced concrete. Civil Engineering Studies, SRS no. 234, University of Illinois, Urbana.

Carrasquillo R.L., Nilson A. H., and Slate F. O., "Properties of High Strength Concrete Subject 
to Short-Term Loads," ACI Journal, Proceedings, V. iS, No. 3, May-June 1981, pp. 171-178.

Chen, J.Z., and Kianoush, M.R., 2005, "Seismic response of concrete rectangular tanks for liquid containing structures", Canadian Journal of Civil Engineering, 32, 739-752.

Dere Y., 2011, "Non-linear finite element analysis of an R/C frame under lateral loading", Mathematical and Computational Applications, Vol. 16, No. 4, pp. 947-958, 2011.

Dogangun, A., Durmus, A., and Ayvaz, Y., 1997, "Earthquake analysis of flexible rectangular tanks using the Lagrangian fluid finite element"،, Euro. J. Mech.-A/Solids, 16: 165-182.

Dogangun, A., and Livaoglu, R., 2004, "Hydrodynamic pressures acting on the walls of rectangular fluid containers“, Structural Engineering and Mechanics, 17 (2), 203-214.

Edvardsen C., 1999, "Water Permeability and Autogenous healing of Cracks in Concrete", ACI Material Journal, Vol. 96, No. 4, pp. 448-454.

Edwards, N., 1969, "A procedure for the dynamic analysis of thin walled cylindrical liquid storage tanks", Ph.D. Thesis, University of Michigan, Ann Arbor, MI, USA.

Elnashai,A.S, Di Sarno, L., 2008, Fundamentals of earthquake engineering, John wiley \& sons Ltd.

Elnashai, A.S. and Mwafy, A.M., 2002. Overstrength and force reduction factors of multistorey reinforced-concrete buildings, The Structural Design of Tall Buildings, 11(5), 329-351.

Epstein, H.I., 1976, "Seismic design of liquid storage tanks", Journal of the Structural Division, ASCE, 102(9): 1659-1673.

European Committee for Standardization (ECS), 1998 and 2012, "Design provisions for earthquake resistance of structures, Part 1- General rules and Part 4 - Silos, tanks and pipelines", Eurocode 8, Brussels, Belgium.

Fajfar P, Gaspersic P. The N2 method for the seismic damage analysis of RC buildings. Earthquake Engineering and Structural Dynamics 1996;25:31-46.

FEMA, NEHRP guidelines for the seismic rehabilitation of buildings. FEMA 273, Federal Emergency Management Agency, 1996. 
FEMA P695, Quantification of Building Seismic Performance Factors, Federal Emergency Management Agency, 2009.

Freeman, S. A., 1990, “On the correlation of code forces to earthquake demands." Proc. $4^{\text {th }}$ U.S.-Japan Workshop on Improvement of Building Structural Design and Construction, ATC15-3 Report, Applied Technology Council, Redwood City, California.

Frosch, R.J., 1999, "Another look at Cracking and Crack Control in reinforced Concrete”, ACI Structural Jornal, V. 96, No. 3, pp. 437-442.

Gaston JR, Siess CP, Newmark NM. A layered finite element non-linear analysis of reinforced concrete plates and shells. Civil Engineering Studies, SRS No. 389, University of Illinois, Urbana, 1972.

Ghaemmaghami, A.R., Moslemi, M., and Kianoush, M.R., 2010, "Dynamic behaviour of concrete liquid tanks under horizontal and vertical ground motions using finite element method", 9th US National and 10th Canadian Conf. on Earthquake Eng., Toronto, Canada.

Gollwitzer, S., and Rackwitz, R., 1990, “On the reliability of Daniels systems.” Struct. Safety, 7, 229-243.

Goodyear Tire and Rubber Company, 1959, "Handbook of Molded and Extruded Rubber", second edition, S-5138.

Hafez A., 2012, "Seismic Response of Ground-Supported Circular Concrete Tanks", Doctor of Philosophy thesis, Ryerson University, Toronto, Canada.

Haroun, M.A., 1983, "Vibration studies and tests of liquid storage tanks", Earthquake Engng. Struct. Dyn., 11, 190-206.

Haroun, M.A., 1984, "Stress analysis of rectangular walls under seismically induced hydrodynamic loads", Bulletin of the Seismological Society of America, 74(3), 1031-1041.

Haroun, M.A., and Housner, G.W., 1981A, "Seismic design of liquid storage tanks", Journal of the Technical Councils of ASCE, 107, 191- 207.

Haroun, M.A., and Housner, G.W., 1981B, "Earthquake response of deformable liquid storage 
tanks", Journal of Applied Mechanics, ASME, 48, 411-418.

Haroun, M.A., and Tayel, M.A., 1985, "Response of tanks to vertical seismic excitations", Earthquake Engng. Struct. Dyn., 13, 583-595.

Haroun, M.A., and Abou-Izzeddine, W. 1992. Parametric study of seismic soil-tank interaction. I: horizontal excitation. ASCE Journal of Structural Engineering, 118(3): 783-797.

Hemmaty, Y., 1998. Modelling of the Shear Force Transferred Between Cracks in Reinforced and Fibre Reinforced Concrete Structures. Proceedings of the ANSYS Conference, Vol. 1, Pittsburgh, Pennsylvania.

Hoskins, L.M. and Jacobsen, L.S. 1934. Water pressure in tank caused by a simulated earthquake. Bulletin of the seismological society of America, 24(1): 21-34.

Housner, G.W., 1952, "Spectrum intensities of strong motion earthquakes", Proc. of Symposium on Earthquake and Blunt Effects on Structures, Earthquake Engineering Research Institute.

Housner, G.W., 1957, "Dynamic pressures on accelerated fluid containers", Bulletin of the Seismological Society of America 47(1), 15-37.

Housner, G.W., 1963, "The dynamic behavior of water tanks", Bulletin of the Seismological Society of America 53(2), 381-389.

Housner, G.W., 1963, "The dynamic pressures on Fluid Containers" Technical Information Document (TID) 7024, Chapter 6 Appendix F, U.S Atomic Energy Commission.

Housner, G.W., 1975, "Measures of severity of earthquake ground shaking", Proceedings of the U.S. National Conference on Earthquake Engineering, EERI, Ann Arbor, MI, 25- 33.

Hunt, B., and Priestley, N., 1978, "Seismic water waves in a storage tank", Bulletin of the Seismological Society of America, 68(2), 487-499.

Husain, M., and Tsopelas, P., 2004. "Measures of structural redundancy in R/C buildings. I: Redundancy indices.” J. Struct. Eng. 130(11), 1651-1658.

Huyse, L., Y. Hemmaty and L.Vandewalle, 1994. Finite Element Modeling of Fiber Reinforced 
Concrete Beams. Proceedings of the ANSYS Conference, Vol. 2, Pittsburgh, Pennsylvania.

Hwang, H. and Shinozuka, M., 1994. "Effects of large earthquake on the design of buildings in eastern united states." Proc. Fifth U.S. National Conference on Earthquake Engineering, Chicago, Illinois.

IBC., 2017, “International Building Code”, International Code Council, Inc., USA: ICC.

Jacobsen, L. S., 1949, "Impulsive hydrodynamics of fluid inside a cylindrical tank and of fluid surrounding a cylindrical pier", Bulletin of the Seismological Society of America, Vol. 39, No. 3, pp. 189-203.

Jacobsen, L. S., and Ayre, R. S., 1951, "Hydrodynamic experiments with rigid cylindrical tanks subjected to transient motions", Bulletin of the Seismological Society of America, 41(4): 313 $-346$.

Kachlakev, D., T. Miller, S. Yim and K. Chansawat, 2001. Finite Element Modeling of Reinforced Concrete Structures Strengthened with FRP Laminates, Civil and Environmental Engineering, DepartmentCalifornia Polytechnic State University, San Luis Obispo.

Kianoush, M.R., and Chen, J.Z., 2006, "Effect of vertical acceleration on response of concrete rectangular liquid storage tanks", Engineering Structures, 28(5), 704-715.

Kianoush, M.R., Mirzabozorg, H., and Ghaemian, M., 2006, "Dynamic analysis of rectangular liquid containers in three-dimensional space", Canadian Journal of Civil Engineering, 33, 501507.

Kianoush, M.R., Acarcan, M., and Dullerud, E, 2006. "Cracking in Liquid-Containing Structures". Concrete international, Vol. 28 No. 4, pp. 62-66.I

Kianoush MR., Acarcan M., and Ziari A., 2008, "Behavior of base restrained reinforced concrete walls under volumetric changes", Journal of Engineering Structure, vol 30, 15261534.

Kim, J.K., Koh, H.M., and Kwahk, I.J., 1996, “Dynamic response of rectangular flexible fluid containers", ASCE Journal of Engineering Mechanics, 122(9), 807-817.

Koh, H.M., Kim, J.K., and Park, J.H., 1998, "Fluid-structure interaction analysis of 3D 
rectangular tanks by a variationally coupled BEM-FEM and comparison with test results", Earthquake Engng. Struct. Dyn., 27, 109-124.

Kono, 1980, "Facts about failures and instability of plant structure (mainly for flat bottom cylindrical storage tanks)", the 31st Nat. Cong, of Theoretical \& Applied Mechanics, pp. 7-12.

Krawinkler, H. K., and Nassar, A. A., 1992. "Seismic design based on ductility and cumulative damage demands and capacities", Nonlinear seismic analysis and design of reinforced concrete buildings. P. Fajfar and H. Krawinkler, eds., Elsevier Science, New York.

Livaoglu, R. 2008. Investigation of seismic behavior of fluid-rectangular tank-soil/foundation systems in frequency domain. Soil Dynamics and Earthquake Engineering, 28(2): 132-146.

Malhotra, P.K., Wenk, T., and Wieland, M., 2000, "Simple procedure for seismic analysis of liquid-storage tanks", Structural Engineering International, International Association for Bridge and Structural Engineering (IABSE), Zurich, Switzerland, 10(3), pp. 197-201.

Mickleborough NC, Ning F, Chan CM. Prediction of the stiffness of reinforced concrete shear walls under service loads. ACI Struct J 1999;96(6):1018-26.

Mikishev, G.N. and Dorozhkin, N.Y. 1961. An experimental investigation of free oscillations of a liquid in containers, Izvestiya Akademii Nauk SSSR, Otdelenie Tekhnicheskikh Nauk, Mekhanika I Mashinostroenie, 4: 48-83.

Miranda, E., and Bertero, V. V., 1994, "Evaluation of strength reduction factors for earthquake resistant design”, Earthquake Spectra, EERI, 10 (2), pp. 357-379.

Minowa, C., 1980, "Dynamic analysis for rectangular water tanks", Recent Advances in Lifeline Earthquake Engineering in Japan, 135-142.

Minowa, C., 1984, "Experimental studies of seismic properties of various type water tanks", Proceedings of Eighth WCEE, San Francisco, 945-952.

Moses, F., 1974, “Reliability of structural systems.” J. Struct. Div., ASCE, 100(9), 18131820 .

Moslemi M, Kianoush MR, Pogorzelski W. Seismic response of liquid-filled elevated tanks. 
Eng Struct 2011;33:2074-84.

Moslemi, M., 2011, "Dynamic Response of Circular and Conical Elevated Tanks", Doctor of Philosophy thesis, Ryerson University, Toronto, Canada.

Mwafy, A.M. and Elnashai, A.S, 2002, Calibration of force reduction factors of RC building, , Journal of Earthquake Engineering, 6(2), 239-273.

Mwafy, A.M. and Elnashai, A.S, 2002, Overstrength and force reduction factors of multistory reinforced-concrete buildings, Struct. Design Tall Build. 11, 329-351 (2002).

Nassar, A. and Krawinkler, H., 1991, “Seismic Demands for SDOF and MDOF Systems”, John A. Blume Earthquake Engineering Center, Report 95, Dept. of Civil Engineering, Stanford University.

Newmark, N. M., and Hall, W. J., 1982, Earthquake spectra and design. Earthquake Engineering Research Institute. Berkeley, California, USA.

NZS 3106, 1986 and 2009, "Code of practice for concrete structures for the storage of liquids", Standards Association of New Zealand, Wellington.

Osteraas, J. D. and H. Krawinkler, 1990. Strength and Ductility Considerations in Seismic, John A. Blume Earthquake Engineering Centre, Report 90, Stanford University, California.

Papanikolaou, V.K., Elnashai, A.S. and Pareva, J.F., 2006. Evaluation of conventional and adaptive pushover analysis II: Comparative results. Journal of Earthquake Engineering, 10 (1), $127-151$.

Park, J.H., Koh, H.M., and Kim, J., 1992, 'Liquid-structure interaction analysis by coupled boundary element - finite element method in time domain", Proceedings of the 7th International Conference on Boundary Element Technology, Albuquerque, New Mexico, Edited by Brebbia, C.A., and Ingber, M.S., Computational Mechanics Publication BETECH/92, Southampton, UK., pp. 89-92.

Priestley, M. J. N., "Analysis and design of circular prestressed concrete storage tanks," New Zealand Concrete Construction, PCI Journal/ July-August 1985, pp 64-85. 
Rinne, J.E., 1967, "Oil storage tanks", The Prince William Sound, Alaska Earthquake of 1964 and Aftershocks, Vol II, Part A, U.S. Coast and Geodetic Survey, Washington D.C., 245-252.

Sadjadi, R., 2009, "Response of Reinforced Concrete Rectangular Liquid Containing Structures under Cyclic Loading”, Doctor of Philosophy dissertation, Ryerson University, Toronto, Canada.

Saiidi M, Sozen MA., Simple nonlinear seismic analysis of R/C structures, Journal of the Structural Division, ASCE 1981;107(ST5):937-51.

Seismosoft, 2016, "SeismoSignal 2016 - A computer program for signal processing of strongmotion data," available from http://www.seismosoft.com.

Sezen, H., and Whittaker, A.S., 2006, "Seismic performance of industrial facilities affected by the 1999 Turkey earthquake", ASCE Journal of Performance of Constructed Facilities, 20(1), 28-36.

Shibata, 1974, "Report of earthquake damages in overseas industrial facilities - Spherical tank and cylindrical tank", Seisan Kenkyu, 26(7), 259-264.

Stehle, J. S., 2002. The Seismic Performance of Reinforced Concrete Wide Band Beam Frames: Interior Connections, University of Melbourne, Australia.

Subhash, S., and Bhattachryya, S.K. 1996. Finite element analysis of fluid-structure interaction effect on liquid retaining structures due to sloshing. Computers and Structures, 59(6): 11651171

Tavakkoli I., 2017, "Non-linear analysis of a nuclear containment structure under high internal pressure", Doctor of Philosophy thesis, Ryerson University, Toronto, Canada.

Timoshenko S, Woinowsky-Krieger S., 1976, "Theory plates and shells (2nd edition)".

Trifunac, M.D., and Brady, A.G., 1975, “A study on the duration of strong earthquake ground motion“, Bulletin of the Seismological Society of America, 65(3), 581-626.

Uang, C. M. and Bertero, V. V., 1986. Earthquake Simulation Tests and Associated Studies of a 0.3-Scale Model of Six-story Concentrically Braced Steel Structures. Earthquake 
Engineering Research Center, Report No. UCB/EERC 86/10, University of California, Berkeley, California.

Uang, C. M., 1991, "Establishing R(or Rw) and Cd factor for Building Seismic provisions." Journal of Structural Engineering, ASCE, 117(1), pp. 19-28.

Uang, C. M. and Maarouf, A., 1993, "Safety and Economy Considerations of UBC Seismic Force Reduction Factors." Proc. the 1993 National Earthquake Conference, Memphis, Tennessee.

Veletsos, A.S., 1984, "Seismic response and design of liquid storage tanks", American Society of Civil Engineers (ASCE), New York, Guidelines for the Seismic Design of Oil and Gas Pipeline Systems.

Veletsos, A.S., and Yang, J.Y., 1977, "Earthquake response of liquid storage thanks", Proc. $2^{\text {nd }}$ Adv. Civil. Eng. through Eng. Mech. Conf., ASCE, North Carolina, 1-24.

Veletsos, A.S., and Tang, Y., 1986, "Dynamics of vertically excited liquid storage tanks", ASCE Journal of Structural Engineering, 112(6), 1228-1246.

Veletsos, A.S., Tang, Y. and Tang H.T. 1992. Dynamic response of flexibly supported liquid storage tanks. ASCE Journal of Structural Engineering, 118: 264-283.

Veletsos, S.A., and Shivakumar, P., 1997, "Dynamic response of tanks containing liquids or solids", Computer Analysis and Design of Earthquake-Resistant Structures, Earthquake Engineering Series V.3, Beskos, D.E., and Anagnostopoulos, S.A., eds., Computational Mechanics Publications, Billerica, Mass., 936 pp.

Wang, C.H., and Wen, Y.K., 2000, "Evaluation of pre-Northridge low-rise steel buildings. II: Reliability.” J. Struct. Eng., 126(10), 1169-1176.

Whittaker, A. S., Uang, C. M., and Bertero, V. V., 1987. Earthquake Simulation Tests and Associated Studies of a 0.3-Scale Model of Six-story Eccentrically Braced Steel Structures. Earthquake Engineering Research Center, Report No. UCB/EERC 87/02, University of California, Berkeley, California.

Whittaker, A. S., Aiken, I. D., Bergman, D., Clark, P. W., Cohen, J., Kelly, J. M., and choll, R. E., 1993, "Code requirements for design and implementation of passive energy dissipation 
systems." Proc., ATC-17-1 Seminar on Seismic Isolation, Passive Energy Dissipation, and Active Control, Vol. 2, ATC, Redwood City, Calif., 497-508.

Willam, K.J., and Warnke, E.P., "Constitutive model for the triaxial behavior of concrete," in International Association for Bridge and Structural Engineering, Bergamo, Italy, 1975.

Winkler, E., Theory of Elasticity and Strength (in German), Prague, Czechoslovakia, 1867, 184 pp. 5.

Wolanski A. J., 2004, "Flexyral behavior of reinforced and prestressed concrete beams using finite element analysis”, Marquette University, Milwaukee, Wisconsin, May 2004.

Yang, J.Y., 1976, “Dynamic behavior of fluid tank system”, Ph.D. Thesis, Civil Engineering, Rice University, Houston, Tex.

Ziari A., and Kianoush M.R., 2009a, "investigation of flexural cracking and leakage in RC elements", Journal of Engineering Structures, 31(5), pp 1056-1067.

Ziari, A., and Kianoush, M.R., 2009b, "Investigation of direct tension cracking and leakage in RC elements", Journal of Engineering Structures, 31:466-474. 